\title{
Beyond communication
}

Citation for published version (APA):

Volgers, C. (2017). Beyond communication: membrane vesicle release during macrophage infection by common respiratory pathogens. [Doctoral Thesis, Maastricht University]. Maastricht University. https://doi.org/10.26481/dis.20171005cv

Document status and date:

Published: 01/01/2017

DOI:

$10.26481 /$ dis.20171005cv

Document Version:

Publisher's PDF, also known as Version of record

\section{Please check the document version of this publication:}

- A submitted manuscript is the version of the article upon submission and before peer-review. There can be important differences between the submitted version and the official published version of record.

People interested in the research are advised to contact the author for the final version of the publication, or visit the DOI to the publisher's website.

- The final author version and the galley proof are versions of the publication after peer review.

- The final published version features the final layout of the paper including the volume, issue and page numbers.

Link to publication

\footnotetext{
General rights rights.

- You may freely distribute the URL identifying the publication in the public portal. please follow below link for the End User Agreement:

www.umlib.nl/taverne-license

Take down policy

If you believe that this document breaches copyright please contact us at:

repository@maastrichtuniversity.nl

providing details and we will investigate your claim.
}

Copyright and moral rights for the publications made accessible in the public portal are retained by the authors and/or other copyright owners and it is a condition of accessing publications that users recognise and abide by the legal requirements associated with these

- Users may download and print one copy of any publication from the public portal for the purpose of private study or research.

- You may not further distribute the material or use it for any profit-making activity or commercial gain

If the publication is distributed under the terms of Article $25 \mathrm{fa}$ of the Dutch Copyright Act, indicated by the "Taverne" license above, 


\section{Beyond communication:}

\section{membrane vesicle release}

during macrophage infection by common respiratory pathogens

Charlotte Volgers 
BEYOND COMMUNICATION:

MEMBRANE VESICLE RELEASE

DURING MACROPHAGE INFECTION BY

COMMON RESPIRATORY PATHOGENS 
(C) Charlotte Volgers, Maastricht 2017

All rights reserved. No part of this thesis may be reproduced, stored in a retrieval system or transmitted in any form or by any means, electronic or mechanical, including photocopy, without prior written permission of the publisher and copyright owner, or where appropriate, the publisher of the articles.

Cover design: evelienjagtman.com

Vesicle illustration: Ruben Volgers

Thesis lay-out: evelienjagtman.com

Printed and published by: Gildeprint

Printing and design of this thesis was financially supported by Izon Science, the Netherlands Society of Medical Microbiology (NVMM), the Netherlands Society for Microbiology (KNVM) and Pfizer.

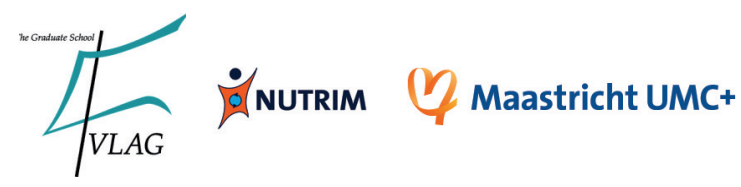

ISBN: 978-94-6233-679-7

The research presented in this dissertation was conducted at NUTRIM School for Nutrition, Toxicology and Metabolism of Maastricht University which participates in the Graduate School VLAG (Food Technology, Agrobiotechnology, Nutrition and Health Sciences), accredited by the Royal Netherlands Academy of Arts and Sciences. 


\section{BEYOND COMMUNICATION:}

MEMBRANE VESICLE RELEASE

DURING MACROPHAGE INFECTION BY

COMMON RESPIRATORY PATHOGENS

\section{PROEFSCHRIFT}

Ter verkrijging van de graad van doctor aan de Universiteit Maastricht

op gezag van de Rector Magnificus Prof. Dr. Rianne M. Letschert volgens het besluit van het College van Decanen

in het openbaar te verdedigen

op donderdag 5 oktober 2017 om 14.00 uur

\section{Door}

Charlotte Volgers 


\section{Promotor}

Prof. Dr. P.H.M. Savelkoul

\section{Co-promotor}

Dr. F.R.M. Stassen

\section{Beoordelingscommissie}

Prof. Dr. P.J. Peters (voorzitter)

Dr. W.T.V. Germeraad

Prof. Dr. B.W.W. Kramer

Dr. R. Nieuwland (Academisch Medisch Centrum Universiteit van Amsterdam)

Prof. Dr. M.H.M. Wauben (Universiteit Utrecht) 


\section{CONTENTS}

Chapter 1 General introduction and outline of the thesis 9

Chapter 2 Gram-negative bacterial membrane vesicle release in response to 37 the host-environment: different threats, same trick?

Critical reviews in Microbiology 2017; published online

Chapter 3 Bead-based flow-cytometry for semi-quantitative analysis of complex vesicle populations released by bacteria and host-cells Microbiology Research 2017; 200:25-32

Chapter 4 Immunomodulatory role for membrane vesicles released by THP1 macrophages and respiratory pathogens during macrophage infection

BMC Microbiology 2017; accepted for publicaton

Chapter 5 Effects of budesonide, fluticasone propionate, and azithromycin on the membrane vesicle release by macrophages and respiratory pathogens during macrophage infection Inflammopharmacology 2017; accepted for publication

Chapter 6 Effects of $\mathrm{N}$-acetylcysteine on the membrane vesicle release and growth of respiratory pathogens FEMS Microbiology Letters 2017; 364(9):fnx078

Chapter 7 General discussion and future directions

Nederlandse samenvatting

Valorisation

List of abbreviations

Dankwoord

List of publications

Vita 

"Curiosity, it keeps us moving forward, exploring, experimenting, opening new doors."

Walt Disney. 



\section{Chapter 1}

General introduction and outline of the thesis 


\section{PREFACE}

Resolution of bacterial infection of the airways engages a multitude of host-defences including innate immune defences. As central players of the innate immune system, phagocytic cells orchestrate several initial responses to infection. These responses, that follow host cell contact with bacteria and bacterial products, involve the release of pro-inflammatory mediators by the host and the concomitant immune cell recruitment. Amongst these bacterial and host-cell derived products are nanosized $(10-300 \mathrm{~nm})$ membrane vesicles released by both the host and by bacteria. Membrane vesicles serve as platforms to confer complex information composed of a plethora of proteins and lipids, from one cell to another. These vesicles provide cells with an additional means to respond to the environment to their advantage and may therefore have a substantial influence on the outcome of infection. 


\section{GENERAL INTRODUCTION}

\section{INVASION OF THE LOWER AIRWAYS - BACTERIAL AIRWAY INFECTION}

Acute infections of the respiratory tract pose a huge burden on society worldwide. The world health organisation (WHO) determined that acute infections of the lower respiratory tract form the most important burden of disease worldwide. It was estimated that, in 2010, acute respiratory infections accounted for 4-6\% of the total disability adjusted life years (DALYs: a measure for the disease burden based on both decreased life expectancy and morbidity in life-years)[1,2]. Clinical conditions associated with or caused by acute lower respiratory tract infections include bacterial or viral bronchitis, influenza, pneumonia, and tuberculosis but also include disease exacerbations of patients with underlying chronic conditions, such as asthma, chronic bronchitis or chronic obstructive airway disease (COPD)[2,3]. Although some of these conditions have an overlapping aetiology, the causative factors for each of these conditions are highly disease specific. Even more so, the aetiology of infection may vary among different countries. This for example has been demonstrated for the bacterial aetiology of community acquired pneumonia (CAP), where there are large differences in the aetiology of CAP between patients from different European countries [4]. Generally, the causative agents for lower respiratory tract infections can be classified as viral, bacterial, or fungal [5-8]. The most important respiratory viruses in this respect include the respiratory syncytial virus, rhinoviruses (in patients with an underlying airway condition), enteroviruses, influenza, parainfluenza, cytomegalovirus, herpes simplex virus, varicella zoster, and adenoviruses [5].

The involvement of bacterial infections in airway inflammation of the lower respiratory tract now becomes increasingly recognized. Although several lines of evidence indicated this, inconsistency in methods to obtain reproducible samples and the lack of sensitive methods for bacterial detection prevented drawing of ultimate conclusions. Also, the identification of bacteria as causative agents of disease exacerbations in patients with asthma or COPD proved complicated for several reasons. Herein, the lack of variation between the infection rate in patients with stable disease and during exacerbations has been one of the most important reasons [9-13]. Recent molecular techniques such as next gen sequencing (NGS) for bacterial identification in complex microbial niches made it possible to make more accurate correlations between bacterial infection and airway inflammation [14]. It has now been estimated based on NGS analyses that bacterial infections account for approximately $50 \%$ of the exacerbations of COPD [11,15-17].

Among the bacteria that are frequently associated with respiratory tract infections are opportunistic bacteria, known as colonizers of the upper respiratory tract, that are associated with inflammation and the pathogenesis of airway disease during invasion of the lower respiratory tract. The most common pathogens involved in airway infection are non-typeable Haemophilus influenzae, Moraxella catarrhalis, Streptococcus pneumoniae, and Pseudomonas aeruginosa [9,13,18-23]. Non-typeable H. infuenzae and M. catarrhalis are frequently associated with exacerbations of disease in patients with COPD and bronchitis. P. aeruginosa is a notorious pathogen that can cause severe airway infection in cystic fibrosis patients $[24,25]$. Moreover, infection with $P$. aeruginosa has also been 
reported to contribute to disease in COPD patients and is associated with approximately $4 \%$ of the COPD exacerbations, mainly in patients with more severe disease $[20,22]$. A particularly strong association has been noticed between the acquisition of a new bacterial strain and the development of an exacerbation, as high as $42.6 \%$ for $P$. aeruginosa, $44.5 \%$ for $H$. influenzae, and $44.7 \%$ for $M$. catarrhalis $[11,21,26,27]$. Finally, infections with these bacteria can increase the susceptibility to infections with other bacteria or viruses $[28,29]$. Viral infection can also predispose to a bacterial super infection, this has mainly been reported for influenza viruses and S. pneumoniae but has also been described for S. pneumoniae and other viruses such as RSV, parainfluenzae viruses, and rhinoviruses [30-33].

\subsection{First barriers - Host defence against bacterial infections of the lower res- piratory tract}

The lungs must provide a surface that allows an optimal gas exchange to provide animals which rely on oxygen respiratory systems with an optimal oxygen supply. At the same time. they act as a barrier that protects the organism against airborne environmental factors, such as harmless particles, noxious particles, a broad range of pathogens and bacteria that enter the lungs by migration of oropharyngeal bacteria [34]. This barrier consists of ciliated bronchial epithelial cells, that facilitate mucociliary clearance in the conducting airways, and alveolar epithelial cells and innate immune cells which provide a general and more directed mechanisms of defence [35]. The lung epithelium forms a multi-layered barrier that consists of - from the apical to the basolateral side - airway surface liquid consisting of mucin and pericellular fluid containing antimicrobial peptides, tight adhesions between epithelial cells, and the stroma. Innate immune cells, mainly macrophages, can be found in between the airway epithelial cells. Together this forms the first line of defence and most of the environmental air particles and pathogens are removed by mucus-mediated clearance [35].

Physiological changes of the respiratory tract, for example a decreasing $\mathrm{pH}$ as a result of inflammation or an increased sputum production (e.g. as is observed during bronchitis) as well as local or systemic alterations in immunity may generate a lung habitat that is favourable for pathogenic bacterial growth [8].

\subsection{Cell-mediated defences - innate immunity against bacterial infections of the lower respiratory tract}

Cell-mediated defences are established by epithelial cells and cells of the innate immune system that reside in local niches within the lung or enter the airways after recruitment by airway epithelial or other immune cells through the release of chemokines like IL-8. Local innate immune cells constitute for $95 \%$ of airway macrophages which makes them critical for the first line of defence against pathogens [36]. Macrophage actions consist of the removal of particulate matter, pathogens, pathogenic components, and dead or dying cells by phagocytosis as well as the initiation and orchestration of subsequent innate and adaptive immunity [3,37-39]. Other innate immune cells that are particularly important for the clearance of airway pathogens are neutrophils that are recruited upon infection. Neutrophils are involved in the clearance of pathogens through the phagocytosis of pathogens, due to their ability to capture pathogens by neutrophil extracellular traps (NETs), and by the production of cytokines and chemokines $[2,3,40]$. 


\subsubsection{Cell-mediated defences - pathogen recognition}

To sense their environment, cells are equipped with receptors including pattern recognition receptors (PRR). These receptors are discussed below in more detail and generally serve to recognize endogenous danger associated molecular patterns (DAMPs) as well as exogenous pathogen associated molecular patterns (PAMPs) [36,41,42]. The expression of the pattern recognition receptors is highly cell type specific [36,37]. In the lower airways, pattern recognition primarily occurs by type II alveolar epithelial cells and innate immune cells and is dependent on the local environment that directs intercellular communication and primes these cells to respond adequately to subsequent triggers $[35,37]$. These receptors enable pathogen recognition, facilitate pathogen uptake and degradation, and subsequently allow a further pathogen characterization, based on features that become exposed upon degradation i.e. bacterial mRNA that is only present in viable bacteria [43]. Amongst these PRRs are the Toll-like receptors (TLRs), nucleotide oligomerization domain (NOD)-like receptors (NLRs), retinoid-inducible gene I (RIG-I)-like receptors (RLRs), other cytosolic sensors for nucleic acid, and C-type lectin receptors [44].

TLRs enable recognition of components that are predominantly pathogen-derived. Typically, lipopolysaccharide (LPS) or lipooligosaccharide (LOS) on the Gram-negative bacterial envelope and a wide variety of other components such as outer membrane proteins, glycoproteins, and lipoproteins are recognized by TLR-4 located on the membrane. Flagellin and lipoprotein recognition occurs also on the membrane by TLR-5 and TLR-2, respectively. Endosomal recognition occurs by TLR-3 and TLR-7 that recognize single- and double-stranded RNA and by TLR-9 that is activated by unmethylated 2'deoxyriboCpG DNA motifs, found in bacteria and viruses $[44,45]$. Other PRRs that are important for the recognition of bacterial products are the NLRS NOD1 and NOD2 that recognizes cytoplasmic bacterial peptidoglycan and DNA. NLRP3 that recognizes various stimuli, such as bacterial muramyl dipeptide, or toxins (e.g. Streptococcal pneumolysin) which initiates formation of the inflammasome complex and the production of IL-1ß and IL-18 [46]. 


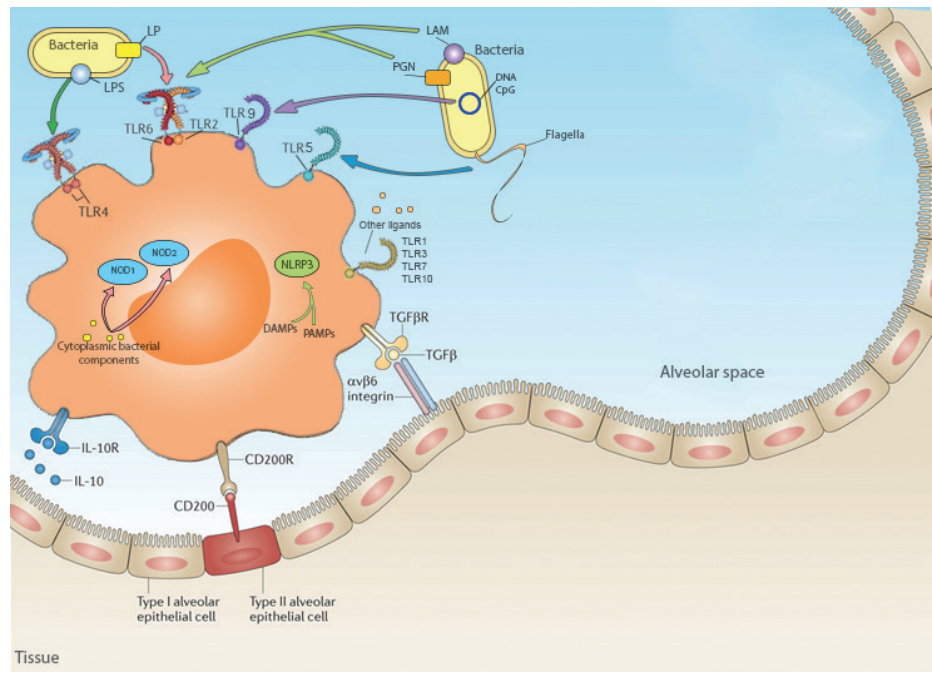

FIGURE 1 Alveolar macrophages reside locally, within niches of the lung alveoli, where they remain in close contact with mostly type II alveolar epithelial cells. Macrophages sense their environment by a range of receptors on their surface. Pathogens and danger signals are identified via e.g. pattern recognition receptors such as Toll-like receptors, NOD-like receptors including NOD1 and 2 and NLRP3. On pathogen recognition, intracellular signalling pathways are activated. Negative regulation can occur by soluble factors and cell-cell contact with the epithelium. Inhibitory receptor-ligand interactions are mainly established by CD200-CD200R and by TGF- $\beta$ and TGF- $\beta$ R. Also soluble mediators such as IL-10 can have an inhibitory effect on pro-inflammation signalling pathways. CD200R: CD200 receptor; IL-10R: IL-10 receptor; TGFßR: TGFß receptor; PGN: peptidoglycan; LP: lipoprotein; LAM: lipoarabinomannan. Figure adapted from [37] with permission.

\subsubsection{Cell-mediated defences - Macrophages as key players in the defence against respiratory pathogens}

Macrophages are the most important innate immune cells found in association with the airway epithelium (figure 1). The macrophage subset is extremely heterogeneous [47-49]. The local environment determines the character of the interactions with the epithelium and primes macrophages for a subsequent response [37]. This response entails the destruction of pathogens directly by phagocytosis, by reactive oxygen species, nitrogen intermediates or indirectly by secretion of cytokines, chemokines, and proteases such as matrix metalloproteinases (MMPs). Macrophages can also initiate and shape innate immune responses either by direct cell-cell contact or by the release of pro-inflammatory mediators that result in the recruitment and programming of e.g. macrophages and neutrophils. As professional antigen presenting cells macrophages can also present antigens in the context of $\mathrm{MHC}$ class I or II to $\mathrm{CD} 8^{+}$or $\mathrm{CD} 4^{+} \mathrm{T}$-cells, respectively, hereby initiating adaptive immunity $[37,47,50]$. 
As macrophages are constantly exposed to a variety of triggers, it is important that their activation is strictly controlled to avoid inappropriate and potentially harmful responses. As is shown in figure 1, this inhibitory signal for macrophage activation can be provided in several ways. Firstly, by interactions with the epithelium through receptor mediated interactions via TGF $\beta R$ with integrin-bound TGF- $\beta$ or via CD200R with CD200 or in ways that depend on soluble factors such as IL-10 [37]. Damage to the epithelium or decreased interactions with the epithelial cells, increase macrophage responsiveness to environmental triggers. Moreover, the release of collectins such as surfactant-associated protein A and D by the epithelium results in a suppression of TLR-2 or TLR-4 induced responses [37]. Other components that modulate phagocyte responses are immunoglobulins (via Fc receptors) and complement (via complement receptors) [36,44]. Other general regulation of inflammatory processes occurs at the level of the negative regulation of pro-inflammatory signalling, as is induced e.g. upon TLR-activation, to prevent an excessive inflammatory response and to resolve inflammation on bacterial clearance. Hereby, recognition of a diverse range of stimuli leads to a context dependent activation which then results in a response that resonates with the initiator. The course of infection is then determined by the interaction between the pathogens, the site of infection, and cells of the host immune system $[43,51]$.

To conclude, macrophages play a key role in the defence against bacterial invasion of the lower respiratory tract. Impairments of this defence lead to decreased pro-inflammatory responses resulting in a decreased bacterial clearance. 


\section{BACTERIAL AND HOST-CELL MEMBRANE VESICLES IN INTERCEL- LULAR COMMUNICATION}

\subsection{The discovery and implications of bacterial and host-cell vesicles}

Already in the 1960s and 1970s the release of nanosized membrane vesicles was observed for Vibrio cholera, Neisseria meningitides, and Escherichia coli, but this received little attention at that time, as these vesicles were considered to be but a mere by-product of bacterial growth [52-55]. Over the years, however, it became clear that vesicle shedding serves bacteria with advantages during growth and infection of the host.

A similar history holds for extracellular release by eukaryotic cells: when the groups of Philip Stahl and Rose Johnstone reported around thirty years ago that reticulocytes shed small membrane vesicles during maturation into red blood cells, it was thought that these vesicles were used by the cells to remove waste [56,57]. Though, when researchers discovered that these vesicles can be used by the cells for communication and that they are involved in important immunological processes, cellular communication by means of extracellular vesicles became a full-fledged research field [58,59]. At present, shedding of host vesicles is a well-recognized process that occurs by virtually all cells of the human body and vesicles have been identified in almost all body fluids and tissues [60].

Investigating vesicle release in vivo to determine their involvement in processes of cell maintenance and immunity and their role in the pathogenesis of disease, however, proved rather difficult. With regard to airway disease, it has been shown that the release of extracellular vesicles occurs by cells that are key players in the disease process and vesicles from different sources have been detected in bronchoalveolar lavage fluid [61,62]. The intrinsic properties that these vesicles exhibit, in vitro or in vivo upon instillation, indicates they can contribute to the pathogenesis of airway disease and acute airway inflammation [63-67]. It remains however highly complicated to comprehend the full extend as to which extracellular vesicles contribute to disease. Hence it is at present important to examine specific aspects of communication by means of extracellular vesicles in isolated processes, in vitro or in vivo $[60,68,69]$.

This also holds true when studying the involvement of extracellular vesicles in processes related to bacterial infection. To study vesicle release is challenging as vesicle release can occur both by the pathogen and the infected host. It has been demonstrated that the release of membrane vesicles in vivo during infection also occurs by the respiratory pathogens non-typeable $H$. influenzae and $M$. catarrhalis. Moreover, it is highly likely that the release of vesicles during infection also occurs by other respiratory pathogens including P. aeruginosa and S. pneumoniae as these bacteria have been shown to shed vesicles during culture conditions [70-72]. Most studies on the release of extracellular vesicles in vitro used models based on macrophages, because they form the first line of defence against infection and because these cells are most frequently targeted by common intracellular microbial pathogens such as the bacteria Mycobacterium tuberculosis, Salmonella typhimurium, or the parasite Toxoplasma gondii [73-77]. 
The conclude, at present it is still complicated to unravel the functionality of host-cell derived and bacterial membrane vesicles released during infection. Studying the mechanisms of release and the functionality of vesicles using culture models will lead to an improved insight and will guide further research.

\subsection{Mechanisms for biogenesis and functional aspects of host-cell membrane vesicles}

\subsubsection{Mechanisms for membrane vesicle biogenesis by host-cells}

Describing vesicle release by the host starts with a clarification of the nomenclature as the nomenclature will be used to describe processes for biogenesis. In general the terms 'membrane vesicles' and 'extracellular vesicles' are used as an umbrella term for nano- and microvesicles, released by cells from all three branches of life (table 1) [78]. Now focussing only on host-cell derived vesicles, the term extracellular vesicle is used for eukaryotic vesicles, again nano- and microvesicles, from different cellular origins. Microvesicles mostly refer to larger vesicles $(200-1000 \mathrm{~nm})$ that are released by extravagation and budding from the cell surface but is also used to describe nanosized vesicles that are released this way. The term exosome is used to describe vesicles that are formed in endocytic compartments. This occurs in specific endocytic compartments that are referred to as multivesicular bodies (MVBs) or multivesicular endosomes (MVEs) [79]. The formation of membrane vesicles in these compartments occurs by the formation of membrane extrusions that then bud of into these compartments. This process can occur through mechanisms that can both be dependent or independent on the endosomal sorting complex required for transport (ESCRT) proteins. During ESCRT-dependent biogenesis, ESCRT-proteins facilitate rearrangements of the MVB membrane, resulting in vesicle formation, and ESCRT proteins can also direct the selection of exosomal cargo $[60,80]$. The transport of MVBs then relies on Rab GTPases, especially on Rab11, Rab27, and Rab35. After endocytic trafficking of the MVB to the plasma membrane, membrane fusion can occur which results in the release of the exosomal content into the extracellular space [79-81]. 


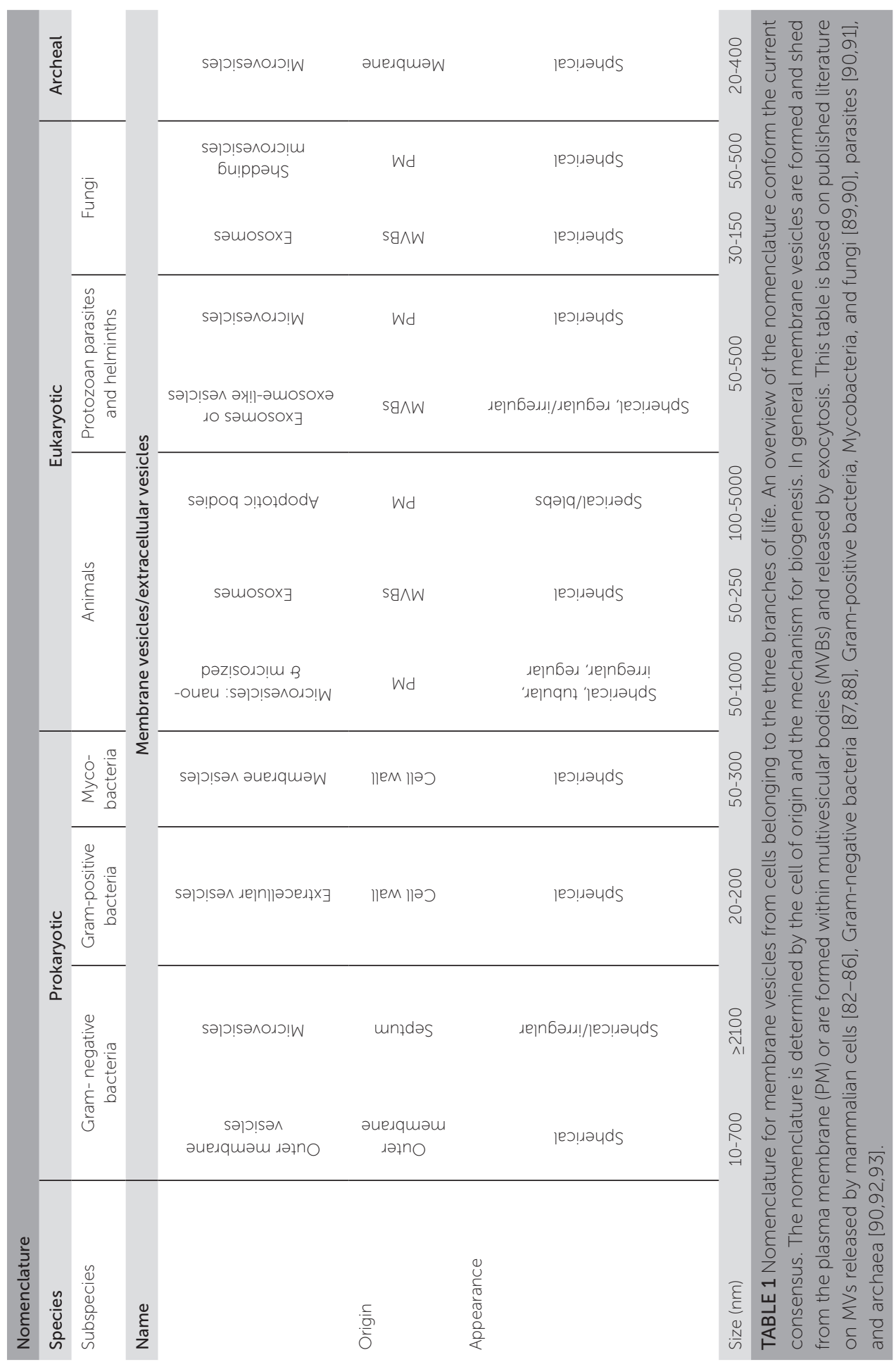




\subsubsection{General physiological activity of host cell-derived vesicles}

The physiological activity of extracellular vesicles is highly context dependent and reflects the nature and state of the host and the environment. An overview of the proteomic, lipidomic, and RNA analysis of extracellular vesicles from cells of diverse backgrounds and experimental conditions (i.e. species, lineage, culture conditions, exposure to growth factors, cytokines and stressors) are provided in Vesiclepedia, VesicleCarta, and EvPedia: compendia of molecular data [94-97]. Recently EV-TRACK: a knowledgebase that guides reporting thereby generating clarity and consensus as well as contributing to the reproducibility of MV-research, was established [98]. Collectively, the studies in this knowledgebase and these compendia identified that extracellular vesicles contain a wide variety of physiologically active components including signalling proteins, receptors, enzymes, cytokines, mRNAs, and miRNAs. Some of these factors are membrane-associated and others are located inside the vesicle lumen that is surrounded by a lipid bilayer. This lipid bilayer provides a platform for membrane-associated proteins and governs protection of the luminal cargo which is sensitive to degradation by enzymes in the extracellular environment. Functional aspects of extracellular vesicles have been extensively studied and mostly in the context of immunity and/or disease. Now there is a large body of evidence that shows that extracellular vesicles affect and coordinate innate and adaptive immune responses, as was reviewed $[68,99,100]$.

The physiological properties of host cell-derived membrane vesicles released during infection will be discussed in paragraph 4.3 .

\subsection{Biogenesis of membrane vesicles by bacteria}

Bacterial membrane vesicles have been shown to be involved in many physiological and pathological processes. They can help bacteria to acquire nutrients, transfer DNA, aid in niche competition with other bacteria, provide protection against anti-bacterial components, and act as carriers of virulence factors [101-103]. The release of these vesicles occurs constituently, but can also occur in response to various stressors [88,104]. Herein, membrane vesicles can provide immediate and ultimate advantages. An example hereof is that membrane vesicles may provide protection against antimicrobial peptides. This can be established indirectly by passive adsorption and transfer of enzymes, or directly by vesicle-mediated release of membrane bound antimicrobial peptides [105,106].

To establish the pathophysiological role of membrane vesicles during infection requires a better understanding how vesicle biogenesis is induced, how membrane vesicles can interact with their environment e.g. by the transfer of virulence factors, and how vesicles can aid bacteria to adapt to their environment.

\subsubsection{Biogenesis of bacterial membrane vesicles by Gram-negative bacteria}

The biogenesis of bacterial membrane vesicles by Gram-negative bacteria in response to host-associated factors and the immediate and ultimate physiological advantages, will be addressed in detail in chapter 2: "Gram-negative bacterial membrane vesicle in response to the host-environment: different threats, same trick?". 


\subsubsection{Biogenesis of bacterial membrane vesicles by Gram-positive bacteria}

As Gram-positive bacteria have a thick cell wall composed of peptidoglycan and (lipo-) teichoic acid that lacks an outer membrane, it was initially thought that the formation of membrane vesicles was limited to Gram-negative bacteria. Recently, however, it became clear that membrane vesicle formation also occurs by Gram-positive bacteria. Although the process of membrane vesicle shedding has been studied more extensively in recent years, it is still not completely understood how these vesicles are being released from the cell wall. As the cell wall of Gram-positive bacteria is alike the fungal cell wall, it has been suggested that the release of membrane vesicles by Gram-positive bacteria resembles the process in fungi. Currently, two, and possibly even three mechanisms have been proposed to explain how membrane vesicles pass the cell wall. The first mechanism proposes that membrane vesicles, after being released from the cell membrane, are pushed through the cell wall by turgor pressure $[107,108]$. This process may be accompanied by proteases that partially "degrade" the cell wall allowing vesicles to pass through, but it is also possible that this protease-directed release forms a second, independent mechanism for release [109-112]. The third mechanism that has been described is based on the release of membrane vesicles via ATP-gated protein channels [107,108].

In contrast to Gram-negative bacteria, there is hardly anything known regarding the mechanisms for the formation of vesicles by Gram-positive bacteria. Currently, there are only two factors known that can modulate the vesicle biogenesis. The first is the alternative transcription factor sigma factor $B$, that regulates the general stress response to nutrient starvation, heat-shock, and other environmental stressors such as exposure to ethanol [113]. One study reveals that sigma factor $B$ is involved in the vesicle formation by Listeria monocytogenes by showing that mutants with deleted sigma factor B exhibit an increased vesicle shedding and shed vesicles with an aberrant morphology [114]. The second factor is virB, and for M. tuberculosis it has been shown that virB modulates the formation of membrane vesicles. VirB deletion was shown to affect the release of virulence factors such as LpqH, Rv1488, and Rv0383c by membrane vesicles [115].

\subsection{Immunomodulation by membrane vesicles released upon infection}

The release of membrane vesicles is a conserved way for intercellular communication and is utilized by both bacteria and host cells, and both vesicle populations are present upon infection (figure 2). How vesicles involved in the communication between host cells may promote pathogen clearance by mediating processes in innate and adaptive immunity, and how vesicles from pathogens contribute to virulence and promote bacterial invasion or niche occupation is discussed below. 


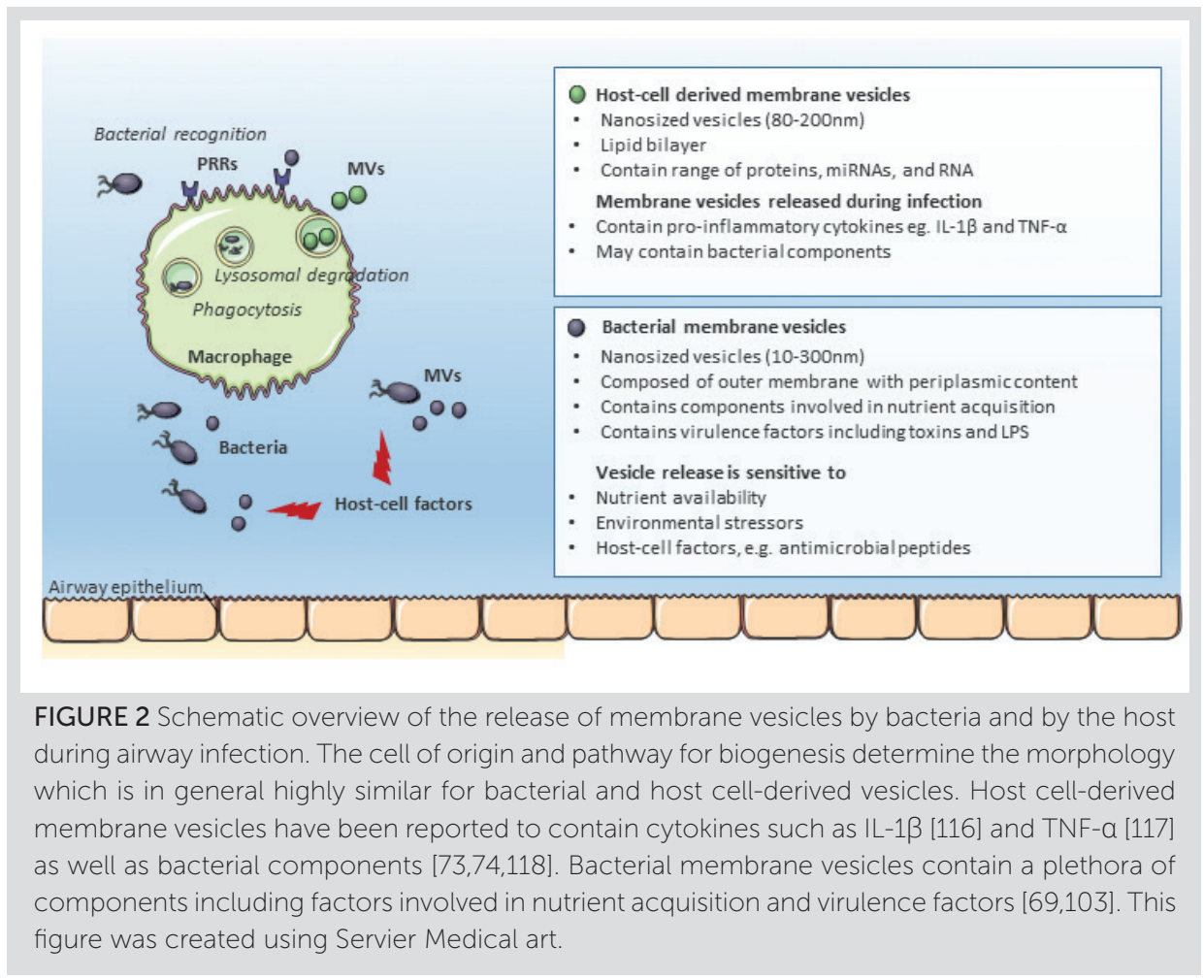

\subsubsection{Immunomodulation by host cell membrane vesicles released during infection}

Since it was first recognized that B-cell-derived membrane vesicles carry functional MHC class II-peptide complexes, evidence on the involvement of extracellular vesicles in innate and adaptive immune processes has accumulated. Currently, it is well recognized that a broad range of physiological processes can be initiated, modulated, and directed by extracellular vesicles. Communication by extracellular vesicles has mainly been investigated in relation to activation and modulation of innate immune responses and with regard to antigen presentation in adaptive immune responses.

Vesicular activation of innate immunity has been shown to occur mainly by the activation of PRRs and has been investigated in many different contexts that involve inflammation or infection as reviewed by Schorey [119]. In this regard, vesicle-associated components include heat-shock proteins such as heat-shock protein 60, 70, and 90 and several pro-inflammatory cytokines including IL-1 $\beta$ and TNF- $\alpha[60,116,120]$. Modulation of innate immunity can occur by vesicle-mediated transfer of cytokines, chemokines, and growth factors such as IL-6, IL-8, and vascular endothelial growth factor and transforming growth factor, as reviewed by Yáñez-Mó et al. [60]. 
Membrane vesicle release following bacterial infection has been studied mostly in the context of intracellular pathogens such as Salmonella typhimurium, M. tuberculosis, and parasites such as Toxoplasma gondii $[73,77,119,121]$. Vesicles released upon such infection exert a strong pro-inflammatory potential, in vitro and in vivo and it has been shown that such vesicles released e.g. by infected macrophages contain several pathogen-derived components $(81,82,83,124,126,127)$. A closer examination of these vesicles indeed revealed that they can carry bacterial components such as glycopeptidolipids LAM and lipoproteins $[75,77,124]$. Therefore, it has been hypothesized that bacterial components are released in the phagosome, then transported through the endosomal compartments to the MVEs, where they are incorporated into the extracellular vesicles. A recent study by Athman and co-workers, however, shed new light on these observations by showing that during infection with $M$. tuberculosis both host cell and bacterial vesicles are being released. Markedly, they found that the bacterial components were predominantly present on the bacterial vesicles. Moreover, the vesicle population that demonstrated immunostimulatory potential was of bacterial origin. Yet, although this study strongly suggests that bacterial cargo is exclusively present on bacterial vesicles, it cannot be ruled out that bacterial components might end up on host cell-derived vesicles as well [77]. In this light another recent study demonstrated that ubiquitinated bacterial components are released in association with host cell vesicles and that inhibition of the ubiquitination machinery inhibits the release of membrane vesicle [76]. Therefore, it is not completely clear yet whether bacterial components can be incorporated into host cell vesicles and how host cell-related processes such as the ubiquitination machinery are involved in the formation and release of the bacterial vesicles. Other situations wherein pathogenic components have been found in association with vesicles were upon virus or parasitic infection. For example, vesicles that contained hepatitis C virus RNA were released upon plasmacytoid dendritic cell infection and Plasmodium yoelii-infected red blood cells were found to release exosomes that contained pathogen-derived proteins $[125,126]$.

\subsubsection{Immunomodulation by bacterial membrane vesicles released by respira- tory pathogens during infection}

Immunomodulation by bacterial membrane vesicles is species dependent, therefore several key immunomodulatory properties of membrane vesicles from non-typeable $H$. influenzae, M. catarrhalis, S. pneumoniae, and P. aeruginosa are summarized in table 2 and will be addressed in this context. Ren et al. demonstrate the release of bacterial membrane vesicles during co-culture of non-typeable $\mathrm{H}$. influenzae with airway epithelial cells and showed that these vesicles interacted with host cells [127]. Another study supported such an interaction between bacterial membrane vesicles and epithelial cells and established that upon vesicle internalization $I L-8$ and the antimicrobial peptide $L L-37$ were released [128]. Proteomic analysis showed that these membrane vesicles contained a wide variety of proteins including several prominent virulence factors including LOS and adhesins [128-130]. Moreover, it has been shown that membrane vesicles of $H$. (para-)influenzae directly interact with B-lymphocytes via the immunoglobulin D B-cell receptor resulting in B-cell proliferation and antibody production. These antibodies, however, were only able to recognize the membrane vesicles indicating that these vesicles can deflect antibody-dependent immune responses [131]. Extensive proteomic profiling of M. catarrhalis membrane vesicles revealed that these vesicles also contained a wide range of bacterial 
proteins, including several virulence factors such as the ubiquitous surface proteins (USP) A1/A2 and the Moraxella IgG-binding protein (MID). Bacterial vesicles were found to interact with TLR2 resulting in their uptake and consequently the release of pro-inflammatory cytokines such as IL-8 [105]. As with membrane vesicles of H. influenzae, M. catarrhalis-derived vesicles were also able to divert adaptive immunity by IgD B-cell receptor activation that i.e. resulted in the release of vesicle-directed IgM but not in the release of bacteria-directed IgG or IgA [132]. Together with Escherichia coli, P. aeruginosa is the most well-studied bacterial species in terms membrane vesicle release, and therefore studies on the physiological activity of these vesicles are manifold. Pseudomonas' membrane vesicles have been shown to carry many virulence factors including LPS, alginate, and phospholipase $C[133,134]$. Moreover, these membrane vesicles have been shown to induce the release of pro-inflammatory cytokines including TNF- $\alpha, I L-1 \beta$, and IL-6, the chemokine IL-8, and the $\beta$-defensins HBD2 and HBD3 [135-138]. A recently discovered mechanism whereby membrane vesicles from $P$. aeruginosa can modulate inflammation is via the transfer of short RNA sequences to epithelial cells. RNAs transferred this way have been shown to inhibit the release of IL-8 [139]. A less well studied microorganism with respect to the release of bacterial membrane vesicles is $S$. pneumoniae. But as proteomic analysis of bacterial membrane vesicles released by S. pneumoniae revealed a wide range of bacterial proteins including virulence factors, it is highly likely that these vesicles also exert a plethora of immunomodulatory activities [70].

In summary, membrane vesicles released during infection can be both bacterial and host cell-derived. Host cell vesicles released in the context of inflammation and infection have been shown to exert a plethora of immuno-modulatory and stimulatory activities. Bacterial vesicles released during infection may promote bacterial invasion by the subversion or modulation of immune responses (e.g. by acting as decoys to escape from antimicrobial peptide attack), but can also aid in bacterial survival during niche occupation through the acquisition of pivotal nutrients. 


\begin{tabular}{|c|c|c|}
\hline Species & Virulence factor & Action \\
\hline \multirow[t]{6}{*}{$\begin{array}{l}\text { Non-typeable } \mathrm{H} \text {. } \\
\text { influenzae }\end{array}$} & Outer membrane protein P5 [128] & $\begin{array}{l}\text { Aids in the adherence to mucosal surfaces [140- } \\
\text { 143]and provides with resistance to classical and } \\
\text { alternative complement-mediated killing [144] }\end{array}$ \\
\hline & Lipooligosaccharide [129] & $\begin{array}{l}\text { Implicated to trigger the release of IL- } 8 \text { by epithelial } \\
\text { cells [128] }\end{array}$ \\
\hline & OMVs in total [131] & $\begin{array}{l}\text { Generated B-cell proliferation via IgD BCR cross } \\
\text { linking which resulted in the release of IgM and } \\
\text { IgG, these immunoglobulins did not recognize } \mathrm{H} \text {. } \\
\text { influenzae bacteria [131] }\end{array}$ \\
\hline & $\beta$-lactamase [145] & $\begin{array}{l}\text { Promotes survival of group A streptococci by } \\
\text { inactivation of amoxicillin [145] }\end{array}$ \\
\hline & $\begin{array}{l}\text { Outer membrane protein } \mathrm{P} 1 \text { and } \\
\text { P2 precursors [128] }\end{array}$ & $\begin{array}{l}\text { Bind complement factor C } 3 \text { in serum [146], OMP } \\
\text { P2 aids colonization by interactions with mucin (as } \\
\text { reviewed by [147]) }\end{array}$ \\
\hline & $\begin{array}{l}\text { Ubiquitous surface protein (Usp) } \\
\text { A1/A2 [148,149] }\end{array}$ & $\begin{array}{l}\text { Binds complement factor C3 in serum [148], UspA1 } \\
\text { is important for the adhesion to host cells and } \\
\text { induces TLR2-dependent inflammatory responses } \\
\text { of pulmonary epithelial cells [150] }\end{array}$ \\
\hline \multirow[t]{6}{*}{ M. catarrhalis } & $\beta$-lactamase [105] & $\begin{array}{l}\text { Promotes survival by inactivation of amoxicillin } \\
\text { [105] }\end{array}$ \\
\hline & Lipooligosaccharide [105] & $\begin{array}{l}\text { Implicated in serum resistance [151] and adherence } \\
\text { [152] }\end{array}$ \\
\hline & $\begin{array}{l}\text { Moraxella immunoglobulin (Ig) D } \\
\text { binding protein (MID) [149] }\end{array}$ & $\begin{array}{l}\text { Binds IgD and functions as an adhesin by mediating } \\
\text { attachment to lung epithelial cells [153,154]. } \\
\text { OMV-associated MID also induces a non-specific } \\
\text { immune response that fails to target M. catarrhalis } \\
\text { itself [155] }\end{array}$ \\
\hline & CpG-DNA motifs [155] & Interacts with TLR9 in B lymphocytes [132] \\
\hline & CopB [149] & $\begin{array}{l}\text { Surface receptor that binds host transferrin and } \\
\text { lactoferrin [156] }\end{array}$ \\
\hline & Phospolipase C [157] & $\begin{array}{l}\text { Can cleave phosphatidylcholine in membrane of } \\
\text { human erythrocytes [158] }\end{array}$ \\
\hline \multirow[t]{7}{*}{ P. aeruginosa } & Alkaline phosphatase [134] & $\begin{array}{l}\text { Important for packing and release of virulence } \\
\text { factors [72] }\end{array}$ \\
\hline & CFTR-inhibitory factor (Cif) [159] & $\begin{array}{l}\text { Epoxide hydrolase activity and downregulates the } \\
\text { cystic fibrosis transmembrane resistance regulator } \\
\text { (CFTR) protein, which aids in the colonization of } \\
\text { epithelial surfaces }\end{array}$ \\
\hline & $\begin{array}{l}\text { Pseudomonas Quinolone Signal } \\
\text { (PQS) and other quinolones/ } \\
\text { quinolines [160] }\end{array}$ & $\begin{array}{l}\text { Quinoline, regulates quorum sensing systems } \\
\text { that intracellular communication, downstream } \\
\text { virulence gene expression and biofilm formation } \\
\text { [161], quinolones/quinolines also exert bactericidal } \\
\text { properties }\end{array}$ \\
\hline & $\beta$-lactamase [162] & $\begin{array}{l}\beta \text {-lactamase promotes bacterial survival by } \\
\text { inactivation of amoxicillin [145] }\end{array}$ \\
\hline & Peptidoglycan hydrolase [163] & Autolysins (bacteriolytic activity) $[163,164]$ \\
\hline & A-band and B-band LPS [134] & $\begin{array}{l}\text { Aid in invasion and internalization and activate } \\
\text { TLR-4 [165] }\end{array}$ \\
\hline & Pneumolysin (Ply) [70] & $\begin{array}{l}\text { Pore forming toxin with several virulent activities (as } \\
\text { reviewed by [166]) }\end{array}$ \\
\hline
\end{tabular}


S. pneumoniae

Ami-AliA/AliB permease [70]

Maltose/maltodextrin ABC transporter, maltose/ maltodextrin-binding protein (MalX) [70]

Transmembrane protein PspA [70]

Transmembrane protein IgA protease [70]

1,4- $\beta$-N-acetylmuramidase (lysozyme, LytC) [70]

Elongation factor Tu (TUF)[70]
Involved in nasopharyngeal colonization (via an unknown mechanism) [167]

MalX deletion mutants display a decreased virulence, is involved in the degradation of alfa glucans and is involved in colonization of hosttissues [168]

Major virulence factor e.g. by functioning as an adhesin that aids bacterial attachment to the host (as reviewed by [169])

Cleaves the Fc receptor from secreted IgA1, hereby preventing opsonophagocytosis. Cleaved IgA1 fragments increase bacterial adherence [170]

Autolysin and involved in bacterial colonization $[171,172]$

Binds complement factor C3 and C3b and the complement inhibitors factor $\mathrm{H}$ and factor $\mathrm{H}$ like protein-1 [173]

\section{Detailed proteomic analysis of membrane vesicle contents}

$\begin{array}{ll}\text { Non-typeable H. influenzae } & {[129,174} \\ \text { M. catarrhalis } & {[149]} \\ \text { S. pneumoniae } & {[133]} \\ \text { P. aeruginosa } & \text { [70] }\end{array}$

TABLE 2 Overview of proteomic studies and studies on virulence factors of membrane vesicles from common respiratory pathogens. 


\section{OBJECTIVES AND OUTLINE OF THIS THESIS}

The outcome of (respiratory) infections is determined by the interplay between bacteria and the host which involves the release of small soluble mediators as well as membrane vesicles. Membrane vesicles confer both the host and bacteria with a means to shape their environment to their advantage. Yet, the fact that membrane vesicles are shed by both bacteria and host cells simultaneously during infection, makes it highly complicated to study the relative contributions of both population in the overall process.

To obtain a better insight in the release and functional properties of membrane vesicles shed upon respiratory infection, in this thesis, several studies were performed to assess the release of membrane vesicles by macrophages and by the common respiratory pathogens non-typeable H. influenzae, M. catarrhalis, S. pneumoniae, and P. aeruginosa. The central hypothesis which was studied in this thesis was that both bacterial and host cell-derived membrane vesicles released upon infection convey a physiological activity. The main focus of this thesis was to study the immuno-stimulatory and-modulatory properties of these different membrane vesicle populations and to establish how therapeutic agents might affect the shedding of these vesicles and the putative pro-inflammatory responses to these vesicles.

The biogenesis and release of membrane vesicles is a highly dynamic process that is sensitive to environmental factors. During infection, within the complex host environment there are numerous factors present that can affect this process either directly or indirectly. In chapter 2, the current consensus on the mechanisms for Gram-negative bacterial membrane vesicle formation is reviewed, thereby focussing on how these mechanisms are affected by host-associated factors.

The release of membrane vesicles can occur both by bacteria and host cells during infection and currently there are no elegant ways to assess the release of bacterial membrane vesicle populations within a mixed vesicle population. In chapter 3 we present a novel method for the semi-quantitative determination of bacterial membrane vesicles by bead-based flow-cytometry. In chapter 4, we studied the immuno-modulating properties of membrane vesicles released by host cells and bacteria during macrophage infection with the common respiratory pathogens non-typeable $H$. influenzae, M. catarrhalis, S. pneumoniae, and $P$. aeruginosa. In chapter 5 and chapter 6 , respectively, we investigated if the corticosteroids fluticasone propionate and budesonide, the macrolide antibiotic azithromycin and $\mathrm{N}$-acetyl-L-cysteine affect the release of, and response to bacterial and host cell membrane vesicles. Finally, in chapter 7 the overall spectrum and implications of the data presented in this thesis are discussed, as well as indications for further research concerning the role of membrane vesicles in infections in general and respiratory diseases in particular. 


\section{REFERENCES}

1. Murray CJL, Vos T, Lozano R, Naghavi M, Flaxman AD, Michaud C, et al. Disability-adjusted life years (DALYs) for 291 diseases and injuries in 21 regions, 1990-2010: A systematic analysis for the Global Burden of Disease Study 2010. Lancet. 2012;380: 2197-2223. doi:10.1016/S0140-6736(12)61689-4

2. Mizgerd JP. Respiratory infection and the impact of pulmonary immunity on lung health and disease. Am J Respir Crit Care Med. 2012;186: 824-829. doi:10.1164/rccm.201206-1063PP

3. Mizgerd J. Acute lower respiratory tract infection. N Engl J Med. 2008;358: 716-727. doi:10.1056/ NEJMra074111.Acute

4. Welte T, Torres A, Nathwani D. Clinical and economic burden of community-acquired pneumonia among adults in Europe. Thorax. 2012;67: 71-79. doi:10.1136/thx.2009.129502

5. Pavia AT. Viral infections of the lower respiratory tract: Old viruses, new viruses, and the role of diagnosis. Clin Infect Dis. 2011;52: 0-5. doi:10.1093/cid/cir043

6. Nguyen LDN, Viscogliosi E, Delhaes L. The lung mycobiome: An emerging field of the human respiratory microbiome. Front Microbiol. 2015;6: 1-9. doi:10.3389/fmicb.2015.00089

7. Lieberman D, Shvartzman P, Korsonsky I. Aetiology of respiratory tract infections: clinical assessment versus serological tests. Br J Gen Pr. 2001;51: 998-1000.

8. Marsland BJ, Gollwitzer ES. Host-microorganism interactions in lung diseases. Nat Rev Immunol. 2014;14 827-35. doi:10.1038/nri3769

9. Murphy TF, Parameswaran Gl, Parameswaran Gl. Moraxella catarrhalis, a human respiratory tract pathogen. Clin Infect Dis. 2009;49: 124-31. doi:10.1086/599375

10. Clancy R, Pang G, Dunkley M, Cripps A. Acute on chronic bronchitis : A model of mucosal immunology. Immunol Cell Biol. 1995;73(5):414-7. doi:10.1038/icb.1995.64

11. Sethi S, Murphy TF. Infection in the pathogenesis and course of chronic obstructive pulmonary disease. N Engl J Med. 2008;359: 2355-2365. doi:10.1056/NEJMra0800353

12. Hill AT, Campbell EJ, Hill SL, Bayley DL, Stockley RA. Association between airway bacterial load and markers of airway inflammation in patients with stable chronic bronchitis. Am J Med. 2000;109(4):288-95. doi:10.1016/S0002-9343(00)00507-6

13. Edwards MR, Bartlett NW, Hussell T, Openshaw P, Johnston SL. The microbiology of asthma. Nat Rev Microbiol. 2012;10(7):459-71. doi:10.1038/nrmicro2801

14. Dickson RP, Erb-Downward JR, Prescott HC, Martinez FJ, Curtis JL, Lama VN, et al. Analysis of culture-dependent versus culture-independent techniques for identification of bacteria in clinically obtained bronchoalveolar lavage fluid. J Clin Microbiol. 2014;52: 3605-3613. doi:10.1128/JCM.01028-14

15. Rosell A, Monsó E, Soler N, Torres F, Angrill J, Riise G, et al. Microbiologic Determinants of Exacerbation in Chronic Obstructive Pulmonary Disease. Arch Intern Med. 2005;165: 891. doi:10.1001/archinte.165.8.891

16. Papi A, Bellettato CM, Braccioni F, Romagnoli M, Casolari P, Caramori G, et al. Infections and Airway Inflammation in Chronic Obstructive Pulmonary Disease Severe Exacerbations. Am J Respir Crit Care Med. 2006;173: 1114-1121. doi:10.1164/rccm.200506-8590C

17. Bafadhel M, McKenna S, Terry S, Mistry V, Reid C, Haldar P, et al. Acute Exacerbations of Chronic Obstructive Pulmonary Disease. Am J Respir Crit Care Med. 2011;184: 662-671. doi:10.1164/rccm.201104-05970C

18. King PT, Sharma R. The lung immune response to nontypeable haemophilus influenzae (lung immunity to nthi). J Immunol Res. 2015;2015. doi:10.1155/2015/706376

19. Gonçalves-de-Albuquerque CF, Silva AR, Burth P, Rocco PRM, Castro-Faria MV, Castro-Faria-Neto HC. Possible mechanisms of Pseudomonas aeruginosa-associated lung disease. Int J Med Microbiol. 2016;306: 20-28. doi:10.1016/j.jijmm.2015.11.001

20. Murphy TF, Brauer AL, Eschberger K, Lobbins P, Grove L, Cai X, et al. Pseudomonas aeruginosa in chronic obstructive pulmonary disease. Am J Respir Crit Care Med. 2008;177: 853-860. doi:10.1164/ rccm.200709-14130C 
21. Desai H, Eschberger K, Wrona C, Grove L, Agrawal A, Grant B, et al. Bacterial colonization increases daily symptoms in patients with chronic obstructive pulmonary disease. Ann Am Thorac Soc. 2014;11: 303-309. doi:10.1513/AnnalsATS.201310-3500C

22. Lieberman D, Lieberman D. Pseudomonal infections in patients with COPD: epidemiology and management. Am J Respir Med. 2003;2: 459-68.

23. Fagon JY, Chastre J, Trouillet JL, Domart Y, Dombret MC, Bornet M, et al. Characterization of distal bronchial microflora during acute exacerbation of chronic bronchitis. Use of the protected specimen brush technique in 54 mechanically ventilated patients. Am Rev Respir Dis. 1990;142: 1004-1008.

24. Davies JC. Pseudomonas aeruginosa in cystic fibrosis: pathogenesis and persistence. Paediatr Respir Rev. 2002;3(2):128-34. doi: 10.1016/S1526 +0550(02)00003-

25. Folkesson A, Jelsbak L, Yang L, Johansen HK, Ciofu O, Høiby N, et al. Adaptation of Pseudomonas aeruginosa to the cystic fibrosis airway: an evolutionary perspective. Nat Rev Microbiol.2012;10: 841-851. doi:10.1038/nrmicro2907

26. Murphy TF, Brauer AL, Schiffmacher AT, Sethi S. Persistent Colonization by Haemophilus influenzae in Chronic Obstructive Pulmonary Disease. Am J Respir Crit Care Med. 2004;170: 266-272. doi:10.1164/ rccm.200403-3540C

27. Murphy TF, Brauer AL, Grant BJB, Sethi S. Moraxella catarrhalis in Chronic Obstructive Pulmonary Disease. Am J Respir Crit Care Med. 2005:172: 195-199. doi:10.1164/rccm.200412-17470C

28. Bellinghausen C, Gulraiz F, Heinzmann ACA, Dentener MA, Savelkoul PHM, Wouters EF, et al. Exposure to common respiratory bacteria alters the airway epithelial response to subsequent viral infection. Respir Res. 2016;17: 68. doi:10.1186/s12931-016-0382-z

29. Sajjan US. H. influenzae potentiates airway epithelial cell responses to rhinovirus by increasing ICAM-1 and TLR3 expression. FASEB J. 2006;20: 2121-2123. doi:10.1096/fj.06-5806fje

30. McCullers $\mathrm{J}$ a. The co-pathogenesis of influenza viruses with bacteria in the lung. Nat Rev Microbiol. 2014;12: 252-62. doi:10.1038/nrmicro3231

31. Bellinghausen C, Rohde GGU, Savelkoul PHM, Wouters EFM, Stassen FRM. Viral-bacterial interactions in the respiratory tract. J Gen Virol. 2016;97: 3089-3102. doi:10.1099/jgv.0.000627

32. Bakaletz LO. Viral-bacterial co-infections in the respiratory tract. Curr Opin Microbiol. 2017:35: 30-35. doi:10.1016/j.mib.2016.11.003

33. Avadhanula V, Rodriguez CA, Devincenzo JP, Wang Y, Webby RJ, Ulett GC, et al. Respiratory viruses augment the adhesion of bacterial pathogens to respiratory epithelium in a viral species- and cell type-dependent manner. J Virol. 2006;80: 1629-36. doi:10.1128/JVI.80.4.1629-1636.2006

34. Mccloskey L, Falkowski NR, Huffnagle GB. Bacterial topography of the healthy human lower respiratory tract. 2017:8: 1-12. doi:10.1128/mBio.02287-16

35. Whitsett $\mathrm{J}$ a, Alenghat T. Respiratory epithelial cells orchestrate pulmonary innate immunity. Nat Immunol. 2015;16: 27-35. doi:10.1038/ni.3045

36. Martin TR, Frevert CW. Innate immunity in the lungs. Proc Am Thorac Soc. 2005;2: 403-11. doi:10.1513/ pats.200508-090JS

37. Hussell T, Bell TJ. Alveolar macrophages: plasticity in a tissue-specific context. Nat Rev Immunol. 2014;14 81-93. doi:10.1038/nri3600

38. Lambrecht BN. Alveolar Macrophage in the Driver's Seat. Immunity. 2006;24: 366-368. doi:10.1016/j. immuni.2006.03.008

39. McCubbrey AL, Curtis JL. Efferocytosis and lung disease. Chest. 2013;143: 1750-1757. doi:10.1378/ chest.12-2413

40. Jaillon S, Galdiero MR, Del Prete D, Cassatella MA, Garlanda C, Mantovani A. Neutrophils in innate and adaptive immunity. Semin Immunopathol. 2013;35: 377-394. doi:10.1007/s00281-013-0374-8

41. Tang D, Kang R, Coyne CB, Zeh HJ, Lotze MT. PAMPs and DAMPs: signal Os that spur autophagy and immunity. Immunol Rev. 2012;249: 158-175. doi:10.1111/j.1600-065X.2012.01146.x 
42. Zaas AK, Schwartz DA. Innate immunity and the lung: Defense at the interface between host and environment. Trends Cardiovasc Med. 2005;15: 195-202. doi:10.1016/j.tcm.2005.07.001

43. Blander JM, Sander LE. Beyond pattern recognition: five immune checkpoints for scaling the microbial threat. Nat Rev Immunol. 2012;12: 215-25. doi:10.1038/nri3167

44. Kawai T, Akira S. The role of pattern-recognition receptors in innate immunity: update on Toll-like receptors. Nat Immunol. 2010;11: 373-84. doi:10.1038/ni.1863

45. Krieg AM. CPG Motifs in bacterial DNA and their immune effects. Annu Rev Immunol. 2002;20: 709-760. doi:10.1146/annurev.immunol.20.100301.064842

46. Mathews RJ, Sprakes MB, McDermott MF. NOD-like receptors and inflammation. Arthritis Res Ther. 2008;10: 228. doi:10.1186/ar2525

47. Schneberger D, Aharonson-Raz K, Singh B. Monocyte and macrophage heterogeneity and Toll-like receptors in the lung. Cell Tissue Res. 2011;343: 97-106. doi:10.1007/s00441-010-1032-2

48. Singh D, Donnelly LE. Now We Know Who You Are: A Clear Description of Mononuclear Phagocyte Subsets in the Human Lung. Am J Respir Crit Care Med. 2016;193: 594-6. doi:10.1164/rccm.201511-2212ED

49. Gordon S, Taylor PR. Monocyte and macrophage heterogeneity. Nat Rev Immunol. 2005:5(12):953-64. doi:10.1038/nri1733

50. Hume DA. Macrophages as APC and the dendritic cell myth. J Immunol. 2008;181: 5829-35. doi:10.4049/ JIMMUNOL.181.9.5829

51. Kaufmann SHE, Dorhoi A. Molecular Determinants in Phagocyte-Bacteria Interactions. Immunity.2016;44: 476-491. doi:10.1016/j.immuni.2016.02.014

52. Chatterjee SN, Das J. Electron microscopic observations on the excretion of cell-wall material by Vibrio cholerae. J Gen Microbiol. 1967;49: 1-11. doi:10.1099/00221287-49-1-1

53. Devoe IW, Gilchrist JE. Release of endotoxin in the form of cell wall blebs during in vitro growth of Neisseria meningitidis. J Exp Med. 1973;138: 1156-67.

54. Bishop DG, Work E. An extracellular glycolipid produced by Escherichia coli grown under lysine-limiting conditions. Biochem J. 1965:96: 567-76.

55. Knox KW, Vesk M, Work E. Relation between excreted lipopolysaccharide complexes and surface structures of a lysine-limited culture of Escherichia coli. J Bacteriol. 1966;92: 1206-17.

56. Harding C, Heuser J, Stahl P. Receptor-mediated endocytosis of transferrin and recycling of the transferrin receptor in rat reticulocytes. J Cell Biol. 1983;97: 329-39.

57. Pan BT, Teng K, Wu C, Adam M, Johnstone RM. Electron microscopic evidence for externalization of the transferrin receptor in vesicular form in sheep reticulocytes. J Cell Biol. 1985;101: 942-8.

58. Raposo G, Nijman HW, Stoorvogel W, Liejendekker R, Harding C V, Melief CJ, et al. B lymphocytes secrete antigen-presenting vesicles. J Exp Med. 1996;183: 1161-72.

59. Zitvogel L, Regnault A, Lozier A, Wolfers J, Flament C, Tenza D, et al. Eradication of established murine tumors using a novel cell-free vaccine: dendritic cell derived exosomes. Nat Med. 1998;4: 594-600. doi:10.1038/nm0598-594

60. Yáñez-Mó M, Siljander PR-M, Andreu Z, et al (2015) Biological properties of extracellular vesicles and their physiological functions. J Extracell Vesicles 4:27066. doi: 10.3402/jev.v4.27066.

61. Nieri D, Neri T, Petrini S, Vagaggini B, Paggiaro P, Celi A, et al. Cell-derived microparticles and the lung Eur Respir Rev. 2016;25: 266-77. doi:10.1183/16000617.0009-2016

62. Kadota T, Fujita Y, Yoshioka Y, Araya J, Kuwano K, Ochiya T. Extracellular Vesicles in Chronic Obstructive Pulmonary Disease. Int J Mol Sci. 2016:17: 1801. doi:10.3390/ijms17111801

63. Torregrosa Paredes P, Esser J, Admyre C, Nord M, Rahman QK, Lukic A, et al. Bronchoalveolar lavage fluid exosomes contribute to cytokine and leukotriene production in allergic asthma. Allergy. 2012;67: 911-9. doi:10.1111/j.1398-9995.2012.02835.x 
64. Qazi KR, Torregrosa Paredes P, Dahlberg B, Grunewald J, Eklund A, Gabrielsson. Proinflammatory exosomes in bronchoalveolar lavage fluid of patients with sarcoidosis. Thorax. 2010;65(11):1016-24. doi: 10.1136/thx.2009.132027

65. Park JA, Sharif AS, Tschumperlin DJ, Lau L, Limbrey R, Howarth P, et al. Tissue factor-bearing exosome secretion from human mechanically stimulated bronchial epithelial cells in vitro and in vivo. J Allergy Clin Immunol. 2012;130: 1375-1383. doi:10.1016/j.jaci.2012.05.031

66. Lässer C, O'Neil SE, Shelke G V., Sihlbom C, Hansson SF, Gho YS, et al. Exosomes in the nose induce immune cell trafficking and harbour an altered protein cargo in chronic airway inflammation. J Transl Med. 2016;14: 181. doi:10.1186/s12967-016-0927-4

67. Soni S, Wilson MR, O'Dea KP, Yoshida M, Katbeh U, Woods SJ, et al. Alveolar macrophage-derived microvesicles mediate acute lung injury. Thorax. 2016;71: 1020-1029. doi:10.1136/thoraxjnl-2015-208032

68. Robbins PD, Morelli AE. Regulation of immune responses by extracellular vesicles. Nat Rev Immunol. 2014;14: 195-208. doi:10.1038/nri3622

69. Schwechheimer C, Kulp A, Kuehn MJ, Berleman J, Auer M, Deatherage B, et al. Modulation of bacterial outer membrane vesicle production by envelope structure and content. BMC Microbiol. BioMed Central; 2014;14: 324. doi:10.1186/s12866-014-0324-1

70. Olaya-Abril A, Prados-Rosales R, McConnell MJ, Martín-Peña R, González-Reyes JA, Jiménez-Munguía I, et al. Characterization of protective extracellular membrane-derived vesicles produced by Streptococcus pneumoniae. J Proteomics. 2014;106: 46-60. doi:10.1016/j.jprot.2014.04.023

71. Beveridge TJ. Virulence Factors Are Released from Pseudomonas aeruginosa in Association with Membrane Vesicles during Normal Growth and Exposure to Gentamicin : a Novel Mechanism of Enzyme Secretion. J bacteriol. 1995;177: 3998-4008.

72. Kadurugamuwa JL, Beveridge TJ. Natural release of virulence factors in membrane vesicles by Pseudomonas aeruginosa and the effect of aminoglycoside antibiotics on their release. J Antimicrob Chemother. 1997;40: 615-21.

73. Bhatnagar S, Shinagawa K, Castellino FJ, Schorey JS. Exosomes released from macrophages infected with intracellular pathogens stimulate a proinflammatory response in vitro and in vivo. Blood. 2007;110: 3234-3244. doi:10.1182/blood-2007-03-079152

74. Bhatnagar S, Schorey JS. Exosomes released from infected macrophages contain Mycobacterium avium glycopeptidolipids and are proinflammatory. J Biol Chem. 2007:282: 25779-25789. doi:10.1074/jbc. M702277200

75. Bhatnagar S, Schorey JS. Exosomes released from infected macrophages contain Mycobacterium avium glycopeptidolipids and are proinflammatory. J Biol Chem. 2007:282: 25779-25789. doi:10.1074/jbc. M702277200

76. Smith VL, Jackson L, Schorey JS, Smith VL, Jackson L, Schorey JS. Ubiquitination as a Mechanism To Transport Soluble Mycobacterial and Eukaryotic Proteins to Exosomes. J Immunol. 2016; doi:10.4049/ jimmunol.1403186

77. Athman JJ, Wang Y, McDonald DJ, Boom WH, Harding C V. Wearsch PA. Bacterial Membrane Vesicles Mediate the Release of Mycobacterium tuberculosis Lipoglycans and Lipoproteins from Infected Macrophages. J Immunol. 2015;195: 1044-53. doi:10.4049/jimmunol.1402894

78. Deatherage BL, Cookson BT. Membrane vesicle release in bacteria, eukaryotes, and archaea: a conserved yet underappreciated aspect of microbial life. Infect Immun. 2012;80: 1948-57. doi:10.1128/IAI.06014-11

79. Raposo G, Stoorvogel W. Extracellular vesicles: exosomes, microvesicles, and friends. J Cell Biol. 2013;200: 373-83. doi:10.1083/jcb.201211138

80. Colombo M, Moita C, van Niel G, Kowal J, Vigneron J, Benaroch P, et al. Analysis of ESCRT functions in exosome biogenesis, composition and secretion highlights the heterogeneity of extracellular vesicles. J Cell Sci. 2013;126: 5553-65. doi:10.1242/jcs.128868

81. Ostrowski M, Carmo NB, Krumeich S, Fanget I, Raposo G, Savina A, et al. Rab27a and Rab27b control different steps of the exosome secretion pathway. Nat Cell Biol. 2010;12: 13-19. doi:10.1038/ncb2000 
82. Gould SJ, Raposo G. As we wait: coping with an imperfect nomenclature for extracellular vesicles. J Extracell vesicles. 2013;2. doi:10.3402/jev.v2i0.20389

83. Théry C, Ostrowski M, Segura E. Membrane vesicles as conveyors of immune responses. Nat Rev Immunol. 2009; 9: 581-593. doi:10.1038/nri2567

84. Fang Y, Wu N, Gan X, Yan W, Morrell JC, Gould SJ. Higher-order oligomerization targets plasma membrane proteins and HIV gag to exosomes. PLoS Biol. 2007:5: e158. doi:10.1371/journal.pbio.0050158

85. Bobrie A, Colombo M, Krumeich S, Raposo G, Théry C. Diverse subpopulations of vesicles secreted by different intracellular mechanisms are present in exosome preparations obtained by differential ultracentrifugation. J Extracell vesicles. 2012;1. doi:10.3402/jev.v1i0.18397

86. Arraud N, Linares R, Tan S, Gounou C, Pasquet JM, Mornet S, et al. Extracellular vesicles from blood plasma: Determination of their morphology, size, phenotype and concentration. J Thromb Haemost. 2014;12: 614-627. doi:10.1111/jth.12554

87. Schwechheimer C, Kuehn MJ. Outer-membrane vesicles from Gram-negative bacteria: biogenesis and functions. Nat Rev Microbiol. 2015;13(10):605-19. doi: 10.1038/nrmicro3525.

88. Kulp A, Kuehn MJ, Annu Rev M. Biological functions and biogenesis of secreted bacterial outer membrane vesicles. Annu Rev Microbiol. 2012;64:163-184. doi: 10.1146/annurev.micro.091208.073413

89. Brown L, Wolf JM, Prados-Rosales R, Casadevall A. Through the wall: extracellular vesicles in Gram-positive bacteria, mycobacteria and fungi. Nat Rev Microbiol. 2015;13: 620-30. doi:10.1038/nrmicro3480

90. Deatheragea BL, Cooksona BT. Membrane vesicle release in bacteria, eukaryotes, and archaea: A conserved yet underappreciated aspect of microbial life. Infect Immun. 2012;80: 1948-1957. doi:10.1128/ |Al.06014-11

91. Marcilla A, Martin-Jaular L, Trelis M, de Menezes-Neto A, Osuna A, Bernal D, et al. Extracellular vesicles in parasitic diseases. J Extracell Vesicles. 2014;3. doi:10.3402/jev.v3.25040

92. Rachel R, Wyschkony I, Riehl S, Huber H. The ultrastructure of Ignicoccus: evidence for a novel outer membrane and for intracellular vesicle budding in an archaeon. Archaea. 2002;1: 9-18.

93. Ellen AF, Albers S-V, Huibers W, Pitcher A, Hobel CF V., Schwarz H, et al. Proteomic analysis of secreted membrane vesicles of archaeal Sulfolobus species reveals the presence of endosome sorting complex components. Extremophiles. 2009;13: 67-79. doi:10.1007/s00792-008-0199-x

94. Simpson RJ, Kalra H, Mathivanan S. ExoCarta as a resource for exosomal research. J Extracell Vesicles. 2012;1: 1-6. doi:10.3402/jev.v1i0.18374

95. Kalra H, Simpson RJ, Ji H, Aikawa E, Altevogt P, Askenase P, et al. Vesiclepedia: A Compendium for Extracellular Vesicles with Continuous Community Annotation. PLoS Biol. 2012;10: e1001450. doi:10.1371/ journal.pbio.1001450

96. Mathivanan S, Fahner CJ, Reid GE, Simpson RJ. ExoCarta 2012: database of exosomal proteins, RNA and lipids. Nucleic Acids Res. 2012;40: D1241-4. doi:10.1093/nar/gkr828

97. Kim D-K, Kang B, Kim OY, Choi D, Lee J, Kim SR, et al. EVpedia: an integrated database of high-throughput data for systemic analyses of extracellular vesicles. J Extracell Vesicles. 2013;2. doi:10.3402/jev.v2i0.20384

98. Van Deun J, Mestdagh P, Agostinis P, Akay Ö, Anand S, Anckaert J, et al. EV-TRACK: transparent reporting and centralizing knowledge in extracellular vesicle research. Nat Methods. 2017;14: 228-232. doi:10.1038/ nmeth.4185

99. Buzas El, Gyorgy B, Nagy G, Falus A, György B, Nagy G, et al. Emerging role of extracellular vesicles in inflammatory diseases. Nat Rev Rheumatol. 2014;10: 356-64. doi:10.1038/nrrheum.2014.19

100. Thery C, Ostrowski M, Segura E. Membrane vesicles as conveyors of immune responses. Nat Rev Immunol. 2009;9: 581-593. doi:10.1038/nri2567

101. MacDonald IA, Kuehn MJ. Offense and defense: microbial membrane vesicles play both ways. Res Microbiol. 2012;163: 607-18. doi:10.1016/j.resmic.2012.10.020

102. Schwechheimer C, Kuehn MJ. Outer-membrane vesicles from Gram-negative bacteria: biogenesis and functions. Nat Rev Microbiol. 2015;13: 605-619. doi:10.1038/nrmicro3525 
103. Ellis TN, Kuehn MJ. Virulence and Immunomodulatory Roles of Bacterial Outer Membrane Vesicles. Microbiol Mol Biol Rev. 2010;74: 81-94. doi:10.1128/MMBR.00031-09

104. Schwechheimer C, Kuehn MJ. Outer-membrane vesicles from Gram-negative bacteria: biogenesis and functions. Nat Rev Microbiol. 2015;13: 605-619. doi:10.1038/nrmicro3525

105. Schaar V, Nordström T, Mörgelin M, Riesbeck K. Moraxella catarrhalis outer membrane vesicles carry $\beta$-lactamase and promote survival of Streptococcus pneumoniae and Haemophilus influenzae by inactivating amoxicillin. Antimicrob Agents Chemother. 2011;55: 3845-53. doi:10.1128/AAC.01772-10

106. Manning AJ, Kuehn MJMJ, McDermott P, Walker R, White D, Kulp A, et al. Contribution of bacterial outer membrane vesicles to innate bacterial defense. BMC Microbiol. 2011;11: 258. doi:10.1186/1471-2180$11-258$

107. Vallejo MC, Nakayasu ES, Longo LVG, Ganiko L, Lopes FG, Matsuo AL, et al. Lipidomic analysis of extracellular vesicles from the pathogenic phase of Paracoccidioides brasiliensis. PLoS One. 2012;7: e39463. doi:10.1371/journal.pone.0039463

108. Rodrigues ML, Nakayasu ES, Oliveira DL, Nimrichter L, Nosanchuk JD, Almeida IC, et al. Extracellular vesicles produced by Cryptococcus neoformans contain protein components associated with virulence. Eukaryot Cell. 2008;7: 58-67. doi:10.1128/EC.00370-07

109. Albuquerque PC, Nakayasu ES, Rodrigues ML, Frases S, Casadevall A, Zancope-Oliveira RM, et al. Vesicular transport in Histoplasma capsulatum : an effective mechanism for trans-cell wall transfer of proteins and lipids in ascomycetes. Cell Microbiol. 2008;10: 1695-1710. doi:10.1111/j.1462-5822.2008.01160.x

110. Rodrigues ML, Nimrichter L, Oliveira DL, Frases S, Miranda K, Zaragoza O, et al. Vesicular polysaccharide export in Cryptococcus neoformans is a eukaryotic solution to the problem of fungal trans-cell wall transport. Eukaryot Cell. 2007;6: 48-59. doi:10.1128/EC.00318-06

111. Oliveira DL, Nakayasu ES, Joffe LS, Guimarães AJ, Sobreira TJP, Nosanchuk JD, et al. Characterization of Yeast Extracellular Vesicles: Evidence for the Participation of Different Pathways of Cellular Traffic in Vesicle Biogenesis. PLoS One. 2010;5: e11113. doi:10.1371/journal.pone.0011113

112. Lee E-Y, Choi D-Y, Kim D-K, Kim J-W, Park JO, Kim S, et al. Gram-positive bacteria produce membrane vesicles: proteomics-based characterization of Staphylococcus aureus-derived membrane vesicles. Proteomics. 2009; 9: 5425-36. doi:10.1002/pmic.200900338

113. Kazmierczak MJ, Wiedmann M, Boor KJ. Alternative sigma factors and their roles in bacterial virulence. Microbiol Mol Biol Rev. 2005;69: 527-43. doi:10.1128/MMBR.69.4.527-543.2005

114. Lee JH, Choi C-W, Lee T, Kim S II, Lee J-C, Shin J-H. Transcription Factor $\sigma B$ Plays an Important Role in the Production of Extracellular Membrane-Derived Vesicles in Listeria monocytogenes. PLoS One. 2013;8: e73196. doi:10.1371/journal.pone.0073196

115. Rath P, Huang C, Wang T, Wang T, Li H, Prados-Rosales R, et al. Genetic regulation of vesiculogenesis and immunomodulation in Mycobacterium tuberculosis. Proc Natl Acad Sci. 2013;110: E4790-7. doi:10.1073/ pnas.1320118110

116. MacKenzie A, Wilson HL, Kiss-Toth E, Dower SK, North RA, Surprenant A. Rapid secretion of interleukin-1 by microvesicle shedding. Immunity. 2001;15: 825-35. doi:10.1016/S1074-7613(01)00229-1

117. Zhang H-G, Liu C, Su K, Yu S, Zhang L, Zhang S, et al. A Membrane Form of TNF- Presented by Exosomes Delays T Cell Activation-Induced Cell Death. J Immunol. 2006;176: 7385-7393. doi:10.4049/jimmunol.176.12.7385

118. Singh PP, LeMaire C Fau - Tan JC, Tan Jc Fau - Zeng E, Zeng E Fau - Schorey JS, Schorey JS, One PL. Exosomes released from M. tuberculosis infected cells can suppress IFN-gamma mediated activation of naive macrophages. PLoS One. 2011;6(4):e18564. doi: 10.1371/journal.pone.0018564

119. Schorey JS, Harding C V. Extracellular vesicles and infectious diseases: new complexity to an old story. 2016. J Clin Invest; 2016;126: 1181-9. doi:10.1172/JCI81132

120. Eltom S, Dale N, Raemdonck KR, Stevenson CS, Snelgrove RJ, Sacitharan PK, et al. Respiratory infections cause the release of extracellular vesicles: implications in exacerbation of asthma/COPD. PLoS One. 2014:9: e101087. doi:10.1371/journal.pone.0101087 
121. Singh PP, Smith VL, Karakousis PC, Schorey JS. Exosomes isolated from mycobacteria-infected mice or cultured macrophages can recruit and activate immune cells in vitro and in vivo. J Immunol. 2012;189: 777-785. doi:10.4049/jimmunol.1103638

122. Bhatnagar S, Shinagawa K, Castellino FJ, Schorey JS. Exosomes released from macrophages infected with intracellular pathogens stimulate a proinflammatory response in vitro and in vivo. Blood. 2007:110: 3234-3244. doi:10.1182/blood-2007-03-079152

123. Giri PK, Schorey JS, One PL. Exosomes derived from M. bovis BCG infected macrophages activate antigen-specific CD4+ and CD8+ T cells in vitro and in vivo. PLoS One. 2008;3(6):e2461. doi:10.1371/ journal.pone.0002461

124. Beatty WL, Ullrich HJ, Russell DG. Mycobacterial surface moieties are released from infected macrophages by a constitutive exocytic event. Eur J Cell Biol. 2001;80: 31-40. doi:10.1078/0171-9335-00131

125. Dreux M, Garaigorta U, Boyd B, Décembre E, Chung J, Whitten-Bauer C, et al. Short-range exosomal transfer of viral RNA from infected cells to plasmacytoid dendritic cells triggers innate immunity. Cell Host Microbe. 2012;12: 558-70. doi:10.1016/j.chom.2012.08.010

126. Martin-Jaular L, Nakayasu ES, Ferrer M, Almeida IC, del Portillo HA. Exosomes from Plasmodium yoelii-Infected Reticulocytes Protect Mice from Lethal Infections. Rénia L, editor. PLoS One. 2011;6: e26588. doi:10.1371/journal.pone.0026588

127. Ren D, Nelson KL, Uchakin PN, Smith AL, Gu X-X, Daines DA, et al. Characterization of extended co-culture of non-typeable Haemophilus influenzae with primary human respiratory tissues. Exp Biol Med. 2012:237(5):540-7. doi: 10.1258/ebm.2012.011377

128. Sharpe SW, Kuehn MJ, Mason KM. Elicitation of epithelial cell-derived immune effectors by outer membrane vesicles of nontypeable Haemophilus influenzae. Infect Immun. 2011;79: 4361-4369. doi:10.1128/ |Al.05332-11

129. Sharpe SW, Kuehn MJ, Mason KM. Elicitation of epithelial cell-derived immune effectors by outer membrane vesicles of nontypeable Haemophilus influenzae. Infect Immun. 2011;79: 4361-4369. doi:10.1128/ |Al.05332-11

130. Roier S, Leitner DR, Iwashkiw J, Schild-Prüfert K, Feldman MF, Krohne G, et al. Intranasal immunization with nontypeable Haemophilus influenzae outer membrane vesicles induces cross-protective immunity in mice. PLoS One. 2012;7. doi:10.1371/journal.pone.0042664

131. Deknuydt F, Nordström T, Riesbeck K. Diversion of the host humoral response: a novel virulence mechanism of Haemophilus influenzae mediated via outer membrane vesicles. J Leukoc Biol. 2014;95: 1-9. doi:10.1189/jlb.1013527

132. Vidakovics MLAP, Jendholm J, Mörgelin M, Månsson A, Larsson C, Cardell L-O, et al. B cell activation by outer membrane vesicles--a novel virulence mechanism. PLoS Pathog. 2010;6: e1000724. doi:10.1371/ journal.ppat.1000724

133. Choi D-S, Kim D-K, Choi SJ, Lee J, Choi J-P, Rho S, et al. Proteomic analysis of outer membrane vesicles derived from Pseudomonas aeruginosa. Proteomics. 2011;11: 3424-3429. doi:10.1002/pmic.201000212

134. Kadurugamuwa JL, Beveridge TJ. Virulence factors are released from Pseudomonas aeruginosa in association with membrane vesicles during normal growth and exposure to gentamicin: a novel mechanism of enzyme secretion. J Bacteriol. 1995;177: 3998-4008.

135. Ellis TN, Leiman SA, Kuehn MJ. Naturally Produced Outer Membrane Vesicles from Pseudomonas aeruginosa Elicit a Potent Innate Immune Response via Combined Sensing of Both Lipopolysaccharide and Protein Components. J Bacteriol. 2010;78: 3822-3831. doi:10.1128/IAl.00433-10

136. Zhao K, Deng X, He C, Yue B, Wu M. Pseudomonas aeruginosa outer membrane vesicles modulate host immune responses by targeting the Toll-like receptor 4 signaling pathway. Infect Immun. 2013;81 4509-18. doi:10.1128/IAl.01008-13

137. Bauman SJ, Kuehn MJ. Purification of outer membrane vesicles from Pseudomonas aeruginosa and their activation of an IL-8 response. Microbes Infect. 2006;8: 2400-2408. doi:10.1016/j.micinf.2006.05.001 
138. Dalcin D, Ulanova M. The Role of Human Beta-Defensin-2 in Pseudomonas aeruginosa Pulmonary Infection in Cystic Fibrosis Patients. Infect Dis Ther. 2013;2: 159-66. doi:10.1007/s40121-013-0015-5

139. Koeppen K, Hampton TH, Jarek M, Scharfe M, Gerber SA, Mielcarz DW, et al. A Novel Mechanism of Host-Pathogen Interaction through sRNA in Bacterial Outer Membrane Vesicles. PLoS Pathog. 2016;12: e1005672. doi:10.1371/journal.ppat.1005672

140. Reddy MS, Bernstein JM, Murphy TF, Faden HS. Binding between outer membrane proteins of nontypeable Haemophilus influenzae and human nasopharyngeal mucin. Infect Immun. 1996;64: 1477-9.

141. Hill DJ, Toleman MA, Evans DJ, Villullas S, Van Alphen L, Virji M. The variable P5 proteins of typeable and non-typeable Haemophilus influenzae target human CEACAM1. Mol Microbiol. 2001;39: 850-862. doi:10.1046/j.1365-2958.2001.02233.x

142. Bookwalter JE, Jurcisek JA, Gray-Owen SD, Fernandez S, McGillivary G, Bakaletz LO. A carcinoembryonic antigen-related cell adhesion molecule 1 homologue plays a pivotal role in nontypeable Haemophilus influenzae colonization of the chinchilla nasopharynx via the outer membrane protein P5-homologous adhesin. Infect Immun. 2008;76: 48-55. doi:10.1128/IAl.00980-07

143. Miyamoto N, Bakaletz LO. Selective adherence of non-typeable Haemophilus influenzae (NTHi) to mucus or epithelial cells in the chinchilla Eustachian tube and middle ear. Microb Pathog. 1996;21: 343-356. doi:10.1006/mpat.1996.0067

144. Rosadini C V, Ram S, Akerley BJ. Outer membrane protein P5 is required for resistance of nontypeable Haemophilus influenzae to both the classical and alternative complement pathways. Infect Immun. 2014;82: 640-9. doi:10.1128/IAI.01224-13

145. Schaar V, Uddbä I, Nordströ T, Riesbeck K. Group A streptococci are protected from amoxicillin-mediated killing by vesicles containing b-lactamase derived from Haemophilus influenzae. J Antimicrob Chemother. 2014:69: 117-120 doi:10.1093/jac/dkt307

146. Hetherington S V. Patrick CC, Hansen EJ. Outer membrane protein binding sites of complement component 3 during opsonization of Haemophilus influenzae. Infect Immun. 1993;61: 5157-63.

147. Foxwell AR, Kyd JM, Cripps AW. Nontypeable Haemophilus influenzae: pathogenesis and prevention. Microbiol Mol Biol Rev. 1998;62: 294-308.

148. Tan TT, Morgelin M, Forsgren A, Riesbeck K. Haemophilus influenzae survival during complement-mediated attacks is promoted by Moraxella catarrhalis outer membrane vesicles. J Infect Dis. 2007;195: 1661-70. doi:10.1086/517611

149. Schaar V, De Vries SPW, Perez Vidakovics MLA, Bootsma HJ, Larsson L, Hermans PWM, et al. Multicomponent Moraxella catarrhalis outer membrane vesicles induce an inflammatory response and are internalized by human epithelial cells. Cell Microbiol. 2011;13: 432-449. doi:10.1111/j.1462-5822.2010.01546.x

150. Slevogt H, Zabel S, Opitz B, Hocke A, Eitel J, N'Guessan PD, et al. CEACAM1 inhibits Toll-like receptor 2triggered antibacterial responses of human pulmonary epithelial cells. Nat Immunol. 2008;9: 1270-1278. doi:10.1038/ni.1661

151. Luke NR, Allen S, Gibson BW, Campagnari AA. Identification of a 3-deoxy-D-manno-octulosonic acid biosynthetic operon in Moraxella catarrhalis and analysis of a KdsA-deficient isogenic mutant. Infect Immun. 2003;71: 6426-34. doi:10.1128/IAI.71.11.6426-6434.2003

152. Akgul G, Erturk A, Turkoz M, Turan T, Ichinose A, Nagatake T, et al. Role of Lipooligosaccharide in the Attachment of Moraxella catarrhalis to Human Pharyngeal Epithelial Cells. Microb Immunol. 2005;49: 931-935

153. Forsgren A, Brant M, Karamehmedovic M, Riesbeck K. The immunoglobulin D-binding protein MID from Moraxella catarrhalis is also an adhesin. Infect Immun. 2003;71: 3302-9. doi:10.1128/IAI.71.6.33023309.2003

154. Riesbeck K, Nordstrom T. Structure and immunological action of the human pathogen Moraxella catarrhalis IgD-binding protein. Crit Rev Immunol. 2006;26: 353-76. 
155. Perez Vidakovics MLA, Jendholm J, Mörgelin M, Månsson A, Larsson C, Cardell L-O, et al. B Cell Activation by Outer Membrane Vesicles-A Novel Virulence Mechanism. PLoS Pathog. 2010;6: e1000724. doi:10.1371/journal.ppat.1000724

156. Aebi C, Stone B, Beucher M, Cope LD, Maciver I, Thomas SE, et al. Expression of the CopB outer membrane protein by Moraxella catarrhalis is regulated by iron and affects iron acquisition from transferrin and lactoferrin. Infect Immun. 1996;64: 2024-30.

157. Cota-Gomez A, Vasil Al, Kadurugamuwa J, Beveridge TJ, Schweizer HP, Vasil ML. PlcR1 and PlcR2 are putative calcium-binding proteins required for secretion of the hemolytic phospholipase C of Pseudomonas aeruginosa. Infect Immun. 1997;65: 2904-13.

158. Ostroff RM, Vasil Al, Vasil ML. Molecular comparison of a nonhemolytic and a hemolytic phospholipase C from Pseudomonas aeruginosa. J Bacteriol. 1990;172: 5915-23.

159. MacEachran DP, Ye S, Bomberger JM, Hogan DA, Swiatecka-Urban A, Stanton BA, et al. The Pseudomonas aeruginosa secreted protein PA2934 decreases apical membrane expression of the cystic fibrosis transmembrane conductance regulator. Infect Immun. 2007:75: 3902-12. doi:10.1128/IAI.00338-07

160. Mashburn LM, Whiteley M. Membrane vesicles traffic signals and facilitate group activities in a prokaryote. Nature. 2005:437: 422-425. doi:10.1038/nature03925

161. Rasko D a., Sperandio V. Anti-virulence strategies to combat bacteria-mediated disease. Nat Rev Drug Discov. 2010;9: 117-128. doi:10.1038/nrd3013

162. Ciofu O, Beveridge TJ, Kadurugamuwa J, Walther-Rasmussen J, Høiby N. Chromosomal beta-lactamase is packaged into membrane vesicles and secreted from Pseudomonas aeruginosa. J Antimicrob Chemother. 2000;45: 9-13.

163. Kadurugamuwa JL, Beveridge TJ. Bacteriolytic effect of membrane vesicles from Pseudomonas aeruginosa on other bacteria including pathogens: conceptually new antibiotics. J Bacteriol. 1996;178: 2767-74.

164. Li Z, Clarke AJ, Beveridge TJ. A major autolysin of Pseudomonas aeruginosa: subcellular distribution, potential role in cell growth and division and secretion in surface membrane vesicles. J Bacteriol. 1996:178: 2479-88.

165. Pier G. Pseudomonas aeruginosa lipopolysaccharide: A major virulence factor, initiator of inflammation and target for effective immunity. Int J Med Microbiol. 2007;297: 277-295. doi:10.1016/j.jimm.2007.03.012

166. Hirst RA, Kadioglu A, O'callaghan C, Andrew PW. The role of pneumolysin in pneumococcal pneumonia and meningitis. Clin Exp Immunol. 2004;138: 195-201. doi:10.1111/j.1365-2249.2004.02611.x

167. Kerr AR, Adrian P V, Estevão S, de Groot R, Alloing G, Claverys J-P, et al. The Ami-AliA/AliB permease of Streptococcus pneumoniae is involved in nasopharyngeal colonization but not in invasive disease. Infect Immun. 2004;72: 3902-6. doi:10.1128/IAI.72.7.3902-3906.2004

168. Ogunniyi AD, Mahdi LK, Trappetti C, Verhoeven N, Mermans D, Van Der Hoek MB, et al. Identification of Genes That Contribute to the Pathogenesis of Invasive Pneumococcal Disease by In Vivo Transcriptomic Analysis. doi:10.1128/IAl.00295-12

169. Rajam G, Anderton JM, Carlone GM, Sampson JS, Ades EW. Pneumococcal Surface Adhesin A (PsaA). Crit Rev Microbiol. 2008;34: 131-142. doi:10.1080/10408410802275352

170. Weiser JN, Bae D, Fasching C, Scamurra RW, Ratner AJ, Janoff EN. Antibody-enhanced pneumococcal adherence requires IgA1 protease. Proc Natl Acad Sci. 2003;100: 4215-4220. doi:10.1073/ pnas.0637469100

171. Garcia P, Gonzalez MP, Garcia E, Garcia JL, Lopez R. The molecular characterization of the first autolytic lysozyme of Streptococcus pneumoniae reveals evolutionary mobile domains. Mol Microbiol. 1999;33: 128-138. doi:10.1046/j.1365-2958.1999.01455.x

172. Gosink KK, Mann ER, Guglielmo C, Tuomanen El, Masure HR. Role of novel choline binding proteins in virulence of Streptococcus pneumoniae. Infect Immun. 2000;68: 5690-5.

173. Mohan S, Hertweck C, Dudda A, Hammerschmidt S, Skerka C, Hallström T, et al. Tuf of Streptococcus pneumoniae is a surface displayed human complement regulator binding protein. Mol Immunol. 2014;62: 249-264. doi:10.1016/j.molimm.2014.06.029 
174. Roier S, Zingl FG, Cakar F, Durakovic S, Kohl P, Eichmann TO, et al. A novel mechanism for the biogenesis of outer membrane vesicles in Gram-negative bacteria. Nat Commun. 2016;7: 10515. doi:10.1038/ ncomms 10515 




\section{Chapter 2}

Gram-negative bacterial membrane vesicle release in response to the host-environment: different threats, same trick?

Charlotte Volgers, Paul H.M. Savelkoul, Frank R.M. Stassen

Critical reviews in Microbiology 2017; published online 


\begin{abstract}
Bacteria are confronted with a multitude of stressors when occupying niches within the host. These stressors originate from host defence mechanisms, other bacteria during niche competition or result from physiological challenges such as nutrient limitation. To counteract these stressors, bacteria have developed a stress-induced network to mount the adaptations required for survival. These stress-induced adaptations include the release of membrane vesicles from the bacterial envelope. Membrane vesicles can provide bacteria with a plethora of immediate and ultimate benefits for coping with environmental stressors. This review addresses how membrane vesicles aid Gram-negative bacteria to cope with host-associated stress factors, focusing on vesicle biogenesis and the physiological functions. As many of the pathways, that drive vesicle biogenesis, confer we propose that shedding of membrane vesicles by Gram-negative bacteria entails an integrated part of general stress responses.
\end{abstract}


"If you had to define stress, it would not be far off if you said it was the process of living. The process of living is the process of having stress and reacting to it." Stanley J. Sarnoff.

\section{INTRODUCTION}

Being single cell organisms, bacteria are constantly exposed to a variety of stressors. During niche occupation within the host, stress can be caused by defence mechanisms (host-associated and/or bacterial) and by passive stress caused by the host physiology, e.g. due to a limited nutrient availability [1-5]. To cope with these stressors, bacteria have developed an integrated network of stress-induced pathways to mount adaptations that aid survival [6]. A frequently observed response to various stressors is the release of bacterial membrane vesicles from the cell envelope [7-9]. These nanosized (10-300 nm) membrane vesicles are released from the envelope, consist of envelope lipids and proteins and contain periplasmic and cytoplasmic components. Membrane vesicles are implicated in many physiological and pathological processes as they can provide bacteria with means to acquire nutrients, aid in niche competition with other bacteria, provide protection against anti-bacterial components, and act as carriers of virulence factors $[8,10,11]$. Despite its high physiological relevance, only few studies have addressed the kinetics and physiological activity of membrane vesicles directly in the context of infection. Hence, it remains poorly understood how bacteria utilize membrane vesicles to cope with the host environment. In this review, we address the question how membrane vesicles aid Gram-negative bacteria to endure host-associated stressors. To get a better insight in this, the following three questions will be addressed: 1) what are the processes involved in vesicle biogenesis, 2) how are these processes triggered by host-associated factors, and 3) how can membrane vesicles contribute to the mechanisms which are being used by bacteria to deal with host-associated stressors. 


\section{BIOGENESIS OF MEMBRANE VESICLES BY GRAM-NEGATIVE BACTERIA}

Membrane vesicles are released from the bacterial envelope. Factors that compromise mechanisms for envelope maintenance, e.g. by affecting protein or lipid transport, are known to drive the formation of membrane vesicles (as reviewed in [8]. As is shown in figure 1, the Gram-negative envelope is composed of an inner glycerophospholipid bilayer, a peptidoglycan layer, and an outer membrane composed of a glycerophospholipid and a lipooligosaccharide layer. The space that separates the outer and inner membrane is termed the periplasmic space $[12,13]$. The mechanisms responsible for membrane vesicle biogenesis can be categorized into three models.

- Model A proposes that vesicle formation is triggered when mechanisms for the maintenance of lipid asymmetry are compromised (Fig. 1 Model A).

- Model B implies that membrane vesicle formation is induced by the accumulation of misfolded or unfolded proteins in the outer membrane (Fig. 1 Model B).

- Model C entails that membrane vesicles are formed because of lipopolysaccharide (LPS) modifications induced by intrinsic and extrinsic factors (Fig. 1 Model C).

The most important aspects of these models will be covered in the following paragraphs, as a starting point to assess how vesicle biogenesis is affected by host-associated factors.

\subsection{Model A: vesicle biogenesis induced by a compromised maintenance of envelope lipid asymmetry}

Envelope stability is established by carefully organized lipid interactions and the maintenance of envelope lipid asymmetry $[12,13]$. These interactions take place between lipids of the outer membrane and the peptidoglycan layer, the peptidoglycan layer and the Tol-Pal complex, and the peptidoglycan layer and outer membrane proteins (Omps) such as Omp A and Braun's lipoprotein (lpp), as is shown in figure 1. Modifications which affect lipid interactions in the envelope will result in the release of membrane vesicles as has been demonstrated elegantly by Deatherage et al. in Salmonella typhimurium [14]. Moreover, they demonstrated that modifications, which reduce the number of outer membrane-peptidoglycan interactions during division, lead to an increased membrane vesicle formation [14]. Also, decreased interactions between membrane lipids and peptidoglycan-associated proteins in the envelope have been shown to increase vesiculation. This is supported by several lines of evidence. First, the deletion of genes that encode either one of the peptidoglycan-associated proteins Oprl (the homologue of lpp), OmpA, Pal or TolA in Pseudomonas aeruginosa resulted an increased vesicle formation $[15,16]$. Similarly, TolA, TolQ, and Tol/Pal deletion mutants of Escherichia coli are characterized by an increased vesicle formation [17-19]. Moreover, OmpA deletion mutants of E. coli, Salmonella spp., Vibrio cholera, and Acinobacter baumanni also show an increased vesicle release $[14,20-22]$. 


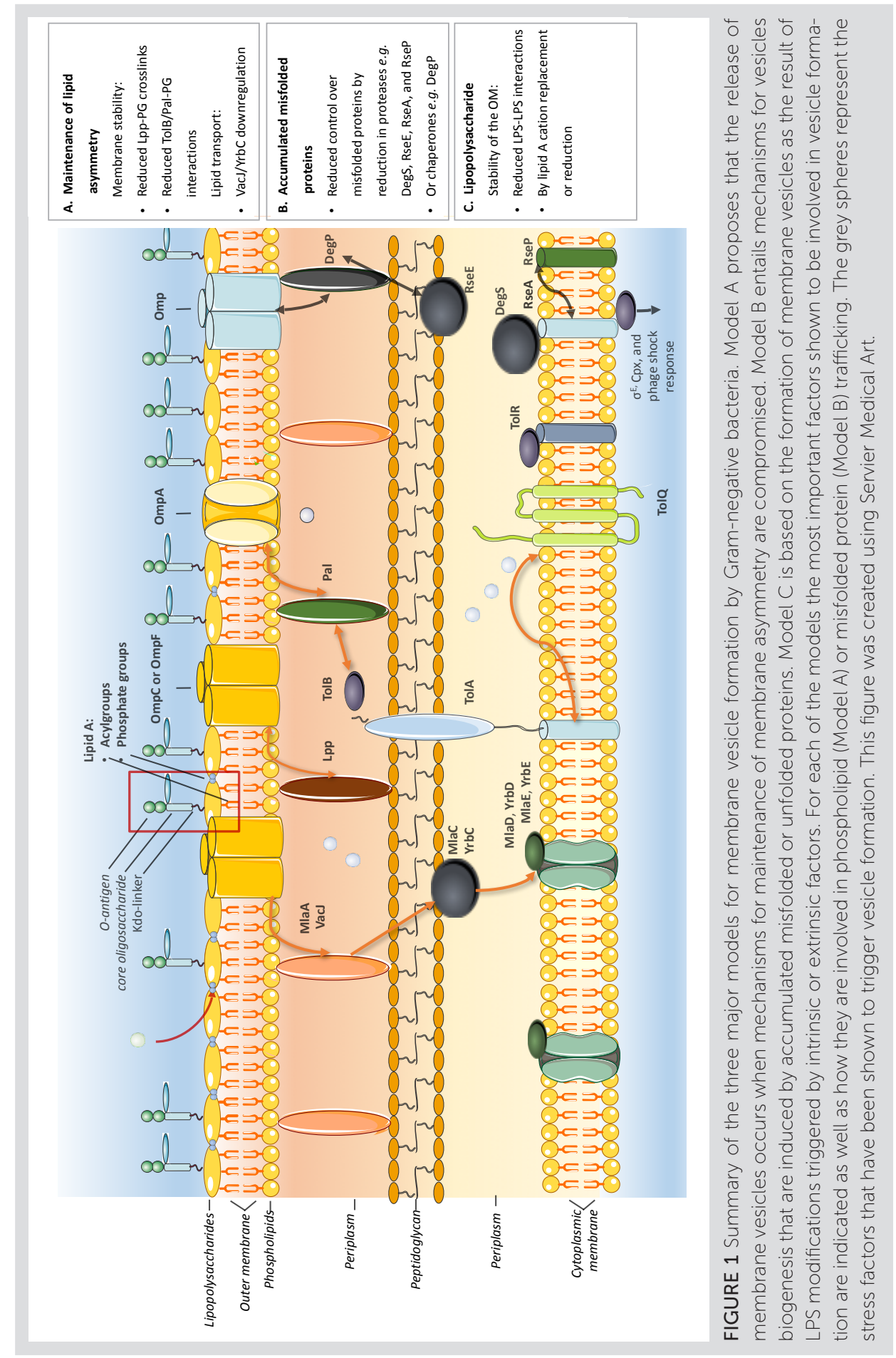


Other factors that have been shown to be involved in the maintenance of the envelope lipid asymmetry are components of ABC-transporters such as the VacJ/YrbC-transporter [12]. Recently, it has been shown in a study by Roier et al. that deletion or downregulation of the $\mathrm{VacJ} / \mathrm{YrbC}-\mathrm{ABC}$ transporter results in the formation of membrane vesicles by Haemophilus influenzae and V. cholerae [23]. For E. coli, this VacJ/YrbC-transporter homologue is known as the Mla (Maintance of outer membrane lipid asymmetry) transporter [24]. Studies on E. coli mutants with deletions in genes that encode Mla pathway proteins confirm that this transporter is involved in the formation of membrane vesicles [23]. Further evidence that a compromised functionality of this transporter enhances vesiculation is provided by Martorana et al. who showed that deletion or repression of components of the Mla transporter results in outer membrane phospholipid accumulation [25], which is a well-known inducer for vesicle formation [8,23].

\subsection{Model B: vesicle biogenesis induced by accumulated envelope compo- nents and extra-cytoplasmic stress responses}

Extra-cytoplasmic stress responses collectively describe mechanisms which respond to stress in systems located in the cell envelope, but outside the cytoplasm [6,26]. To date, three important stress responses have been shown to affect the release of membrane vesicles: 1) the sigma factor $E\left(\sigma^{\mathrm{E}}\right)$ response, 2) the two-component regulator Cpx response, and 3) the phage shock response [27].

The $\sigma^{E}$ and Cpx pathways, which are both activated by misfolded outer membrane proteins, generally contribute to bacterial pathogenesis and are required for the generation of resistance to a wide variety of stressors [6]. Genes under the control of $\sigma^{E}$ and Cpx partially overlap and encode proteins that are involved in the degradation and folding of envelope polypeptides (e.g. proteases and chaperones) and proteins involved in the formation and modulation of LPS. For the $\sigma^{\mathrm{E}}$ pathway, impairments have been shown to result in the accumulation of misfolded outer membrane proteins and an increased vesicle release. This was observed for $E$. coli and $P$. aeruginosa where mutations in RpoE (which encodes the $\sigma^{E}$ ) and $A l g \cup$ (that encodes the $P$. aeruginosa $\sigma^{E}$ homologue, sigma factor $H$ ) promoted vesicle release $[27,28]$. In E. coli, increased vesiculation was also observed upon deletion of the periplasmic sensor proteases RseA, DegS, and RseP which are involved in the recognition of unfolded/misfolded or accumulated free outer membrane proteins [29-32]. Other important components of the $\sigma^{\mathrm{E}}$ pathway are the protease/chaperone proteins known as DegP (E. coli) and MucD (P. aeruginosa). DegP and MucD mutants strains proved unable to control the amount of unfolded membrane proteins and exhibited an increased vesiculation [27,33,34].

Vesicle formation is also affected by the Cpx stress response in a similar fashion as the $\sigma^{E}$ response as deletion mutants of Cpx showed an increased vesicle formation which implies this pathway inhibits processes that induce vesiculation [27].

The release of membrane vesicles can also be affected by other extra-cytoplasmic stress responses such as the phage shock response that confers protection against e.g. hydrophobic organic solvents, ethanol, high temperature, a high $\mathrm{pH}$, and phage infection [6]. For example, exposure of S. typhimurium to $10 \%$ ethanol or E. coli to an increased tem- 
peratures or T4-bacteriophage infection have all been shown to lead to increased vesicle release $[27,35,36]$.

To conclude model B proposes a model for vesiculation in response to stressors that induce the accumulation of envelope components and/or as a consequence of inadequate coping with extra-cytoplasmic stress responses leading to accumulated envelope components.

\subsection{Model C: vesicle biogenesis induced by factors that interact with or induce LPS modifications}

The stability of the outer membrane is critically determined by interactions between LPS molecules on the surface of the outer membrane. The number and strength of these LPS-LPS interactions relies on the structure of LPS. Typically, LPS is composed of three domains: 1) lipid A that is anchored in the outer membrane, 2) the core domain that is linked to lipid A by the 3-deoxy-D-manno-oct-2-ulosonic acid (Kdo), and 3) the O-antigen (see Fig. 1 Model C). The core domain and O-antigen protrude into the extracellular environment.

LPS-LPS interactions are based on salt bridges formed by cations (e.g. $\mathrm{Mg}^{2+}$ and $\mathrm{Ca}^{2+}$ ) between the terminal phosphates located at the lipid A domain, and anionic sites on the core region of LPS [37]. External factors that affect these salt bridges and the LPS phenotype or conformation have been shown to affect the vesicle production. It has been posed that the mechanism by which this occurs depends on an increased membrane bending as the result of a) charge repulsion between two LPS moieties $[28,38,39]$ and/or b) the incorporation of certain external factors into the outer membrane $[39,40]$.

Charge repulsion depends on the orientation and composition of LPS (e.g. lipid A phosphorylation status and composition of the $O$-antigen) and can be neutralized by the formation of salt bridges [39,41]. Moreover, the acylation status can also affect the release of membrane vesicles. Elhenawy et al. proposed that this is mediated by the conformational change of LPS from cone-shaped towards a more cylindrical shape. Consequently, the negative charged groups (e.g., the phosphate groups on lipid A) are then brought in a closer proximity, resulting in charge repulsion and increased membrane bending [42]. The factors that have been shown to induce the vesiculation as well as the consequences of the LPS/LOS composition will be discussed below in more detail.

External factors that act on LPS are cationic antimicrobial peptides and cations such as $\mathrm{Mg}^{2+}$. The cationic antimicrobial peptides will be addressed in the paragraph on antimicrobial peptide-induced vesicle release (vide infra). Cations like $\mathrm{Mg}^{2+}$ have been shown to support the stability of outer membrane and addition of $\mathrm{MgCl}_{2}$ to E. coli cultures was found to repress the production of membrane vesicles [43]. Moreover, it has been shown that the LPS phenotype has a major impact on the formation of membrane vesicles. For $P$. aeruginosa, it has been shown that there are two types of LPS expressed, namely a short form (A-band LPS) and a longer form (B-band LPS) that has a high negative charge. This length and charge are determined by the O-antigen [44]. Strikingly, only the B-band LPS was found to be present in naturally formed membrane vesicles. Furthermore, P. aeruginosa strains that only expressed the A-band LPS showed a diminished vesicle release 
[45]. For S. typhimurium and E. coli it has been shown that LPS lipid A modifications are controlled by the two-component system PhoPQ $[46,47]$. This PhoPQ system is conserved in many Gram-negative bacterial species and senses low extracellular levels of $\mathrm{Mg}^{2+}$ and antimicrobial peptides such as polymyxin B (as reviewed by Groisman [47]). Direct evidence for the involvement of PhoPQ in vesicle biogenesis was provided by studies that demonstrated an increased vesicle formation by S. typhimurium and E. coli strains which overexpress the PhoPQ-induced components PagL and PagC (enzymes that de-acylate lipid A), respectively $[42,48]$. Importantly, this was shown to occur independently of the $\sigma^{e}$ and Cpx stress responses [42].

An extensive assessment of the outer membrane vesicle release by E. coli identified many enzymes of the LPS biogenesis pathway to be involved in the formation of membrane vesicles [49]. Several studies show an increased vesiculation on PagL overexpression: PagL is known to remove a secondary acyl group from the 3th position [42,50-52]. This is in line with the proposed model that the de-acylation pattern of lipid A alters the orientation of lipid A, which results in an increased membrane curvature $[42,53,54]$. However, as was suggested by Elhenawy et al., conditions that result in activation of PagL by PhoPQ perhaps also lead to the activation of other lipid A modifying enzymes. So, although de-acylation itself can result in an increased membrane vesicle release, it is possible that these effects are cancelled-out by other lipid A modifications. Moreover, de-acylated lipid A ( $L p x M$ deletion mutants) or monophosphorylated penta-acylated mutants ( $L p x M / L p x F$ double deletions mutants) did not show or only showed a slightly increased vesiculation as compared to wild-type bacteria $([55,56]$ and personal communication with Dr. SH. Kim and Prof. M. DeLisa, respectively).

Bacteria can modulate their LPS in response to their environment, which include changes in temperature, $\mathrm{pH}, \mathrm{MgCl}_{2}, \mathrm{NaCl}$, phosphate, sucrose concentrations, oxygen stress, and exposure to antimicrobial peptides [13,57-60]. Moreover, LPS modifications can also result from the activation of other pathways that affect vesiculation, such as a compromised functioning of the Tol-Pal system or ABC transporters as these mechanisms are involved in the biogenesis and/or transport of lipopolysaccharide components [17,61,62]. Therefore, it will be highly relevant to determine how the bacterial "vesiculation" phenotype is shaped by the environment, not only with a focus on the LPS phenotype but also on outer membrane characteristics that comprise the accumulation of misfolded proteins and the maintenance of the lipid asymmetry. 


\section{BACTERIAL VESICLE RELEASE IN RESPONSE TO HOST-ASSOCIATED ENVIRONMENTAL FACTORS}

The previous paragraphs summarised various studies in which deletion mutants were used to provide insights in processes at the bacterial envelope that drive the formation of membrane vesicles. The next step will be to determine how this can be integrated into physiological conditions. Essential progress is made by studies that performed transcriptome analysis of bacteria upon exposure to environmental stressors that are known to induce the release of membrane vesicles. When gene expression profiles of Neisseria meningitidis in response to several stressors were assessed, high resemblance was observed between the gene expression profiles of cysteine-deprived bacteria, bacteria exposed to oxidative stress, heat shock or iron depletion, and bacteria during interaction with host-cells [63]. This indicates that pathways induced by these stressors congregate and that the formation of outer membrane vesicles can form an integrated part of general stress responses. In the following paragraphs, we will address how host-related factors such as nutrient availability and antibacterial components affect the membrane vesicle release (summarized in table 1 ).

\subsection{Nutrient deprivation}

A study by van de Waterbeemd et al. demonstrated that cysteine depletion induces growth phase transition from the logarithmic into the stationary phase and that this results in an upregulation of genes related to oxidative stress including the iron-sulphur cluster, metal ion uptake, and stress [63]. Based on this, the authors proposed that cysteine depletion impairs the sulphur supply required to produce iron-sulphur complexes and that this results in oxidative stress and the formation of membrane vesicles. Nutrient depletion in general causes oxidative stress which results in the induction of extra-cytoplasmic stress responses (Model B)[6]. It is possible that oxidative stress affects membrane vesicle formation by modulation of the LPS biosynthesis (Model C) as the oxidative stress induced genes OxyR and SoxRS [64] were found to induce the expression of genes involved in lipid A and peptidoglycan biosynthesis, metal ion transport, and amino-acid biosynthesis [65]. Moreover, it was found that iron-limiting conditions induce an increased vesicle biogenesis by downregulating the $\mathrm{VacJ} /$ Yrb components of the VacJ/Yrb ABC transporter [23]. Thus, nutrient deprivation can also affect processes involved in the maintenance of the lipid asymmetry (Model A). Oxidative stress is also induced by other physiological conditions than nutrient deprivation, therefore vesiculation induced by oxidative stress will be discussed in more detail in the section on physiological stressors. Whether environmental stressors trigger one common mechanism for membrane vesicle formation or whether there are different processes on the membrane that account for vesicle formation is still largely unknown.

\subsection{Antimicrobial peptides and antibiotics}

Increased membrane vesicle formation in response to antimicrobial peptides and antibiotics is a well-described phenomenon. The antimicrobial peptides are classified and addressed here as bacteria-derived (i.e. quinolines, quinolones, and polymyxins: cationic antibiotics produced by Paenibacillus polymyxa), host-associated (i.e. lysozyme), or cationic antibiotics (i.e. aminoglycosides). Generally, the peptides and the antibiotics that trigger the formation of membrane vesicles have been shown to be cell envelope-di- 
rected, to induce the SOS response (oxidative stress), to alter the LPS structure, or a combination of the above [66]. Therefore, they can trigger the vesicle formation by one of the three models described above (A: lipid asymmetry maintenance, B: extra-cytoplasmic stress responses or C: LPS modification).

Bacteria-derived antimicrobial peptides, that have been shown to induce the release of membrane vesicles, are quinolones, quinolines, and polymyxins. Quinolones and quinolines are part of the quorum sensing system which allows bacteria to communicate and coordinate group actions. The antimicrobial quinoline PQS is the most important quorum sensing signal of $P$. aeruginosa and a potent inducer of membrane vesicle formation $[39,67,68]$. Interestingly, it has been demonstrated that PQS can induce its own release and the release of other quinolines and quinolones in a membrane vesicle-mediated way [69]. It seems likely that these signalling molecules can subsequently also trigger the release of additional/other membrane vesicles as several quinolones are structurally similar to PQS [70-72]. Despite this high similarity, at present only PQS is known to trigger the release of membrane vesicles and PQS was required and sufficient for membrane vesicle formation [73]. The mechanism behind this PQS-induced formation of membrane vesicles depends on the interaction of $P Q S$ with the lipid A region of LPS. The current hypothesis is that it increases the formation of membrane vesicles by disrupting the $\mathrm{Mg}^{2+}$ and $\mathrm{Ca}^{2+}$ salt bridges between the LPS molecules and by insertion into the outer membrane $[28,40]$. Although PQS is only produced by $P$. aeruginosa were it forms an intrinsic factor that stimulates the formation of membrane vesicles [39,69], it has been demonstrated that exogenously added PQS can also serve as an extrinsic factor for the formation of membrane vesicles by other Gram-negative bacteria $[39,43,73]$. Moreover, it also has to be noted that PQS can induce the formation of membrane vesicles by Gram-positive bacteria and even red blood cells, suggesting that PQS can also induce the release of membrane vesicles by alternative mechanisms $[40,43]$.

Polymyxin B and colistin are bacterial antimicrobial peptides that target the outer membrane by replacing $\mathrm{Mg}^{2+}$ and $\mathrm{Ca}^{2+}$ cations thereby destabilizing LPS-LPS bonds [74]. As indicated earlier, such destabilisation is a well-known stimulus for vesicle release. In line with this, MacDonald et al. reported that treatment of $P$. aeruginosa with polymyxin $B$ resulted in an increased vesicle release [75]. Also, the exposure of E. coli to polymyxin B and colistin enhanced the membrane vesicle release [76]. Importantly, host-associated environmental factors may also determine the sensitivity to vesiculation for example by the activation of two-component regulators. The most prominent two-component regulator by which this has been shown to occur is PhoPQ [77]. As mentioned earlier binding of antimicrobial peptides by S. typhimurium and E. coli can be sensed by the PhoPQ and $P h o P Q$ deletion mutants show an increased sensitivity to antimicrobial peptides $[46,78,79]$. Moreover, it was shown for S. typhimurium that low Mg ${ }^{2+}$ levels activate PhoPQ which was consequently found to promote resistance to these peptides $[46,47,80]$. Although, as the body's divalent cation levels are as high as 1-2 mM, it was thought that this system was not induced in the host [81]. A study based on S. typhimurium showed that high cation levels repress the PhoPQ system and that antimicrobial peptides, even in the presence of these cations, induce an activation [82]. Moreover, for $P$. aeruginosa it has been shown that this PhoPQ system is upregulated on contact with epithelial cells (within the presence of cations) and that this resulted in PhoPQ dependent modifications of lipid A [83]. To conclude, 
the host environment can result in the upregulation of PhoPQ and PagL dependent lipid A modifications leading to a decreased susceptibility to antimicrobial peptides. Although no direct link between vesiculation and host environment upregulation of PhoPQ has been made, it is tempting to speculate that the host environment can hereby affect the sensitivity to vesiculation.

At present the best studied host-associated antimicrobial peptide involved in membrane vesicles release is lysozyme. Lysozyme is released among others by epithelial cells and is found within the phagosome of phagocytes where it aids in bacterial degradation. Several studies have shown that exposure of $P$. aeruginosa and Francisella novicida to lysozyme not only results in cell lysis but also in the release of outer membrane vesicles. It acts as an antimicrobial substance by mimicking cationic antimicrobial peptides by its enzymatic muramidase activity $[84,85]$. As a muramidase, it interacts with the peptidoglycan structure and hydrolyses the glycosidic bond between the $\mathrm{N}$-acetylmuramic acid and $\mathrm{N}$-acetylglucosamine residues of the peptidoglycan backbone. Additionally, lysozymes' cationic peptide can also disrupt the outer membrane $[71,86]$. And although there is currently no consensus on the mechanism by which this occurs, it has been suggested that lysozyme induces the release of membrane vesicles in a similar fashion as gentamicin by the disruption of LPS-LPS bonds, as will be described below [85].

Several antibiotics, like gentamicin, amikacin, ciprofloxacin, mitomycin C and D-cycloserin have also been shown to induce vesicle formation. Gentamicin is known to inhibit the bacterial protein synthesis and the consensus is that it gains access to the cell via holes in the outer membrane that are created by membrane destabilization. This membrane destabilization occurs when gentamicin binds sites on LPS that are normally occupied by the $\mathrm{Mg}^{2+}$ and $\mathrm{Ca}^{2+}$ cations. This subsequently destabilizes the salt bridges between the LPS molecules resulting in disruptions of the outer membrane and results in an increased vesicle formation [87]. Moreover, treatment with another aminoglycoside amikacin has also been shown to induce vesiculation as it triggers the formation of blebs on the outer membrane by destabilization of LPS-LPS bonds [88]. Treatment of P. aeruginosa with ciprofloxacin, an antibiotic that leads to DNA damage and the activation of the SOS stress response, also enhanced the release of membrane vesicles [89]. This SOS stress response was required for the vesicle release as a mutant strain deficient in a protein critical for the induction of this stress response, showed a compromised vesicle release. A similar phenomenon is observed for several other antibiotics including mitomycin $C$ and $\mathrm{D}$-cycloserin. Mitomycin C is also thought to activate the SOS stress response in Shigella dysenteriae and has been shown to induce vesiculation [90-92].

Bacterial modification of the outer membrane in response to environmental factors such as antimicrobial peptides is an important strategy for survival. For example, a lipid A de-acylation is known to lead to a decreased susceptibility to cationic antimicrobial peptides. Also, some commensal bacteria that express the lipid A phosphatase LpxF displayed an enhanced resistance to antimicrobial peptides [93,94]. Therefore, to fully understand how environmental factors affect the release of membrane vesicles, it will be of the essence to link how bacterial modification of the outer membrane associates with the release of membrane vesicles. 


\subsection{Physiological stressors}

Besides the stressors mentioned above, it has been reported that physiological barriers such as oxidative stress, temperature, and oxygen tension can trigger stress responses and the release of bacterial membrane vesicles.

Oxidative stress has been shown to be a potent inducer of membrane vesicle release as hydrogen peroxide triggered the membrane vesicle release from $N$. meningitis [95] and $P$. aeruginosa [67]. As was mentioned above in the paragraph on nutrient deprivation, the exact mechanism behind this is still unclear. Yet it is known that oxidative stress, caused e.g. by the release of reactive oxygen species by host immune cells [96], can trigger the extra-cytoplasmic stress response and may affect the biogenesis of LPS. Also, it is well-known that changes in temperature can alter the lipid composition and thereby affect the release of membrane vesicles (94). This has been shown to occur in a species-dependent manner [6] For example, in E. coli exposure to increasing temperatures increased vesiculation [27], while in $P$. aeruginosa the release of membrane vesicles was not affected by changes in temperature, although the composition of the vesicles changed under these conditions [60,67].

Another important factor that can affect the release of outer membrane vesicles is oxygen stress. Sabra et al. show that oxygen limitation markedly reduced the release of extracellular proteins by $P$. aeruginosa [97]. In contrast, increased oxygen tension enhanced the vesicle release and the vesicle B-band LPS content of the vesicles [57].

\subsection{Other host-associated factors}

Finally, it has been reported that neuropeptides can also trigger the release of bacterial membrane vesicles which has been demonstrated for Salmonella enterica serovar Typhi upon exposure to norepinephrine [98]. As norepinephrine is already known to increase bacterial pathogenicity including by the enhancement of bacterial adhesion, motility and toxin release [99-103], it is possible that the release of membrane vesicles in response to norepinephrine contributes to this pathogenicity. Bacteria mostly come in contact with epinephrine and norepinephrine in the bloodstream and in the gut respectively [104,105], but it also has been shown that macrophages produce these peptides [106]. 


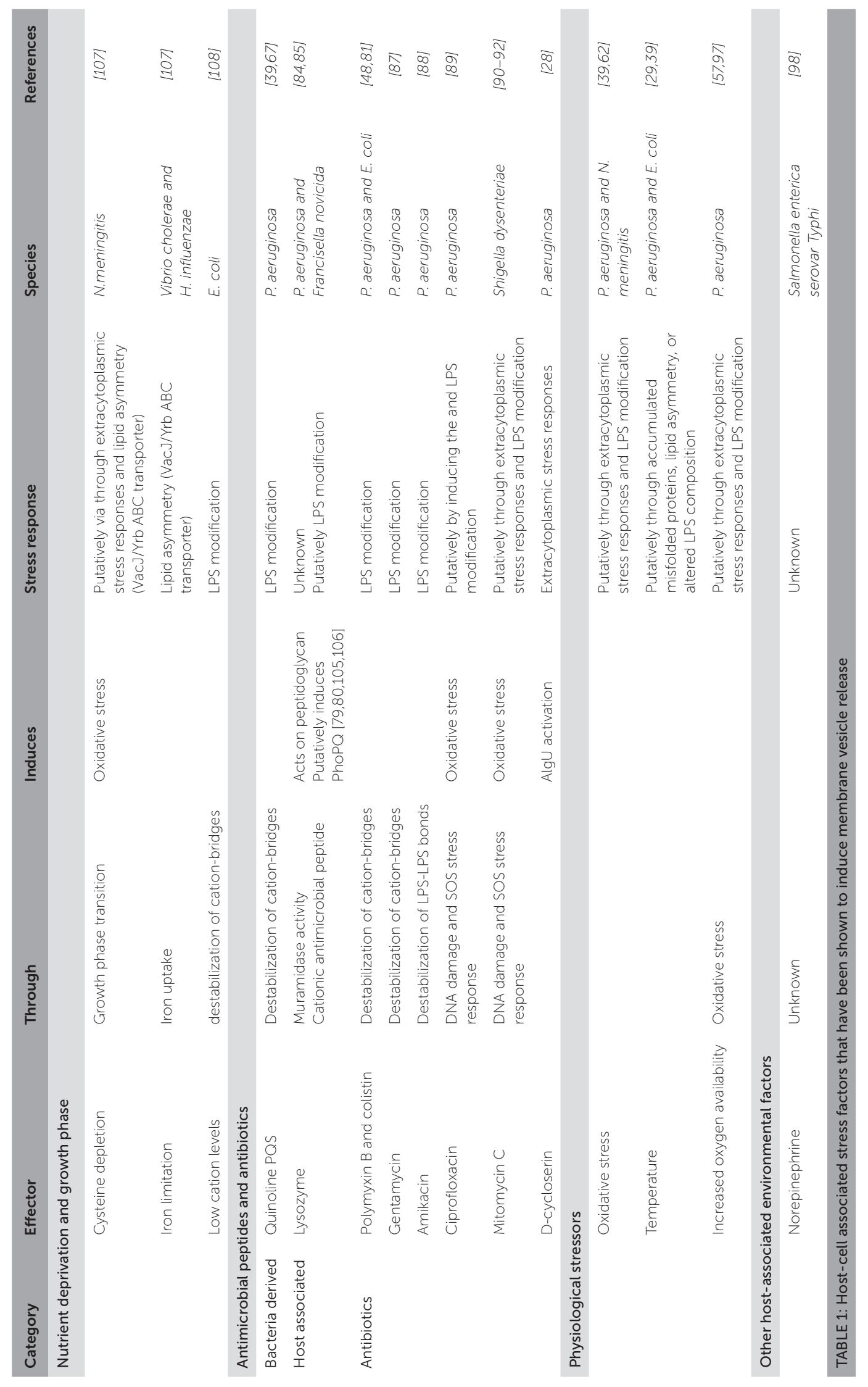




\section{PHYSIOLOGICAL ROLES OF BACTERIAL MEMBRANE VESICLES}

During exposure to acute or chronic environmental stressors, early sensing of and adaptation to these stressors are key for bacterial survival. The release of membrane vesicles has been shown to be sensitive to various stressors that can be encountered during infection as part of the host response or during niche occupation. In the next section. we will discuss several ways how bacterial membrane vesicles can provide bacteria with a competitive advantage when exposed to acute and chronic host-associated stressors.

\subsection{Protection against innate and adaptive immunity}

Bacterial invasion of the host initiates an immune response that generally involves the innate immune and complement system and may engage the adaptive immune system [76]. The physiological activity of membrane vesicles in this respect either consists of providing direct protection or by suppression of the immune response. An example of bacterial membrane vesicle-mediated protection against host factors is the protection of Porphyromonas gingivalis and Neisseria gonorrhoeae from human serum which was established by absorption of bactericidal factors [111-113]. Moreover, it has been demonstrated for a variety of bacteria that their membrane vesicles can also protect against complement [114]. For example, protection against complement factor C3 can be mediated by the outer membrane protein $\mathrm{P} 5$, which can be found in membrane vesicles from $H$. influenzae $[115,116]$. Protection against complement factor $\mathrm{C} 3$ has also been demonstrated for lipooligosaccharide and ubiquitous surface protein Usp A1/A2 on M. catarrhalis vesicles [114,117], and IgG binding protein SbI on vesicles from S. aureus [118]. Moreover, Vidakovics et al. demonstrated that M. catarrhalis also utilizes membrane vesicles to escape from adaptive immunity. This study shows that membrane vesicles can directly prevent the uptake and destruction of $M$. catarrhalis by tonsillar B cells and that this occurs in a super antigen MID dependent fashion [119].

It is well-known that bacteria suppress the immune response by modifying the LPS lipid A composition towards a less immunogenic or immunosilent form to promote bacterial survival during host niche occupation or invasion [120,121]. Interestingly, there seems to be a link between the LPS alterations that lead to this reduced immunogenicity and the release of membrane vesicles. The consequences for the physiological activity will be discussed below.

LPS is a major constituent of the bacterial envelope and of membrane vesicles. The structure of LPS critically determines whether it can be considered a virulence factor/toxin or whether is involved in the establishment and maintenance of immune homeostasis [37,122-124]. Important herein are the number of acyl chains and the phosphate groups on the lipid-A region of LPS. Hexa-acylated lipid A is known to exert the strongest agonistic activity and penta- or tetra-acylated in general have a lower agonistic activity but may even have an antagonistic activity [125].

It has been shown that both the background as well as the environment are determinants for the structure of the LPS [37,126-129]. S. typhimurium mutants that over-express PagL exhibit a phenotype that is characterized by an increased production of vesicles which 
are highly enriched in de-acylated lipid A [42]. Although it was not tested in this study, it is highly likely that the acylation phenotype has consequences for the immunogenicity of these vesicles, as de-acylated lipid A has strongly reduced immunostimulatory properties $[52,130]$. Besides the acylation pattern, the phosphate groups on lipid A also determine the immunogenicity of LPS [125]. Most lipid A structures contain two phosphate groups, which facilitate cation bridges and determine the stability of the outer membrane by facilitating these LPS-LPS bonds $[39,71,131]$. But as these groups also render bacteria susceptible to cationic antimicrobial peptides, a deletion or loss can therefore protect bacteria from these peptides. A deletion or loss of phosphate groups has also been shown to weaken the agonistic properties of LPS $[93,126,132,133]$. At present it is known that 4 'dephosphorylated-penta-acylated lipid A under natural conditions only leads to a slightly increased vesiculation (as was described above in 'Model C') $([55,56]$, and personal communication Dr. SH.Kim and Prof. M. DeLisa, respectively).

This is also reflected by the LPS phenotype of commensals. To achieve intestinal immune homeostasis a microbiota composition that is characterized by a low LPS endotoxicity is required $[93,125,134,135]$. A highly relevant study in this context is a study by Cullen et al. that shows that intestinal commensal bacteria accomplish this by LpxF mediated lipid A dephosphorylation [93]. Mass-spectrometric analysis established that the lipid A of human gut bacteria typically is 4'dephosphorylated-penta-acylated [93]. That this is reflected in lipid A composition of membrane vesicles from commensals is supported by a study by Elhenawy et al. which demonstrates that membrane vesicles from the common human gut commensal Bacteroides thetaoitaomicron were characterized by a 4'dephosphorylated penta-acylated lipid A moiety [136]. This implies a similar LPS phenotype for the outer membrane and outer membrane vesicles. Finally, it is key to mention that this lipid A phenotype also renders a phenotype that is highly resistant to cationic microbial peptides, suggesting that this phenotype may also affect the susceptibility to antimicrobial peptide induced vesiculation.

As membrane vesicles which contain a less immunogenic LPS may have therapeutic vaccine potential, the immune responses to these "detoxified" membrane vesicles have been studied extensively $[13,137]$. Studies have shown that membrane vesicles with pentatetra-acylated and/or mono-/dephosphorylated LPS are characterized by a reduced toxicity (as compared to hexa-acylated bisphosphorylated LPS) [55,137-140]. An elegant study by Kang et al. demonstrated that this may also have implication for regulation of immunity by commensals. This study, that characterized both the gut microbiome and the vesicle composition, showed that not all commensals release membrane vesicles and that the release of these vesicles predominantly occurs by bacteria that fall under the genera Bacteroidetes, Akkermansia, and Bifidobacteria. But more importantly they also show that membrane vesicles from the commensal Akkermansia muciniphila can provide protection against inflammation induced by $E$. coli-derived membrane vesicles and against DSS-induced colitis [141].

To conclude, structural alterations such as a decreased lipid A acylation or the loss of phosphate groups may render a phenotype that releases vesicles with weaker agonistic or even antagonistic properties that may serve to protect from immune recognition. Future 
research will be required 1) to assess the vesicle release by commensals and pathogens and 2) to determine whether vesicles from commensals are more immunoquiescent in character.

\subsection{Protection from antimicrobial peptides and antibiotics}

Within the host niche there may be a high level of competition amongst bacteria, and bacteria have adopted various strategies which aid in this competition. The release of bacterial antimicrobial peptides (bacteriocins), including quinolones and quinolines is one of them. As was mentioned above, the quinoline PQS is a potent inducer for the formation of membrane vesicles [142]. As PQS is known for its bacteriolytic properties, it has been suggested that PQS binding triggers the formation of membrane vesicles to 'shake off' $P Q S$ and other bacteriocins to prevent further damage. Although little is known on how membrane vesicle directly protect bacteria from the harmful effects of antimicrobial peptides, this theory is supported by data presented by Marsland and colleagues who showed that upon the addition of the PQS, $60-80 \%$ of this peptide was immediately removed by membrane vesicle formation [73].

Direct membrane vesicle-mediated protection against antimicrobial peptides and antibiotics has been demonstrated for polymyxin B and colistin $[28,76]$. Manning et al. demonstrated that treatment of $E$. coli with polymyxin $B$ and colistin induced the release of membrane vesicles which subsequently protected bacteria by adsorption of the peptides [76]. As it has been reported that antimicrobial peptides can bind the lipid A region of LPS it is highly likely that this adsorption occurs by the binding to membrane vesicle-associated LPS $[5,125]$. This is supported by the finding that vesicles from the E. coli ETEC strain, which contains an altered LPS structure rendering it resistance to polymyxin B, were unable to provide polymyxin B-sensitive strains with membrane vesicle-dependent protection [76] Bacterial vesicles can also transfer enzymes which protect against antibiotics as has been shown in a study by Schaar et al. [143]. They showed that exposure of M. catarrhalis to amoxicillin induces the release of $\beta$-lactamase-containing membrane vesicles that yielded protection against amoxicillin. The packing of $\beta$-lactamase into membrane vesicles was also observed for P. aeruginosa and Streptococcus aureus [143-145].

To conclude, at present it is recognized that membrane vesicles can provide protection against several antimicrobial peptides and antibiotics.

\subsection{Nutrient acquisition}

Besides active defence strategies there are also other properties of MVs membrane vesicles that contribute to bacterial survival and overcome host defence strategies to prevent bacterial niche occupation. A potent host strategy herein is the creation of an environment devoid of crucial nutrients such as iron. In response, bacteria have developed several ways to obtain iron from their environment (as reviewed by Schaible et al. [146]). However, as discussed before, iron and cysteine starvation are two well-known factors that trigger bacterial membrane vesicle release. Interestingly, there is compelling evidence demonstrating that membrane vesicles can contain factors (e.g. siderophores) that can bind iron and aid in the acquisition of iron. Membrane vesicles of $N$. meningitis have been shown to carry proteins for iron binding and uptake [147]. The presence of several proteins 
involved in the acquisition of iron has also been demonstrated for Moraxella membrane vesicles and these vesicles have been found to carry i.e. transferrin-binding protein $B$ and CopB $[148,149]$. Moreover, P. gingivalis-derived membrane vesicles have been shown to contain the heme binding protein FetB and several gingipains which are also involved in iron acquisition [150]. The release of siderophore-containing membrane vesicles has been demonstrated for Klebsiella pneumoniae, P. aeruginosa and Mycobacterium tuberculosis [151-153]. 


\section{CONCLUSION: DIFFERENT THREATS, SAME TRICK}

Bacteria are constantly exposed to a variety of stressors and many of them are now known to trigger the release of membrane vesicles from the outer membrane. Although mechanisms behind the membrane vesicle biogenesis are more and more understood, a general notion on the position of membrane vesicles in stress responses still needs to be unravelled. Yet, it is becoming clear that there are several aspects in the mechanisms for biogenesis which are common. An elegant example hereof that was addressed in this review, is a recent study by Roier et al. that reveals a mechanism for the membrane vesicle biogenesis that is highly conserved among Gram-negative bacteria. This mechanism depends on the $\mathrm{VacJ} / \mathrm{YrbC}$ ABC transporter and was found to be sensitive to iron depletion [23]. Another prominent example of a highly-conserved mechanism for the release of membrane vesicles is the modification of LPS and the release of membrane vesicles in response to environmental factors that bind LPS.

From a physiological perspective, membrane vesicles can aid in the acquisition of nutrients but also serve to protect from antimicrobial peptides, antibiotics, and innate and adaptive immune attacks. Protection from antimicrobial peptides is provided in two ways. Directly, when these peptides bind the bacterial outer membrane, the formation of membrane vesicles enables bacteria to 'shake off' threatening antimicrobial peptides to prevent further damage. Released membrane vesicles can act as decoys and provide further protection against these peptides. Finally, the structure of LPS is not static, but subject to constant remodelling and bacteria can modulate their LPS in response to environmental changes. Bacteria that modulate their LPS towards a less pro-inflammatory form also have been shown to release membrane vesicles with diminished pro-inflammatory characteristics. Moreover, it has been shown that membrane vesicles can provide as decoys to escape innate and adaptive immune responses. Hereby membrane vesicles may also help bacteria to shape their environment.

There is substantial evidence that indicates there is a high similarity between the different stress response pathways that are induced by environmental stressors like nutrient stress, oxidative stress, and interaction with the host $[49,95]$. An improved insight on how these stress responses affect the bacterial vesiculation phenotype as well as how they affect the composition and immunogenicity of the vesicles will be key in understanding how commensals and pathogens can conquer host defence mechanism during infection/ colonization. This is particularly important as the release of membrane vesicles is also associated with virulence, tolerance, the acquisition of nutrients, and antibiotic resistance. This knowledge is of paramount therapeutic value, not only can it benefit the development of detoxified membrane vesicles for vaccination purposes, it may also help to prevent phenotypic alterations that result in increased (membrane-vesicle mediated) bacterial resilience to treatment regimens. 


\section{REFERENCES}

1. Ribet D, Cossart P. How bacterial pathogens colonize their hosts and invade deeper tissues. Microbes Infect. 2015;17: 173-183. doi:10.1016/j.micinf.2015.01.004

2. Cobey S. Pathogen evolution and the immunological niche. Ann N Y Acad Sci. 2014;1320: 1-15. doi:10.1111/nyas.12493

3. Rohmer L, Hocquet D, Miller SI. Are pathogenic bacteria just looking for food? Metabolism and microbial pathogenesis. Trends Microbiol. 2011;19: 341-348. doi:10.1016/j.tim.2011.04.003

4. Freestone P. Communication between Bacteria and Their Hosts. Scientifica. 2013;2013:361073. doi:10.1155/2013/361073

5. Brogden $\mathrm{K}$ a. Antimicrobial peptides: pore formers or metabolic inhibitors in bacteria? Nat Rev Microbiol. 2005;3: 238-50. doi:10.1038/nrmicro1098

6. Rowley G, Spector M, Kormanec J, Roberts M. Pushing the envelope: extracytoplasmic stress responses in bacterial pathogens. Nat Rev Microbiol. 2006;4: 383-394. doi:10.1038/nrmicro1394

7. Kulp A, Kuehn MJ, Annu Rev M. Biological functions and biogenesis of secreted bacterial outer membrane vesicles. Ann Rev Microbiol. 2012;64:163-164. doi: 10.1146/annurev.micro.091208.073413

8. Schwechheimer C, Kuehn MJ. Outer-membrane vesicles from Gram-negative bacteria: biogenesis and functions. Nat Rev Microbiol. 2015;13: 605-619. doi:10.1038/nrmicro3525

9. Deatherage BL, Lara JC, Bergsbaken T, Barrett SLR, Lara S, Cookson BT. Biogenesis of bacterial membrane vesicles. Mol Microbiol. 2009;72: 1395-1407. doi:10.1111/j.1365-2958.2009.06731.x

10. MacDonald IA, Kuehn MJ. Offense and defense: microbial membrane vesicles play both ways. Res Microbiol. 2012;163: 607-18. doi:10.1016/j.resmic.2012.10.020

11. Kuehn MJ, Kesty NC. Bacterial outer membrane vesicles and the host-pathogen interaction. Genes Dev. 2005;19: 2645-55. doi:10.1101/gad.1299905

12. Silhavy TJ, Ruiz N, Kahne D. Advances in understanding bacterial outer-membrane biogenesis. Nat Rev Microbiol. 2006:4: 57-66. doi:10.1038/nrmicro1322

13. Henderson JC, Zimmerman SM, Crofts AA, Boll JM, Kuhns LG, Herrera CM, et al. The Power of Asymmetry : Architecture and Assembly of the Gram-Negative Outer Membrane Lipid Bilayer. 2016; 255-278. doi:10.1146/annurev-micro-102215-095308

14. Deatherage BL, Lara JC, Bergsbaken T, Barrett SLR, Lara S, Cookson BT. Biogenesis of bacterial membrane vesicles. Mol Microbiol. 2009;72: 1395-1407. doi:10.1111/j.1365-2958.2009.06731.x

15. Schooling SR, Beveridge TJ. Membrane Vesicles : an Overlooked Component of the Matrices of Biofilms. J. Bacteriol. 2006;188: 5945-5957. doi:10.1128/JB.00257-06

16. Wessel AK, Liew J, Kwon T, Marcotte EM, Whiteley M. Role of Pseudomonas aeruginosa peptidoglycan-associated outer membrane proteins in vesicle formation. J Bacteriol. 2013;195: 213-9. doi:10.1128/ JB.01253-12

17. Pietras Z, Jagusztyn-krynicka K. Peptidoglycan-associated lipoprotein ( Pal ) of Gram-negative bacteria : function, structure, role in pathogenesis and potential application in immunoprophylaxis. FEMS Microbiol Lett. 2009; doi:10.1111/j.1574-6968.2009.01659.x

18. Balsalobre C, Silván JM, Berglund S, Mizunoe Y, Uhlin BE, Wai SN. Release of the type I secreted alpha-haemolysin via outer membrane vesicles from Escherichia coli. Mol Microbiol. 2006;59: 99-112. doi:10.1111/j.1365-2958.2005.04938.x

19. Bernadac A, Gavioli M, Lazzaroni JC, Raina S, Lloubès R. Escherichia coli tol-pal mutants form outer membrane vesicles. J Bacteriol. 1998;180: 4872-8.

20. Song T, Mika F, Lindmark B, Liu Z, Schild S, Bishop A, et al. A new Vibrio cholerae sRNA modulates colonization and affects release of outer membrane vesicles. Mol Microbiol. 2008;70: 100-11. doi:10.1111/ j.1365-2958.2008.06392.x 
21. Sonntag I, Schwarz H, Hirota Y, Henning U. Cell envelope and shape of Escherichia coli: multiple mutants missing the outer membrane lipoprotein and other major outer membrane proteins. J Bacteriol. 1978;136: 280-5.

22. Moon DC, Choi CH, Lee JH, Choi C-W, Kim H-Y, Park JS, et al. Acinetobacter baumannii outer membrane protein A modulates the biogenesis of outer membrane vesicles. J Microbiol. 2012;50: 155-60. doi:10.1007/s12275-012-1589-4

23. Roier S, Zingl FG, Cakar F, Durakovic S, Kohl P, Eichmann TO, et al. A novel mechanism for the biogenesis of outer membrane vesicles in Gram-negative bacteria. Nat Commun. 2016;7: 10515. doi:10.1038/ ncomms 10515

24. Malinverni JC, Silhavy TJ. An ABC transport system that maintains lipid asymmetry in the Gram-negative outer membrane. Proc Natl Acad Sci. 2009;106: 8009-8014. doi:10.1073/pnas.0903229106

25. Martorana AM, Motta S, Di Silvestre D, Falchi F, Dehò G, Mauri P, et al. Dissecting Escherichia coli Outer Membrane Biogenesis Using Differential Proteomics. PLoS One. 2014; 9: e100941. doi:10.1371/journal. pone.0100941

26. Ruiz N, Kahne D, Silhavy TJ. Advances in understanding bacterial outer-membrane biogenesis. Nat Rev Microbiol. 2006;4: 57-66. doi:10.1038/nrmicro1322

27. McBroom AJ, Kuehn MJ. Release of outer membrane vesicles by Gram-negative bacteria is a novel envelope stress response. Mol Microbiol. 2007;63: 545-558. doi:10.1111/j.1365-2958.2006.05522.x

28. MacDonald IA, Kuehna MJ. Stress-induced outer membrane vesicle production by Pseudomonas aeruginosa. J Bacteriol. 2013;195: 2971-2981. doi:10.1128/JB.02267-12

29. McBroom AJ, Johnson AP, Vemulapalli S, Kuehn MJ. Outer membrane vesicle production by Escherichia coli is independent of membrane instability. J Bacteriol. 2006;188: 5385-92. doi:10.1128/JB.00498-06

30. Kim DY. Two stress sensor proteins for the expression of sigmaE regulon : DegS and RseB. J Microbiol. 2015;53: 306-310. doi:10.1007/s12275-015-5112-6

31. Sohn J, Grant R a., Sauer RT. OMP Peptides Activate the DegS Stress-Sensor Protease by a Relief of Inhibition Mechanism. Structure. 2009;17: 1411-1421. doi:10.1016/j.str.2009.07.017

32. Alba BM, Leeds JA, Onufryk C, Lu CZ, Gross CA. DegS and YaeL participate sequentially in the cleavage of RseA to activate the $\sigma \mathrm{E}$-dependent extracytoplasmic stress response. Genes Dev. 2002; 2156-2168. doi:10.1101/gad.1008902.ing

33. Mogensen JE, Otzen DE. Interactions between folding factors and bacterial outer membrane proteins. Mol Microbiol. 2005;57: 326-46. doi:10.1111/j.1365-2958.2005.04674.x

34. Tashiro Y, Sakai R, Toyofuku M, Sawada I, Nakajima-Kambe T, Uchiyama H, et al. Outer Membrane Machinery and Alginate Synthesis Regulators Control Membrane Vesicle Production in Pseudomonas aeruginosa. J Bacteriol. 2009;191: 7509-7519. doi:10.1128/JB.00722-09

35. Manning AJ, Kuehn MJMJ, McDermott P, Walker R, White D, Kulp A, et al. Contribution of bacterial outer membrane vesicles to innate bacterial defense. BMC Microbiol. 2011;11: 258. doi:10.1186/1471-2180$11-258$

36. Loeb MR, Kilner J. Release of a special fraction of the outer membrane from both growing and phage T4-infected Escherichia coli B. Biochim Biophys Acta. 1978; 514: 117-27.

37. Alexander C, Rietschel ET. Bacterial lipopolysaccharides and innate immunity. J Endotoxin Res. SAGE Publications; 2001;7: 167-202. doi:10.1177/09680519010070030101

38. Mashburn-Warren LM, Whiteley M. Special delivery: vesicle trafficking in prokaryotes. Mol Microbiol. 2006;61: 839-846. doi:10.1111/j.1365-2958.2006.05272.x

39. Mashburn-Warren L, Howe J, Garidel P, Richter W, Steiniger F, Roessle M, et al. Interaction of quorum signals with outer membrane lipids: insights into prokaryotic membrane vesicle formation. Mol Microbiol. 2008;69: 491-502. doi:10.1111/j.1365-2958.2008.06302.x

40. Schertzer JW, Whiteley M. A Bilayer-Couple Model of Bacterial Outer Membrane Vesicle. 2012;3: 1-7. doi:10.1128/mBio.00297-11.Editor 
41. Kadurugamuwa JL, Beveridge TJ. Natural release of virulence factors in membrane vesicles by Pseudomonas aeruginosa and the effect of aminoglycoside antibiotics on their release. J Antimicrob Chemother. 1997;40: 615-21.

42. Elhenawy W, Bording-Jorgensen M, Valguarnera E, Haurat MF, Wine E, Feldman MF. LPS Remodeling Triggers Formation of Outer Membrane Vesicles in Salmonella. MBio. 2016;7: e00940-16. doi:10.1128/ mBio.00940-16

43. Tashiro Y, Ichikawa S, Nakajima-Kambe T, Uchiyama H, Nomura N. Pseudomonas quinolone signal affects membrane vesicle production in not only gram-negative but also gram-positive bacteria. Microbes Environ. 2010;25: 120-125. doi:10.1264/jsme2.ME09182

44. Lam JS, Taylor VL, Islam ST, Hao Y, Kocíncová D. Genetic and Functional Diversity of Pseudomonas aeruginosa Lipopolysaccharide. Front Microbiol. 2011;2: 118. doi:10.3389/fmicb.2011.00118

45. Haurat MF, Elhenawy W, Feldman MF. Prokaryotic membrane vesicles: new insights on biogenesis and biological roles. Biol Chem. 2015:396: 95-109. doi:10.1515/hsz-2014-0183

46. Guo L, Lim KB, Gunn JS, Bainbridge B, Darveau RP, Hackett M, et al. Regulation of Lipid A Modifications by Salmonella typhimurium Virulence Genes phoP-phoQ. Science. 1997;276.

47. Groisman EA. The pleiotropic two-component regulatory system PhoP-PhoQ. J Bacteriol. 2001;183: 1835-42. doi:10.1128/JB.183.6.1835-1842.2001

48. Kitagawa R, Takaya A, Ohya M, Mizunoe Y, Takade A, Yoshida S, et al. Biogenesis of Salmonella enterica serovar typhimurium membrane vesicles provoked by induction of PagC. J Bacteriol. 2010;192: 5645-56. doi:10.1128/JB.00590-10

49. Kulp AJ, Sun B, Ai T, Manning AJ, Orench-rivera N. Genome-Wide Assessment of Outer Membrane Vesicle Production in Escherichia coli. 2015; 1-16. doi:10.1371/journal.pone.0139200

50. Brozek KA, Raetz CR. Biosynthesis of lipid A in Escherichia coli. Acyl carrier protein-dependent incorporation of laurate and myristate. J Biol Chem. American Society for Biochemistry and Molecular Biology: 1990;265: 15410-7.

51. Trent MS. Biosynthesis, transport, and modification of lipid A. Biochem Cell Biol. 2004;82: 71-86 doi:10.1139/o03-070

52. Kawasaki K, Ernst RK, Miller SI. 3-O-deacylation of lipid A by PagL, a PhoP/PhoQ-regulated deacylase of Salmonella typhimurium, modulates signaling through Toll-like receptor 4. J Biol Chem. 2004;279: 20044-8. doi:10.1074/jbc.M401275200

53. Schromm AB, Brandenburg K, Loppnow H, Moran AP, Koch MHJ, Rietschel ET, et al. Biological activities of lipopolysaccharides are determined by the shape of their lipid A portion. Eur J Biochem. 2000;267: 2008-2013. doi:10.1046/j.1432-1327.2000.01204.x

54. Zimmerberg J, Kozlov MM. How proteins produce cellular membrane curvature. Nat Rev Mol Cell Biol. 2006:7: 9-19. doi:10.1038/nrm1784

55. Lee T-Y, Kim C-U, Bae E-H, Seo S-H, Jeong DG, Yoon S-W, et al. Outer membrane vesicles harboring modified lipid A moiety augment the efficacy of an influenza vaccine exhibiting reduced endotoxicity in a mouse model. Vaccine. 2016; doi:10.1016/j.vaccine.2016.12.025

56. Chen L, Valentine JL, Huang C-J, Endicott CE, Moeller TD, Rasmussen JA, et al. Outer membrane vesicles displaying engineered glycotopes elicit protective antibodies. Proc Natl Acad Sci USA. doi:10.1073/ pnas.1518311113

57. Sabra W, Lunsdorf H, Zeng a. P. Alterations in the formation of lipopolysaccharide and membrane vesicles on the surface of Pseudomonas aeruginosa PAO1 under oxygen stress conditions. Microbiology. 2003;149: 2789-2795. doi:10.1099/mic.0.26443-0

58. Kropinski AM, Lewis V, Berry D. Effect of growth temperature on the lipids, outer membrane proteins, and lipopolysaccharides of Pseudomonas aeruginosa PAO. J Bacteriol. 1987;169: 1960-6.

59. McGroarty EJ, Rivera M. Growth-dependent alterations in production of serotype-specific and common antigen lipopolysaccharides in Pseudomonas aeruginosa PAO1. Infect Immun. 1990;58: 1030-7. 
60. Makin SA, Beveridge TJ. Pseudomonas aeruginosa PAO1 ceases to express serotype-specific lipopolysaccharide at 45 degrees C. J Bacteriol. 1996;178: 3350-2.

61. Gaspar JA, Thomas JA, Marolda CL, Valvano MA. Surface expression of O-specific lipopolysaccharide in Escherichia coli requires the function of the TolA protein. Mol Microbiol. 2000;38: 262-275. doi:10.1046/ j.1365-2958.2000.02094.x

62. Vines ED, Marolda CL, Balachandran A, Valvano MA. Defective O-Antigen Polymerization in tolA and pal Mutants of Escherichia coli in Response to Extracytoplasmic Stress. J Bacteriol. 2005;187: 3359-3368. doi:10.1128/JB.187.10.3359-3368.2005

63. van de Waterbeemd B, Zomer G, van den IJssel J, van Keulen L, Eppink MH, van der Ley P, et al. Cysteine Depletion Causes Oxidative Stress and Triggers Outer Membrane Vesicle Release by Neisseria meningitidis; Implications for Vaccine Development. PLoS One. 2013;8. doi:10.1371/journal.pone.0054314

64. Cabiscol E, Tamarit J, Ros J. Oxidative stress in bacteria and protein damage by reactive oxygen species. IntMicrobiol. 2000;3: 3-8.

65. Seo SW, Kim D, Szubin R, Palsson BO. Genome-wide Reconstruction of OxyR and SoxRS Transcriptional Regulatory Networks under Oxidative Stress in Escherichia coli K-12 MG1655. Cell Rep. 2015;12: 1289-1299. doi:10.1016/j.celrep.2015.07.043

66. Kohanski M a, Dwyer DJ, Collins JJ. How antibiotics kill bacteria: from targets to networks. Nat Rev Microbiol. 2010;8: 423-35. doi:10.1038/nrmicro2333

67. Macdonald IA, Macdonald IA. Characterizing Stress-Induced Outer Membrane Vesicle Production in Pseudomonas aeruginosa. J. Bacteriol. 2013;195(13):2971-2981. doi: 10.1128/JB.02267-12

68. Tashiro Y, Ichikawa S, Nakajima-Kambe T, Uchiyama H, Nomura N. Pseudomonas Quinolone Signal Affects Membrane Vesicle Production in not only Gram-Negative but also Gram-Positive Bacteria. Microbes Environ.2010;25: 120-125. doi:10.1264/jsme2.ME09182

69. Mashburn LM, Whiteley M. Membrane vesicles traffic signals and facilitate group activities in a prokaryote. Nature. 2005:437: 422-425. doi:10.1038/nature03925

70. Lecomte S, Baron MH, Chenon MT, Coupry C, Moreau NJ. Effect of magnesium complexation by fluoroquinolines on their antibacterial properties. Antimicrob Agents Chemother. 1994;38: 2810-2816. doi:10.1128/AAC.38.12.2810

71. Marshall AJ, Piddock LJ. Interaction of divalent cations, quinolones and bacteria. J Antimicrob Chemother. 1994;34: 465-83.

72. Mashburn-Warren L, Howe J, Garidel P, Richter W, Steiniger F, Roessle M, et al. Interaction of quorum signals with outer membrane lipids: Insights into prokaryotic membrane vesicle formation. Mol Microbiol. 2008;69: 491-502. doi:10.1111/j.1365-2958.2008.06302.x

73. Mashburn LM, Whiteley M. Membrane vesicles traffic signals and facilitate group activities in a prokaryote Nature. 2005:437: 422-425. doi:10.1038/nature03925

74. Moore RA., Hancock REW. Involvement of outer membrane of Pseudomonas cepacia in aminoglycoside and polymyxin resistance. Antimicrob Agents Chemother. 1986;30: 923-926. doi:10.1128/AAC.30.6.923

75. Macdonald IA, Kuehn MJ. Stress-induced outer membrane vesicle production by Pseudomonas aeruginosa. J Bacteriol. 2013;195: 2971-81. doi:10.1128/JB.02267-12

76. Manning AJ, Kuehn MJ, McDermott P, Walker R, White D, Kulp A, et al. Contribution of bacterial outer membrane vesicles to innate bacterial defense. BMC Microbiol. 2011;11: 258. doi:10.1186/1471-2180$11-258$

77. Poole K. Bacterial stress responses as determinants of antimicrobial resistance. 2012; 1-21. doi:10.1093/ $\mathrm{jac} / \mathrm{dks} 196$

78. Trent MS, Pabich W, Raetz CR, Miller SI. A PhoP/PhoQ-induced Lipase (PagL) that catalyzes 3-O-deacylation of lipid A precursors in membranes of Salmonella typhimurium. J Biol Chem. 2001;276: 9083-92. doi:10.1074/jbc.M010730200 
79. Dalebroux ZD, Matamouros S, Whittington D, Bishop RE, Miller SI. PhoPQ regulates acidic glycerophospholipid content of the Salmonella Typhimurium outer membrane. Proc Natl Acad Sci U S A. 2014;111: 1963-8. doi:10.1073/pnas.1316901111

80. Shi Y, Cromie MJ, Hsu F-F, Turk J, Groisman EA. PhoP-regulated Salmonella resistance to the antimicrobial peptides magainin 2 and polymyxin B. Mol Microbiol. 2004;53: 229-241. doi:10.1111/j.13652958.2004.04107.x

81. Fernández L, Gooderham WJ, Bains M, McPhee JB, Wiegand I, Hancock REW. Adaptive resistance to the 'last hope' antibiotics polymyxin B and colistin in Pseudomonas aeruginosa is mediated by the novel two-component regulatory system ParR-ParS. Antimicrob Agents Chemother. 2010;54: 3372-3382. doi:10.1128/AAC.00242-10

82. Bader MW, Sanowar S, Daley ME, Schneider AR, Cho U, Xu W, et al. Recognition of Antimicrobial Peptides by a Bacterial Sensor Kinase. Cell. 2005;122: 461-472. doi:10.1016/j.cell.2005.05.030

83. Gellatly SL, Needham B, Madera L, Trent MS, Hancock REW. The Pseudomonas aeruginosa PhoP-PhoQ two-component regulatory system is induced upon interaction with epithelial cells and controls cytotoxicity and inflammation. Infect Immun. 2012;80: 3122-31. doi:10.1128/IAI.00382-12

84. McCaig WD, Koller A, Thanassi DG. Production of outer membrane vesicles and outer membrane tubes by Francisella novicida. J Bacteriol. 2013;195: 1120-32. doi:10.1128/JB.02007-12

85. Metruccio MME, Evans DJ, Gabriel MM, Kadurugamuwa JL, Fleiszig SMJ. Pseudomonas aeruginosa Outer Membrane Vesicles Triggered by Human Mucosal Fluid and Lysozyme Can Prime Host Tissue Surfaces for Bacterial Adhesion. Front Microbiol. 2016;7: 871. doi:10.3389/fmicb.2016.00871

86. Davis KM, Weiser JN. Modifications to the peptidoglycan backbone help bacteria to establish infection. Infect Immun. 2011;79: 562-570. doi:10.1128/IAl.00651-10

87. Martin NL, Beveridge TJ. Gentamicin interaction with Pseudomonas aeruginosa cell envelope. Antimicrob Agents Chemother. 1986;29: 1079-87.

88. Walker SG, Beveridge TJ. Amikacin disrupts the cell envelope of Pseudomonas aeruginosa ATCC 9027. Can J Microbiol. 1988;34: 12-18. doi:10.1139/m88-003

89. Maredia R, Devineni N, Lentz P, Dallo SF, Yu J, Guentzel N, et al. Vesiculation from Pseudomonas aeruginosa under SOS. ScientificWorldJournal. 2012;2012: 402919. doi:10.1100/2012/402919

90. Gray MD, Lampel KA, Strockbine NA, Fernandez RE, Melton-Celsa AR, Maurelli AT. Clinical isolates of Shiga toxin 1a-producing Shigella flexneri with an epidemiological link to recent travel to Hispañiola. Emerg Infect Dis. 014;20: 1669-77. doi:10.3201/eid2010.140292

91. Kogoma T, Torrey TA, Connaughton MJ. Induction of UV-resistant DNA replication in Escherichia coli: Induced stable DNA replication as an SOS function. MGG Mol Gen Genet. 1979;176: 1-9. doi:10.1007/ BF00334288

92. Dutta S, lida K, Takade A, Meno Y, Nair GB, Yoshida S. Release of Shiga toxin by membrane vesicles in Shigella dysenteriae serotype 1 strains and in vitro effects of antimicrobials on toxin production and release. Microbiol Immunol. 2004;48: 965-9.

93. Cullen TW, Schofield WB, Barry NA, Putnam EE, Rundell EA, Trent MS, et al. Antimicrobial peptide resistance mediates resilience of prominent gut commensals during inflammation. Science. 2015;347: 170-5 doi:10.1126/science.1260580

94. Cullen TW, Schofield WB, Barry NA, Putnam EE, Rundell EA, Trent MS, et al. Antimicrobial peptide resistance mediates resilience of prominent gut commensals during inflammation. Science. 2015;347: 170-175. doi:10.1126/science.1260580

95. van de Waterbeemd B, Zomer G, van den IJssel J, van Keulen L, Eppink MH, van der Ley P, et al. Cysteine Depletion Causes Oxidative Stress and Triggers Outer Membrane Vesicle Release by Neisseria meningitidis; Implications for Vaccine Development. PLoS One. 2013;8: e54314. doi:10.1371/journal. pone.0054314

96. Nathan C, Cunningham-Bussel A. Beyond oxidative stress: an immunologist's guide to reactive oxygen species. Nat Rev Immunol. 2013;13: 349-61. doi:10.1038/nri3423 
97. Sabra W, Kim EJ, Zeng AP. Physiological responses of Pseudomonas aeruginosa PAO1 to oxidative stress in controlled microaerobic and aerobic cultures. Microbiology. 2002;148: 3195-3202. doi:10.1099/00221287-148-10-3195

98. Karavolos MH, Bulmer DM, Spencer H, Rampioni G, Schmalen I, Baker S, et al. Salmonella Typhi sense host neuroendocrine stress hormones and release the toxin haemolysin E. EMBO Rep. 2011;12: 252-258. doi:10.1038/embor.2011.4

99. Vlisidou I, Lyte M, van Diemen PM, Hawes P, Monaghan P, Wallis TS, et al. The Neuroendocrine Stress Hormone Norepinephrine Augments Escherichia coli O157:H7-Induced Enteritis and Adherence in a Bovine Ligated Ileal Loop Model of Infection. Infect Immun. 2004;72: 5446-5451. doi:10.1128/IAI.72.9.54465451.2004101.

100. Lyte M, Erickson AK, Arulanandam BP, Frank CD, Crawford MA, Francis DH. Norepinephrine-Induced Expression of the K99 Pilus Adhesin of Enterotoxigenic Escherichia coli. Biochem Biophys Res Commun. 1997;232: 682-686. doi:10.1006/bbrc.1997.6356

101. Lyte M, Arulanandam BP, Frank CD. Production of Shiga-like toxins by Escherichia coli O157:H7 can be influenced by the neuroendocrine hormone norepinephrine. J Lab Clin Med. 1996;128: 392-8.

102. Nakano M, Takahashi A, Sakai Y, Nakaya Y. Modulation of pathogenicity with norepinephrine related to the type III secretion system of Vibrio parahaemolyticus. J Infect Dis. 2007;195: 1353-60. doi:10.1086/513275

103. Bearson BL, Bearson SMD. The role of the QseC quorum-sensing sensor kinase in colonization and norepinephrine-enhanced motility of Salmonella enterica serovar typhimurium. Microb Pathog. 2008;44: 271-278. doi:10.1016/j.micpath.2007.10.001

104. Boyanova L. Stress hormone epinephrine (adrenaline) and norepinephrine (noradrenaline) effects on the anaerobic bacteria. Anaerobe. 2017;44: 13-19. doi:10.1016/j.anaerobe.2017.01.003

105. Hughes DT, Sperandio V. Inter-kingdom signalling : communication between bacteria and their hosts. Nature. 2008;6: 111-120. doi:10.1038/nrmicro1836102.

106. Flierl MA, Rittirsch D, Nadeau BA, Sarma JV, Day DE, Lentsch AB, et al. Upregulation of Phagocyte-Derived Catecholamines Augments the Acute Inflammatory Response. Bozza P, editor. PLoS One. 2009; 4: e4414. doi:10.1371/journal.pone.0004414

107. Roier S, Zingl FG, Cakar F, Durakovic S, Kohl P, Eichmann TO, et al. A novel mechanism for the biogenesis of outer membrane vesicles in Gram-negative bacteria. Nat Commun. 2016;7: 10515. doi:10.1038/ ncomms10515

108. Tashiro Y, Sakai R, Toyofuku M, Sawada I, Nakajima-Kambe T, Uchiyama H, et al. Outer membrane machinery and alginate synthesis regulators control membrane vesicle production in Pseudomonas aeruginosa. J Bacteriol. 2009;191: 7509-19. doi:10.1128/JB.00722-09

109. Macfarlene ELA, Kwasnicka A, Hancock REW. Role of Pseudomonas aeruginosa Phop-PhoQ in resistance to antimicrobial cationic peptides and aminoglycosides. Microbiology. 2000;146: 2543-2554. doi:10.1099/00221287-146-10-2543

110. Kwon DH, Lu CD. Polyamines induce resistance to cationic peptide, aminoglycoside, and quinolone antibiotics in Pseudomonas aeruginosa PAO1. Antimicrob Agents Chemother. 2006;50: 1615-1622. doi:10.1128/AAC.50.5.1615-1622.2006

111. Grenier D, Bertrand J, Mayrand D. Porphyromonas gingivalis outer membrane vesicles promote bacterial resistance to chlorhexidine. Oral Microbiol Immunol. 1995;10: 319-20.

112. Pettit RK, Judd RC. The interaction of naturally elaborated blebs from serum-susceptible and serum-resistant strains of Neisseria gonorrhoeae with normal human serum. Mol Microbiol. 1992;6: 729-34. Available: http://www.ncbi.nlm.nih.gov/pubmed/1574002

113. Grenier D, Bélanger M. Protective effect of Porphyromonas gingivalis outer membrane vesicles against bactericidal activity of human serum. Infect Immun. 1991;59: 3004-8.

114. Tan TT, Mörgelin M, Forsgren A, Riesbeck K. Haemophilus influenzae Survival during Complement-Mediated Attacks Is Promoted by Moraxella catarrhalis Outer Membrane Vesicles. J Infect Dis. 2007;195: 1661-1670. doi:10.1086/517611 
115. Rosadini C V. Ram S, Akerley BJ. Outer membrane protein P5 is required for resistance of nontypeable Haemophilus influenzae to both the classical and alternative complement pathways. Infect Immun. 2014:82: 640-9. doi:10.1128/IAI.01224-13

116. Sharpe SW, Kuehn MJ, Mason KM. Elicitation of epithelial cell-derived immune effectors by outer membrane vesicles of nontypeable haemophilus influenzae. Infect Immun. 2011;79: 4361-4369. doi:10.1128/ |Al.05332-11

117. Nordström T, Blom AM, Tan TT, Forsgren A, Riesbeck K. lonic binding of C3 to the human pathogen Moraxella catarrhalis is a unique mechanism for combating innate immunity. J Immunol. 2005;175: 3628-36.

118. Burman JD, Leung E, Atkins KL, O'Seaghdha MN, Lango L, Bernadó P, et al. Interaction of human complement with Sbi, a staphylococcal immunoglobulin-binding protein: indications of a novel mechanism of complement evasion by Staphylococcus aureus. J Biol Chem. 2008;283: 17579-93.

119. Perez Vidakovics MLA, Jendholm J, Mörgelin M, Månsson A, Larsson C, Cardell L-O, et al. B Cell Activation by Outer Membrane Vesicles-A Novel Virulence Mechanism. PLoS Pathog. 2010;6: e1000724. doi:10.1371/journal.ppat.1000724

120. Needham BD, Carroll SM, Giles DK, Georgiou G, Whiteley M, Trent MS. Modulating the innate immune response by combinatorial engineering of endotoxin. Proc Natl Acad Sci U S A. 2013;110: 1464-9. doi:10.1073/pnas.1218080110

121. Raetz CRH, Reynolds CM, Trent MS, Bishop RE. Lipid A modification systems in gram-negative bacteria. Annu Rev Biochem. 2007:76: 295-329. doi:10.1146/annurev.biochem.76.010307.145803

122. Montminy SW, Khan N, McGrath S, Walkowicz MJ, Sharp F, Conlon JE, et al. Virulence factors of Yersinia pestis are overcome by a strong lipopolysaccharide response. Nat Immunol. 2006;7: 1066-1073. doi:10.1038/ni1386

123. Munford RS, Varley AW, Jr CJ, Pirofski L, Casadevall A, Dommett R, et al. Shield as Signal: Lipopolysaccharides and the Evolution of Immunity to Gram-Negative Bacteria. PLoS Pathog. 2006;2: e67. doi:10.1371/ journal.ppat.0020067

124. Netea MG, van Deuren M, Kullberg BJ, Cavaillon J-M, Van der Meer JWM, Luderitz O, et al. Does the shape of lipid A determine the interaction of LPS with Toll-like receptors? Trends Immunol. 2002;23: 135-9. doi:10.1016/S1471-4906(01)02169-X

125. Steimle A, Autenrieth IB, Frick JS. Structure and function: Lipid A modifications in commensals and pathogens. Int J Med Microbiol. 2016;306: 290-301. doi:10.1016/j.ijmm.2016.03.001

126. Guo L, Lim KB, Poduje CM, Daniel M, Gunn JS, Hackett M, et al. Lipid A acylation and bacterial resistance against vertebrate antimicrobial peptides. Cell. 1998;95: 189-98. doi:10.1016/S0092-8674(00)81750-X

127. Beutler B, Rietschel ET. Timeline: Innate immune sensing and its roots: the story of endotoxin. Nat Rev Immunol. 2003;3: 169-176. doi:10.1038/nri1004

128. Maeshima N, Fernandez RC. Recognition of lipid A variants by the TLR4-MD-2 receptor complex. Front Cell Infect Microbiol. 2013;3: 3. doi:10.3389/fcimb.2013.00003

129. Park BS, Song DH, Kim HM, Choi B-S, Lee H, Lee J-O. The structural basis of lipopolysaccharide recognition by the TLR4-MD-2 complex. Nature. 2009;458: 1191-1195. doi:10.1038/nature07830

130. Kawano M, Manabe T, Kawasaki K. Salmonella enterica serovar Typhimurium lipopolysaccharide deacylation enhances its intracellular growth within macrophages. FEBS Lett. 2010;584: 207-212. doi:10.1016/j. febslet.2009.11.062

131. Mashburn-Warren LM, Whiteley M. Special delivery: Vesicle trafficking in prokaryotes. Mol Microbiol. 2006;61: 839-846. doi:10.1111/j.1365-2958.2006.05272.x

132. Matsuura M. Structural modifications of bacterial lipopolysaccharide that facilitate Gram-negative bacteria evasion of host innate immunity. Front Immunol. 2013;4: 1-9. doi:10.3389/fimmu.2013.00109

133. Needham BD, Trent MS. Fortifying the barrier: the impact of lipid A remodelling on bacterial pathogenesis. Nat Rev Microbiol. 2013;11: 467-481. doi:10.1038/nrmicro3047 
134. Lebeer S, Vanderleyden J, Keersmaecker SCJ De. Host interactions of probiotic bacterial. Nat Rev Microbiol. 2010;8: 171-184. doi:10.1038/nrmicro2297

135. Vatanen T, Kostic AD, d'Hennezel E, Siljander H, Franzosa EA, Yassour M, et al. Variation in Microbiome LPS Immunogenicity Contributes to Autoimmunity in Humans. Cell. 2016;165: 842-853. doi:10.1016/j. cell.2016.04.007

136. Elhenawy W, Debelyy MO, Feldman MF. Preferential Packing of Acidic Glycosidases and Proteases into Bacteroides Outer Membrane Vesicles. MBio. 2014; 5: e00909-14-e00909-14. doi:10.1128/mBio.0090914

137. Baker JL, Chen L, Rosenthal JA, Putnam D, DeLisa MP. Microbial biosynthesis of designer outer membrane vesicles. Curr Opin Biotechnol. 2014;29: 76-84. doi:10.1016/j.copbio.2014.02.018

138. Ho D, Kim S, Kang W, Seok Y, Lee S, Lee S, et al. Adjuvant effect of bacterial outer membrane vesicles with penta-acylated lipopolysaccharide on antigen-specific T cell priming. Vaccine. 2011;29: 8293-8301. doi:10.1016/j.vaccine.2011.08.102

139. Waterbeemd B Van De, Streefland M, Ley P Van Der, Zomer B, Dijken H Van, Martens D, et al. Improved $\mathrm{OMV}$ vaccine against Neisseria meningitidis using genetically engineered strains and a detergent-free purification process. Vaccine. 2010;28:4810-6. doi:10.1016/j.vaccine.2010.04.082

140. Moreno G, Rumbo M. Outer membrane vesicles obtained from Bordetella pertussis Tohama expressing the lipid A deacylase PagL as a novel acellular vaccine candidate. Vaccine. 2014;29(8):1649-56. doi:10.1016/j.vaccine.2010.12.068

141. Kang CS, Ban M, Choi EJ, Moon HG, Jeon JS, Kim DK, et al. Extracellular Vesicles Derived from Gut Microbiota, Especially Akkermansia muciniphila, Protect the Progression of Dextran Sulfate Sodium-Induced Colitis. PLoS One. 2013;8. doi:10.1371/journal.pone.0076520

142. Hibbing ME, Fuqua C, Parsek MR, Peterson SB. Bacterial competition: surviving and thriving in the microbial jungle. Nat Rev Microbiol. 2010;8: 15-25. doi:10.1038/nrmicro2259

143. Schaar V, Nordström T, Mörgelin M, Riesbeck K. Moraxella catarrhalis outer membrane vesicles carry $\beta$-lactamase and promote survival of Streptococcus pneumoniae and Haemophilus influenzae by inactivating amoxicillin. Antimicrob Agents Chemother. 2011;55: 3845-53. doi:10.1128/AAC.01772-10

144. Ciofu O, Beveridge TJ, Kadurugamuwa J, Walther-Rasmussen J, Høiby N. Chromosomal beta-lactamase is packaged into membrane vesicles and secreted from Pseudomonas aeruginosa. J Antimicrob Chemother. 2000;45: 9-13.

145. Lee E-Y, Choi D-Y, Kim D-K, Kim J-W, Park JO, Kim S, et al. Gram-positive bacteria produce membrane vesicles: proteomics-based characterization of Staphylococcus aureus-derived membrane vesicles. Proteomics. 2009:9: 5425-36. doi:10.1002/pmic.200900338

146. Schaible UE, Kaufmann SH. Iron and microbial infection. NatRevMicrobiol. 2004;2: 946-953. doi:10.1038/ nrmicro1116

147. Lappann M, Otto A, Becher D, Vogel U. Comparative proteome analysis of spontaneous outer membrane vesicles and purified outer membranes of Neisseria meningitidis. J Bacteriol. 2013;195: 4425-35. doi:10.1128/JB.00625-13

148. Aebi C, Stone B, Beucher M, Cope LD, Maciver I, Thomas SE, et al. Expression of the CopB outer membrane protein by Moraxella catarrhalis is regulated by iron and affects iron acquisition from transferrin and lactoferrin. Infect Immun. 1996;64: 2024-30.

149. Schaar V, De Vries SPW, Perez Vidakovics MLA, Bootsma HJ, Larsson L, Hermans PWM, et al. Multicomponent Moraxella catarrhalis outer membrane vesicles induce an inflammatory response and are internalized by human epithelial cells. Cell Microbiol. 2011;13: 432-449. doi:10.1111/j.1462-5822.2010.01546.x

150. Veith PD, Chen YY, Gorasia DG, Chen D, Glew MD, O'Brien-Simpson NM, et al. Porphyromonas gingivalis outer membrane vesicles exclusively contain outer membrane and periplasmic proteins and carry a cargo enriched with virulence factors. J Proteome Res. 2014;13: 2420-2432. doi:10.1021/pr401227e 
151. Lee JC, Lee EJ, Lee JH, Jun SH, Choi CW, Kim S II, et al. Klebsiella pneumoniae secretes outer membrane vesicles that induce the innate immune response. FEMS Microbiol Lett. 2012;331: 17-24. doi:10.1111/ j.1574-6968.2012.02549.x

152. Maredia R, Devineni N, Lentz P, Dallo SF, Yu J, Guentzel N, et al. Vesiculation from Pseudomonas aeruginosa under SOS. ScientificWorldJournal. 2012;2012: 402919. doi:10.1100/2012/402919

153. Prados-Rosales R, Baena A, Martinez LR, Luque-Garcia J, Kalscheuer R, Veeraraghavan U, et al. Mycobacteria release active membrane vesicles that modulate immune responses in a TLR2-dependent manner in mice. J Clin Invest. 2011; 121(4):1471-83. doi:10.1172/JCI44261 



\section{Chapter}

Bead-based flow-cytometry for semi-quantitative analysis of complex vesicle populations released by bacteria and host-cells

Charlotte Volgers, Birke J. Benedikter, Gert E. Grauls, Paul H.M. Savelkoul, Frank R.M. Stassen

Microbiology Research 2017; 200:25-32 


\section{ABSTRACT}

During infection, the release of nano-sized membrane vesicle is a process which is common both for bacteria and host cells. Host cell-derived membrane vesicles can be involved in innate and adaptive immunity whereas bacterial membrane vesicles can contribute to bacterial pathogenicity. To study the contribution of both membrane vesicle populations during infection is highly complicated as most vesicles fall within a similar size range of 30-300 $\mathrm{nm}$. Specialized techniques for purification are required and often no single technique complies on its own. Moreover, techniques for vesicle quantification are either complicated to use or do not distinguish between host cell-derived and bacterial membrane vesicle subpopulations. Here we demonstrate a bead-based platform that allows a semi-quantitatively analysis by flow-cytometry of bacterial and host-cell derived membrane vesicles. We show this method can be used to study heterogeneous and complex vesicle populations composed of bacterial and host-cell membrane vesicles. The easy accessible design of the protocol makes it also highly suitable for screening procedures to assess how intrinsic and environmental factors affect vesicle release.
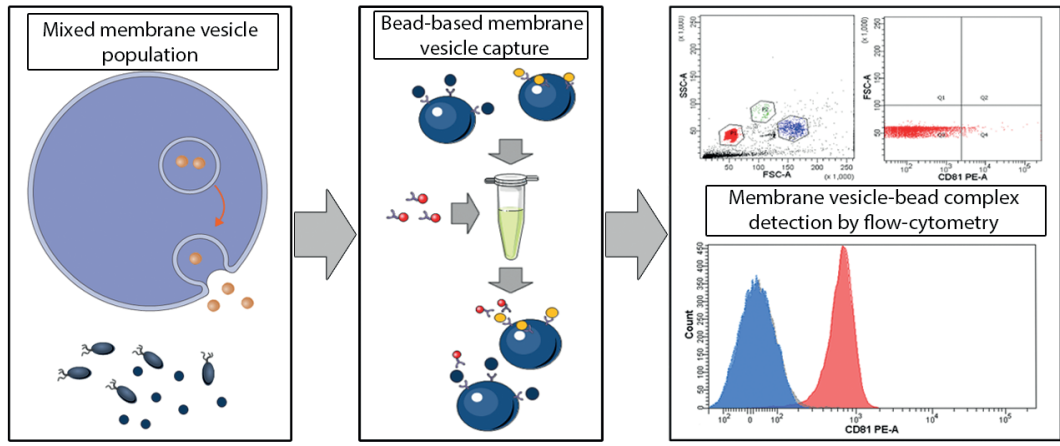

Sample processing time: 3-4 hours; incubation times: overnight and 1 hour; flow-cytometric analysis $\leq 2 \mathrm{~min} /$ sample. Graphical abstract was created using Servier Medical Art. 


\section{INTRODUCTION}

The shedding of nano-sized (30-300 nm)-membrane vesicles is a highly conserved process amongst bacteria, archaea, and eukaryotes. Depending on their origin and the context for release, these membrane vesicles govern functions in survival, communication and defense [1]. Thus, membrane vesicles released during infection constitute a mixture of bacterial and host-cell vesicles that can operate in host-pathogen interactions [2-4].

To study vesicle release kinetics as well as their phenotypic and functional aspects specialized techniques are required. Currently used assays for detection or quantitative analysis of individual particles include flow-cytometry and microscopy-based methods as well as particle detection by nanoparticle tracking or tunable resistive pulse sensing (TRPS) analysis [5-7]. Methods for the analysis of the gross vesicle population include Western blotting and conventional flow-cytometry. Amidst, there are flow-cytometry-based techniques for the analysis of vesicle subgroups that are more sensitive than methods for gross analysis, but less sensitive than approaches for single particle detection [7-10]. Each of these techniques has its own strengths and weaknesses and optimal vesicle analysis usually requires the use of a combination of techniques [7,11]. Assays that enable the quantification and comparison of membrane vesicle populations are essential but most techniques are either complicated to use, not able to distinguish between vesicle subpopulations, or both. A relatively easy to use technique for the detection of membrane vesicles is based on bead-based flow-cytometry. By using 4- $\mu \mathrm{M}$-sized latex beads, this assay overturns the size-related problems which prevent membrane vesicle analysis by conventional flow-cytometry. As these beads are coated with antibodies directed against specific marker proteins, they can be used to capture specific membrane vesicle subpopulations. Bead-bound vesicles can subsequently be stained with fluorescently labeled detection antibodies whereupon the total complex can be analysed by flow-cytometry. The beads are gated on their forward and side scatter so that fluorescent intensity of the bead-bound vesicles can be determined. This assay has already proven its value in the semi-quantitative determination of host- cell membrane vesicle release [12-14].

In this study, we present a novel application for this methodology. We modified the assay and made it appropriate for assessing bacterial vesicle release, i.c. membrane vesicles from two common respiratory pathogens Moraxella catarrhalis (Mrc) and Pseudomonas aeruginosa (Psa). This modified assay can be used to distinguish bacterial and host-cell vesicle populations in complex samples such as obtained upon infection. 


\section{MATERIAL AND METHODS}

\subsection{Reagents and antibodies}

Latex aldehyde beads (4- $\mu$ M) were purchased from Invitrogen (Paisley, UK). The antibody against Psa was from Aviva (OAMA02609, Aviva Systems Biology, San Diego, CA. USA). The rabbit serum against Mrc (strain A $1.39 \mathrm{~N}$, isolated from children in a primary school in Nieuwegein, the Netherlands, 1989), was kindly provided by Dr. J.P. Hays (Erasmus University Medical Centre, Rotterdam, the Netherlands). Antibodies were purified using the antibody serum purification kit based on protein A (Abcam, Cambridge, MA, USA) Hereafter, antibody were quantified by the MicroBCA protein assay (Pierce, Rockford, IL, USA). Antibody conjugations were performed using a PE-labeling kit from Abcam (Cambridge, MA, USA). Antibodies (100 $\mathrm{\mu g}$ per conjugation) were PE-conjugated according the manufacturers' instructions (Abcam, Cambridge, MA, USA). Antibodies against CD63 (unconjugated, mouse-anti-human clone H5C6), CD81 (PE con- jugated, mouse-anti-human clone JS-81) and isotype control (PE mouse IgG1K) antibodies were from BD (BD Bioscience, Franklin Lakes, NJ, USA). HRP-conjugated secondary antibodies were from R\&D systems (Minneapolis, MN, USA). For Western blot analysis all working dilutions were 1:1000, except for Mrc where a dilution of 1:40 was used. Samples for Western blot analysis were diluted in sample buffer prepared with XT-sample buffer (Bio-Rad, Hercules, CA, USA), urea (8 M), protease inhibitor complete (Roche GmbH, Mannheim, Germany), and reducing agent TCEP (Bio-Rad, Hercules, CA, USA) or water, to obtain reducing or non-reducing conditions, respectively.

\subsection{Bacterial culture}

The bacterial strains used were Psa ATCC 27853 and a local clinical Mrc isolate (Maastricht University Medical Center, The Netherlands). All strains were cultured at 5\% CO2 and 37 ${ }^{\circ} \mathrm{C}$ overnight on blood plates. After culture, several colonies were isolated and resuspended until an optical density of $0.5 \mathrm{McFarland}\left(1.5 \times 10^{8}\right.$ colony forming units $\left.(\mathrm{cfu}) / \mathrm{ml}\right)$ in RPMI1640. Bacteria were then cultured in complete vesicle-depleted culture medium with $5 \%$ fetal calf serum (FCS). Vesicle-depleted medium was obtained by the overnight centrifugation of RPMI1640 containing 30\% FCS, glucose (22.5\%), and sodium pyruvate $(100 \mathrm{mM})$ at $100.000 \times \mathrm{g}$ using a 70Ti rotor with a k-factor of 44 in an Optima L-90K ultracentrifuge (Beckman Coulter, Fullterton, CA, USA). This medium was then combined with FCS-free RPMI1640 with glucose and sodium pyruvate to obtain vesicle-depleted complete culture medium containing $5 \%$ FCS. Bacteria $\left(5 \times 10^{8} \mathrm{cfu} / \mathrm{ml}\right)$ were cultured in this vesicle-depleted medium for $4 \mathrm{~h}$ for flow-cytometric analysis.

\subsection{Cell culture}

The human monocytic THP-1 cell line (ATCC-TIB202) was maintained in RPMI1640 (Sigma, St. Louis, MO, USA) supplemented with 10\% FCS (Lonza, Verviers, Belgium), glucose (22.5\%), sodium pyruvate $(100 \mathrm{mM})$, and $\beta$-mercaptoethanol $(25 \mathrm{mM})$ and cultured at $5 \% \mathrm{CO}_{2}$ and $37^{\circ} \mathrm{C}$. For monocyte differentiation, cells were seeded at $0.5 \times 10^{6}$ cells per well in a 24-wells plate or at $1 \times 10^{7}$ cells per flask in a T75 flask and stimulated for 72 h with 200 nM phorbol 12-myristate 13-acetate (PMA; Sigma, St. Louis, MO, USA). 


\subsection{Macrophage infection}

Prior to infection, PMA-differentiated monocytes were washed 3 times with PBS and the medium was replaced with complete vesicle depleted culture medium with $5 \%$ FCS (prepared as described above). Hereupon, macrophages were infected for $6 \mathrm{~h}$ with either one of the bacteria or both at a multiplicity of infection of 10. After infection, the medium was harvested, processed and used for bead-based flow-cytometry as described below.

\subsection{Isolation of bacterial and macrophage-derived membrane vesicles}

For Western blotting analysis of the vesicles and the cell lysates, macrophages in T75 flasks and bacteria were cultured for $6 \mathrm{~h}$ after which the conditioned media were used for vesicle isolation. Cells were harvested by scraping in PBS, pelleted and lysed in NP-40 lysis buffer (150 mM NaCl, 1\% NP-40, and $50 \mathrm{mM}$ Tris). Additionally, bacteria were cultured for $4 \mathrm{~h}$ at $4.5 \times 10^{8}$, hereafter the cells were pelleted and lysed in NP-40 and the conditioned media were used for vesicle isolation. Membrane vesicle isolation from the conditioned media was performed by ultracentrifugation. Herefore, the conditioned media were first cleared from cells and cell debris by sequential centrifugation at $300 \times g$ and $1200 \times g$ for $10 \mathrm{~min}$. Then, the supernatants were filtered using $0.22-\mu \mathrm{M}$ filters and transferred to ultraclear Quickseal tubes (Beckman Coulter, Fullerton, CA, USA) and centrifuged for 90 min at $100.000 \times g$ using a 70Ti rotor, K-factor 44 in an Optima L-90K ultracentrifuge (both Beckman Coulter, Fullterton, CA, USA). The vesicle pellet was resuspended in 150 $\mu \mathrm{l}$ PBS and kept at $-80^{\circ} \mathrm{C}$ until further use. The protein content of the whole cell lysates (WCL) and the vesicle pellets was determined by the Micro BCA protein assay.

\subsection{Western blotting}

For Western blot analysis, ultracentrifugation pellets or cell lysates were diluted in sample buffer (Biorad, Hercules, CA, USA, non-reducing for a-CD81 and a-CD63), and loaded on a $12 \%$ SDS-page gel. After electrophoresis and protein transfer to a nitrocellulose membrane (Fisher Scientific, Waltham, MA, USA), the membranes were blocked overnight in Tris-buffered saline (TBS) with 5\% (w/v) milk powder after which they were washed with TBS with $0.05 \%(v / v)$ Tween and incubated with primary antibodies against CD63, CD81, $\operatorname{Mrc}(1: 20)$ or Psa in TBS with 5\% (w/v) BSA for $3 \mathrm{~h}$. Next, the membranes were washed and incubated with a horse radish peroxidase (HRP)-labeled secondary antibody in TBS for $2 \mathrm{~h}$. Antibodies were used at 1:1000 unless otherwise indicated. On incubation, the membranes were washed and the detection was performed by using chemiluminescence substrate (Sigma, St. Louis, MO, USA). Whole cell lysates were used as a positive control. 


\subsection{Flow-cytometric analysis}

\subsubsection{Preparation of antibody-coated latex aldehyde beads}

This method is based on the assay developed by Ostrowski et al. and was used accordingly for the determination of CD63/CD81+ host cell-derived vesicles or adopted for the determination of bacterial vesicle release [14] Overall, 3 different bead sets were prepared as follows: a total of $1 \times 10^{8} 4-\mu \mathrm{M}$ aldehyde-sulfate beads was washed in $150 \mu \mathrm{l}$ MES buffer (all washing steps were performed at $3000 \times g$ for $10 \mathrm{~min}$ ) and coated with $35 \mu \mathrm{g}$ antibody against CD63, Mrc, or Psa (in a total of $250 \mu \mathrm{l}$ ), overnight at $4{ }^{\circ} \mathrm{C}$ while keeping the solution under constant agitation at $6500 \mathrm{rpm}$. Antibodies supplied as serum were purified before use (as described in the reagents and antibodies section). After coating, the remaining free binding sites on the beads were blocked by washing the beads 3 times with $0.22-\mu \mathrm{M}$ filtered PBS with $4 \%(\mathrm{w} / \mathrm{v})$ bovine serum albumin (BSA). Hereafter the beads were resuspended and kept in a total of $500 \mu \mathrm{l}$ storage buffer (PBS with $0.1 \%(\mathrm{v} / \mathrm{v})$ glycine and $0.1 \%(\mathrm{w} / \mathrm{v})$ sodium azide) at $4{ }^{\circ} \mathrm{C}$.

\subsubsection{Bead-based flow-cytometry}

After culture or infection the supernatants were processed by centrifugation. Supernatants from bacterial cultures were processed by 2 subsequent centrifugation steps at $1200 \times g$ while supernatants obtained after infection were processed by 2 centrifugation steps (300 $\times g$ followed by $1200 \times g$ both for $10 \mathrm{~min}$ ). Then, the supernatants were filtered using 0.22- $\mu \mathrm{M}$ filters and a total of 50,000 (1 $\mu \mathrm{ll}$ ) of a-Mrc- and a-CD63-coated beads and 250,000 (5 $\mu \mathrm{l}$ ) of a-Psa-coated beads were added to $200 \mu \mathrm{l}$ of the processed supernatants and incubated overnight at room temperature under constant agitation at $6500 \mathrm{rpm}$. The optimal number of beads was determined in earlier experiments. Several bead-bacteria ratios (with a range between 1:20 and 1:200) were tested to reach an amount that resulted in sufficient vesicle binding without reaching a saturation, as this would prevent to determine an increase in the vesicle concentration. This way the optimal bead concentrations for each platform was established. After overnight vesicle capture, the beads were washed twice with $0.22-\mu \mathrm{M}$ filtered PBS with $2 \%(\mathrm{w} / \mathrm{v}) \mathrm{BSA}$ and incubated with an analogous secondary PE-conjugated antibody for $1 \mathrm{~h}$ at room temperature under constant agitation and protected from light. For the macrophage-derived vesicles, a PE-labeled isotype antibody was used as a control for non-specific Fc receptor binding and for the bacterial vesicles unconditioned medium was used as a control. Then, the beads were washed twice in $0.22 \mu \mathrm{M}$ filtered PBS with $2 \%(\mathrm{w} / \mathrm{v}) \mathrm{BSA}$, whereafter the pellets were resuspended in $300 \mu \mathrm{LBS}$ and analyzed by flow- cytometry on a FACSCanto ${ }^{\mathrm{TM}}$ (BD Bioscience, Franklin Lakes, NJ, USA). Analyses were performed using FACSDiva Software. Single beads were gated on their forward and side scatter. The quartile distribution within a dot plot, based on the fluorescent intensity of single beads, was then used to calculate the relative fluorescent intensity. Quartile gate 4 was set on $2 \%$ for beads incubated with unconditioned medium. The relative fluorescence intensity, expressed in arbitrary units $(A U)$, was then calculated by multiplying the number and the fluorescence intensity of the positive beads in quartile 4.

\subsection{Tunable resistive pulse sensing (TRPS)-based analysis}

Prior to TRPS-based analysis, the media were concentrated to $500 \mu \mathrm{l}$ on Ultra-15 10-kDa Amicon centrifugal filter units (Millipore, Billerica, MA, USA) by 15 min of centrifugation 
at $4000 \times g$ at room temperature. Then, the absolute vesicle concentration in the supernatants was determined by TRPS-based analysis using the qNano Gold (Izon Science Ltd., Oxford, UK) using Izon Control Suite Software v3.2. Measurements were conducted using an NP150-pore with a stretch of $47 \mathrm{~mm}$, a transmembrane voltage of $0.48 \mathrm{~V}$ (giving a baseline current of $\pm 100 \mathrm{nA}$ ), and a pressure of 6 mbar. Measurements were performed for $10 \mathrm{~min}$ and repeated when system instabilities occurred. The samples were calibrated with $114 \mathrm{~nm}$ polystyrene calibration beads that were diluted in culture medium at a concentration of $1 \times 10^{9}$ particles $/ \mathrm{ml}$. Concentration calculations were performed using Graph-Pad Prism 5 Software (Graph-Pad, San Diego, CA, USA) and Microsoft Office Excel (version 2010, Microsoft).

\subsection{Statistical analyses}

Linear regression was performed using Graph-Pad Prism 5 Software (Graph-Pad, San Diego, CA, USA). A non-parametric Mann-Whitney test was performed to determine the statistical variance. Differences were considered significant when $p \leq 0.05$. 


\section{RESULTS}

\subsection{Reactivity of the antibodies}

Western blotting analysis was performed to assess whether antibodies were reactive with epitopes on bacterial membrane vesicles isolated by ultracentrifugation. All antibodies were found to be reactive with whole cell lysates as well as the membrane vesicles (Fig. 1). The reactivity of the a-CD63 and a-CD81 antibodies (CD63 and CD81 are proteins that are highly enriched on extracellular vesicles) to macrophage-derived membrane vesicles was confirmed while cell lysates remained negative. Hereafter, the antibodies were used to establish the platform for flow cytometric analysis. The first step was to validate each platform for its reactivity and its specificity. As is shown in Fig. 2, all assays were confirmed to be positive only for the corresponding MVs.

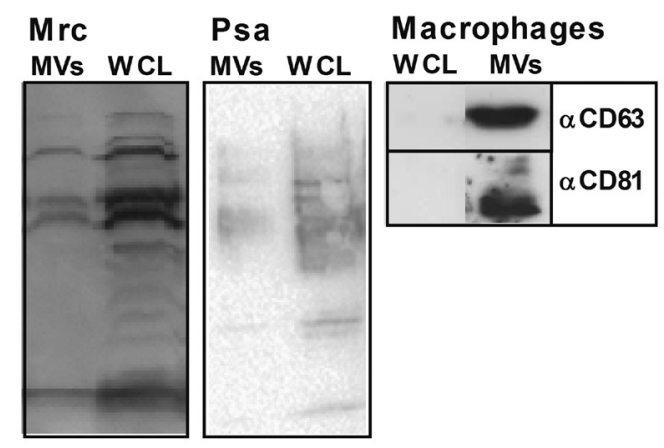

FIGURE 1. Analysis of membrane vesicles and whole cells lysates of bacteria and macrophages by Western blotting. The reactivity of antibodies with bacterial membrane vesicles and host cell-derived vesicles (MVs) as well as whole bacterial and host cell lysates (WCL) was determined by Western blotting. Moraxella catarrhalis (Mrc)- and Pseudomonas aeruginosa (Psa)- derived bacterial membrane vesicles (respectively 10 and $25 \mu \mathrm{g}$ ) isolated from conditioned media from bacterial cultures by ultracentrifugation, were subjected to SDSPAGE, transferred to nitrocellulose membranes and stained using antibodies against Mrc, Psa, CD63, and CD81. Whole bacterial and host cell lysates $(50 \mu \mathrm{g})$ were used as a positive control.

\subsection{Analysis of purified bacterial vesicles by bead-based flow-cytometry}

Next, we aimed to determine if this platform qualifies for the semi-quantitative detection of bacterial membrane vesicles and to determine the experimental variation of this assay. To test this, conditioned media from bacterial suspensions at $0.5 \times 10^{8} \mathrm{CFU} / \mathrm{ml}$ were obtained, aliquoted in 3 portions to be tested in separate experiments. Then, the assay was applied on 4 sequential 1:1 serial dilutions. Fig. 3 shows a concentration dependent decrease in the fluorescence intensity and shows there is a low inter-experimental variation. Moreover, these results show a high variation in the absolute fluorescence intensity among the vesicle-bead complexes from the different bacteria. 

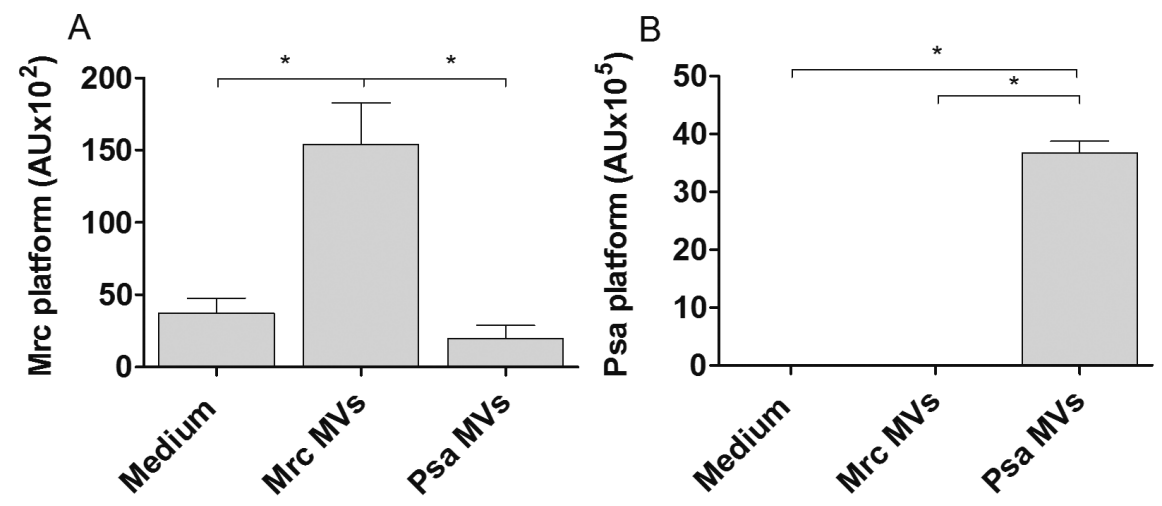

FIGURE 2. Validation of the bead-based platforms by flow-cytometric analysis. Validation of the specificity of the bead-based platforms to detect Mrc- and Psa-derived membrane vesicles by flow-cytometric analysis. Beads coated with antibodies directed against either Mrc or Psa were added to control medium or media that were conditioned by Mrc and Psa for $4 \mathrm{~h}$ at $0.5 \times 10^{8} \mathrm{CFU} / \mathrm{ml}$. The arbitrary units for the Mrc- (A) and Psa- (B) platforms were determined by flow-cytometry (mean \pm SEM, $n=3$ ). $p<0.05$.

\subsection{Correlation between the relative and absolute concentration}

The correlation between the absolute and the relative concentration is shown in Fig. 4. Linear regression of the slopes revealed $R^{2}$ values close to 1 indicating that there is a strong correlation between both variables (Mrc: $R^{2}=0.954$ and Psa: $R^{2}=0.967$ ). These data demonstrate that bead-based flow cytometry assay can indeed be used for semi-quantitative analyses. Moreover, the high correlation indicates that the combination of bead-based flow-cytometry with TRPS-based analysis can also be used to infer the absolute concentration of vesicle subpopulations. 

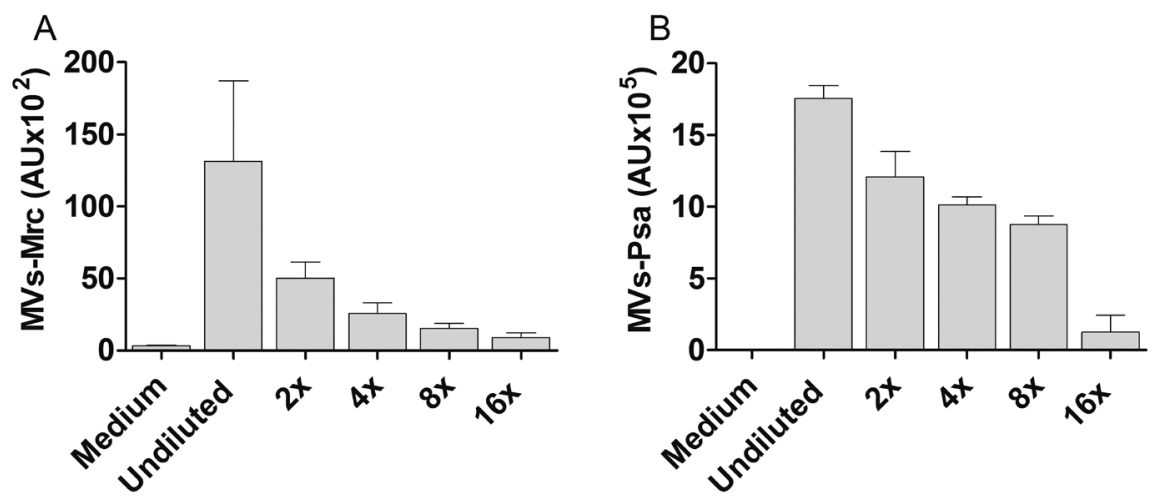

FIGURE 3. Flow-cytometric analysis of bacterial vesicles. Beads were added to 2-fold dilution series with a total of 5 dilutions, using supernatants from Mrc or Psa monocultures, cultured for $4 \mathrm{~h}$ at $0.5 \times 10^{8} \mathrm{CFU} / \mathrm{ml}$. After vesicle capture, the arbitrary units for Mrc-MVs (A) and Psa-MVs (B) were determined by flow-cytometry (mean \pm SEM, $n=3$ ).
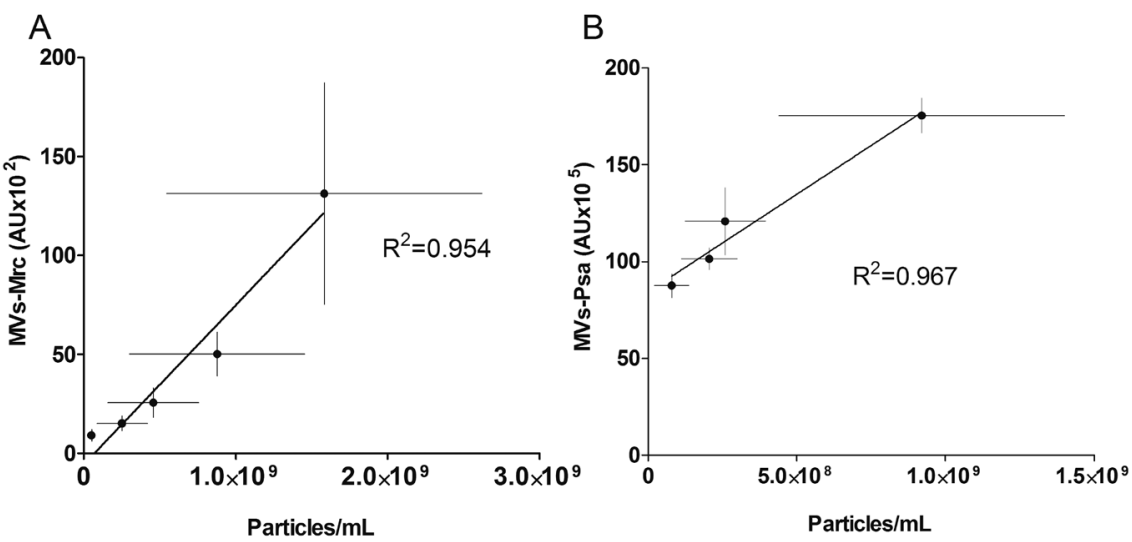

FIGURE 4. Correlation between the absolute and the relative vesicle concentration. The absolute vesicle concentration was determined by TRPS-based analysis of supernatants from bacterial cultures that were concentrated (20-fold) on 10-kDa Amicon filter units. The relative membrane vesicle concentration was then plotted against the absolute concentration to determine the correlation. Linear regression of the slopes revealed $\mathrm{R}^{2}$ correlations of 0.954 for Mrc-MVs (A) and 0.967 for Psa-MVs (B). Plots are based on the average values of 3 independent experiments. 


\subsection{Bead-based flow-cytometry to determine bacterial and host-cell vesicle release upon (co-)infection}

For analysis of mixed populations we used an in-vitro model based on THP-1 macrophages infected with Mrc, Psa, both Mrc and Psa or were left uninfected. To demonstrate that this assay indeed allows the semi-quantitative detection method of membrane vesicles, the harvested supernatants of Mrc- or Psa-infected macrophages and uninfected macrophages were used undiluted or 2-and 4-times diluted. Fig. 5 A-C show dilution-dependent decreases in the amount of bacterial vesicles during infection and host cell-derived CD63/CD81+ vesicles by uninfected macrophages. Additionally, we demonstrate that infection results in a significantly increased release of CD63/CD81+ host cell-derived vesicles, while co-infection significantly increased the release of Mrc-, Psa-, and CD63/CD81 ${ }^{+}$ membrane vesicles (Fig. 5 D-F)

\subsection{Workflow and principle of bead based-flow-cytometry}

The typical workflow for the improved method is depicted in Fig. 6. After infection, the supernatants are harvested and processed by centrifugation and filtration whereupon antibody-coated beads are added for overnight vesicle capture. Then, the bead-vesicle complexes are washed and stained by PE-conjugated secondary antibodies after which the fluorescence intensity can be determined by flow-cytometry. Scatter plots and fluorescence intensity histograms can subsequently be used for analysis. A scatter plot on the forward and side scatter of the bead-vesicle complexes allows to gate (gate 1) on single bead-vesicle complexes (the events in gate 2 and 3 are complexes clustered in duplicates or triplicates). A scatter plot of the fluorescence intensity of single complexes is then used to measure the percentage positive beads. The settings of the quartiles were adjusted using the plots of the unconditioned media for which the percentage positive beads in quartile 4 was set at $2 \%$. Histograms on the beads in quartile 4 can then be used to determine the fluorescence intensity of the beads under experimental conditions, here shown for macrophage-derived vesicles released on infection with Mrc (red), together with histograms for the control conditions (unconditioned medium (grey) and the isotype control (blue)). Calculations are made using tables of statistics to determine the relative concentration in arbitrary units (AU) by multiplication of the percentage and median fluorescence intensity of the positive beads. 

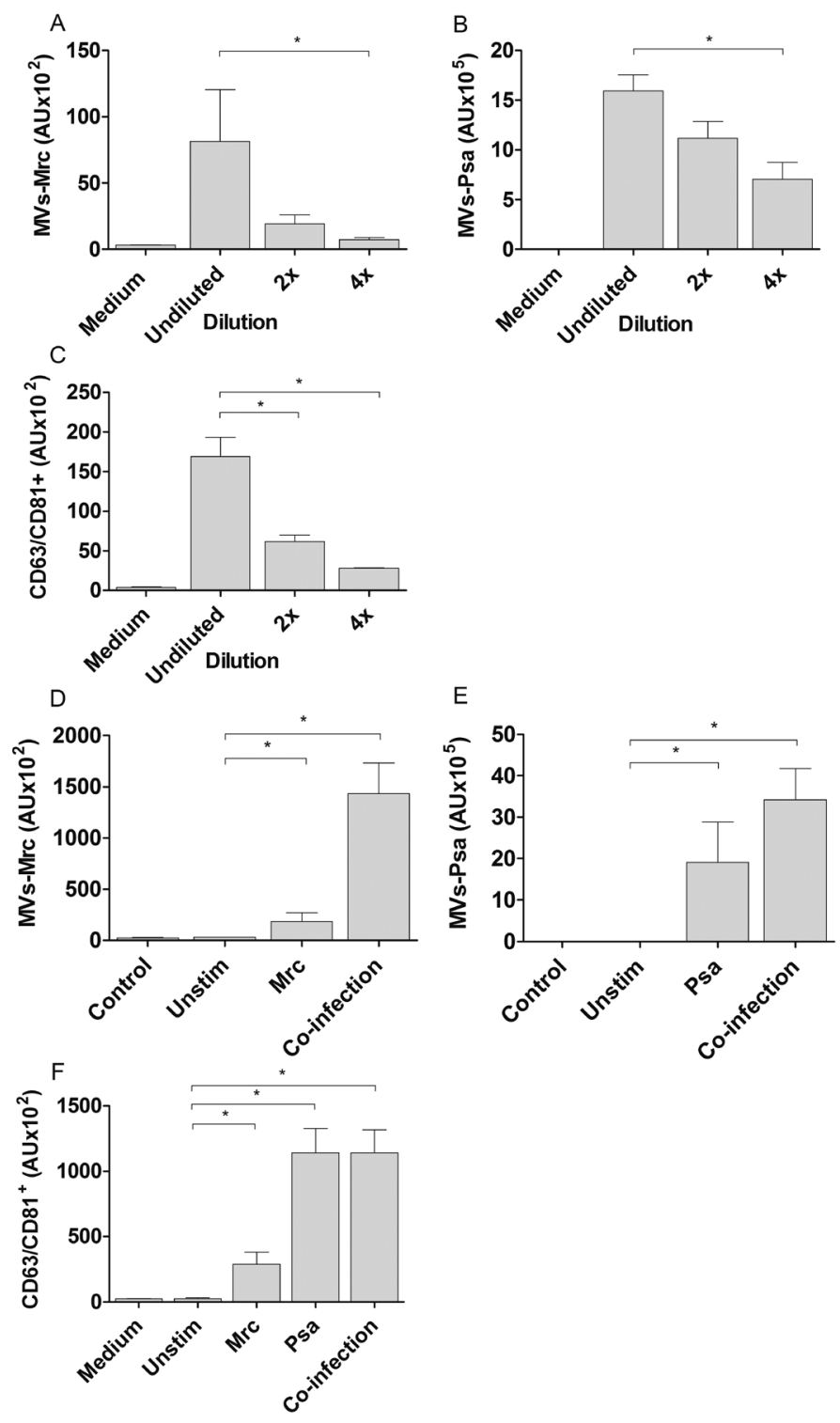

FIGURE 5. Flow-cytometric analysis of bacterial and host cell vesicle release upon infection. Semi-quantitative determination of bacterial and host-cell vesicles in supernatants of macrophages infected for $6 \mathrm{~h}$. Supernatants obtained after infection with Mrc (A) or Psa (B) or supernatants of uninfected macrophages (C) were used undiluted and 2- and 4-times diluted and assessed by flow-cytometry. The bacterial membrane vesicle release during infection with Mrc (D) and Psa (E) was compared to the release during co-infection. The release of host cell vesicles by macrophages after infection by Mrc, Psa, or co-infection (F). Results are mean \pm SEM from 3 independent experiments. $p<0.05$. 


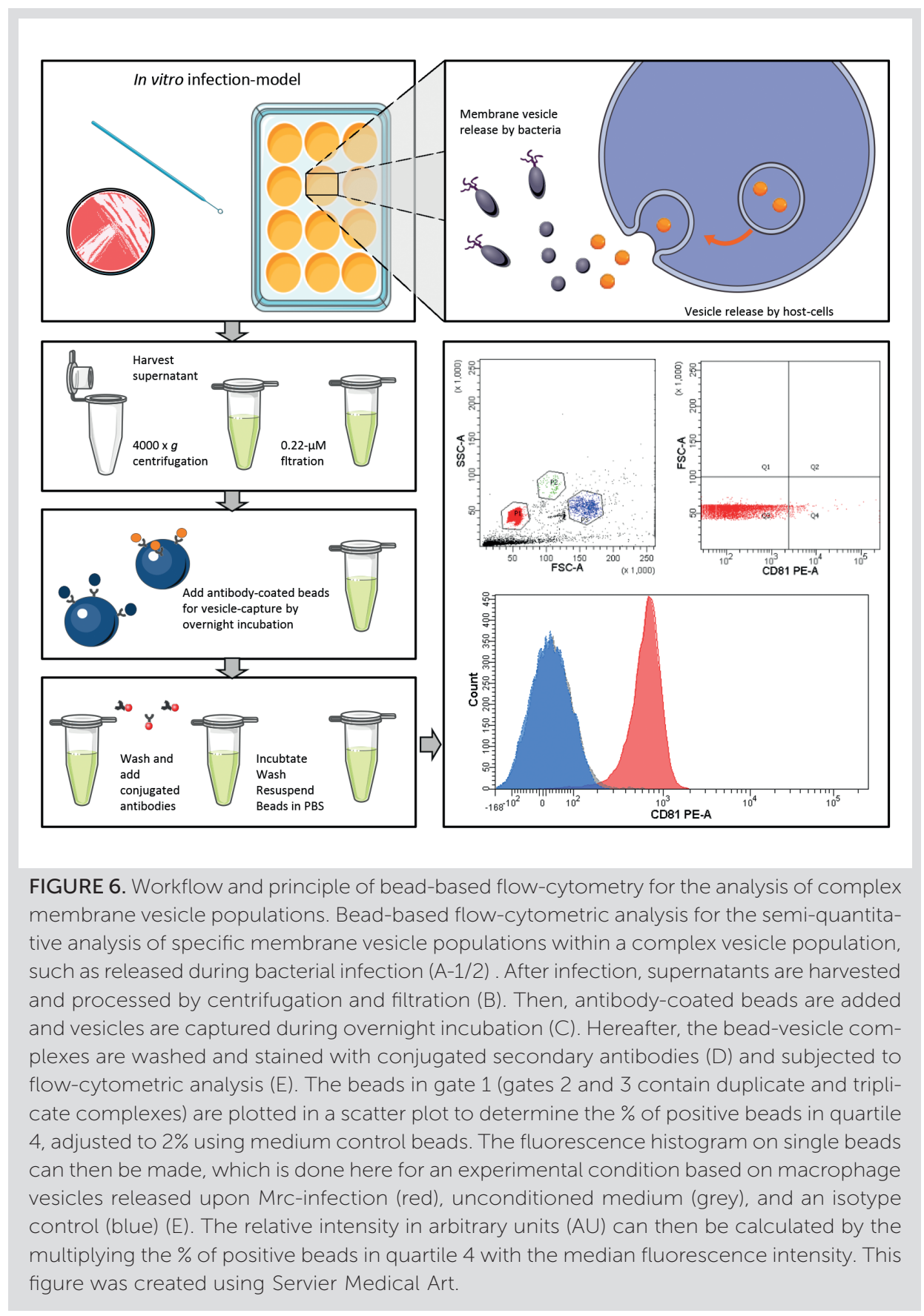




\section{DISCUSSION AND CONCLUSION}

In this paper, we present a novel application of the bead-based flow-cytometry assay for the semi-quantitative analysis of specific bacterial and host cell vesicle populations within complex samples, such as obtained after infection. Membrane vesicle shedding during infection is a putatively important process in host-pathogen interactions. A better understanding of mechanisms for release of membrane vesicles during infection and how these are affected by environmental factors is required. To assess this is complicated as most membrane vesicles fall within the same size range of $30-300 \mathrm{~nm}$. Conventional techniques that allow vesicle quantification at a single particle level generally have certain limitations as they may require highly specialized equipment $[5,15]$, extensive sample pre-processing, or are not able to distinguish between different vesicle subpopulations (as compared by $[6,7]$ ).

The application presented in the present study was originally developed by Thery et al. for the analysis of exosomes and has since then shown to be useful to study the processes that drive exosome release $[13,14]$. We found that the relative vesicle amount determined by flow-cytometry correlated well with the absolute vesicle concentration determined by TRPS demonstrating that this bead-based method is a practical tool for semi-quantitative vesicle detection. We show that there was little variation between separate experiments, making this assay highly reproducible. When this assay is adopted for custom applications we recommend validation of this assay accordingly, since it is imperative to start with the assessment of the antibody reactivity and to test for linearity to establish the concentration range over which this assay can be applied. The upper detection limit is reached when the beads are saturated and display none or little variation in the fluorescent intensity. The lower detection limit is reached when the signal can no longer be distinguished from the background signal. To further decrease the lower limit, we suggest to concentrate the samples. Apart from this, the platforms used in this study show a high variation in the absolute fluorescent intensity among the vesicle-bead complexes from the different bacteria. This variation could have been introduced by a higher affinity of the antibody to one or multiple vesicle-associated antigens per se or by the abundance of the antigen on the vesicle populations. Yet, as this assay can only be used to determine the relative abundance (relative to the control condition and other conditions based on the same platform), this does not affect the eventual interpretation of the results.

In this study, we showed that this method can be used to study the release of specific membrane vesicle subpopulations in complex samples composed of multiple types of vesicles, e.g. following infection of host cells by bacteria. The application of this assay on undiluted and diluted supernatants resulted in a dilution-dependent decrease in relative fluorescence intensity, confirming that this method allows the detection of relative changes in the vesicle concentration. Given the strong correlation between the relative concentrations (bead-based flow-cytometry) and the absolute numbers (TRPS), our data indicate that the methodology described here can be used to infer the absolute vesicle concentration of a specific vesicle population within a heterogeneous vesicle population. Determination of an absolute vesicle concentration can be performed with the use of a reference sample of the given specific vesicle population. So, to assess the release of ves- 
icles by bacteria or host cells during infection, a condition that is solely based on vesicles released by bacteria or cells can be used as a reference.

The advantages of this technique are abundant. Firstly, no specialized and costly equipment is required, making this technique highly accessible. As this technique is based on the "in sample"-capture of vesicles, which also limits the processing time to $3-4 \mathrm{~h}$, the introduction of processing-related artifacts is circumvented. Also, smaller volumes can be used, and processing is eased by the use of $4-\mu \mathrm{M}$-sized beads, making this method cheaper and less laborious then most conventional methods. As the flow-cytometric detection is based on the 4- $\mu \mathrm{M}$-sized beads, the gates can be applied based on the forward and side scatter. Hence, signals that may interfere with other assays such as antibody aggregates, other aggregated proteins and soluble proteins do not complicate the measurements. Moreover, this assay offers a versatile platform that allows the simultaneous analysis of different phenotypic vesicle characteristics as beads can be coated with multiple antibodies. Also, labeling of bead-bound vesicles yields a higher fluorescence intensity in comparison with individual vesicles and thereby allows the detection of less abundant vesicle populations. Inevitably, this technique also has some disadvantages. By choosing (a set of) specific antibodies to coat the beads, it cannot be excluded that subsets of vesicles which do not express this specific marker will not be recognized. Therefore, when specific subsets of vesicles are to be detected, it is recommended to use a combination of the most common and well accepted membrane vesicle markers (e.g. CD9/63/81 for host cell derived vesicles). Also, it has been shown that the vesicle composition may change when the circumstances change, notably if this applies to an epitope that is targeted by the antibody of choice this can be crucial. This for example has been shown for $P$. aeruginosa where exposure to stressors including oxygen tension, hydrogen peroxide, and gentamycin has been shown to affect the vesicles' LPS phenotype. In these circumstances, it is important to determine if this has an effect on vesicle capture and detection.

Taken together, this method has been shown a valuable tool in assessing the release of membrane vesicles under a variety of conditions. In case of a homogeneous vesicle population, e.g. from a specific cell line, other techniques like high resolution flow-cytometry, dedicated flow-cytometry, nanoparticle tracking analysis, or TRPS may be found superior, but in more complex samples this method allows a rapid and accurate (semi-quantitative) analysis of specific vesicle subpopulations. Moreover, the versatility and ease of this platform may also be further exploited e.g. for vesicle arrays by using different coating-antibody and conjugated-antibody combinations or by using fluorescent or magnetic beads. Therefore, in our opinion this assay provides a valuable addition to the rapidly growing offer of techniques for vesicle detection as a fast and easy approach for the semi-quantitative assessment of vesicle subpopulations in complex samples. 


\section{ACKNOWLEDGEMENTS}

The authors wish to thank dr. J. P. Hays from the Erasmus University Medical Centre (Erasmus MC), Rotterdam, the Netherlands for kindly providing the rabbit antisera to Moraxella catarrhalis used in this publication.

\section{FUNDING INFORMATION}

This research did not receive any specific grant from funding agencies in the public, commercial, or not-for-profit sectors. 


\section{REFERENCES}

1. Deatherage BL, Lara JC, Bergsbaken T, Barrett SLR, Lara S, Cookson BT. Biogenesis of bacterial membrane vesicles. Mol Microbiol. 2009;72: 1395-1407. doi:10.1111/j.1365-2958.2009.06731.x

2. Berleman J, Auer M. The role of bacterial outer membrane vesicles for intra- and interspecies delivery. Environ Microbiol. 2013;15: 347-354. doi:10.1111/1462-2920.12048

3. Schorey JS, Harding C V. Extracellular vesicles and infectious diseases: new complexity to an old story. J Clin Invest. 2016;126: 1181-9. doi:10.1172/JCI81132

4. Schwechheimer C, Kuehn MJ. Outer-membrane vesicles from Gram-negative bacteria: biogenesis and functions. Nat Rev Microbiol. 2015;13: 605-619. doi:10.1038/nrmicro3525

5. van der Vlist EJ, Nolte-'t Hoen ENM, Stoorvogel W, Arkesteijn GJ a, Wauben MHM. Fluorescent labeling of nano-sized vesicles released by cells and subsequent quantitative and qualitative analysis by high-resolution flow cytometry. Nat Protoc. 2012;7: 1311-26. doi:10.1038/nprot.2012.065

6. van der Pol E, Coumans F a W, Grootemaat a. E, Gardiner C, Sargent IL, Harrison P, et al. Particle size distribution of exosomes and microvesicles determined by transmission electron microscopy, flow cytometry, nanoparticle tracking analysis, and resistive pulse sensing. J Thromb Haemost. 2014;12: 1182-1192. doi:10.1111/jth.12602

7. Witwer KW, Buzás El, Bemis LT, Bora A, Lässer C, Lötvall J, et al. Standardization of sample collection, isolation and analysis methods in extracellular vesicle research. J Extracell vesicles. 2013;2. doi:10.3402/ jev.v2i0.20360

8. Inglis H, Norris P. Danesh A. Techniques for the Analysis of Extracellular Vesicles Using Flow Cytometry. J Vis Exp. 2015; e52484-e52484. doi:10.3791/52484

9. Pospichalova V, Svoboda J, Dave Z, Kotrbova A, Kaiser K, Klemova D, et al. Simplified protocol for flow cytometry analysis of fluorescently labeled exosomes and microvesicles using dedicated flow cytometer. J Extracell Vesicles. 2015;4: 25530. doi:10.3402/jev.v4.25530

10. Wieser A, Storz E, Liegl G, Peter A, Pritsch M, Shock J, et al. Efficient quantification and characterization of bacterial outer membrane derived nano-particles with flow cytometric analysis. Int J Med Microbiol. 2014;304: 1032-1037. doi:10.1016/j.ijmm.2014.07.012

11. Lacroix R, Robert S, Poncelet P, Dignat-George F. Overcoming limitations of microprticles measurement by flow cytometry. Semin Thromb Hemost. 2010;36: 807-818. doi:10.1055/s-0030-1267034

12. Clayton A, Court J, Navabi H, Adams M, Mason MD, Hobot JA, et al. Analysis of antigen presenting cell derived exosomes, based on immuno-magnetic isolation and flow cytometry. Journal of Immunological Methods. 2001; 247, 163-174. doi:10.1016/S0022-1759(00)00321-5

13. Clotilde Thery, Aled Clayton, Sebastian Amigorena GR. Isolation and Characterization of Exosomes from Cell Culture Supernatants. Curr Protoc Cell Biol. 2006; Chapter 3: 1-29. doi:10.1002/0471143030. cb0322s30

14. Ostrowski M, Carmo NB, Krumeich S, Fanget I, Raposo G, Savina A, et al. Rab27a and Rab27b control different steps of the exosome secretion pathway. Nat Cell Biol. 2010;12: 13-19. doi:10.1038/ncb2000

15. Hoen ENMN-'t, van der Vlist EJ, Aalberts M, Mertens HCH, Bosch BJ, Bartelink W, et al. Quantitative and qualitative flow cytometric analysis of nanosized cell-derived membrane vesicles. Nanomedicine Nanotechnology. 2012;8: 712-720. doi:10.1016/j.nano.2011.09.006 



\section{Chapter 4}

Immunomodulatory role for membrane vesicles released by THP-1 macrophages and respiratory pathogens during macrophage infection

Charlotte Volgers, Birke J. Benedikter, Gert E. Grauls, Paul H.M. Savelkoul, Frank R.M. Stassen

BMC Microbiology 2017; accepted for publicaton 


\begin{abstract}
During infection, inflammation is partially driven by the release of mediators which facilitate intercellular communication. Amongst these mediators are small membrane vesicles (MVs) that can be released by both host cells and Gram-negative and-positive bacteria. Bacterial membrane vesicles are known to exert immuno-modulatory and -stimulatory actions. Moreover, it has been proposed that host cell-derived vesicles, released during infection, also have immunostimulatory properties. In this study, we assessed the release and activity of host cell-derived and bacterial MVs during the first hours following infection of THP-1 macrophages with the common respiratory pathogens non-typeable Haemophilus influenzae, Moraxella catarrhalis, Streptococcus pneumoniae, and Pseudomonas aeruginosa. Using a combination of flow cytometry, tunable resistive pulse sensing (TRPS)-based analysis, and electron microscopy, we demonstrated that the release of MVs occurs by both host cells and bacteria during infection. MVs released during infection and bacterial culture were found to induce a strong pro-inflammatory response by naive THP-1 macrophages. On the other hand, these MVs may also induce tolerance of host cells to a second immunogenic stimulus and lead to an enhanced number of adherent and intracellular bacteria. In conclusion, bacterial MVs may play a dual role during infection, as they can both trigger immunity but also contribute to bacterial survival.
\end{abstract}




\section{INTRODUCTION}

Inflammation in response to bacterial infection results from contact of host cells with bacteria or bacterial products and this process is directed by an extensive communication between cells of the infected tissues, immune cells, and bacteria [1,2]. Involved in this communication are small soluble mediators as well as nanosized membrane vesicles (MVs) that are released by bacteria and by host cells [3-6].

Bacterial MVs have gained a considerable interest over the past decades as they are involved in physiological and pathological processes by transferring functional vesicular cargos to recipient cells or by direct vesicle-mediated target cell activation in bacteriahost cell interactions. The release of MVs by Gram-negative bacteria has been studied extensively (as reviewed by Schwechheimer and Kuehn [4,7]). More recently it has been revealed that Gram-positive bacteria also shed MVs (as reviewed by Brown et al. [8]). MV release takes place not only during bacterial culture but also during infection, both in vitro and in vivo [7-9]. Yet, only a few studies assessed bacterial MV shedding during infection, and consequently the kinetics for release as well as the functionality of MVs shed during infection have remained poorly addressed [10-12].

From the perspective of the host, previous studies have shown that MVs shed upon infection with intracellular pathogens have immunostimulatory and-modulatory properties [13-15]. Initially it was anticipated that this was the result of the incorporation of bacterial components into host MVs. However, this has been questioned recently by findings of Athman et al. showing that bacterial cargo-containing MVs, shed upon infection with Mycobacterium tuberculosis, are mostly of bacterial origin [13]. Thus, MVs released during infection are most likely a complex mixture of both bacterial and host-derived MVs.

To obtain clarity on the dynamics of MV shedding during infection, we studied the release kinetics and examined the functional activity of both host cell-derived and bacterial MVs released by THP-1 macrophages infected with non-typeable Haemophilus influenzae (NTHi), Moraxella catarrhalis (Mrc), Streptococcus pneumoniae (Spn), and Pseudomonas aeruginosa (Psa), which are well-known opportunistic pathogens most frequently involved in lower respiratory tract infections in humans [14-16]. We found that MV release occurs by both the host and bacteria during infection, by bacteria during culture and that both MV populations have pro-inflammatory and immuno-modulating properties. 


\section{MATERIALS AND METHODS}

\section{Cells and media}

Human monocytic cells (THP-1, ATCC-TIB202) were cultured at $5 \% \mathrm{CO}_{2}$ and $37^{\circ} \mathrm{C}$ in RPMI1640 (Sigma, St. Louis, MO, USA) containing 10\% fetal calf serum (FCS) (Lonza, Verviers, Belgium) with glucose $(0.045 \%)$, sodium pyruvate $(200 \mu \mathrm{M})$, and $\beta$-mercaptoethanol $(50 \mu \mathrm{M})$. For monocyte differentiation, cells were stimulated for 72 hours with $200 \mathrm{nM}$

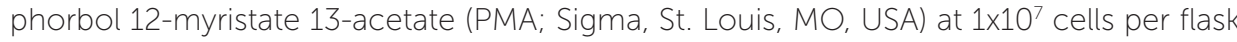
in T75-flasks, at $0.5 \times 10^{6}$ cells per well when using a 24 -well plate, and at $1 \times 10^{4}$ per well for 96 -well plates. After differentiation, the medium was replaced with complete culture medium with 5\% FCS which had previously been depleted of vesicles. Vesicle-depleted medium was obtained by the overnight centrifugation of RPMI1640 containing 30\% FCS, glucose, and sodium pyruvate at $100.000 \times g$ using a 70Ti-rotor, K-factor 44 in an Optima L-90K ultracentrifuge (both Beckman Coulter, Fullerton, CA, USA). By combining this medium with FCS-free RPMI1640 medium with glucose and sodium pyruvate, 5\% FCS vesicle-free culture medium was obtained.

\section{Reagents and antibodies}

Antibodies against CD63 (unconjugated, mouse-anti-human clone H5C6) and CD81 (PE conjugated, mouse-anti-human clone JS-81) were obtained from BD (BD Biosciences, Franklin Lakes, NJ, USA). Purified lipopolysaccharide (LPS) from Escherichia coli was purchased from Sigma (St. Louis, MO, USA). Pam3CSK4 was obtained from InvivoGen (InvivoGen, San Diego, CA, USA). Polymyxin B sulfate salt was from Sigma (St. Louis, MO, USA).

\section{Bacterial strains, culture conditions, and heat-inactivation}

The following bacterial strains were used: NTHi (ATCC-49247), Psa (ATCC-27853), Spn (ATCC-49619), and a clinical Mrc isolate obtained at the academic hospital of Maastricht (Academic Hospital Maastricht (AZM), the Netherlands). All strains were pre-cultured overnight on blood plates at $5 \% \mathrm{CO}_{2}$ and $37^{\circ} \mathrm{C}$, except for NTHi which was pre-cultured on vitalex-supplemented chocolate agar plates (Oxoid, Wesel, Germany). After overnight growth, several colonies were picked and resuspended at 0.5 McFarland $\left(1.5 \times 10^{8}\right.$ colony forming units (cfu) $\mathrm{ml}^{-1}$ ) in RPMI1640. These suspensions were then used for infection or culture experiments. For bacterial culture, bacteria were added to $30 \mathrm{ml}$ of vesicle-depleted culture medium supplemented with 5\% FCS, prepared as described in the cells and media section, and cultured for 4 hours. For heat-inactivation, bacterial suspensions were exposed for 60 minutes to $65^{\circ} \mathrm{C}$. After heat-inactivation, the inactivated bacteria were washed twice with phosphate buffered saline (PBS) and resuspended at 0.5 McFarland. Inactivation was confirmed by overnight plating of $150 \mu \mathrm{l}$ of the bacterial suspension on blood plates at $5 \% \mathrm{CO}_{2}$ and $37^{\circ} \mathrm{C}$, except for NTHi which was cultured on vitalex-supplemented chocolate agar plates.

\section{Infection or stimulation of THP-1 macrophages with (heat-inactivated) bacteria}

Infection and stimulation of THP-1 macrophages was performed at an MOI of 10. For vesicle isolation infections were performed in T75-flasks. $1 \times 10^{7}$ adherent THP-1 macro- 
phages were washed twice with PBS after which they were infected, stimulated with heat-inactivated bacteria, or left untreated in $30 \mathrm{ml}$ of vesicle-depleted culture medium for 4 hours. Next, the culture medium was harvested for MV isolation. For semi-quantitative MV analysis by bead-based flow cytometry, cells were infected or stimulated for 2-8 hours on 24-well plates and the supernatants were collected.

\section{Determination of the number of intracellular bacteria}

THP-1 macrophages seeded on 24-well plates were infected for 2-8 hours. Hereafter the cells were washed 3 times with PBS, then medium containing $300 \mu \mathrm{g} / \mathrm{ml}$ gentamicin was added and after 2 hours, cells were washed 3 times with PBS, lysed by adding $300 \mu \mathrm{l}$ distilled water with $0.025 \%$ saponin for 10 minutes, and neutralized using $700 \mu$ l culture medium. The number of adherent and intracellular bacteria was then determined by bacterial plating of 2 different dilutions.

\section{Cytotoxicity assay}

A dimethylthiazol diphenyltetrazolium bromide (MTT) assay was used to determine the cell viability. THP-1 macrophages seeded in 24-well plate were infected for 2-8 hours, washed with PBS, whereafter medium containing $0.5 \mathrm{mg} / \mathrm{ml}$ MTT (Sigma, St. Louis, MO, USA) was added. Cells were incubated for 1 hour, then the medium was removed and DMSO was added to dissolve the formazan crystals. The optical density (OD) at the wavelength of $540 \mathrm{~nm}$ was determined and the OD relative to uninfected control cells was used to determine the percentage of viable cells.

\section{MV concentration and purification from conditioned medium using ultrafiltration and size exclusion chromatography (SEC)}

Conditioned media (30 ml) obtained upon infection or culture were centrifuged at $300 \times$ $g$ for 10 minutes followed by two $1200 \times g$ centrifugation steps for 10 minutes. After this the supernatants were filtered through $0.22-\mu \mathrm{m}$ filters. Hereafter $2 \mathrm{ml}$ samples were taken and stored at $-80^{\circ} \mathrm{C}$ until further analysis. The remaining supernatants were concentrated by ultrafiltration (as described by Lobb et al. [17]) and purified by SEC. For ultrafiltration, the conditioned media were concentrated to $500 \mu \mathrm{l}$ in 2 runs at $4000 \times g$ for 15 minutes at room temperature using Amicon ultra-15 10-kDa centrifugal filter units (Millipore, Billerica, MA, USA). The concentrates were then purified by sepharose columns as described by Boing et al. with some minor modifications [18]. Briefly, $30 \mathrm{ml}$ sepharose CL-2B (GE Healthcare, Uppsala, Sweden) was washed twice with PBS, and $10 \mathrm{ml}$ sepharose was used to stack TELOS $15 \mathrm{ml}$ filtration column (Kinesis Scientific Experts, St. Neots, Cambridgeshire, UK). Next, the concentrates were loaded onto the column and fractions of $0.5 \mathrm{ml}$ were eluted using PBS. Fractions 7-11 were found to be highly enriched for MVs and negative for free protein (determined by flow cytometry and microBCA). These fractions were pooled and stored at $-80^{\circ} \mathrm{C}$ until use. For electron microscopic analysis, the isolations were performed according to the same protocol except for the initial bacterial culture or cell culture conditions: bacterial culturing was performed overnight using a total $2 \times 10^{9} \mathrm{cfu}$ in a total of $60 \mathrm{ml}$ RPMI without FCS. Conditioned medium from THP-1 macrophages was obtained from 4 T75-flasks containing $1 \times 10^{7}$ cells and $30 \mathrm{ml}$ medium per flask in vesicle-depleted culture medium after 4 hours of culturing at $37^{\circ} \mathrm{C}$. 


\section{MV analysis by TRPS}

The concentration and size distribution of the MVs were determined by TRPS using the qNano Gold (Izon Science Ltd., Oxford, UK). This technique identifies individual particles in suspension by detecting a change in the voltage applied across a nanopore within a membrane when particle pass through this pore. Measurements were conducted using an NP150-rated pore with a fixed stretch of $47 \mathrm{~mm}$, a transmembrane voltage of $0.48 \mathrm{~V}$ (led to a baseline current of $\pm 100 \mathrm{nA}$ ), and a pressure of 6 mbar. To prevent particle aggregation, solution G (Izon Science Ltd. Oxford, UK) was added (10\%) to the supernatants diluted (1:1) in solution Q (Izon Science Ltd. Oxford, UK), each sample was measured for 10 minutes. The samples were calibrated using $114 \mathrm{~nm}$ polystyrene calibration beads (CPC100, Izon Science Ltd. Oxford, UK) at a concentration of $1 \times 10^{9}$ particles $\mathrm{ml}^{-1}$ diluted in culture medium. All reagents were purchased from Izon (Reagent kit (type RK1) for EV analysis, Izon Science Ltd., Oxford, UK). Data were analysed using Izon Control Suite Software v3.2 and concentration calculations were performed using Graph-Pad Prism 5 Software (Graph-Pad, San Diego, CA, USA) and Microsoft Office Excel (version 2010, Microsoft) and corrected for residual vesicles found to be present in the vesicle-depleted culture medium.

\section{Flow cytometric analysis of MVs using antibody-coated latex beads}

A bead-based flow cytometric assay was used for the semi-quantitative analysis of CD63/ CD $81^{+}$host cell-derived MVs. This method is based on the assay described previously $[19,20]$. Briefly, 4- $\mu m$-sized aldehyde-sulfate beads were washed in MES buffer and coated with an antibody against CD63, a marker for host-cell MVs. Antibody-coated beads were incubated overnight with $200 \mu \mathrm{l}$ of processed supernatant obtained after macrophage infection/stimulation, or with vesicle-free control medium. The supernatants were processed by centrifugation at $300 \times \mathrm{g}$, at $1200 \times \mathrm{g}$, and $0.22-\mu \mathrm{M}$ filtration. During overnight incubation, the samples were kept under constant agitation at $6500 \mathrm{rpm}$ at room temperature (RT). The next day, beads were washed twice with $0.22-\mu \mathrm{M}$ filtered PBS with $2 \%(\mathrm{~W} / \mathrm{V})$ bovine serum albumin (BSA) and incubated under continuous shaking with PE-conjugated anti-CD81 (Abcam, Cambridge, MA, USA). Then, the beads were washed and diluted in $300 \mu \mathrm{l}$ PBS for analysis by flow cytometry on a FACSCanto ${ }^{\top M}$ (BD Biosciences, Franklin Lakes, NJ, USA). Analyses were performed using FACSDiva Software and the threshold for the percentage of PE-positive beads was based on control beads incubated in culture medium and set at $2 \%$. The relative amount of MVs, expressed in arbitrary units (AU), was calculated by the multiplication of the number of positive beads with the median fluorescence intensity.

\section{Pro-inflammatory and immuno-modulating characteristics}

THP-1 macrophages were seeded in a 96-well plate, washed twice with PBS and provided with fresh complete vesicle-depleted culture medium with 5\% FCS. Hereupon, cells were exposed to $20 \mu \mathrm{l}$ of the SEC purified MVs (isolated after macrophage infection), bacterial MVs (bMVs), host-cell derived extracellular vesicles (EVs: isolated after macrophage stimulation with heat-inactivated bacteria) or whole heat-inactivated bacteria for 16 hours. To determine the effect of MV pre-exposure on the response to a subsequent TLR-4 or TLR2/1 challenge with LPS or Pam3CSK4, respectively, THP-1 macrophages were cultured, treated, and stimulated as described above for a period of 4 hours. After 4 hours of stimulation with MVs, the cells were washed 3 times with PBS and after the addition of 
vesicle-depleted culture medium, re-stimulated with either LPS (100 $\mathrm{ng} \mathrm{m}^{-1}$ ) or Pam3CSK4 (50 $\mathrm{ng} \mathrm{ml}^{-1}$ ) for 16 hours. The vesicle amounts $(20 \mathrm{\mu l})$ used for the THP-1 macrophage exposures represent 2 times the physiological concentration that is theoretically present in a physiological situation (i.e. the amount of vesicles that is present after an 4 hour infection of $1 \times 10^{7}$ THP-1 macrophages with either one of the bacteria at an $\mathrm{MOI}$ of 10). This volume represents this amount of vesicles is based on the recovery as determined by TRPS-based analysis of the vesicle concentration in conditioned culture medium and of the purified vesicles as obtained on vesicle enrichment using ultrafiltration and vesicle purification by SEC. The recovery was determined using MVs from infection experiments (Fig 5D: MVs-SEC; based on NTHi and Mrc) and calibration beads (Fig 5D: beads-SEC; based on $114 \mathrm{~nm}$-sized Izon ${ }^{\circledR}$ calibration beads). The culture supernatants were harvested hereafter and used for cytokine measurements.

\section{The effect of vesicle exposure on the number of adherent and intracellular bacteria}

THP-1 macrophages seeded in 24-well plates were washed 3 times with PBS after which $300 \mu \mathrm{l}$ complete vesicle-depleted culture medium with 5\% FCS was added. Then 200 $\mu \mathrm{l}$ of the MV-containing SEC fraction was added to the appropriate wells and the cells were pre-exposed to the vesicles for 1 hour. Upon pre-exposure, the cells were infected with either one of the bacteria at a $\mathrm{MOI}$ of 50 for 1 hour. After infection, the cells were washed 3 times with PBS to remove free bacteria, then cells were either left untreated, to determine the total amount of adherent and intracellular bacteria, or the cells were treated with gentamicin as described above to determine the number of intracellular bacteria. After bacterial plating of 2 different dilutions, the number intracellular bacteria was determined and the number of adherent bacteria was determined by subtracting the number of bacteria left after gentamicin treatment from the number obtained in the absence of gentamicin.

\section{Cytokine measurements}

The release of TNF- $\alpha, I L-8$, and IL-1 $\beta$ by THP-1 macrophages was determined by enzymelinked immuno-sorbent assay (ELISA). The human Ready-Set-Go ELISA kits were obtained from eBiosciences and the assays were performed according the manufacturers' instructions (Affymetrix eBioscience, Santa Clara, CA, USA).

\section{Cryo-electron microscopy}

Upon MV isolation and purification by ultrafiltration and SEC the MV-containing SEC fractions were further concentrated to $100 \mu \mathrm{l}$ using Amicon ultra-4 10-kDa centrifugal filter units (Millipore, Billerica, MA, USA). Vitrified specimens were prepared by loading a grid into an FEI Mark IV Vitrobot (FEI Company, Eindhoven, The Netherlands), adding $5 \mu \mathrm{l}$ of MV-suspension to the grid, and then immediately blotting the grid for 1 second before plunge-freezing in liquid ethane which was kept at its melting point by liquid nitrogen using a Vitrobot environmental chamber that was maintained at 95\% humidity. For microscopy, grids were mounted in a Gatan cryoholder in liquid nitrogen and transferred to a Tecnai T12 Spirit microscope (FEI Company, Eindhoven, the Netherlands). Images were acquired with a 4096x4096 pixel CCD Eagle camera (FEI Company, Eindhoven, the Netherlands) at $120 \mathrm{kV}$ with a temperature between $-170^{\circ} \mathrm{C}$ and $-175^{\circ} \mathrm{C}$. Image analysis to determine 
the median MV-diameter was performed using ImageJ processing software (National institutes of Health, Bethesda, USA).

\section{Statistical analysis}

Statistical analysis was performed using Graph-Pad Prism 5 Software (Graph-Pad, San Diego, CA, USA). Statistical dispersion was determined by calculation of the standard error of the mean. One-way analysis of variance (ANOVA) was performed in combination with the Bonferroni multiple comparison test to determine statistical significance of the variances between multiple groups. An unpaired t-test was performed for the statistical analysis of the variance between the means of 2 groups. p-values were considered significant when $<0.05$. 


\section{RESULTS}

To study vesicle release during short-term infection of THP-1 macrophages and during culture of NTHi, Mrc, Spn, and Psa, we first aimed to characterize MVs shed by unstimulated THP-1 macrophages and during culture. Cryo-EM analysis revealed that THP-1 macrophages release MVs under control conditions and that the release of MVs occurs by all bacteria during culture (Fig. 1A-E). Also, the morphology of the bacterial MVs was highly comparable between the different species with an overall median diameter of 60 $\mathrm{nm}$ with an interquartile range (IQR) of 54-70 nm whereas the size of the THP-1 macrophages-derived MVs was found to be larger at 117 with an IQR of 98-146 nm (Fig. 1F).
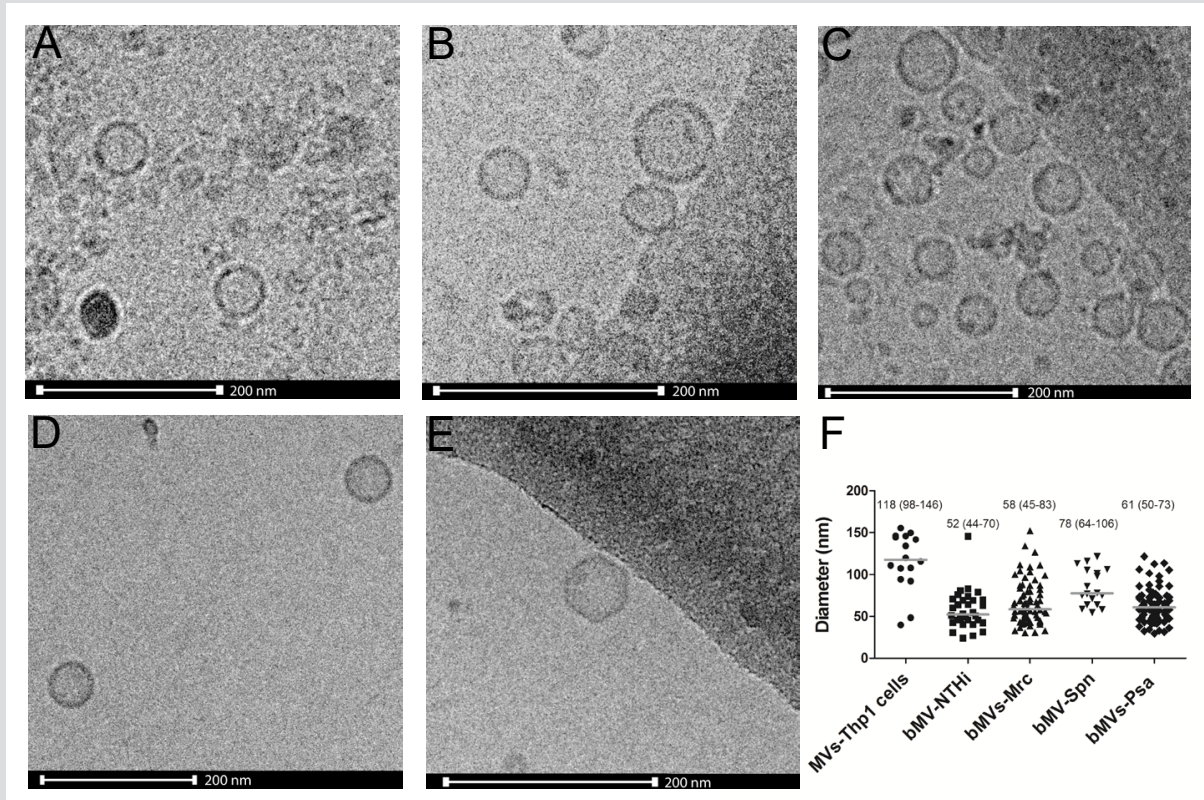

$\mathrm{F}$

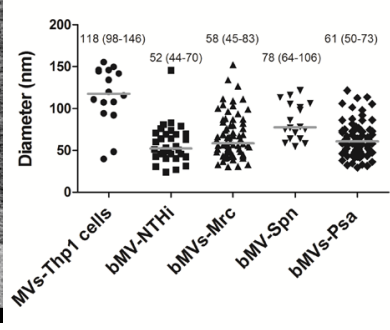

FIGURE 1: Cryo-EM analysis of MVs released by THP-1 macrophages (A) or during bacterial culture of NTHi (B), Mrc (C), Spn (D), and Psa (E). MVs released during bacterial culture show a similar size and appearance. The median is based on the diameter as obtained by cryo-EM imaging (F). Scale bar represents $200 \mathrm{~nm}$.

Next, we determined the size distribution and median size of MVs shed by unstimulated THP-1 macrophages and bacteria during 4 hours of culture by TRPS. A similar distribution and size range (Fig. $2 \mathrm{~A}$ and $2 \mathrm{C}$ ). Regarding the concentrations, although there were less MVs released by Spn (3.8 (IQR 2.5-4.3) $\times 10^{8}$ particles $\mathrm{ml}^{-1}$ ) as compared to the other bac-

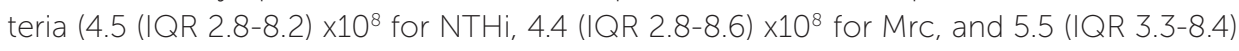
$\times 10^{8}$ particles $\mathrm{ml}^{-1}$ for Psa), this difference was not statistically significant (Fig. 2E). 
Having characterized the MV release by both THP-1 macrophages and bacteria under control culture conditions, we continued with the characterization of the mixed MV populations released during infection. Macrophages were infected with the bacteria for 4 hours after which the size and concentrations of the MV populations were determined. The size-distribution of the mixed MV populations shed during infection were found to be highly similar (Fig. 2B). Overall there was little variation in the MV size and the median size was found to be $107 \mathrm{~nm}$ with an IQR of 105-115 (Fig. 2D). With respect to the concentration, the absolute numbers tended to be somewhat increased upon infection with NTHi and Mrc compared to the aggregate number that was released by individual bacteria and THP-1 macrophages. This increase was, however, not significant (NTHi: 4.5 (IQR

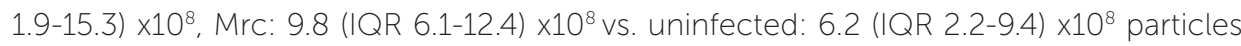
$\left.\mathrm{ml}^{-1}\right)$ (Fig. 2F). Infection with Spn did not result in a change in the concentration of MVs (6.2 (IQR 5.5-9.4) $\times 10^{8}$ particles $\mathrm{ml}^{-1}$ ). THP-1 macrophage infection with Psa, on the other hand, significantly increased the MV release when compared to control conditions (Psa: 3.2 (IQR 1.2-4.5) $\times 10^{9}$ vs. uninfected: 6.2 (IQR 2.2-9.4) $\times 10^{8}$ particles $\mathrm{ml}^{-1}$, p0.05) (Fig. 2F).

After the analysis of the whole MV population released during infection, the release of host-cell MVs over time, during infection, was determined. Using a semi-quantitative flow cytometry-based assay, we established the release of $\mathrm{CD} 63^{+} / \mathrm{CD} 81^{+}$host-cell MVs: CD63 and CD81 are both members of the tetraspanin family and highly enriched on host cell-derived MVs. We found that the release of $\mathrm{CD} 63^{+} / \mathrm{CD} 81^{+}$host cell MVs under control conditions was time-dependent and highest after 8 hours (Fig. 3A). Likewise, during infection the release of vesicles also increased in a time-dependent way. For all conditions the vesicle release at 8 hours was found to be significantly increased over the vesicle release at 2 hours (except for the NTHi-based condition) (Fig. 3A). When compared to the release under control conditions, after 8 hours of infection there was a tendency towards an increased host cell MV release by infected cells (Fig. 3C). Moreover, to determine whether viable bacteria were required for this induction, the MV release by THP-1 macrophages was determined following stimulation with heat-inactivated bacteria (Fig. 3B). Interestingly, although the number of MVs released by host cells following exposure to heat-inactivated NTHi or Mrc was not different from the number of MVs released following infection with viable bacteria, numbers were lower for THP-1 macrophages exposed to heat-inactivated Psa or Spn. These data suggest that, at least for Psa and Spn, viable bacteria are required to evoke an increased MV release by host cells. 

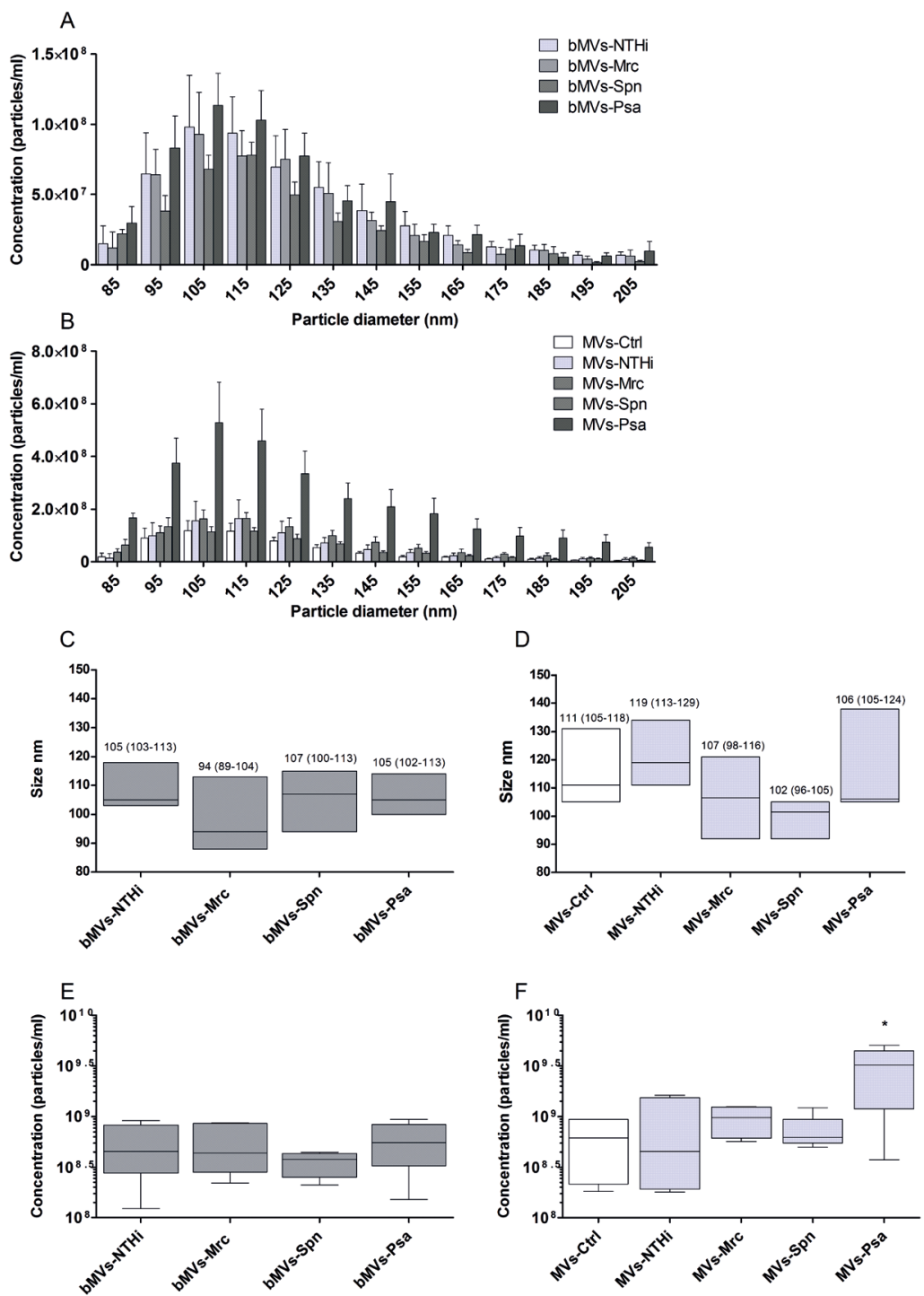

FIGURE 2: Tunable resistive pulse sensing-based characterization of MVs released upon infection with or culture of NTHi, Mrc, Spn, and Psa. Conditioned media of bacterial cultures (bMVs) were used to assess the vesicle size and numbers of vesicles released (A). Also, MV release by uninfected THP1 macrophages (MVs-Ctrl) and by THP1 macrophages after 4 hours of infection with different bacteria (MVs-NTHi, -Mrc, -Psa, -Spn) was determined (B). The median diameter and interquartile range (between brackets) was calculated and is given for bacterial MVs (C) and for the mixed MV population released by cells and bacteria during infection (D). Box and whisker plots (E-F) indicate the median (line in box), 25th and 75th percentiles (outer lines of box) and the minimal and maximal values (whiskers) for the bacterial MV concentration (E) and the concentration of MVs released upon infection (F). Results are from 6 independent experiments. * $p<0.05$. 

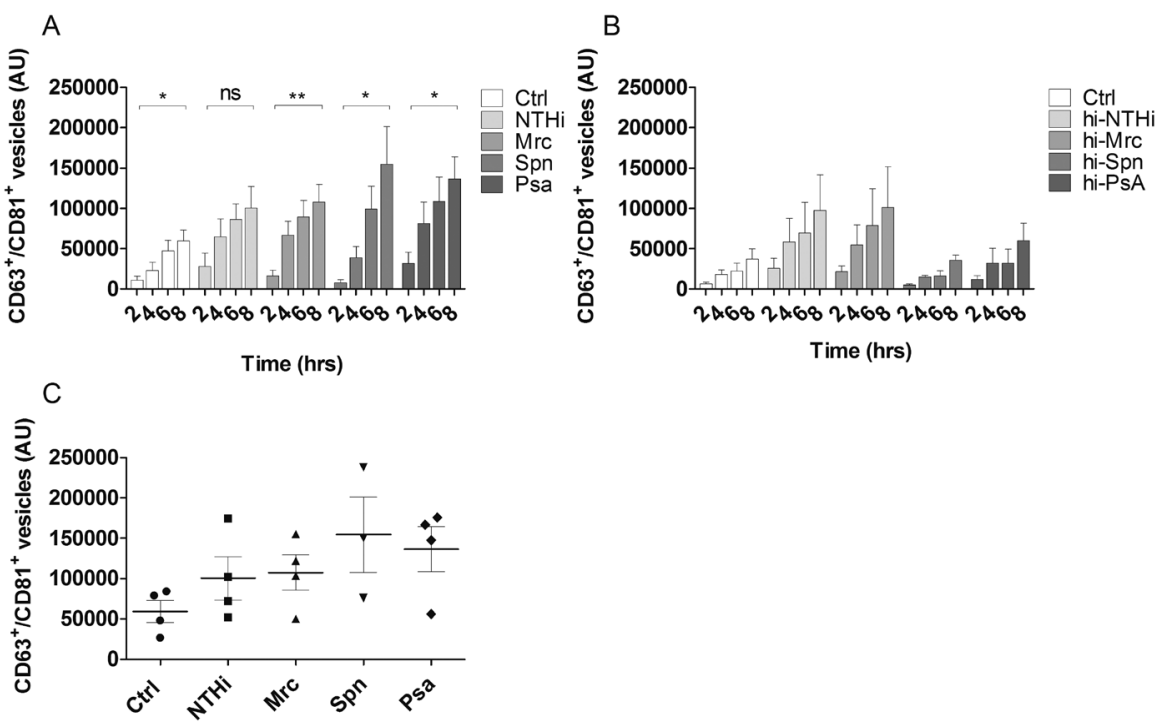

FIGURE 3: Time dependent increase in the release of CD63/CD81 ${ }^{+}$host cell MVs, by uninfected THP-1 macrophages (Ctrl), and by THP-1 macrophages upon exposure to viable or heat-inactivated NTHi, Mrc, Spn, and Psa. THP-1 macrophages were infected (A) or stimulated with (heat-inactivated) bacteria (B) at an $\mathrm{MOI}$ of 10 for 2, 4, 6, and 8 hours. The supernatants were collected and used for bead-based flow cytometric analysis to determine (A) the relative number of CD63/CD81+ MVs after infection ( $n=4$ except for spn ( $n=3$ ) or (B) stimulation with heat-inactivated bacteria $(n=3)$. After infection, the MV release increased over time and at all the 8 hour time points the MV numbers for all conditions were significantly increased over the 2 hour time points, except for NTHi. After stimulation with heat-inactivated bacteria, no significant increase was found between MVs release at 8 hours and 2 hours of stimulation (C). After 8 hours of infection there was a tendency towards an increased release of MVs for all pathogens as compared to control, which was significant after Psa-infection ( $n=4$ except for spn: $n=3$ ). Data are means \pm the SEM. ${ }^{\star} p<0.05,{ }^{*} p<0.01$

Finally, we determined the effect of infection on the cell viability and number of intracellular bacteria over the course of infection. We found that the cell viability was not altered by an infection with NTHi, Mrc, and Spn (Fig. 4E). Infection with Psa, however, led to a $60 \%$ reduction in cell viability after 4 hours and a $70 \%$ reduction after 8 hours of infection. Moreover, the number of intracellular bacteria was found to increase over time for all bacteria except for Psa. Recently it was shown that intracellular bacteria also release MVs [13], therefore these findings implicate that during infection, bacterial MVs can be released both by intra- and extracellular bacteria (Fig. 4A-D). Taken together our results show that both bacterial and host cell MVs are released during infection. 

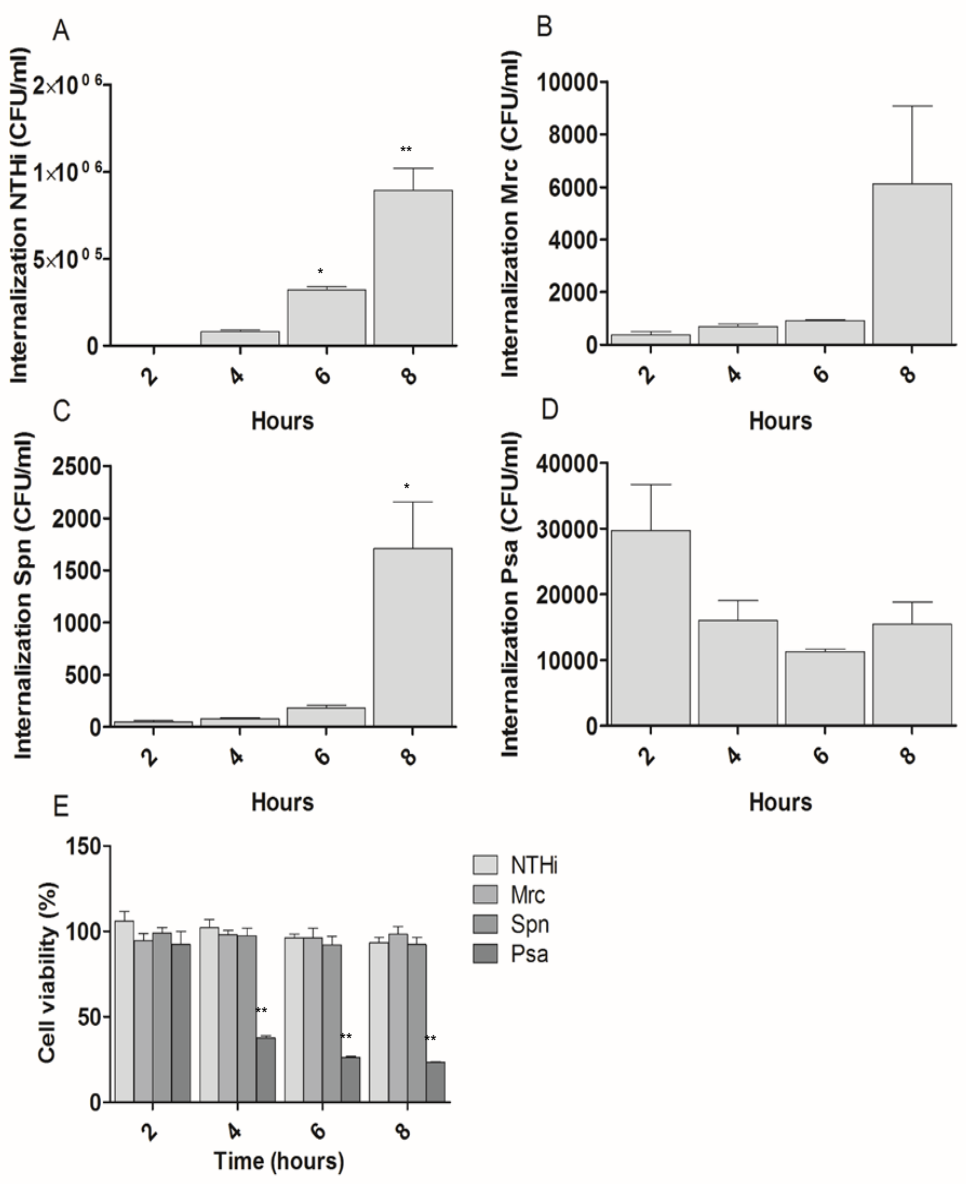

FIGURE 4: The number of intracellular bacteria and the cell viability over time after infection with various bacteria. THP-1 macrophages were infected for 2, 4, 6, and 8 hours with NTHi, Mrc, Spn or Psa, then washed, treated with $300 \mu \mathrm{g}$ gentamicin and lysed to determine the number of intracellular bacteria (A). The viability of THP-1 macrophages was determined over the course of infection (B). Data are represented as the mean $\pm \operatorname{SEM}(n=3) .{ }^{*} p<0.05,{ }^{* *} p<0.01$. 
Careful characterizations of the MV protein content in previous studies identified immunogenic bacterial proteins on MVs. Therefore, functional aspects of bacterial MVs, MVs derived from infected THP-1 macrophages and of MVs from THP-1 macrophages stimulated with heat-inactivated bacteria were studied. To this end, the release of several pro-inflammatory cyto- and chemokines by naive THP-1 macrophages upon MV exposure was assessed. The number of MVs used for these exposures represents 2-times the physiological MV-concentration that cells are theoretically exposed to when cells are infected with the bacteria at an $\mathrm{MOI}$ of 10 (as described in the materials and methods section). This amount is based on the vesicle recovery after SEC (Figure 5D). Bacterial MVs elicited the release of TNF-a, IL-8 and IL-1 $\beta$ by naive THP-1 macrophages, albeit with different potencies for the different bacterial species (Fig. 5A-C, respectively). For example, stimulation with MVs derived from NTHi resulted in the release of $>1 \mathrm{ng} \mathrm{m}^{-1} \mathrm{TNF}-\mathrm{a}$, while the amount of TNF-a release upon stimulation by Mrc and Psa MVs was far less pronounced and Spn MVs were even unable to induce a significant release of TNF-a. These variations were comparable with the variations observed on stimulation with whole (heat-inactivated) bacteria (Fig. 5A). When naive THP-1 macrophages were stimulated with MVs obtained after infection, the amounts of TNF-a released were almost identical to the amounts released when stimulated with bacterial MVs only. This suggests that the bacterial MVs are primarily responsible for activation of naive THP-1 macrophages, which is supported by the almost complete absence of TNF-a release following stimulation with MVs of THP-1 macrophages that were exposed to heat-inactivated bacteria, a vesicle population that exclusively consists of host cell-derived MVs.

Earlier it has been shown that several of the PAMPs associated with MVs are well-known ligands for Toll-like receptors (TLRs) (as reviewed by Ellis et al. [21]). Therefore, the next aim was to determine whether MV-associated LPS is responsible for the MV-induced TNF-a response. To neutralize the effects of MV-associated LPS, polymyxin B (a compound that binds to the lipid A region of LPS) was used. The specificity of polymyxin B was confirmed as it only blunted the LPS-induced TNF- release by naive THP-1 macrophages $(2.2 \pm 0.3$ to $0.2 \pm 0.2 \mathrm{ng} \mathrm{ml}^{-1}$ ), but not the TNF-a release induced by the TLR2/1 ligand PAM3CSK4 $\left(2.3 \pm 0.1\right.$ to $\left.1.9 \pm 0.2 \mathrm{ng} \mathrm{ml}^{-1}\right)$. Polymyxin B was found to significantly reduce the TNF-a release in response to NTHi MVs or MVs isolated from NTHi-infected THP-1 macrophages (Fig. 6A and 6B). The response to MVs from the Gram-positive Spn were not considerably affected. Moreover, the Mrc-MV-induced TNF-a response also remained unaffected. 

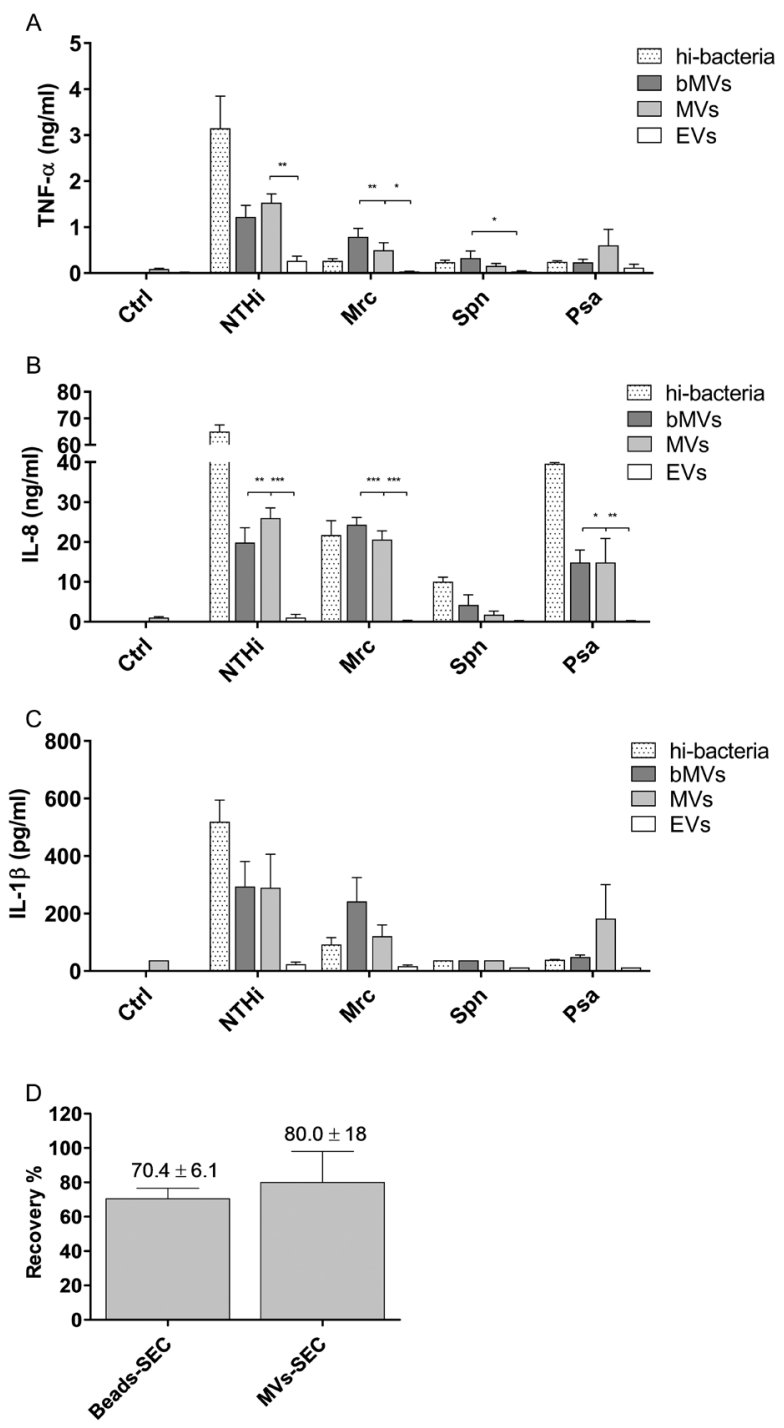

FIGURE 5: THP-1 macrophages were exposed for 16 hours to MVs released during bacterial culture (bMVs), infection (MVs), vesicles from THP-1 macrophages that were stimulated with heat-inactivated bacteria (EVs), and to whole heat-inactivated bacteria at an MOI of 0.1 (hi-bacteria). Then the release of the pro-inflammatory cyto- or chemokines TNF- $a(A), I L-8(B)$ and IL-1 $\beta$ (C) was determined by ELISA. The number of MVs used for these exposures represents 2-times the physiological MV-concentration cells are theoretically exposed to when cells are infected with the bacteria at an $\mathrm{MOI}$ of 10 . To calculate the amount of MVs to be used for these experiments we determined the vesicle recovery following vesicle-enrichment using ultrafiltration and vesicle purification by SEC using TRPS on MVs from infection experiments (MVs-SEC; based on NTHi and Mrc) and calibration beads (beads-SEC; based on $114 \mathrm{~nm}$-sized Izon $®$ calibration beads) (D). Data are represented as the mean $\pm \operatorname{SEM}(n \geq 4) .{ }^{*} p<0.05,{ }^{*} p<0.01,{ }^{* * *} p<0.001$. 

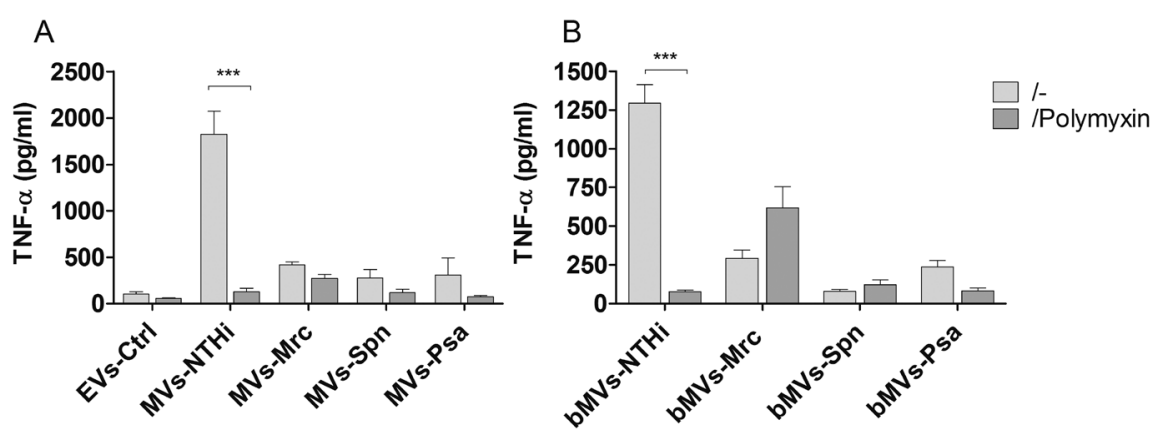

FIGURE 6: Effect of polymyxin B treatment on the TNF-a release in response to MVs released during infection or bacterial culture. THP-1 macrophages were pre-incubated for 1 hour with polymyxin B prior to overnight stimulation with MVs released upon infection (MVs, A) or bacterial culture (bMVs, B). Data are represented as the mean \pm $\operatorname{SEM}(n=3) .{ }^{* \star *} p<0.001$.

To determine how bacterial MVs or MVs shed upon infection modulate a subsequent pro-inflammatory response to bacteria, THP-1 macrophages were pre-incubated with MVs for 4 hours and subsequently exposed to LPS or Pam3CSK4, thereby mimicking bacterial infection. Pre-incubation with NTHi-derived MVs as well as MVs derived from NTHi-infected THP-1 macrophages significantly blunted the TNF-a response to both LPS and Pam3CSK4 (Fig. 7A). Moreover, pre-exposure to Mrc MVs also significantly reduced the response to secondary stimulation with Pam3CSK4 (Fig. 7B). Psa and Spn MVs or MVs from infected THP-1 macrophages did not significantly reduce the release of TNF-a in response to LPS or Pam3CSK4 (Fig. 7C-D, respectively). These results indicate that the presence of MV-associated TLR-agonists determines the subsequent response to a LPS or Pam3CSK4 challenge. 
A
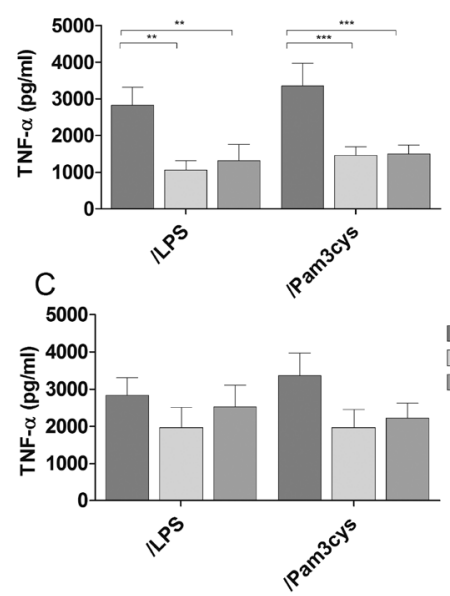

B
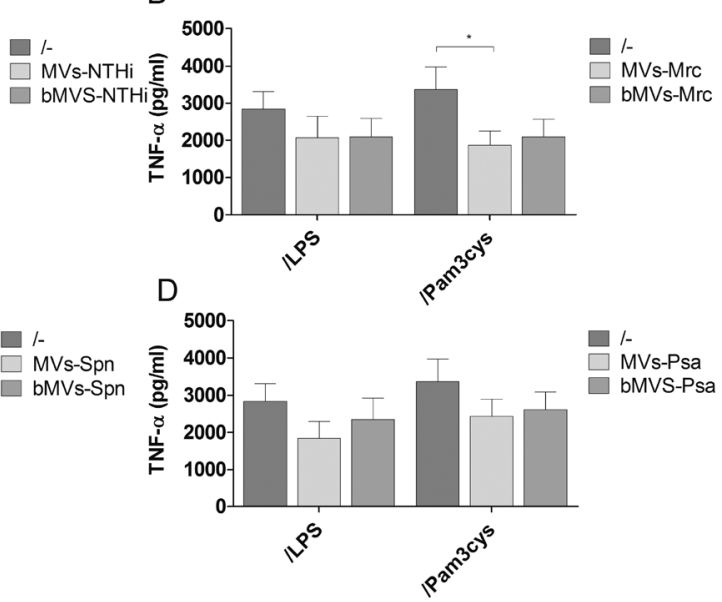

FIGURE 7: The pro-inflammatory response to a secondary challenge with LPS or Pam3CSK4 is blunted after THP-1 macrophages pre-exposure to MVs released during infection or bacterial culture. The TNF-a response to LPS or Pam3CSK4 upon MVs pretreatment was determined and is shown separately for bacterial MVs (bMVs) or mixed MVs isolated from THP-1 macrophages infected with NTHi (A), Mrc (B), Psa (C), and Spn (D). THP-1 macrophages were pre-incubated with purified MVs/bMVs for 1 hour before secondary stimuli were added and the cells were exposed overnight to these components or to a combination. Data are represented as the mean \pm SEM $\left.(n \geq 4) .{ }^{*} p<0.05,{ }^{* \star} p<0.01,{ }^{* \star *} p<0.001\right)$.

To further elucidate how MVs shed upon infection affect the course of infection, the next aim was to determine whether MV exposure affects the bacterial adhesion and the number of intracellular bacteria. To assess this, THP-1 macrophages were pre-exposed for 1 hour to the MVs after which the bacteria were added. After another hour, the cells were washed and left either untreated (to assess for the number of adherent and intracellular bacteria) or were treated with gentamicin (to determine the number of intracellular bacteria). When exposed to MVs from NTHi, Mrc, and Spn there was a trend towards an increased bacterial adhesion but the intracellular bacterial load was not affected (Fig. $8 \mathrm{~A}-\mathrm{C})$. However, exposure to MVs from Psa-infected cells significantly enhanced number of adherent and intracellular bacteria (Fig. 8D). 

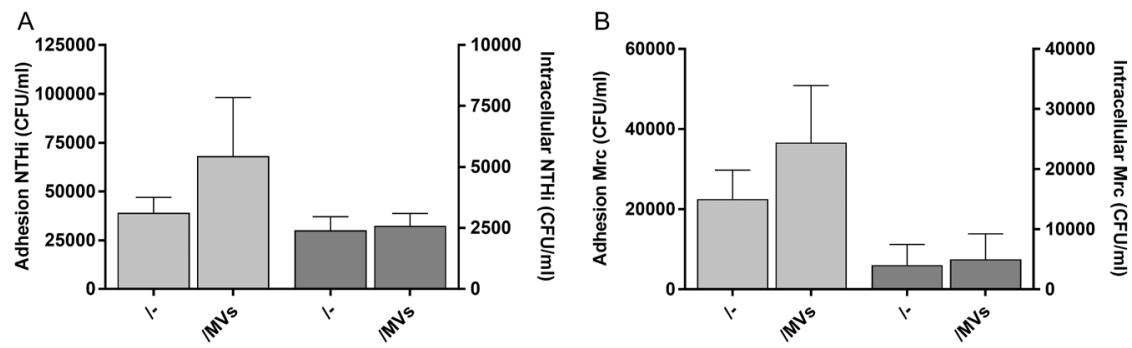

C
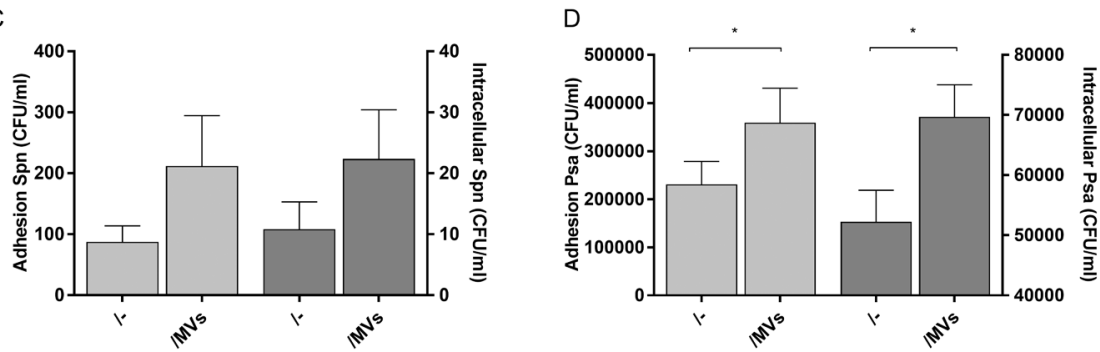

FIGURE 8: Number of adherent and intracellular bacteria after exposure of THP-1 macrophages to MVs released by infected THP-1 macrophages or bacteria during culture. The effect of MV-exposure on the adhesion and intracellular bacteria are shown separately for the conditions based on NTHi (A), Mrc (B), Spn (C), and Psa (D). THP-1 macrophages were pre-incubated with purified $\mathrm{MVs} / \mathrm{bMVs}$ for 1 hour before the cells were infected with either one of the bacteria (MOI 50) for 1 hour in the presence of the vesicles. Bacterial counts (CFU/ml) were determined by plating of bacterial serial dilutions. Data are represented as the mean $\pm \operatorname{SEM}(n \geq 4) .{ }^{*} p<0.05$. 


\section{DISCUSSION}

In this study, we demonstrated that a variety of bacterial species release MVs both during culture and infection of host cells. In addition, we show that THP-1 macrophages also release MVs, both under control conditions and during infection. Moreover, we showed that MVs released during infection have immuno-stimulating and-modulating properties.

Previous studies have shown that the shedding of bacterial MVs may provide bacteria with a selective advantage as it may aid bacterial internalization of host tissues (as reviewed by Kaparakis-Liaskos, 2015 [3]). In addition, during infection these vesicles can also evoke the release of pro-inflammatory cytokines as they carry PAMPs. MVs from M. catarrhalis, non-typeable $H$. influenzae, and $P$. aeruginosa have been detected in patients with various airway conditions suggesting that these MVs may also contribute to the pathogenesis of airway diseases [12,22-24]. Regarding the dynamics and characteristics of bacterial MVs released upon long-term bacterial culture, these have been studied extensively [22,25-28]. However, these characteristics are still poorly defined for MVs shed upon short-term infection. Moreover, MVs are also being released by the host both under control conditions and during infection, and it is unknown whether these MVs also exhibit immuno-stimulatory or -modulatory properties. Therefore, in this study we determined the release and functional properties of both bacterial and host cell MVs released upon infection of THP-1 macrophages with different bacterial species.

Analyses with both cryo-EM and TRPS confirmed the shedding of MVs upon bacterial culture and by THP-1 macrophages under control conditions. Strikingly, the median diameter of the bacterial MVs which was obtained by cryo-EM was found to be smaller than that obtained by TRPS (56.7 (IQR 53.7-73.4) vs 105.0 (IQR 95.5- 110.8) nm). It is possible that this discrepancy is introduced by the cutoff value of the lower threshold of the qNano (previously established at 70-100 nm [29]). This may have led to the inability of the qNano to discriminate signals generated by smaller MVs from the background noise, resulting in a size that was skewed towards a larger MV diameter. Regarding the total number of MVs released, TRPS analysis revealed a significant increase in the number of MVS released during Psa infection, and a similar tendency was observed for the other bacteria. Likewise, bead-based flow cytometric analysis also revealed that the release of CD63/ CD81+ host cell MVs also increased upon infection. Remarkably, the magnitude of the Psa-induced increase release of CD63/CD81+ MVs was in the same range of the other conditions which does not explain the results obtained by TRPS analysis that showed an almost 10-fold increase upon Psa infection. In this study we also determined two other aspects that consider the macrophage infections namely the number of intracellular bacteria and the host-cell viability after infection. This latter revealed a high percentage of cell death already upon 4 hours of Psa-infection, therefore it is likely that these vesicles are apoptotic bodies or nanosized membrane structures released from death or dying cells [30]. However, further research will be required to establish the origin of this MV population. This difference in cytotoxicity between Psa and the other bacteria could have been caused by differences in secretion system-associated virulence factors [31]. It has been shown that the cytotoxicity of Psa correlates with the expression of the type III secretion system which enables Psa to inject highly cytotoxic exotoxins into the host 
cell [32]. Moreover, we observed an increase in the number of intracellular bacteria (total number determined by bacterial invasion/phagocytosis, intracellular growth as well as bacterial killing after phagocytosis) over the course of infection for all bacteria except for Psa which likely resulted from its cytotoxicity. As it has been shown that the release of membrane vesicles by bacteria can also occur by intracellular bacteria, the bMVs released during macrophage infection could, therefore, have been originated from extra- as well as intracellular bacteria.

Another interesting observation made by TRPS-analysis is that there are no significant differences in the numbers of bacterial MVs shed by either the three Gram-negative bacteria or the Gram-positive Spn. This comparable release by both Gram-positive and Gram-negative bacteria might be an important finding as the release of MVs by Gram-positive bacteria has only been recognized recently (as reviewed by Brown et al. [8]). The release of MVs by Gram-negative bacteria is acknowledged as an evolutionarily conserved process for which at least 3 different mechanisms of release have been described. Future research needs to reveal whether the release of MVs by Gram-positive bacteria is likewise evolutionary conserved.

Earlier studies have demonstrated that next to external stressors (e.g. by nutrient depletion) the biogenesis of MVs can be affected by the growth stage [22,28,33-35]. Most studies on MV shedding use bacterial cultures that are in the late exponential or stationary growth phase for the isolation of outer membrane vesicles [21,26,33,36]. External stressors may also induce a growth stage transition towards stationary growth [37]. Our study shows that bacterial MV production also occurs during the early growth phase, both by the Gram-negative bacteria as well as by the Gram-positive Spn. Future research on the $M V$ biogenesis and on factors that affect the MV release such as the growth phase and environmental factors will result in an improved understanding of the MV production and functional activity. To conclude, by using electron microscopic analysis, TRPS-based analysis, and flow cytometry we demonstrated that both bacterial and host cell MVs are released during infection.

The functional properties of bacterial MVs, including those released by the airway pathogens used in this study, have been studied previously (as reviewed by Ellis and Kuehn [21]). Moreover, studies have demonstrated the release of immuno-stimulatory host cell MVs during infection. These immuno-stimulatory properties of host cell-derived MVs have been attributed to the presence of several bacterial outer membrane proteins assumed to be present in these host cell vesicles [38-40]. Yet, this has recently been disputed by Athman and colleagues who demonstrated that host cells infected with Mycobacterium tuberculosis released two distinct MV populations, containing either host cell molecules (CD63) CD9) or bacterial components [13]. Here we determined the biological properties of the MVs shed upon infection and compared them to those of pure bacterial MVs shed during culture. Additionally, the immuno-stimulatory properties of MVs isolated from THP-1 macrophages following stimulation with heat-inactivated bacteria were determined. The MV population released by infected THP-1 macrophages elicited the release of significant amount of pro-inflammatory cytokines by naive macrophages, which was comparable to the amount of pro-inflammatory cytokine release following stimulation with pure bacterial 
MVs. We observed that this pro-inflammatory cytokine response was induced in a species-specific manner and that it was not induced by Spn-derived MVs. In line with previous studies we found that MVs released upon stimulation with heat-inactivated intracellular pathogens failed to induce a significant pro-inflammatory response $[13,43]$. Overall, these results show that both host cell and bacterial MVs are released during infection and that particularly bacterial MVs have a strong immuno-stimulatory potential.

Studies that assessed the composition and function of bacterial MVs released upon culture identified several TLR-agonists on the membranes of these MVs [22,26,41-46]. Here, experiments with polymyxin B, a compound that antagonizes LPS, showed that the MV-induced pro-inflammatory response is predominantly dependent on the presence of LPS on MVs of NTHi and Psa but not Mrc. Our results are consistent with what has previously been published by Sharpe et al. who show that NTHi-derived MVs contain several immuno-stimulatory proteins including lipooligosaccharide (LOS) [36]. That LOS induces the release of TNF-a in a TLR-4 dependent manner was elegantly demonstrated in a study by Lorenz et al. [47]. In contrast, our results show that polymyxin B was not able to neutralize the Mrc-MVs in their ability to induce the release of TNF-a. This is in line with previous research that demonstrates the pro-inflammatory properties of these $M V s$ are dependent on the presence of TLR-2 ligands [26]. Furthermore, previous studies on the composition and immunogenicity of Psa-derived MVs show that these vesicles can elicit potent pro-inflammatory responses due to the presence of several TLR-4 agonists [21], which supports our findings that polymyxin B reduced the TNF-a response to these MVs.

Previous studies that examined the effects of bacterial MVs demonstrate that a prolonged exposure to TLR-agonists-bearing MVs can also lead to TLR-desensitisation [48,49]. In our study this was found to be pathogen dependent and mostly restricted to NTHi and Mrc. As a significant decrease was also observed upon pre-exposure to the analogous TLR-ligands, it is highly likely that this desensitisation was indeed TLR-mediated. A study by Waller et al. demonstrated that this TLR-2/4-induced desensitisation was dependent on IL-10 as the TNF-a responses was reinstated upon neutralization of IL-10. Moreover, it was shown that the IL-10 release induced on TLR-2 and TLR-4 activation, depended on a signalling pathway involving PI3K/PKB/AKt/mTOR [48]. We determined the levels of IL-10 following stimulation of naïve macrophages with a variety of host cell-derived and bacterial vesicles and only very low $\mathrm{IL}-10$ levels $(<5 \mathrm{pg} / \mathrm{ml})$ were found under all conditions (results not shown). Therefore, we consider it unlikely that the observed MV-induced tolerance was IL-10 dependent.

Several studies investigating the functional properties of bacterial MVs demonstrated an enhanced bacterial adhesion upon MV exposure. The effects elicited by these MVs were shown to be mediated by vesicle-associated virulence [49,50]. Likewise, we could demonstrate that MVs released by THP-1 macrophages during infection all tended to increase bacterial adhesion irrespective of the bacteria used. Moreover, the number of intracellular bacteria after exposure of THP-1 macrophages to MVs from Psa-infected cells was also found to be significantly increased. Further studies to examine the intracellular bacterial survival and determine the effects of our findings on the bacterial clearance will be required to establish the implications of our findings. 
Although the release of MVs by Gram-negative bacteria in culture has been studied in more detail, only a few studies addressed bacterial MV shedding during infection. Here we demonstrated that bacterial MVs are released during bacterial culture and within 4 hours after infection. Although both the mixed vesicle population released upon infection as well as pure bacterial MVs were found to have a profound pro-inflammatory potential, pre-exposure to these MVs led to a significant reduction in the pro-inflammatory response to a secondary challenge. Moreover, MVs released upon infection also led to an increased number of adherent and intracellular bacteria.

Taken together, these findings show evidence that MVs trigger a strong immune response and increase the number of intracellular bacteria. The latter requires a careful interpretation as on one hand it may indicate increase bacterial invasion while it also might be indicative for enhanced early phagocytosis. Further research will be required to elucidate how these MVs may serve bacteria to overcome the host-immune response. A better understanding of these processes may help to find new therapies to combat bacterial respiratory infections.

\section{DECLARATIONS}

Ethics approval and consent for publication: not applicable. The datasets used and/or analyzed during the current study are available from the corresponding author on reasonable request. The authors declare that they have no competing interests in this section. CV, BB, and GG made substantial contributions to the acquisition and/or analysis and interpretation of data. FS and PS have been involved in drafting the manuscript and revising it for important intellectual content. All authors read and approved the final manuscript. This research received no specific grant from any funding agency in the public, commercial or not-for-profit sectors. The authors wish to thank dr. J. P. Hays from the Erasmus University Medical Centre (Erasmus MC), Rotterdam, the Netherlands for kindly providing the rabbit antisera to Moraxella catarrhalis used in this publication. We also thank Prof. C. López-lglesias from the Electron Microscopy Unit of the Maastricht University for performing the cryo-electron microscopic imaging. 


\section{REFERENCES}

1. Kaufmann SHE, Dorhoi A. Molecular Determinants in Phagocyte-Bacteria Interactions. Immunity. 2016;44: 476-491. doi:10.1016/j.immuni.2016.02.014

2. Marsland BJ, Gollwitzer ES. Host-microorganism interactions in lung diseases. Nat Rev Immunol. 2014;14 827-35. doi:10.1038/nri3769

3. Kaparakis-Liaskos M, Ferrero RL. Immune modulation by bacterial outer membrane vesicles. Nat Rev Immunol. 2015;15: 375-387. doi:10.1038/nri3837

4. Schwechheimer C, Kuehn MJ. Outer-membrane vesicles from Gram-negative bacteria: biogenesis and functions. Nat Rev Microbiol. 2015:13:605-19. doi:10.1038/nrmicro3525

5. Yáñez-Mó M, Siljander PR-M, Andreu Z, Bedina Zavec A, Borràs F, Editl. B, et al. Biological properties of extracellular vesicles and their physiological functions. J Extracell Vesicles. 2015;4: 27066. doi:10.3402/ jev.v4.27066

6. Schorey JS, Harding C V. Extracellular vesicles and infectious diseases: new complexity to an old story. J Clin Invest. 2016;126: 1181-9. doi:10.1172/JCI81132

7. Kuehn MJ, Kesty NC. Bacterial outer membrane vesicles and the host-pathogen interaction. Genes Dev 2005;19: 2645-55. doi:10.1101/gad.1299905

8. Brown L, Wolf JM, Prados-Rosales R, Casadevall A. Through the wall: extracellular vesicles in Gram-positive bacteria, mycobacteria and fungi. Nat Rev Microbiol. 2015;13: 620-30. doi:10.1038/nrmicro3480

9. Schwechheimer C, Kuehn MJ. Outer-membrane vesicles from Gram-negative bacteria: biogenesis and functions. Nat Rev Microbiol. 2015;13: 605-619. doi:10.1038/nrmicro3525

10. Tan TT, Mörgelin M, Forsgren A, Riesbeck K. Haemophilus influenzae Survival during Complement-Mediated Attacks Is Promoted by Moraxella catarrhalis Outer Membrane Vesicles. J Infect Dis. 2007;195: 1661-1670. doi:10.1086/517611

11. Vidakovics MLAP, Jendholm J, Mörgelin M, Månsson A, Larsson C, Cardell L-O, et al. B cell activation by outer membrane vesicles--a novel virulence mechanism. PLoS Pathog. 2010;6: e1000724. doi:10.1371/ journal.ppat.1000724

12. Ren D, Nelson KL, Uchakin PN, Smith AL, Gu X-X, Daines DA, et al. Characterization of extended co-culture of non-typeable Haemophilus influenzae with primary human respiratory tissues. Exp Biol Med. 2012;237:540-7. doi:10.1258/ebm.2012.011377

13. Athman JJ, Wang Y, McDonald DJ, Boom WH, Harding C V, Wearsch PA. Bacterial Membrane Vesicles Mediate the Release of Mycobacterium tuberculosis Lipoglycans and Lipoproteins from Infected Macrophages. J Immunol. 2015;195: 1044-53. doi:10.4049/jimmunol.1402894

14. Sethi S, Murphy TF. Infection in the pathogenesis and course of chronic obstructive pulmonary disease. N Engl J Med. 2008;359: 2355-2365. doi:10.1056/NEJMra0800353

15. Dickson RP, Huffnagle GB. The Lung Microbiome: New Principles for Respiratory Bacteriology in Health and Disease. PLOS Pathog. 2015;11: e1004923. doi:10.1371/journal.ppat.1004923

16. Desai H, Eschberger K, Wrona C, Grove L, Agrawal A, Grant B, et al. Bacterial colonization increases daily symptoms in patients with chronic obstructive pulmonary disease. Ann Am Thorac Soc. 2014;11 303-309. doi:10.1513/AnnalsATS.201310-3500C

17. Lobb RJ, Becker M, Wen SW, Wong CSF, Wiegmans AP, Leimgruber A, et al. Optimized exosome isolation protocol for cell culture supernatant and human plasma. J Extracell Vesicles. 2015;1: 1-11. doi:10.3402/ jev.v4.27031

18. Böing AN, van der Pol E, Grootemaat AE, Coumans FAW, Sturk A, Nieuwland R. Single-step isolation of extracellular vesicles by size-exclusion chromatography. J Extracell Vesicles. 2014; 3:23430. doi:10.3402/ jev.v3.23430.

19. Ostrowski M, Carmo NB, Krumeich S, Fanget I, Raposo G, Savina A, et al. Rab27a and Rab27b control different steps of the exosome secretion pathway. Nat Cell Biol. 2010;12: 13-19. doi:10.1038/ncb2000 
20. Volgers C, Benedikter BJ, Grauls GE, Savelkoul PHM, Stassen FRM. Bead-based flow-cytometry for semi-quantitative analysis of complex membrane vesicle populations released by bacteria and host cells. Microbiol. Res. 2017:200:25-32. doi:10.1016/j.micres.2017.04.003

21. Ellis TN, Kuehn MJ. Virulence and Immunomodulatory Roles of Bacterial Outer Membrane Vesicles. Microbiol Mol Biol Rev. 2010;74: 81-94. doi:10.1128/MMBR.00031-09

22. Olaya-Abril A, Prados-Rosales R, McConnell MJ, Martín-Peña R, González-Reyes JA, Jiménez-Munguía I, et al. Characterization of protective extracellular membrane-derived vesicles produced by Streptococcus pneumoniae. J Proteomics. 2014;106: 46-60. doi:10.1016/j.jprot.2014.04.023

23. Perez Vidakovics MLA, Jendholm J, Mörgelin M, Månsson A, Larsson C, Cardell L-O, et al. B Cell Activation by Outer Membrane Vesicles-A Novel Virulence Mechanism. PLoS Pathog. 2010; 6: e1000724. doi:10.1371/journal.ppat.1000724

24. Bauman SJ, Kuehn MJ. Purification of outer membrane vesicles from Pseudomonas aeruginosa and their activation of an IL-8 response. Microbes Infect. 2006;8: 2400-2408. doi:10.1016/j.micinf.2006.05.001

25. Chutkan H, MacDonald I, Manning A, Kuehn MJ. Quantitative and Qualitative Preparations of Bacterial Outer Membrane Vesicles. Methods in molecular biology. 2013. pp. 259-272. doi:10.1007/978-1-62703245-2_16

26. Schaar V, De Vries SPW, Perez Vidakovics MLA, Bootsma HJ, Larsson L, Hermans PWM, et al. Multicomponent Moraxella catarrhalis outer membrane vesicles induce an inflammatory response and are internalized by human epithelial cells. Cell Microbiol. 2011;13: 432-449. doi:10.1111/j.1462-5822.2010.01546.x

27. Roier S, Zingl FG, Cakar F, Durakovic S, Kohl P, Eichmann TO, et al. A novel mechanism for the biogenesis of outer membrane vesicles in Gram-negative bacteria. Nat Commun. 2016;7: 10515. doi:10.1038/ ncomms 10515

28. MacDonald IA, Kuehna MJ. Stress-induced outer membrane vesicle production by Pseudomonas aeruginosa. J Bacteriol. 2013;195: 2971-2981. doi:10.1128/JB.02267-12

29. van der Pol E, Coumans FW, Grootemaat E, Gardiner C, Sargent IL, Harrison P, et al. Particle size distribution of exosomes and microvesicles determined by transmission electron microscopy, flow cytometry, nanoparticle tracking analysis, and resistive pulse sensing. J Thromb Haemost. 2014;12: 1182-1192. doi:10.1111/jth.12602

30. György B, Szabó TG, Pásztói M, Pál Z, Misják P, Aradi B, et al. Membrane vesicles, current state-of-the-art: emerging role of extracellular vesicles. Cell. Mol. Life Sci. 2011;68:2667-88. doi:10.1007/s00018-0110689-3

31. Coburn B, Sekirov I, Finlay BB. Type III secretion systems and disease. Clin. Microbiol. Rev. 2007:20:53549. doi:10.1128/CMR.00013-07

32. Anantharajah A, Buyck JM, Faure E, Glupczynski Y, Rodriguez-Villalobos H, De Vos D, et al. Correlation between cytotoxicity induced by Pseudomonas aeruginosa clinical isolates from acute infections and IL-1 $\beta$ secretion in a model of human THP-1 monocytes. Pathog. Dis. 2015;73:ftv049. doi:10.1093/femspd/ ftv049

33. Roier S, Zingl FG, Cakar F, Durakovic S, Kohl P, Eichmann TO, et al. A novel mechanism for the biogenesis of outer membrane vesicles in Gram-negative bacteria. Nat Commun. 2016;7: 10515. doi:10.1038/ ncomms10515

34. McBroom AJ, Kuehn MJ. Release of outer membrane vesicles by Gram-negative bacteria is a novel envelope stress response. Mol Microbiol. 2007;63: 545-558. doi:10.1111/j.1365-2958.2006.05522.x

35. Tashiro Y, Ichikawa S, Shimizu M, Toyofuku M, Takaya N, Nakajima-Kambe T, et al. Variation of physiochemical properties and cell association activity of membrane vesicles with growth phase in Pseudomonas aeruginosa. Appl Environ Microbiol. 2010; doi:10.1128/AEM.02794-09

36. Sharpe SW, Kuehn MJ, Mason KM. Elicitation of epithelial cell-derived immune effectors by outer membrane vesicles of nontypeable haemophilus influenzae. Infect Immun. 2011;79: 4361-4369. doi:10.1128/ |Al.05332-11 
37. van de Waterbeemd B, Zomer G, van den IJssel J, van Keulen L, Eppink MH, van der Ley P, et al. Cysteine Depletion Causes Oxidative Stress and Triggers Outer Membrane Vesicle Release by Neisseria meningitidis; Implications for Vaccine Development. PLoS One. 2013;8. doi:10.1371/journal.pone.0054314

38. Beatty WL, Ullrich HJ, Russell DG. Mycobacterial surface moieties are released from infected macrophages by a constitutive exocytic event. Eur J Cell Biol. 2001;80: 31-40. doi:10.1078/0171-9335-00131

39. Bhatnagar S, Shinagawa K, Castellino FJ, Schorey JS. Exosomes released from macrophages infected with intracellular pathogens stimulate a proinflammatory response in vitro and in vivo. Blood. 2007;110: 3234-3244. doi:10.1182/blood-2007-03-079152

40. Singh PP, LeMaire C, Tan JC, Zeng E, Schorey JS. Exosomes released from M. tuberculosis infected cells can suppress IFN-gamma mediated activation of naive macrophages. PLos One. 2010; 6:e18564. doi: 10.1371/journal.pone.0018564

41. Sharpe SW, Kuehn MJ, Mason KM. Elicitation of epithelial cell-derived immune effectors by outer membrane vesicles of nontypeable Haemophilus influenzae. Infection Immun. 2011; 79:4361-4369. doi: 10.1128/IAI.05332-11

42. Manning AJ, Kuehn MJMJ, McDermott P, Walker R, White D, Kulp A, et al. Contribution of bacterial outer membrane vesicles to innate bacterial defense. BMC Microbiol. 2011;11: 258. doi:10.1186/1471-2180$11-258$

43. Ellis TN, Leiman SA, Kuehn MJ. Naturally Produced Outer Membrane Vesicles from Pseudomonas aeruginosa Elicit a Potent Innate Immune Response via Combined Sensing of Both Lipopolysaccharide and Protein Components. 2010;78: 3822-3831. doi:10.1128/IAl.00433-10

44. Choi D-S, Kim D-K, Choi SJ, Lee J, Choi J-P, Rho S, et al. Proteomic analysis of outer membrane vesicles derived from Pseudomonas aeruginosa. Proteomics. 2011:11: 3424-3429. doi:10.1002/pmic.201000212

45. Chimalapati S, Cohen JM, Camberlein E, MacDonald N, Durmort C, Vernet T, et al. Effects of deletion of the Streptococcus pneumoniae lipoprotein diacylglyceryl transferase gene lgt on ABC transporter function and on growth in vivo. PLoS One. 2012;7: e41393. doi:10.1371/journal.pone.0041393

46. Malley R, Henneke P, Morse SC, Cieslewicz MJ, Lipsitch M, Thompson CM, et al. Recognition of pneumolysin by Toll-like receptor 4 confers resistance to pneumococcal infection. Proc Natl Acad Sci. 2003:100: 1966-1971. doi:10.1073/pnas.0435928100

47. Lorenz E, Chemotti DC, Jiang AL, MCDougal LD. Differential involvement of toll-like receptors 2 and 4 in the host response to acute respiratory infections with wild-type and mutant Haemophilus influenzae strains. Infect Immun. 2005;73: 2075-82. doi:10.1128/IAI.73.4.2075-2082.2005

48. Waller T, Kesper L, Hirschfeld J, Dommisch H, Kölpin J, Oldenburg J, et al. Porphyromonas gingivalis Outer Membrane Vesicles Induce Selective Tumor Necrosis Factor Tolerance in a Toll-Like Receptor 4and mTOR-Dependent Manner. Infect Immun. 2016:84: 1194-204. doi:10.1128/IAl.01390-15

49. Pollak CN, Delpino MV, Fossati CA, Baldi PC. Outer Membrane Vesicles from Brucella abortus Promote Bacterial Internalization by Human Monocytes and Modulate Their Innate Immune Response. PLoS One. 2012; doi:10.1371/journal.pone.0050214

50. Meyer DH, Fives-Taylor PM. Characteristics of adherence of Actinobacillus actinomycetemcomitans to epithelial cells. Infect Immun. 1994;62: 928-35. 



\section{Chapter 5}

Effects of budesonide, fluticasone propionate, and azithromycin on the membrane vesicle release by macrophages and respiratory pathogens during macrophage infection

Charlotte Volgers, Pauline H.M. Hellebrand, Gert E. Grauls, Paul H.M. Savelkoul, Frank H.R. Stassen

Inflammopharmacology 2017; accepted for publication 


\begin{abstract}
Patients with more severe chronic obstructive pulmonary disease (COPD) frequently experience exacerbations and it is estimated that up to $50 \%$ of these exacerbations are associated with bacterial infections. The mainstay treatment for these infectionrelated exacerbations constitutes the administration of glucocorticoids, alone or in combination with antibiotics. A recent line of evidence demonstrates that many hormones including the steroid beclomethasone can also directly affect bacterial growth, virulence, and antibiotic resistance. The effect of these regimens on the release of potentially virulent and toxic membrane vesicles is at present unclear. In this study we determined the effect of several pharmacological agents on membrane vesicle release by and bacterial growth of common respiratory pathogens. We found that neither the release of membrane vesicles nor the bacterial growth was affected by the glucocorticoids budesonide and fluticasone. Azithromycin only inhibited the growth of Moraxella catarrhalis but no effects were observed on bacterial membrane vesicle release at a concentration that is achieved locally in the epithelial lining on administration. The macrophage proinflammatory response to membrane vesicles was significantly reduced after treatment with budesonide and fluticasone but not by azithromycin treatment. Our findings suggest that these glucocorticoids may have a positive effect on infectionrelated inflammation although the bacterial growth and membrane vesicle release remained unaffected.
\end{abstract}




\section{INTRODUCTION}

Chronic obstructive pulmonary disease (COPD) is a progressive airway disease that is characterized by excessive inflammation resulting in airway limitation and a progressive decline in lung function [1]. Moreover, patients with moderate and severe disease often experience exacerbations of disease [2]. These exacerbations are frequently triggered by infectious insults and it has been estimated that bacterial infections account for up to $50 \%$ of the exacerbations [3].

Standard treatment of patients that experience an exacerbation consists of the administration of systemic corticoids alone or combined with antibiotics [4,5,6]. Moreover, it has been shown in several large randomized trials that patients with stable disease may benefit from the use of inhaled corticosteroids (ICS) and antibiotics as these can reduce the number of exacerbations [7-9]. Apart from their antibacterial effects, macrolide antibiotics also have been shown to reduce inflammation $[10,11]$. ICS, on the other hand, may have controversial effects on the defence against bacteria. Although they are able to reduce epithelial invasion by airway pathogens, this might be at the expense of resistance to infections as ICS also inhibit the release of antimicrobial peptides and suppress inflammatory processes [12-14]. Alternatively, ICS may also have a direct effect on the bacteria as recent studies have shown that hormones such as catecholamines and steroid hormones can also directly affect bacterial growth, virulence, and gene expression $[15,16]$.

Bacterial membrane vesicles are released by bacteria in response to a variety of stressors. These nanosized (30-300 nm) vesicles do not only contribute to bacterial virulence, they also increase resistance to certain antimicrobial peptides and antibiotics. Moreover, they can exert strong pro-inflammatory responses $[17,18]$. Therefore, understanding bacterial behaviour in terms vesiculation may help to improve treatment strategies. Moreover, host-cells are also known to release membrane vesicles [19] and several pro-inflammatory properties have been assigned to membrane vesicles released in the context of infection and inflammation [20,21].

In this study, we aimed to address if treatment with the glucocorticoids budesonide and fluticasone and the antibiotic azithromycin a) affects membrane vesicle release by bacteria and macrophages, and b) suppresses the pro-inflammatory response to these membrane vesicles released by some of the most common respiratory bacterial pathogens. 


\section{MATERIALS AND METHODS}

\section{Reagents and antibodies}

Budesonide (BUD), fluticasone propionate (FLUT), and azithromycin (AZI) were from Sigma (Sigma Aldrich, St. Louis, MO, USA). The anti-Haemophilus influenzae type b (a-Hib; clone 1079/457) monoclonal antibody was obtained from Acris (Acris GmbH, Herford, Germany). The rabbit serum against Moraxella catarrhalis (Mrc, strain A $1.39 \mathrm{~N}$, isolated from children in a primary school in Nieuwegein, the Netherlands, 1989), was kindly provided by Dr. J. Hays (Erasmus University, Rotterdam, the Netherlands). The polyclonal antibody against Pseudomonas aeruginosa (Psa) (OAMA02609) was from Antibodies online (Aviva Systems Biology, San Diego, CA, USA). a-CD63 (unconjugated, mouse-antihuman clone $\mathrm{H} 5 \mathrm{C} 6$ ) and a-CD81 (PE conjugated, mouse-anti-human clone JS-81) were from BD (BD Bioscience, Franklin Lakes, NJ, USA). Purification of antibodies from serum was performed using the antibody serum purification kit based on protein A (Abcam, Cambridge, MA, USA). Antibodies for detection for flow cytometric analyses, were PE conjugated using a PE-labeling kit from Abcam according the manufacturers' instructions (Cambridge, MA, USA).

\section{Bacterial strains and culture}

The following bacterial strains were selected: Haemophilus influenzae (NTHi, ATCC49247), Pseudomonas aeruginosa (Psa, ATCC-27853), Streptococcus pneumoniae (Spn, ATCC-49619), and a clinical Moraxella catarrhalis (Mrc) isolate (University Medical Centre Maastricht (MUMC+), the Netherlands). The ATCC strains are well characterized and recommended by ATCC for quality control and antimicrobial susceptibility testing. All bacteria were cultured overnight on blood plates except for NTHi which was cultured on vitalex-supplemented chocolate agar plates (Oxoid, Wesel, Germany) at $5 \% \mathrm{CO}_{2}$ and $37^{\circ} \mathrm{C}$. After overnight pre-culture, bacteria were resuspended at $0.5 \mathrm{McFarland}\left(1.5 \times 10^{8}\right.$ colony forming units $(\mathrm{cfu}) / \mathrm{ml}$ ) in RPMI1640 and used for infection or culture experiments. For bacterial culture, bacteria were used at $5 \times 10^{7} \mathrm{cfu} / \mathrm{ml}$ and cultured without or with BUD, FLUT, or AZI for 6 hours in $10 \mathrm{ml}$ RPMI1640. Next, the conditioned media were processed by centrifugation at $1200 \times g$ for 10 minutes, at room temperature. The pelleted bacteria were washed, diluted in PBS and the optical density was determined at $600 \mathrm{~nm}$ using optical methacrylate disposable cuvettes (Sarstedt, Newton, NC, USA). The supernatants were centrifuged again at $1200 \times g$ for 10 minutes, and the supernatants were filtered through $0.22 \mu \mathrm{M}$ filters. Hereafter, the supernatants were further concentrated 20 times to a total of $500 \mu \mathrm{l}$ by centrifugation at $4000 \times g$ for 15 minutes using Amicon ultra-15 10-kDa centrifugal filter units (Millipore, Billerica, MA, USA).

Membrane vesicles (MVs) used for the stimulation of THP1 macrophages were obtained from bacterial cultures (at a density of $1 \times 10^{8} \mathrm{cfu} / \mathrm{ml}$ ) following culturing for 4 hours in 30 $\mathrm{ml}$ complete vesicle-depleted medium containing 5\% FCS, that was obtained as described in the "cells and media" section below. Upon culture, supernatants were depleted from bacteria by 2 centrifugation steps at $1200 \times g$ for 10 minutes and $0.22 \mu \mathrm{m}$ filtration. The supernatants that were cleared from bacteria were then further processed by ultrafiltration and size-exclusion chromatography (SEC), as described below. 


\section{Cells and media}

The human monocytic cell line THP-1 (ATCC-TIB202) was maintained in RPMI1640 (Sigma, St. Louis, MO, USA) supplemented with 100 mM sodium pyruvate, 22.5\% glucose, 25 mM $\beta$-mercaptoethanol, and 10\% fetal calf serum (FCS) (Lonza, Verviers, Belgium) and cultured at $5 \% \mathrm{CO}_{2}$ and $37^{\circ} \mathrm{C}$. For monocyte differentiation, cells were seeded in a 24 wells plate at $0.5 \times 10^{6}$ cells/well or in a 96 -wells plate at $1 \times 10^{4}$ cells/well and stimulated for 72 hours with 200 nM phorbol 12-myristate 13-acetate (PMA; Sigma, St. Louis, MO, USA). THP-1 macrophage stimulations were performed in vesicle-depleted medium containing 5\% FCS (complete vesicle-depleted medium). This medium was obtained by combining vesicle-depleted RPMI1640 medium with 30\% FCS with FCS-free medium (both supplemented with sodium pyruvate and glucose). Vesicle depleted medium was generated by overnight centrifugation at $100.000 \times g$ using a 70Ti-rotor, k-factor 44 in an Optima L-90K ultracentrifuge (both Beckman Coulter, Fullerton, CA, USA).

\section{Macrophage infection for membrane vesicle analysis}

THP-1 macrophages seeded in 24-wells plates were washed 3 times with PBS and medium was replaced with complete vesicle-depleted medium. Hereafter the cells were pretreated with BUD $(0.1 \mu \mathrm{M})$, FLUT $(0.1 \mu \mathrm{M})$, or AZI $(3 \mu \mathrm{g} / \mathrm{ml})$ for 1 hour, the concentrations were previously calculated to represent a concentration as can be obtained locally upon administration by inhalation [22-24]. After pretreatment, macrophages were infected with one of the bacteria at a multiplicity of infection of 10 for 6 hours. After infection, the medium was harvested, processed by centrifugation at $300 \times g$ and $1200 \times g$, filtrated with a $0.22 \mu \mathrm{M}$ micropore filter and subsequently analyzed by flow-cytometry.

\section{Membrane vesicle concentration and purification from conditioned medium using ultrafiltration and SEC}

The bacteria-cleared conditioned media obtained from bacterial cultures were subjected to ultrafiltration [25] and SEC [26]. First, the cleared conditioned media were concentrated to $500 \mu \mathrm{l}$ in 2 runs at $4000 \times \mathrm{g}$ for 15 minutes at room temperature using Amicon ultra-15 10-kDa centrifugal filter units (Millipore, Billerica, MA, USA) [25]. Then, the concentrates were purified by SEC using sepharose columns as described by Boing et al. with minor modifications [26]. For this a TELOS $15 \mathrm{ml}$ filtration column (Kinesis Scientific Experts, St. Neots, Cambridgeshire, UK) was stacked with a total of $10 \mathrm{ml}$ sepharose CL-2B (GE Healthcare, Uppsala, Sweden). The concentrates were loaded onto the column and fractions of $0.5 \mathrm{ml}$ were eluted using PBS. The fractions that were found to be highly enriched for MVs and negative for free protein (fractions 7-11 as was determined by flow cytometry and microBCA, Pierce, Rockford, IL, USA) were pooled and stored at $-80^{\circ} \mathrm{C}$ until further use.

\section{Flow cytometric analysis of membrane vesicles using antibody-coated latex beads}

A bead-based flow cytometric assay based on a method that was previously described by Volgers et al. 2017 [27] was used for the semi-quantitative analysis of bacterial MVs and $\mathrm{CD} 3^{+} / \mathrm{CD} 81^{+}$host cell-derived MVs. Four $\mu \mathrm{m}$ sized aldehyde-sulfate beads were washed in MES buffer, coated with a-CD63 antibody, or antibodies directed against bacterial vesicles (with the exception of Spn as we could not establish this assay for Spn). Antibody- 
coated beads were incubated overnight with processed supernatants $(200 \mu \mathrm{l})$ obtained after infection under constant agitation at $1000 \mathrm{rpm}$ at room temperature. Next, beads were washed twice with $0.22 \mu \mathrm{M}$ filtered PBS with $2 \%(\mathrm{w} / \mathrm{v})$ bovine serum albumin (BSA) and incubated with PE-conjugated detection antibodies (a-CD81-PE for host cell vesicles or an PE-conjugated a-bacterial antibody) for 90 minutes under continuous agitation at room temperature. Bacterial antibodies were PE-conjugated using a PE-conjugation kit (Abcam, Cambridge, MA, USA) according the manufacturer's instructions. Then, the vesicle-bead complexes were washed, suspended in PBS $(300 \mu \mathrm{l})$, and used for flow cytometric analysis using a FACSCanto ${ }^{T M}$ (BD Bioscience, Franklin Lakes, NJ, USA). The lower threshold for detection was set at $2 \%$ based on the percentage of PE-positive control beads (based on culture-medium). Analyses were performed using FACSDiva Software. The relative concentration was expressed in arbitrary units (AU), calculated by the multiplication of the number of positive beads with the median fluorescence intensity.

\section{MV analysis by tunable resistive pulse sensing}

Tunable resistive pulse sensing analysis was used to determine the MV-concentration using the qNano Gold, the Izon Control Suite Software v3.2 and the reagent kit (type RK1) for EV analysis from Izon (Izon Science Ltd., Oxford, UK). The measurements were performed using a NP150-pore. The stretch was fixed at $47 \mathrm{~mm}$, the pressure kept at 6 mbar, and a baseline current of \pm 100 nA was maintained. Solution G was added (10\%) to supernatants that were diluted in solution $Q(1: 1)$ and each sample was measured for 10 minutes and measurements were repeated when system instabilities occurred. The samples were calibrated using $114 \mathrm{~nm}$ polystyrene calibration beads (CPC100, Izon Science Ltd., Oxford, UK) at a concentration of $1 \times 10^{9}$ particles $/ \mathrm{ml}$ diluted in culture medium.

\section{Macrophage stimulation with membrane vesicles}

Stimulation of THP-1 macrophages with MVs was performed using macrophages seeded in 96-wells plates. Prior to stimulation, the cells were washed three times with PBS whereafter the medium was replaced with complete vesicle depleted medium. Then the cells were pre-treated with BUD $(0.1 \mu \mathrm{M})$, FLUT $(0.1 \mu \mathrm{M})$, or AZI $(3 \mu \mathrm{g} / \mathrm{ml})$ for 1 hour. Next, the cells were washed again after which they were exposed to $20 \mu \mathrm{l}$ of the MVcontaining SEC fractions, without or in the presence of BUD, FLUT, or AZI, in complete vesicle-depleted medium for 16 hours. Hereafter, the culture supernatants were harvested and used for cytokine measurements.

\section{Cytokine measurements}

TNF-a levels in the supernatants from the stimulation experiments were determined by enzyme-linked immuno-sorbent assay (ELISA) using the human Ready-Set-Go TNF-a ELISA kit eBioscience (Affymetrix eBioscience, Santa Clara, CA, USA).

\section{Statistical analysis}

Statistical analysis was performed using Graph-Pad Prism 5 Software (Graph-Pad, San Diego, CA, USA). Statistical dispersion was determined by calculation of the standard error of the mean. A Mann-Whitney t-test was performed for the statistical analysis of the variance between the means of two groups. P-values were considered significant when $<0.05$. 


\section{RESULTS}

\section{Effect of BUD, FLUT, and AZI on bacterial and host cell membrane vesicle release during infection}

First, the effect of BUD, FLUT and AZI on bacterial membrane vesicle release was determined. This was done semi-quantitatively by flow-cytometry based on antibodycoated beads. We found that neither FLUT nor BUD significantly affected the vesicle release by NTHi and Mrc (Fig. 1 A and B). Treatment with AZI also did not affect the membrane vesicle release (Fig. 1C).
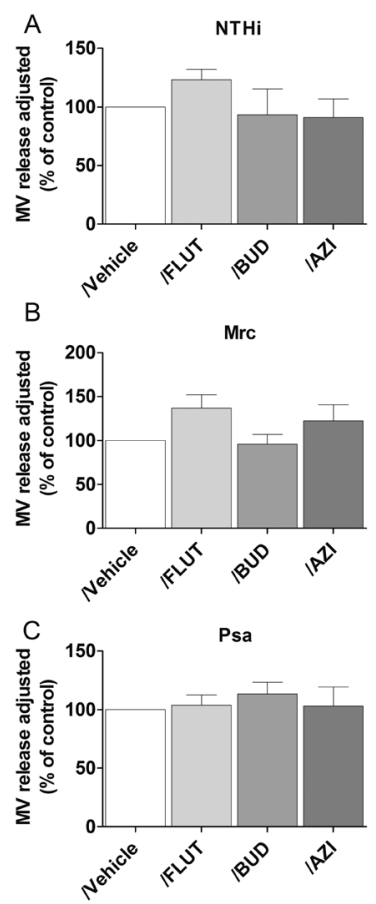

FIGURE 1. Flow cytometric analysis of the bacterial membrane vesicle release during macrophage infection in the presence or absence of pharmacological agents. Macrophages were infected with NTHi (A), Mrc (B), or Psa (C) for 4 hours at an $\mathrm{MOI}$ of 10 in the continuous presence of FLUT, BUD or AZI. The relative counts are expressed here as the percentage of the untreated control condition $(n=3)$. 
The release of membrane vesicles is highly conserved and apart from the bacteria, also the host cells are known to release membrane vesicles. We therefore assessed the effect of BUD, FLUT, and AZI treatment on the release of $\mathrm{CD} 63^{+} / \mathrm{CD} 81^{+}$host cell vesicles by macrophages under control conditions and upon infection. Neither treatment with BUD and FLUT, nor with AZI, was found to affect the release of host cell membrane vesicles (Fig. 2).

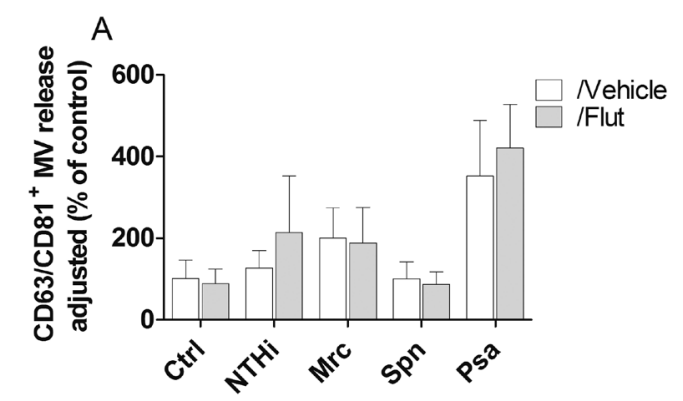

$B$
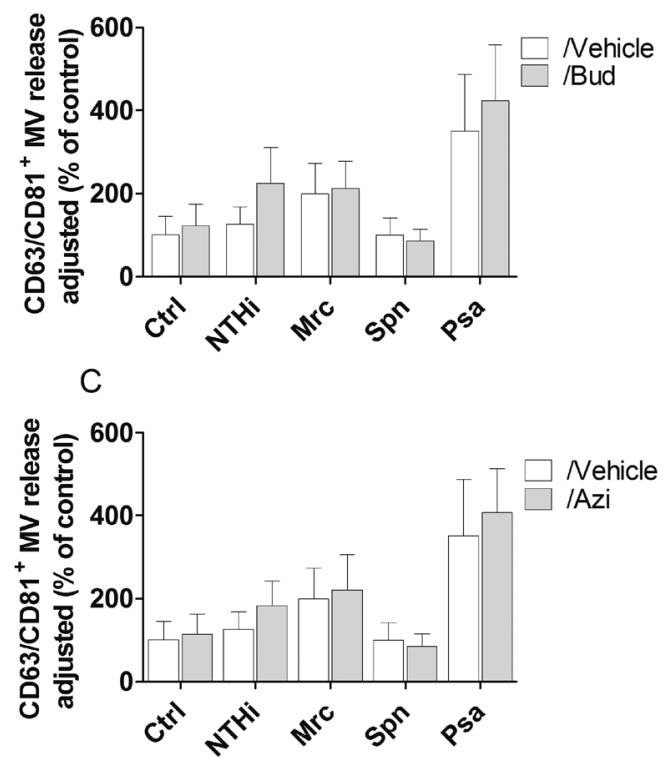

FIGURE 2. Flow cytometric analysis of $C D 63^{+} / C D 81^{+}$membrane vesicle release by macrophages during infection in the presence or absence of pharmacological agents. Macrophages were infected with NTHi, Mrc, Spn, or Psa for 4 hours at an MOI of 10 in the continuous presence of FLUT (A), BUD (B) or AZI (C). Data are expressed here as the percentage of the untreated control condition. $(n=3)$. 


\section{Bacterial MV release in response to BUD, FLUT, and AZI}

Next, we aimed to determine how the bacterial membrane vesicle release is affected by BUD, FLUT and AZI in the absence of host cells. Vesicle release after 6 hours of culture without or with these drugs was determined by tunable resistive pulse sensing analysis. We observed that treatment with neither FLUT, BUD nor AZI affected the release of bacterial membrane vesicles (Fig. 3A).

Next, we determined if FLUT, BUD, or AZI had any effect on the bacterial growth. To assess this, the relative number of bacteria was determined upon treatment with FLUT, BUD, and $\mathrm{AZI}$, which was done by measuring the optical density. As shown in figure 3B, only the Mrc counts were significantly reduced after bacterial culture in the presence of AZI.

\section{Effect of BUD, FLUT, and AZI on the TNF-a response to immuno-stimulatory bacterial membrane vesicles}

Since bacterial membrane vesicles can possess a strong pro-inflammatory character [28-32]), our next aim was to establish if BUD, FLUT, and AZI affected the TNF-a release by naïve macrophages in response to bacteria membrane vesicles. MVs from both NTHi and Mrc induced the release of TNF-a by macrophages, while the response to MVs from Psa and Spn was less pronounced. Treatment with BUD and FLUT significantly reduced the release of TNF-a by macrophages in response to bacterial membrane vesicles from NTHi and Mrc (Fig. 4A and 4B). In contrast, the TNF-a release in response to Spn and Psa MVs was not affected by BUD or FLUT. No significant effect of AZI was found on the TNF-a response to either NTHi-, Mrc-, Spn- or Psa-derived membrane vesicles (Fig. 4C). 


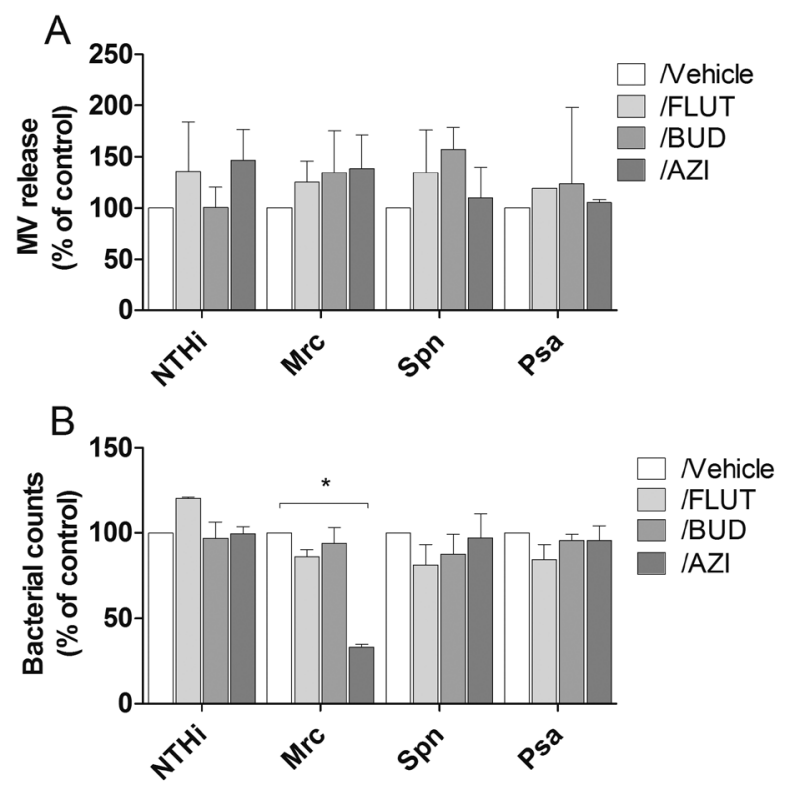

FIGURE 3. Effect of BUD, FLUT, and AZI on the MV release and bacterial growth during culture. NTHi, Mrc, Spn, or Psa were cultured for 6 hours in the continuous presence of FLUT, BUD or AZI. MV release was determined by TRPS-analysis (A) and the bacterial growth was determined with the optical density of the bacterial suspensions at $600 \mathrm{~nm}$ (B). $\left(n=3,{ }^{\star} p<0.05\right)$. 

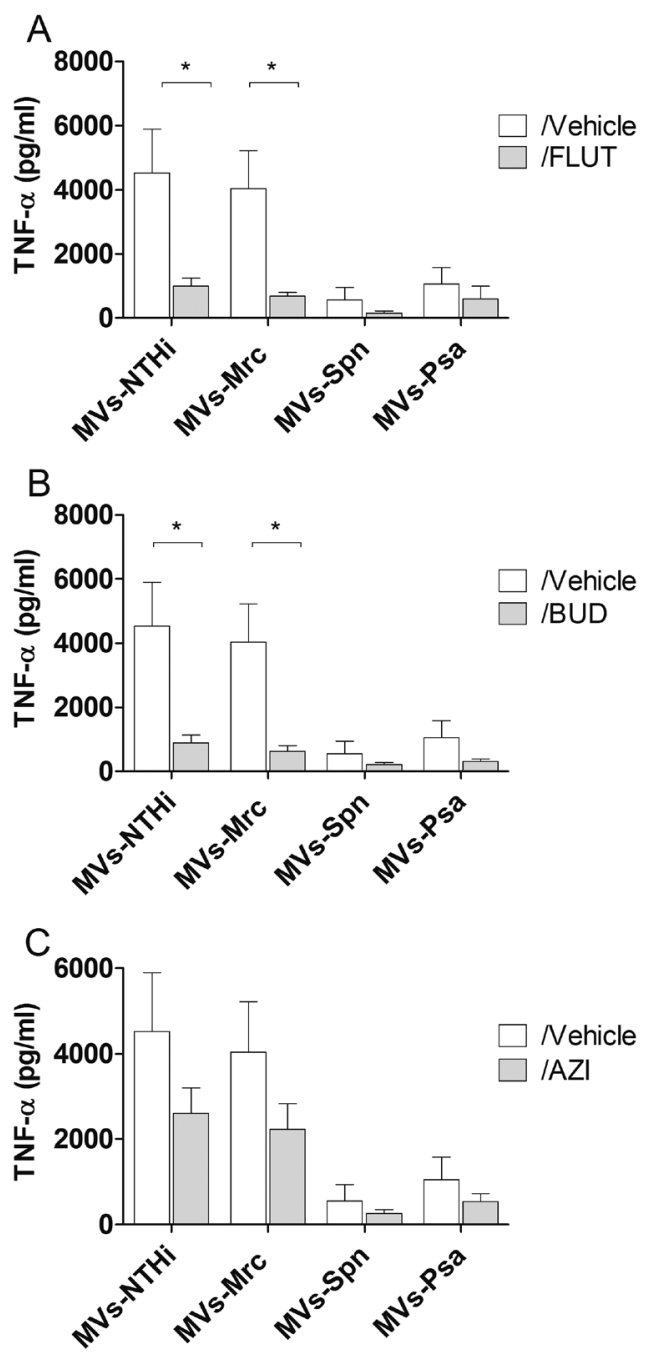

FIGURE 4. Effect of FLUT, BUD and AZI on the TNF-a release by naive macrophages in response to bacteria membrane vesicles. Macrophages were pre-treated for 1 hour with FLUT (A), BUD (B), or AZI (C), before they were exposed overnight to purified membrane vesicles released during culture of NTHi, Mrc, Spn, or Psa. The TNF-a release was determined by ELISA. $\left(n=4,{ }^{\star} p<0.05\right)$. 


\section{DISCUSSION}

In this study, we determined if the glucocorticoids budesonide (BUD) and fluticasone propionate (FLUT), and the antibiotic azithromycin (AZI) affected the release of bacterial membrane vesicles. Results demonstrated that neither the release of bacterial nor host cell vesicles was altered by any of the drugs. Moreover, except for Mrc, whose growth was significantly reduced by AZI, bacterial growth was not affected by any of the drugs. In contrast, the release of TNF-a by vesicle-stimulated macrophages was significantly reduced by the glucocorticoids, but not by AZI.

Recently it has been shown that non-typeable Haemophilus influenzae exposure to glucocorticoids results in a phenotype that resembles the RpoE knock-out phenotype, and is characterized by an enhanced antibiotic resistance and biofilm formation [16] The activation of this RpoE gene, which is part of the $\sigma^{E}$ stress response pathway, has been associated with the release of membrane vesicles by Gram-negative bacteria [18]. This inspired us to hypothesize that glucocorticoids might trigger the release of bacterial membrane vesicles. However, we found that neither FLUT nor BUD at concentrations that can be attained locally on inhalation, affected the release of bacterial membrane vesicles. Moreover, several antibiotics have also been shown to induce the release of bacterial membrane vesicles [33-35]. In our hands, however, AZI at a concentration that is achieved locally in vivo on treatment did not affect the membrane vesicle release, neither during infection nor in culture. Remarkably, only the bacterial growth of Mrc was significantly reduced by AZI. We also anticipated that the growth of NTHi and Spn would have been inhibited since the minimum inhibitory concentrations (MICS), which were determined for these bacteria using azithromycin sensitivity testing strips, are far below the AZI concentration used in our experiments: NTHi: 0.125-; Mrc: 0.125-, Spn: $1.5 \mu \mathrm{g} / \mathrm{mL}$. For Psa, we obtained a MIC of $12 \mu \mathrm{g} / \mathrm{mL}$ which may explain why no reduced bacterial numbers were observed on AZI treatment of Psa. These results were also consistent with previously reported MIC values for NTHi $(0.25-4 \mu \mathrm{g} / \mathrm{ml})$, Mrc $(0.25-0.5 \mu \mathrm{g} / \mathrm{ml})$, and 8-512 $\mu \mathrm{g} / \mathrm{ml}$ for Psa but not for Spn $(0.25-0.5 \mu \mathrm{g} / \mathrm{ml})[35,37]$. The reason for this discrepancy remains unclear as it has been shown that azithromycin can be bactericidal already at early time points [38]. As it has been shown previously that membrane vesicles can contribute to the resistance against certain antibiotics [39], it will be interesting to determine whether membrane vesicles participate in the increased azithromycin resistance.

As these drugs are known for their immunosuppressive properties, we additionally determined their effects on the release of TNF-a by naive macrophages in response to bacterial membrane vesicles. We found that both budesonide and fluticasone inhibited the membrane vesicle-induced TNF-a release. This was in line with previous studies that demonstrated that BUD and FLUT have anti-inflammatory properties $[10,23,40,41]$. Although some studies have acknowledged an anti-inflammatory effect to AZI [10,11], we did not observe a reduce pro-inflammatory response to bacterial membrane vesicles after AZI treatment. 
It should be noted that in our studies we used a THP-1 macrophage cell model. These PMAdifferentiated THP-1 cells show a high similarity with monocyte-derived macrophages both in morphology and behaviour [42]. Yet, it cannot be excluded that their responsiveness regarding membrane vesicle release following infection might be different from alveolar macrophages whose phenotype might be slightly different because of differences in the local micro-environment [43]. Several studies indicate that the release of membrane vesicles in response to an inflammatory stimulus (i.e. LPS), occurs in a similar fashion by THP-1 and by alveolar macrophages [44,45], however alveolar macrophages should be used in future studies before definite conclusions on the vesicle release in the context of infection can be drawn. Moreover, we did not determine the effects of BUD, FLUT, and AZI on the release of vesicles under more physiologically relevant conditions, i.e. in the presence of pro-inflammatory mediators or during cigarette smoke exposure. It cannot be excluded that these conditions affect the sensitivity to treatment. Finally, this study only quantified the membrane vesicles on treatment with BUD, FLUT, or AZI, but did not characterize the vesicles. Vesicle characterization may reveal whether these agents are able to affect the composition and thereby possibly physiological aspects of these vesicles. Therefore, this may be a subject for further investigation.

To conclude, glucocorticoids and antibiotics are frequently prescribed to treat COPD patients in particular during an exacerbation [4-6]. Treatment with glucocorticoids is considered an effective treatment for COPD patients that experience an exacerbation, as it increases the rate of lung function improvement and treatment success mostly because it significantly reduces local inflammation $[6,46]$. Regarding the use of antibiotics, up to $50 \%$ of all exacerbations are associated with bacterial infections [47-50]. Therefore, this study aimed to determine how these drugs affect several aspects that to some extent may determine the course of infection: the bacterial growth, vesicle release and proinflammatory response to these membrane vesicles. Our study shows that the bacterial growth and membrane vesicle release are not affected by FLUT, BUD or AZI treatment. Treatment with FLUT and BUD, however, was efficient to reduce the pro-inflammatory response to bacterial membrane vesicles. The implications of these findings with respect to the effects of these glucocorticoids on airway inflammation and on the resolution of infection need to be further investigated. 


\section{REFERENCES}

1. Barnes PJ. Immunology of asthma and chronic obstructive pulmonary disease. Nat Rev Immunol. 2008;8 183-192. doi:10.1038/nri2254

2. O'Reilly JF, Williams AE, Holt K, Rice L. Defining COPD exacerbations: impact on estimation of incidence and burden in primary care. Prim Care Respir J. 2006;15: 346-53. doi:10.1016/j.pcrj.2006.08.009

3. Sethi S, Murphy TF. Infection in the pathogenesis and course of chronic obstructive pulmonary disease. N Engl J Med. 2008;359: 2355-2365. doi:10.1056/NEJMra0800353

4. Walters JA, Gibson PG, Wood-Baker R, Hannay M, Walters EH. Systemic corticosteroids for acute exacerbations of chronic obstructive pulmonary disease. Cochrane database Syst Rev. 2009; CD001288. doi:10.1002/14651858.CD001288.pub3

5. Laue J, Reierth E, Melbye H. When should acute exacerbations of COPD be treated with systemic corticosteroids and antibiotics in primary care: a systematic review of current COPD guidelines. npj Prim Care Respir Med. 2015:25: 15002. doi:10.1038/npjpcrm.2015.2

6. Ram FS, Rodriguez-Roisin R, Granados-Navarrete a, Garcia-Aymerich J, Barnes NC. Antibiotics for exacerbations of chronic obstructive pulmonary disease. Cochrane database Syst Rev. 2016; 2-4. doi:10.1002/14651858.CD004403.pub2

7. Kew KM, Dias S, Cates CJ. Long-acting inhaled therapy (beta-agonists, anticholinergics and steroids) for COPD: a network meta-analysis. Cochrane Database of Systematic Reviews. 2014; CD010844 doi:10.1002/14651858.CD010844.pub2

8. Donath E, Chaudhry A, Hernandez-Aya LF, Lit L. A meta-analysis on the prophylactic use of macrolide antibiotics for the prevention of disease exacerbations in patients with Chronic Obstructive Pulmonary Disease. Respir Med. 2013;107: 1385-1392. doi:10.1016/j.rmed.2013.05.004

9

Han MK, Tayob N, Murray S, Dransfield MT, Washko G, Scanlon PD, et al. Predictors of chronic obstructive pulmonary disease exacerbation reduction in response to daily azithromycin therapy. Am J Respir Crit Care Med. 2014;189: 1503-1508. doi:10.1164/rccm.201402-02070C

10. Brusselle GG, Joos G. Is there a role for macrolides in severe asthma? Curr Opin Pulm Med. 2014;20 95-102. doi:10.1097/MCP.0000000000000017

11. Čulić O, Eraković V. Parnham MJ. Anti-inflammatory effects of macrolide antibiotics. Eur J Pharmacol. 2001;429: 209-229. doi:10.1016/S0014-2999(01)01321-8

12. Wang P, Wang X, Yang X, Liu Z, Wu M, Li G, et al. Budesonide suppresses pulmonary antibacterial host defense by down-regulating cathelicidin-related antimicrobial peptide in allergic inflammation mice and in lung epithelial cells. BMC Immunol. 2013;14: 7. doi:10.1186/1471-2172-14-7

13. Barbier M, Agustí A, Albertí S. Fluticasone propionate reduces bacterial airway epithelial invasion. Eur Respir J. 2008;32: 1283-8. doi:10.1183/09031936.00020608

14. Mitchell GB, Al-Haddawi MH, Clark ME, Beveridge JD, Caswell JL. Effect of Corticosteroids and Neuropeptides on the Expression of Defensins in Bovine Tracheal Epithelial Cells. Infect Immun. 2007;75: 1325-1334. doi:10.1128/IAl.00686-06

15. Freestone P. Communication between Bacteria and Their Hosts. Scientifica. 2013;2013: 361073 doi:10.1155/2013/361073

16. Earl CS, Keong TW, An S, Murdoch S, McCarthy Y, Garmendia J, et al. Haemophilus influenzae responds to glucocorticoids used in asthma therapy by modulation of biofilm formation and antibiotic resistance. EMBO Mol Med. 2015;7: 1018-33. doi:10.15252/emmm.201505088

17. Kaparakis-Liaskos M, Ferrero RL. Immune modulation by bacterial outer membrane vesicles. Nat Rev Immunol. 2015;15: 375-387. doi:10.1038/nri3837

18. Schwechheimer C, Kulp A, Kuehn MJ, Berleman J, Auer M, Deatherage B, et al. Modulation of bacterial outer membrane vesicle production by envelope structure and content. BMC Microbiol. 2014;14: 324 doi:10.1186/s12866-014-0324-1 
19. Koifman N, Biran I, Aharon A, Brenner B, Talmon Y. A direct-imaging cryo-EM study of shedding extracellular vesicles from leukemic monocytes. J Struct Biol. 2017; doi:10.1016/j.jsb.2017.02.004

20. Schorey JS, Harding C V. Extracellular vesicles and infectious diseases: new complexity to an old story. 2016. J Clin Invest; 2016;126: 1181-9. doi:10.1172/JCI81132

21. Yáñez-Mó M, Siljander PR-M, Andreu Z, Bedina Zavec A, Borràs F, Editl. B, et al. Biological properties of extracellular vesicles and their physiological functions. J Extracell Vesicles. 2015;4: 27066. doi: 10.3402/ jev.v4.27066

22. Wagner C, Goldmann T, Rohmann K, Rupp J, Marwitz S, Loria JR detto, et al. Budesonide Inhibits Intracellular Infection with Non-Typeable Haemophilus influenzae despite Its Anti-Inflammatory Effects in Respiratory Cells and Human Lung Tissue: A Role for p38 MAP Kinase. Respiration. 2015:90:416-425. doi:10.1159/000439226

23. Ek A, Larsson K, Siljerud S, Palmberg L. Fluticasone and budesonide inhibit cytokine release in human lung epithelial cells and alveolar macrophages. Allergy. 1999;54: 691-699. doi:10.1034/j.13989995.1999.00087.x

24. Olsen KM, Pedro GSS a N, Gann LP, Gubbins PO, Halinski DM, Campbell GD. Intrapulmonary pharmacokinetics of azithromycin in healthy volunteers given five oral doses. Antimicro Agents Chemother. 1996;40: 2582-2585.

25. Lobb RJ, Becker M, Wen SW, Wong CSF, Wiegmans AP, Leimgruber A, et al. Optimized exosome isolation protocol for cell culture supernatant and human plasma. J Extracell Vesicles. 2015;1: 1-11. doi:10.3402/ jev.v4.27031

26. Böing AN, van der Pol E, Grootemaat AE, Coumans FAW, Sturk A, Nieuwland R. Single-step isolation of extracellular vesicles by size-exclusion chromatography. J Extracell Vesicles. 2014; 3:23430. doi:10.3402/ jev.v3.23430.

27. Volgers C, Benedikter BJ, Grauls GE, Savelkoul PHM, Stassen FRM. Bead-based flow-cytometry for semiquantitative analysis of complex membrane vesicle populations released by bacteria and host cells Microbiol Res. 2017;200: 25-32. doi:https://doi.org/10.1016/j.micres.2017.04.003

28. Ellis TN, Kuehn MJ. Virulence and Immunomodulatory Roles of Bacterial Outer Membrane Vesicles. Microbiol Mol Biol Rev. 2010;74: 81-94. doi:10.1128/MMBR.00031-09

29. Schaar V, De Vries SPW, Perez Vidakovics MLA, Bootsma HJ, Larsson L, Hermans PWM, et al. Multicomponent Moraxella catarrhalis outer membrane vesicles induce an inflammatory response and are internalized by human epithelial cells. Cell Microbiol. 2011;13: 432-449. doi:10.1111/j.14625822.2010.01546.x

30. Olaya-Abril A, Prados-Rosales R, McConnell MJ, Martín-Peña R, González-Reyes JA, Jiménez-Munguía I, et al. Characterization of protective extracellular membrane-derived vesicles produced by Streptococcus pneumoniae. J Proteomics. 2014;106: 46-60. doi:10.1016/j.jprot.2014.04.023

31. MacDonald IA, Kuehna MJ. Stress-induced outer membrane vesicle production by Pseudomonas aeruginosa. J Bacteriol. 2013;195: 2971-2981. doi:10.1128/JB.02267-12

32. Ren D, Nelson KL, Uchakin PN, Smith AL, Gu X-X, Daines DA, et al. Characterization of extended coculture of non-typeable Haemophilus influenzae with primary human respiratory tissues. Exp Biol Med. 2012;237:540-7. doi:10.1258/ebm.2012.01137711377

33. Kadurugamuwa JL, Beveridge $\mathrm{TJ}$. Virulence factors are released from Pseudomonas aeruginosa in association with membrane vesicles during normal growth and exposure to gentamicin: a novel mechanism of enzyme secretion. J Bacteriol. 1995;177: 3998-4008.

34. Schaar V, Nordström T, Mörgelin M, Riesbeck K. Moraxella catarrhalis outer membrane vesicles carry B-lactamase and promote survival of Streptococcus pneumoniae and Haemophilus influenzae by inactivating amoxicillin. Antimicrob Agents Chemother. 2011;55: 3845-53. doi:10.1128/AAC.01772-10

35. Hakenbeck R, Martin C, Morelli G. Streptococcus pneumoniae proteins released into medium upon inhibition of cell wall biosynthesis. J Bacteriol. 1983;155: 1372-1381. 
36. Leclercq R, Cantón R, Brown DFJ, Giske CG, Heisig P, MacGowan AP, et al. EUCAST expert rules in antimicrobial susceptibility testing. Clin Microbiol Infect. 2013;19: 141-160. doi:10.1111/j.14690691.2011.03703.x

37. Imperi F, Leoni L, Visca P. Antivirulence activity of azithromycin in Pseudomonas aeruginosa. Front Microbiol. 2014;5: 178. doi:10.3389/fmicb.2014.00178

38. Drago L, De Vecchi E, Nicola L, Legnani D, Gismondo MR. Kinetic bactericidal activity of telithromycin, azithromycin and clarithromycin against respiratory pathogens. APMIS. 2005;113: 655-63. doi:10.1111/j.1600-0463.2005.apm_195.x

39. Schwechheimer C, Kuehn MJ. Outer-membrane vesicles from Gram-negative bacteria: biogenesis and functions. Nat Rev Microbiol. 2015;13: 605-619. doi:10.1038/nrmicro3525

40. Khair OA, Devalia JL, Abdelaziz MM, Sapsford RJ, Tarraf H, Davies RJ. Effect of Haemophilus influenzae endotoxin on the synthesis of IL-6, IL-8, TNF-alpha and expression of ICAM-1 in cultured human bronchial epithelial cells. Eur Respir J. 1994;7: 2109-16.

41. Fattal-German M, Le Roy Ladurie F, Lecerf F, Berrih-Aknin S. Expression of ICAM-1 and TNF alpha in human alveolar macrophages from lung-transplant recipients. Ann N Y Acad Sci. 1996;796: 138-48.

42. Daigneault M, Preston JA, Marriott HM, Whyte MKB, Dockrell DH. The identification of markers of macrophage differentiation in PMA-stimulated THP-1 cells and monocyte-derived macrophages. PLoS One. 2010;5. doi:10.1371/journal.pone.0008668

43. Hussell T, Bell TJ. Alveolar macrophages: plasticity in a tissue-specific context. Nat Rev Immunol. 2014;14: 81-93. doi:10.1038/nri3600

44. Eltom S, Dale N, Raemdonck KR, Stevenson CS, Snelgrove RJ, Sacitharan PK, et al. Respiratory infections cause the release of extracellular vesicles: implications in exacerbation of asthma/COPD. PLoS One. 2014; 9: e101087. doi:10.1371/journal.pone.0101087

45. Soni S, Wilson MR, O'Dea KP, Yoshida M, Katbeh U, Woods SJ, et al. Alveolar macrophage-derived microvesicles mediate acute lung injury. Thorax. 2016;71:1020-1029. doi:10.1136/thoraxjnl-2015-208032

46. Jen R, Rennard SI, Sin DD. Effects of inhaled corticosteroids on airway inflammation in chronic obstructive pulmonary disease: a systematic review and meta-analysis. Int J Chron Obstruct Pulmon Dis. 2012;7: 587-95. doi:10.2147/COPD.S32765

47. Bafadhel M, McKenna S, Terry S, Mistry V, Reid C, Haldar P, et al. Acute Exacerbations of Chronic Obstructive Pulmonary Disease. Am J Respir Crit Care Med. 2011;184: 662-671. doi:10.1164/rccm.201104-05970C

48. Papi A, Bellettato CM, Braccioni F, Romagnoli M, Casolari P, Caramori G, et al. Infections and Airway Inflammation in Chronic Obstructive Pulmonary Disease Severe Exacerbations. Am J Respir Crit Care Med. 2006;173: 1114-1121. doi:10.1164/rccm.200506-8590C

49. Wilkinson TMA, Hurst JR, Perera WR, Wilks M, Donaldson GC, Wedzicha JA. Effect of Interactions Between Lower Airway Bacterial and Rhinoviral Infection in Exacerbations of COPD. Chest. 2006;129: 317-324. doi:10.1378/chest.129.2.317

50. Hurst JR, Perera WR, Wilkinson TMA, Donaldson GC, Wedzicha JA. Systemic and Upper and Lower Airway Inflammation at Exacerbation of Chronic Obstructive Pulmonary Disease. Am J Respir Crit Care Med. 2006:173: 71-78. doi:10.1164/rccm.200505-7040C 



\section{Chapter}

Effects of N-acetyl-L-cysteine on the membrane vesicle release and growth of respiratory pathogens

Charlotte Volgers, Birke J. Benedikter, Pauline H.M. Hellebrand, Paul H.M. Savelkoul, Frank R.M. Stassen

FEMS Microbiology Letters 2017; 364(9):fnx078 


\begin{abstract}
Bacterial infections contribute to the disease progression of chronic obstructive pulmonary disease by stimulating mucus production in the airways. This increased mucus production and other symptoms are often alleviated when patients are treated with mucolytics such as N-acetyl-L-cysteine (NAC). Moreover, NAC has been suggested to inhibit bacterial growth. Bacteria can release membrane vesicles (MVs) in response to stress, and recent studies report a role for these proinflammatory MVs in the pathogenesis of airways disease. Yet, until now it is not clear whether NAC also affects the release of these MVs. This study set out to determine whether NAC, at concentrations reached during high-dose nebulization, affects bacterial growth and $\mathrm{MV}$ release of the respiratory pathogens non-typeable Haemophilus influenzae (NTHi), Moraxella catarrhalis (Mrc), Streptococcus pneumoniae (Spn) and Pseudomonas aeruginosa (Psa). We observed that NAC exerted a strong bacteriostatic effect, but also induced the release of proinflammatory MVs by NTHi, Mrc and Psa, but not by Spn. Interestingly, NAC also markedly blunted the release of TNF-a by naive macrophages in response to MVs. This suggests that the application of NAC by nebulization at a high dosage may be beneficial for patients with airway conditions.
\end{abstract}




\section{INTRODUCTION}

Chronic obstructive pulmonary disease (COPD) is a respiratory condition that poses a huge burden on the society worldwide [1,2]. Patients with COPD often show an increased mucus production, sputum purulence and cough [3-5]. To alleviate symptoms, mucolytics are frequently prescribed [6-9]. A commonly administered mucolytic is N-acetyl-Lcysteine (NAC): a small thiol-containing antioxidant that acts by disrupting disulphide bonds in mucus [7,10]. Two recent meta-analyses concluded that patients with COPD experience less exacerbations after oral NAC administration $[9,11]$.

Bacterial respiratory infections are the main cause of exacerbations in patients with COPD and bacteria also have been shown to contribute the progression of stable disease [12-15]. A variety of studies has shown that NAC does not only have anti-oxidant or anti-inflammatory characteristics, but also bacteriostatic properties [16-20]. These bacteriostatic effects of NAC are thought to be mediated by the inhibition of cysteine utilization by bacteria [16]. It is now understood that cysteine deprivation, besides its bacteriostatic action, also induces a bacterial stress response which is characterized by the release of bacterial membrane vesicles (MVs) [21]. MVs carry several bacterial virulence factors causing them to exert strong pro-inflammatory responses (as reviewed in [22,23]).

Therefore, in this study we examined the effect of NAC on both the MV release and growth of the common respiratory pathogens non-typeable Haemophilus influenzae, (NTHi), Moraxella catarrhalis (Mrc), Streptococcus pneumoniae (Spn), and Pseudomonas aeruginosa (Psa). Moreover, we determined if NAC affects the MV-induced pro-inflammatory responses. 


\section{MATERIALS AND METHODS}

\section{Reagents and antibodies}

NAC (Sigma, St. Louis, MO, USA) was dissolved at $200 \mathrm{mM}$, the $\mathrm{pH}$ was corrected to 7.0-8.0. Antibodies against CD63 (uncon- jugated, mouse-anti-human clone H5C6) and CD81 (PE conju- gated, mouse-anti-human clone JS-81) were obtained from BD (BD Bioscience, Franklin Lakes, NJ, USA). The anti-Haemophilus influenzae type b (a-Hib; clone 1079/457) monoclonal antibody was obtained from Acris (Acris GmbH, Herford, Germany). The rabbit serum against Mrc (strain A $1.39 \mathrm{~N}$, isolated from children in a primary school in Nieuwegein, the Netherlands (1989)), was kindly provided by Dr J. Hays (Erasmus University, Rotterdam, the Netherlands). The antibody against Psa was from Antibodies online (Antibodies online, neat raised in guinea pig). Anti- bodies were purified using the antibody serum purification kit based on protein A (Abcam, Cambridge, MA, USA). For flow cytometric analysis, detection antibodies were PE conjugated using PE-labeling kits from Abcam. One hundred microgram of each antibody was PE conjugated according to the manufacturer's instructions.

\section{Bacterial strains and culturing}

The following bacterial strains were used: NTHi (ATCC-49247), Psa (ATCC-27853), Spn (ATCC-49619), and a Mrc clinical isolate (University Medical Centre Maastricht (MUMC+), the Netherlands). Mrc, Spn, and Psa were pre-cultured on blood plates and NTHi was cultured on vitalex-supplemented chocolate agar plates (Oxoid, Wesel, Germany) overnight at $5 \% \mathrm{CO}_{2}$ and $37^{\circ} \mathrm{C}$. After overnight pre-culture, bacterial suspensions with a density of 0.5 McFarland $\left(1.5 \times 10^{8}\right.$ colony forming units $\left.(\mathrm{cfu}) / \mathrm{ml}\right)$ were prepared. These suspensions were then used to prepare bacterial cultures or for infection experiments. Bacteria were cultured at $5 \times 10^{7} \mathrm{cfu} / \mathrm{ml}$ with or without $\operatorname{NAC}(5,25$, or $50 \mathrm{mM})$ for 6 hours in $10 \mathrm{ml}$ RPMI1640. NTHi and Mrc were cultured in medium supplied with $10 \mu \mathrm{g} / \mathrm{ml}$ hemin and nicotinamide adenine dinucleotide (NAD) (both from Sigma, St. Louis, MO, USA). After 6 hours, cultures were centrifuged at $1200 \times \mathrm{g}$ for 10 minutes, at room temperature. The pelleted bacteria were washed, diluted in PBS and the optical density was determined at $600 \mathrm{~nm}$ in optical methacrylate disposable cuvettes (Sarstedt, Newton, NC, USA). The supernatant was again centrifuged at $1200 \times \mathrm{g}$ for 10 minutes to deplete possible remnant bacteria, followed by filtering the supernatants through $0.22 \mu \mathrm{m}$ filters. To allow MV quantification by tunable resistive pulse sensing supernatants were concentrated 20 times to a final volume of 500 $\mu \mathrm{l}$ by centrifugation at $4000 \times \mathrm{g}$ for 15 minutes using Amicon ultra-15 10-kDa centrifugal filter units (Millipore, Billerica, MA, USA).

Bacterial MVs for the stimulation experiments were obtained from bacteria that were cultured for 4 hours in $30 \mathrm{ml}$ complete vesicle-depleted medium (prepared as described in the cells and media section) at a density of $1 \times 10^{8} \mathrm{cfu} / \mathrm{ml}$. Upon culture, supernatants were depleted from bacteria by two centrifugation steps at $1200 \times \mathrm{g}$ for 10 minutes and $0.22 \mu \mathrm{m}$ filtration. Cleared supernatants were then further processed by ultrafiltration and size-exclusion chromatography (SEC), as described below. 


\section{Cells and media}

Human monocytic THP-1 cells (ATCC-TIB202) were cultured at $5 \% \mathrm{CO}_{2}$ and $37^{\circ} \mathrm{C}$ in RPMI1640 (Sigma) containing 10\% fetal calf serum (FCS) (Lonza, Verviers, Belgium) with glucose (22.5\%), sodium pyruvate (100 mM), and $\beta$-mercaptoethanol (25 mM). Monocytes, seeded at $0.5 \times 10^{6}$ cells per well in 24 -wells plates, $1 \times 10^{4}$ per well in 96 -wells plates and $1 \times 10^{7}$ cells in T75-flasks, were differentiated using 200 nM phorbol 12-myristate 13-acetate (PMA; Sigma) for 72 hours. Hereafter, the medium was replaced with vesicle-depleted culture medium containing 5\% FCS containing glucose (22.5\%), and sodium pyruvate (100 mM), hereafter referred to complete vesicle-depleted medium. Medium with 30\% FCS was depleted from abundant and possibly confounding bovine membrane vesicles by combining FCS-free culture medium with vesicle-depleted medium with 30\% FCS. Vesicle-depleted medium with 30\% FCS was obtained by the overnight centrifugation at $100.000 \times \mathrm{g}$ using a 70Ti-rotor, K-factor 44 in an Optima L-90K ultracentrifuge (both Beckman Coulter, Fullerton, CA, USA).

\section{Infection of macrophages for MV analysis}

For macrophage infections in 24-wells plates, cells were washed three times with PBS whereafter the medium was replaced with complete vesicle-depleted culture medium. Hereupon, macrophages were infected with either one of the bacteria at a multiplicity of infection of 10. After 6 hours of infection the medium was harvested, processed by two centrifugation steps at $1200 \times \mathrm{g}$ for 10 minutes and $0.22 \mu \mathrm{m}$ filtration, and used for bead-based flow-cytometry.

\section{MV concentration and purification from conditioned medium using ultrafiltration and SEC}

MVs were concentrated from bacteria-cleared supernatants by using ultrafiltration [24] and separated from protein by SEC [25]. This method for vesicle isolation is considered one of the most appropriate methods for the isolation of mammalian extracellular vesicles as it provides with an efficient standardized method for the generation of pure intact membrane vesicle populations [24-26]. For ultrafiltration, the cleared-supernatants were concentrated 60 times to $500 \mu \mathrm{l}$ in two centrifugation runs at $4000 \times \mathrm{g}$ for 15 minutes at room temperature using Amicon ultra-15 10-kDa centrifugal filter units (Millipore). The method for membrane vesicle purification by SEC was performed as previously described by Boing et al., with minor alterations [25]. Briefly, a 15 ml-TELOS filtration column (Kinesis Scientific Experts, St. Neots, Cambridgeshire, UK) was stacked with $10 \mathrm{ml}$ sepharose CL-2B (GE Healthcare, Uppsala, Sweden). Next, the concentrates were loaded onto the column and eluted using PBS. Twenty-four fractions of $500 \mu \mathrm{l}$ were collected and the MV-containing fraction (based on five pooled fractions: 7-11, previously identified to be highly enriched for MVs and negative for free proteins) was stored at $-80^{\circ} \mathrm{C}$ until further use.

\section{MV analysis by tunable resistive pulse sensing}

The MV-concentration was determined by tunable resistive pulse sensing using the qNano Gold, the Izon Control Suite Software v3.2 and the reagent kit (type RK1) for EV analysis from Izon (Izon Science Ltd., Oxford, UK). Measurements were conducted using a NP150pore with a fixed stretch of $47 \mathrm{~mm}$, a transmembrane voltage of $0.48 \mathrm{~V}$ (led to a baseline current of $\pm 100 \mathrm{nA})$, and a pressure of 6 mbar. Solution G was added (10\%) to superna- 
tants that were diluted in solution $Q(1: 1)$ and each sample was measured for 10 minutes and measurements were repeated when system instabilities occurred. The samples were calibrated using $114 \mathrm{~nm}$ polystyrene calibration beads (CPC100, Izon Science Ltd.) at a concentration of $1 \times 10^{9}$ particles $/ \mathrm{ml}$ diluted in culture medium.

\section{Flow cytometric analysis of MVs using antibody-coated latex beads}

Bead-based flow cytometry was used for the semi-quantitative analysis of MVs released by macrophages and bacteria. This method was previously described $[27,28]$ and was adopted here for bacterial vesicle quantification [29]. Briefly, 4- $\mu$ m-sized aldehyde-sulfate beads were washed in MES buffer and coated with anti-CD63 for host-cell vesicles or with an antibody against one of the bacterial membrane vesicles. Antibody-coated beads were incubated overnight with $200 \mu \mathrm{l}$ of cleared supernatant under constant agitation at 1000 rpm at room temperature. Next, the beads were washed twice with $0.22 \mu \mathrm{m}$ filtered PBS with $2 \%(\mathrm{w} / \mathrm{v}$ ) bovine serum albumin (BSA) and incubated with a PE-conjugated detection antibody, for 90 minutes at room temperature under continuous agitation. Anti-bacterial antibodies were PE-conjugated using a PE-conjugation kit (Abcam) following the manufacturer's instructions and for the host-cell MVs, the detection was based on anti-CD81-PE labeled detection antibodies. After incubation with the PE-labeled detection antibodies, the beads were washed and suspended in $300 \mu \mathrm{l}$ PBS for flow cytometric analysis on a FACSCanto ${ }^{T M}$ (BD Bioscience, Franklin Lakes, NJ, USA). The lower threshold for detection was set at $2 \%$ based on the percentage of PE-positive control beads (incubated with unconditioned culture-medium). Analyses were performed using FACSDiva Software. The relative amount of MVs was calculated by the multiplication of the percentage of positive beads with the median fluorescence intensity and expressed relative to the control (as $\%$ of control).

\section{Macrophage stimulation with membrane vesicles}

Stimulation of macrophages with MVs was performed using macrophages seeded in 96-wells plates. Prior to stimulation, macrophages in 96-wells plates were washed three times with phosphate buffered saline (PBS) were after the medium was replaced with vesicle-depleted culture medium with 5\% FCS. Then, cells were exposed to $20 \mu \mathrm{l}$ of the MV-containing SEC fraction for 16 hours, without or in the presence of NAC (5 MM, 5 mM or $25 \mathrm{mM}$ ). Hereafter, the culture supernatants were harvested and used for cytokine measurements.

\section{Assessment of the bacterial growth and adhesion and internalization}

To assess for bacterial growth during culture the optical density at $600 \mathrm{~nm}$ was determined at a path length of $1 \mathrm{~cm}$ using a spectrophotometer (Novaspec II: Pharmacia Biotech, Uppsala, Sweden) [30]. PMA-stimulated monocytes seeded in 24-wells plates were washed three times with PBS after which vesicle-depleted culture medium was added. Next, the cells were infected with either one of the bacteria at an MOI of 10 for 4 hours. After infection, the media were collected to assess bacterial survival (and for flow cytometric analysis of bacterial and host-cell membrane vesicle release). To assess bacterial survival, bacteria were pelleted by centrifugation at $1200 \times$ g, resuspended in $1 \mathrm{ml}$ PBS, whereupon bacterial dilutions were made and plated. In addition to bacterial survival, bacterial adhesion and internalization were determined. After the supernatant was harvested, cells 
were washed three times with PBS and lysed by adding $0.025 \%$ saponin in distilled water for 10 minutes. After neutralization, by the addition of culture medium, bacterial adhesion and internalization was determined by bacterial plating. The number of adhered and internalized bacteria were then determined by counting.

\section{Cytokine measurements}

The human Ready-Set-Go TNF-a enzyme-linked immuno-sorbent assay (ELISA) kit (Affymetrix eBioscience, Santa Clara, CA, USA) was used to determine the TNF-a release according the manufacturers' instructions.

\section{Statistical analyses}

Statistical analysis was performed using Graph-Pad Prism 5 Software (Graph-Pad, San Diego, CA, USA). Statistical dispersion was determined by calculation of the standard error of the mean. A Mann-Whitney t-test was performed for the statistical analysis of the variance between the means of two groups. p-values were considered significant when $<0.05$. 


\section{RESULTS}

\section{The effect of NAC on bacterial growth}

First it was determined whether NAC affects the growth of the common respiratory pathogens NTHi, Mrc, Spn, and Psa. We initially determined if the growth was affected by NAC concentrations of 5-50 mM, a concentration based on the estimated concentration of 30 mM that may be achieved in the lower airway upon administration of $300 \mathrm{mg}$ NAC by nebulization and which may therefore be physiologically relevant [31]. As shown in figure 1, in the presence of $50 \mathrm{mM}$ NAC bacterial growth was reduced by $43 \%, 66 \%$, and $80 \%$ of the Gram-negative bacteria NTHi, Mrc, and Psa, respectively. Finally, the bacterial growth of the Gram-positive Spn was also reduced by $47 \%$.

\section{Bacterial MV release in response to NAC}

Next, the effect of NAC on the release of bacterial MVs was assessed by tunable resistive pulse sensing-based analysis. We observed that the addition of NAC at a concentration of $5 \mathrm{mM}$ resulted in a twofold and threefold increase in the release of NTHi and Mrc MVs, respectively (Fig. 1B). This MV release was also increased after treatment with higher concentrations, albeit to a lesser extent. Yet, since NAC markedly inhibited bacterial growth (Fig. 1A), we adjusted the release of MVs for the number of bacteria present in each culture condition. After adjustment, the bacterial MV release was found to be increased threefold for NTHi and even fivefold for Mrc (Fig. 1B). Although the bacterial MV release by Psa initially did not seem to be affected by NAC (Fig. 1A), when the percentage was adjusted for the number of bacteria the MV release was found to be increased fivefold. Overall this suggests that although NAC significantly inhibited bacterial growth of these Gram-negative bacteria, the release of MVs per bacterium seemed to be increased in the presence of NAC. The release of MVs by Spn tended to decrease upon treatment and disappeared when adjustments for the total bacterial numbers were made suggesting that this decrease was the consequence of the reduced number of bacteria (Fig. 1A).

\section{The effects of NAC on bacterial growth during infection}

As bacterial infections of the airways are associated with prominent activation of alveolar macrophages, we examined the effects of NAC treatment on bacterial survival and MV release in an in vitro infection model [32]. First, we determined bacterial growth and adhesion/internalization after macrophage infection with either one of the bacteria, and determined how this was affected by 25 mM NAC. NAC treatment almost completely prevented bacterial growth and adhesion/internalization of NTHi and Mrc (Fig. 2A and 2B). Treatment of Psa-infected macrophages had inconsistent effects on the bacterial growth and hardly affected adhesion/internalization (Fig. 2A and 2B). Finally, treatment of Spn led to a $\sim 50 \%$ reduction of the bacterial growth but did not affect the adherence/ internalization (Fig. 2A and 2B) 


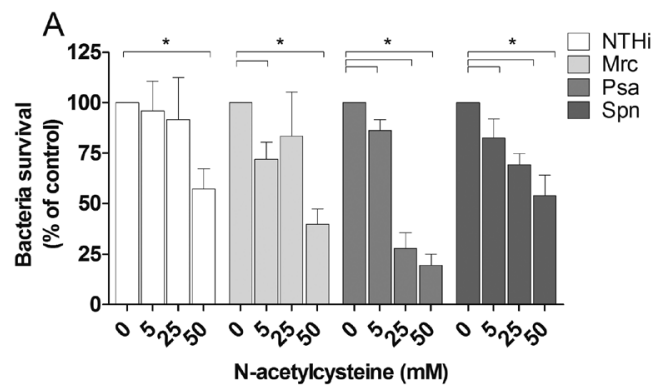

B

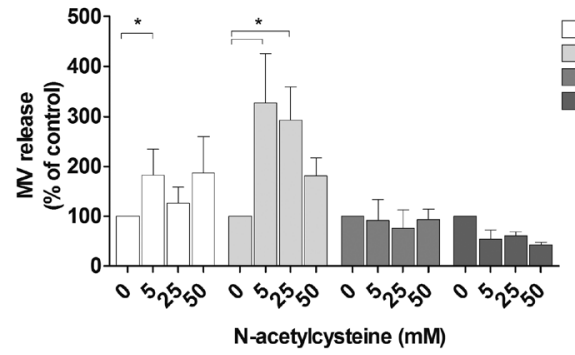

C

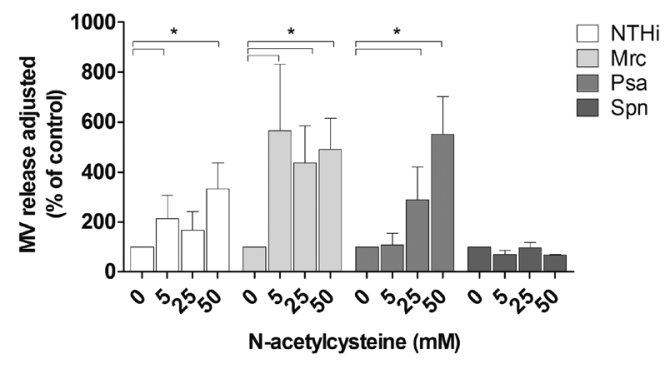

FIGURE 1. Bacterial growth and MV release by respiratory pathogens during bacterial culture with or without NAC. NTHi, Mrc, Spn and Psa were cultured for $6 \mathrm{~h}$ without or in the presence of $\mathrm{NAC}(5,25$ or $50 \mathrm{mM})$. Bacterial growth was determined with the optical density of the bacterial suspensions at $600 \mathrm{~nm}(\mathrm{~A})$. Additionally, the $\mathrm{MV}$ release was determined by tunable resistive pulse sensing $(\mathbf{B})$ and the $M V$ release was adjusted for the number of bacteria (C). All values are presented here as percentage of the untreated control condition. ( $n=3, * P<0.05)$ 

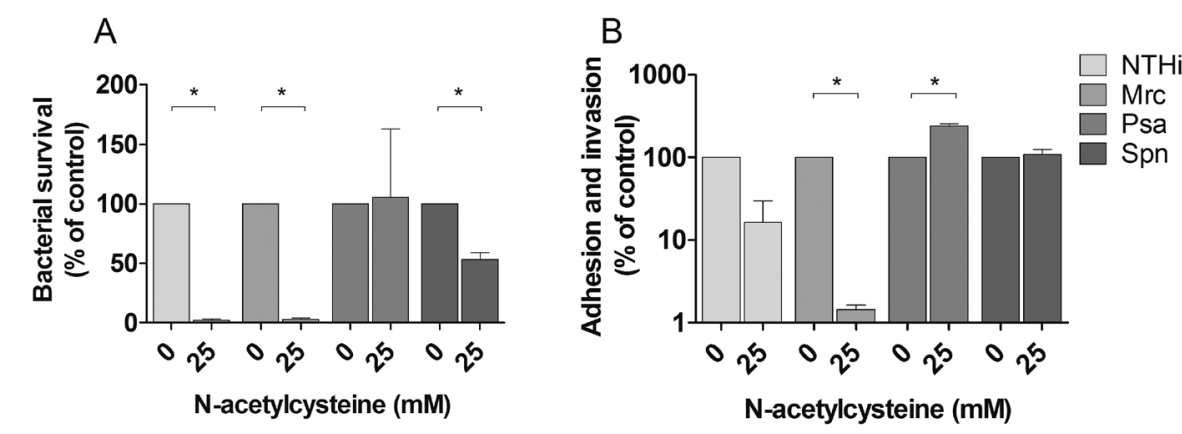

FIGURE 2. The effect of NAC on bacterial survival and adhesion and internalization of respiratory pathogens during macrophage infection. Bacterial survival and adhesion/internalization were determined after $4 \mathrm{~h}$ of infection with NTHi, Mrc, Spn and Psa without or with $25 \mathrm{mM}$ NAC. Bacteria were quantified by plating and the counts are expressed as percentage of the untreated control. ( $n=3, * P<0.05)$

\section{The effect of NAC on the release of bacterial and host cell-derived MVs during macrophage-infection}

Next, we studied if bacterial MV shedding during macrophage infection was affected by NAC. In the first set of experiments, tunable resistive pulse sensing was used to quantify MVs in a bacterial monoculture. However, during infection the MV population released consisted of both bacterial and host-cell MVs. Therefore, a bead-based flow-cytometry assay for the semi-quantitative determination of MVs was applied here. Unfortunately, we failed to establish this platform for Spn so we could not quantify the release for this species in this setting.

At a concentration of $25 \mathrm{mM}$, NAC increased the MV release by NTHi and Mrc (Fig. 3A). When adjustments were made for the total number of bacteria, this increase was fivefold for NTHi and tenfold for Mrc (pf 0.05 vs control, Fig. 3B). Regarding Psa, when adjustments were made, the MV release was found to increase on treatment with $25 \mathrm{mM} \mathrm{NAC} \mathrm{(Fig.} \mathrm{3B).}$

MV shedding during infection is a dynamic process that occurs by both bacteria as well as by the host. As it has been shown previously that host cell-derived MVs also have immuno-stimulatory properties [33-35], we additionally determined the effect of NAC on the release of $\mathrm{CD} 63^{+} / \mathrm{CD} 81^{+} \mathrm{MVs}$ by macrophages. Treatment with $25 \mathrm{mM}$ NAC significantly reduced the release of host-derived vesicles by macrophages, irrespective of the bacteria they were infected with (Fig. 4)

\section{The pro-inflammatory response to MVs is reduced by NAC}

In earlier experiments, we demonstrated that bacterial MVs induce the release of pro-inflammatory cytokines by naïve macrophages [57]. Here, we determined if this pro-inflammatory response induced by MVs from NTHi, Mrc, Spn, and Psa was affected by NAC treatment. As is shown in figure 5, all MV populations except those of Spn, induced the release of TNF-a by naive macrophages, albeit with different potencies. The response of 
macrophages to MVs was dose dependently reduced in the presence of NAC for all conditions except for Spn (Fig. 5A). Importantly, we determined that this decreased release of TNF-a was not the result of a treatment-induced cytotoxicity as NAC treatment was not found to have a cytotoxic effects (Fig. 5B). Interestingly, MVs from NTHi and Mrc showed to have cytotoxic effects that could be prevented by NAC treatment.
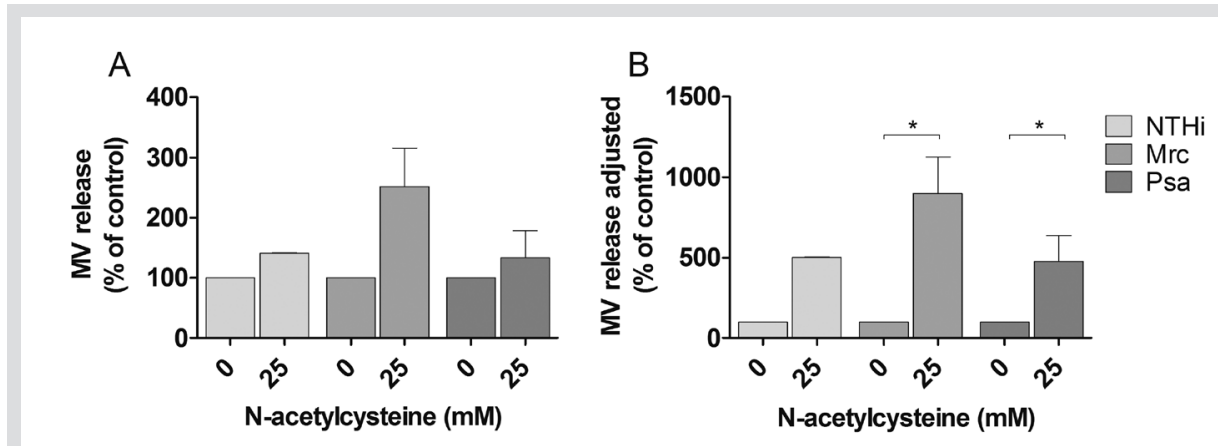

FIGURE 3. Bacterial MV release by respiratory bacteria during infection without or with 25 mM NAC. The bacterial MV release after $4 \mathrm{~h}$ of infection in the presence $25 \mathrm{mM}$ NAC or under control conditions was determined by bead-based flow cytometry. The relative counts are presented here as a percentage of the untreated control (A). Moreover, the release was adjusted for the total number of bacteria present. $\left(n=3,{ }^{\star} P<0.05\right)$

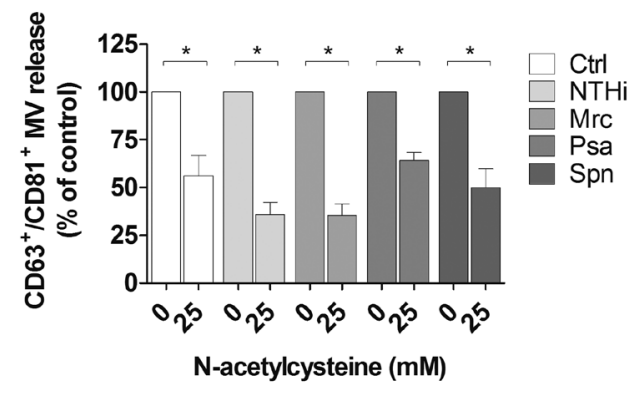

FIGURE 4. MV release by macrophages after infection with either one of the respiratory pathogens in the presence or absence of $25 \mathrm{mM}$ NAC. The release of CD63+/CD81+ $\mathrm{MVs}$ by macrophages after $4 \mathrm{~h}$ of infection with either one of the bacteria (multiplicity of infection of 10) in the presence or absence of 25 mM NAC was determined by beadbased flow cytometry. The relative counts are expressed here as a percentage of the untreated control $(n=3, * P<0.05)$. 


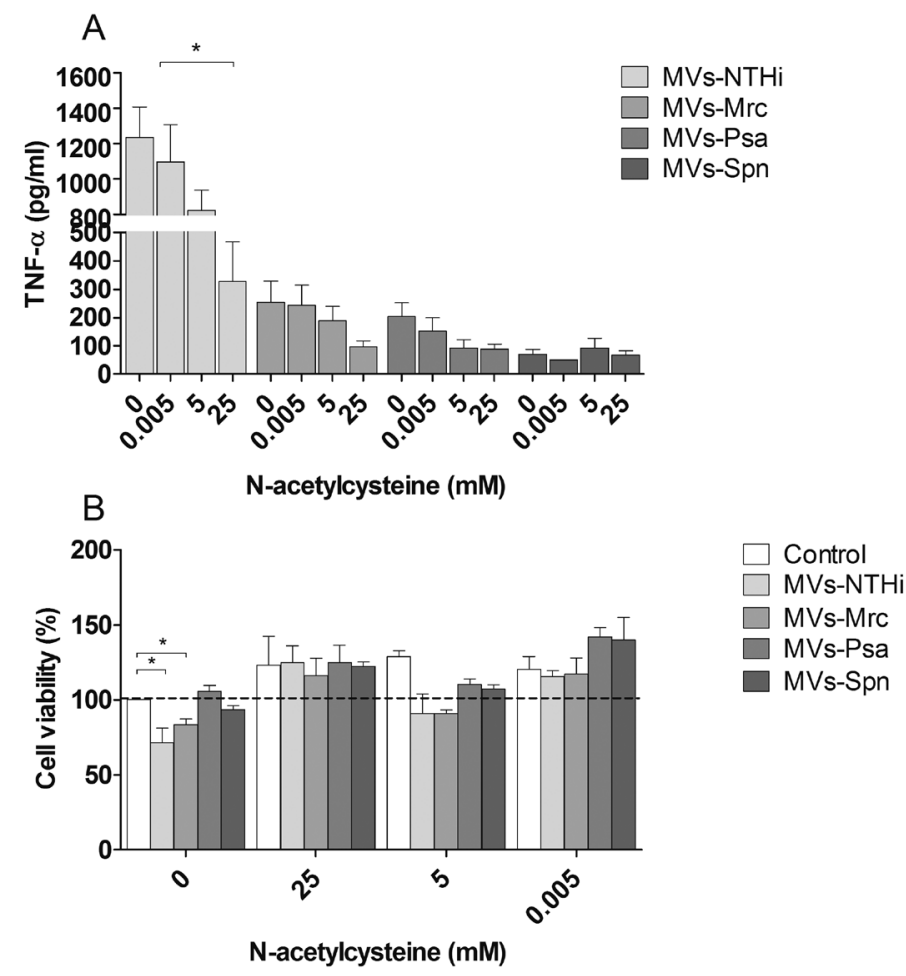

FIGURE 5. The effect of NAC on the TNF-a response by naive macrophages af- ter stimulation with bacterial MVs. Macrophages were exposed to bacterial MVs without or in the continuous presence of $\operatorname{NAC}(0.005,5$ or $25 \mathrm{mM})$ overnight, where after the release of TNF-a was determined (data for Mrc-, Psa-, and Spn-MVs are plotted on the right $y$-axis) (A). The cell viability after overnight MV exposure and/or NAC treatment was determined by a MTT assay $(B)$. The results are presented as the mean \pm SEM $(n=$ $3, * P<0.05)$. 


\section{DISCUSSION}

NAC is best known for its mucolytic properties, and because of its additional antioxidant and anti-inflammatory properties, it is an attractive drug in COPD therapy $[9,11,6-8]$. Moreover, bacteriostatic characteristics have been assigned to NAC in several studies $[17-20,36]$. In the present study, we confirmed this bacteriostatic effect as the growth of several respiratory pathogens was markedly inhibited by NAC. Therefore, as many exacerbations result from bacterial infections, the therapeutic effect of NAC may be beyond its mucolytic and anti-inflammatory and anti-oxidative properties. Additionally, in the present study we demonstrate that NAC, despite an enhancement of the release of pro-inflammatory MVs by the Gram-negative bacteria used in this study, suppressed the release of inflammatory cytokines by naive macrophages in response to these MVs.

There is a great demand for new treatments that relieve airway obstruction and inflammatory processes in patients with COPD [37]. Treatment with mucolytics, most prominently NAC, has been shown to alleviate these symptoms [9,11]. Moreover, (part of) these patients frequently suffer from severe exacerbations which are mostly caused by respiratory infections. Recently, Cazzola et al. concluded from their meta-analysis that patients with or without airway obstruction that received oral NAC treatment had a decreased risk of exacerbations of COPD, although higher doses were required in patients with obstruction [11]. There are indications that this protective effect of NAC may not only rely on its mucolytic, anti-oxidant or anti-inflammatory effects, but also on its antibacterial activity. One study by Riise et al. shows that COPD patients that received oral NAC therapy had a significant reduction of the intrabronchial bacterial numbers [38]. This antibacterial activity has already been demonstrated in the '70 by Parry and Neu [16], who demonstrated that NAC inhibited the growth of both Gram-negative and Gram-positive bacteria. Likewise, we also found that NAC caused a dose-dependent growth reduction of all bacteria tested. Also, during infection of naive macrophages, survival of NTHi and Mrc was significantly reduced in the presence of NAC. Adhesion of these two Gram-negative bacteria was markedly diminished by NAC. This is in accordance by findings by others, who also demonstrated that the presence of NAC significantly reduced the ability of Spn, NTHi or Psa to adhere to epithelial cells, in vitro $[17,19,36,39,40]$. These data suggest a possible role for NAC beyond its well-known effects.

The release of $\mathrm{MVS}$, which have been shown to be important vehicles for the simultaneous delivery of many effector molecules to host cells, is a common feature for both Gram-negative and Gram-positive bacteria [23,41]. MVs may influence the course of infection and the host immune response by presenting pathogen-associated molecular patterns (PAMPs) and antigens to their respective host receptors. A potential involvement of bacterial MVs in the pathogenesis of lung disease is indicated by several studies that demonstrate that bacterial MVs are present in infected tissues [42-44]. Moreover, it has been demonstrated that demonstrated that bacterial MVs are well able to activate immune cells and induce the release of pro-inflammatory cytokines. Additionally, bacterial MVs have been shown to facilitate replication of Legionella pneumophilia in infected macrophages or to induce emphysema via IL-17A-mediated neutrophilic inflammation $[45,46]$. Thus, inhibition of bacterial MV release might be beneficial for the course of pulmonary disease associated 
with infection (and other infection-related diseases). Here we examined the effects of NAC on the release of MVs by common respiratory pathogens. We provide evidence that treatment markedly enhanced the release of these vesicles by all Gram-negative bacteria when corrected for the number of bacteria. In contrast, no effects on the MV release by the Gram-positive Spn were observed.

The proposed mechanism by which NAC inhibits bacterial growth is by inhibiting the cysteine utilization by bacteria [16]. Additionally, this may also explain how NAC triggers the release of $M V s$ as a recent study showed that the inhibition of cysteine utilization in Neisseria meningitis cultures had bacteriostatic effects and promoted the release of bacterial MVs [21]. That the bacteriostatic effects of NAC are likely due to the inhibition of cysteine utilization might also explain the species-specific effects observed. Since the cysteine requirements differ among bacteria and can even vary between strains, these differences may affect the bacterial sensitivity to NAC [47].

We also showed that particularly MVs from the Gram-negative bacteria stimulated the release of TNF-a by nave macrophages. This is in accordance with earlier studies demonstrating a MV-induced release of pro-inflammatory cytokines and chemokines in vitro as a well as in vivo [44,48-51]. Thus, in view of the enhanced release of MVs by our Gram-negative bacteria, the therapeutic potential of NAC may be limited as it may hereby enhance the pulmonary inflammation. However, when we stimulated naive macrophages with bacterial MVs, the release of TNF-a could be dose-dependently inhibited by increasing concentrations of NAC. This suggests that NAC might be able to counteract its pro-inflammatory effect due to the enhanced bacterial MV release by inhibiting the subsequent release of pro-inflammatory cytokines by activated immune cells. Additional studies are warranted to further examine the net effect of NAC in pulmonary bacterial infections.

Although several in vitro studies have shown that NAC has potent anti-oxidant and anti-inflammatory (as reviewed by Sadowska et al. [52]), as well as bacteriostatic properties [16-20,36], this was mostly at concentrations which are hard to achieve by oral administration. E.g., upon oral administration of 600 mg thrice daily for five days, NAC could not be detected in the epithelial lining fluid, bronchoalveolar lavage fluid (BALF) or lung tissue $[53,54]$. Yet, for certain respiratory conditions, such as idiopathic pulmonary fibrosis and cystic fibrosis, NAC is administered by nebulization (350 mg, twice daily), whereby a high local bioavailability is reached $[55,56]$. In view of the present data, which suggest that also COPD patients may benefit from high local NAC concentrations, nebulization might form an attractive alternative in the treatment of these patients.

To summarize, in the current study we demonstrated that high NAC concentrations exert bacteriostatic effects on NTHi, Mrc, Spn, and Psa cultures and on NTHi and Mrc during macrophage infection. On the other hand, this inhibition of the bacterial growth was accompanied by an increased MV release. However, as our results also show that NAC markedly reduces the pro-inflammatory response to MVs, it is likely that the increased MV release is of little consequence. This may implicate that NAC administration by nebulization may have a positive treatment outcome during airway infections, such as bacterial exacerbations of COPD, but only when administered at a high concentration. Future 
research will be required to study these effects in vivo and to determine the long-term effects of NAC treatment on respiratory infection and exacerbations. 


\section{REFERENCES}

1. Pauwels R. Global initiative for chronic obstructive lung diseases (GOLD): time to act. Eur Respir J. 2001;18: 901-2. doi:10.1183/09031936.01.0027401

2. Lopez AD, Mathers CD, Ezzati M, Jamison DT, Murray CJL. Global and regional burden of disease and risk factors, 2001: systematic analysis of population health data. Lancet. 2006:367: 1747-57. doi:10.1016/ S0140-6736(06)68770-9

3. Hauber HP, Foley SC, Hamid Q. Mucin overproduction in chronic inflammatory lung disease. Can Respir J. 2006;13: 327-335

4. Miravitles M. Cough and sputum production as risk factors for poor outcomes in patients with COPD Respir Med. 2011;105: 1118-28. doi:10.1016/j.rmed.2011.02.003

5. Montes De Oca M, Halbert RJ, Lopez MV, Perez-Padilla R, Tálamo C, Moreno D, et al. The chronic bronchitis phenotype in subjects with and without COPD: The PLATINO study. Eur Respir J. 2012;40: 28-36. doi:10.1183/09031936.00141611

6. van Overveld FJ, Demkow U, Górecka D, de Backer WA, Zielinski J. New developments in the treatment of COPD: comparing the effects of inhaled corticosteroids and $\mathrm{N}$-acetylcysteine. J Physiol Pharmacol. 2005;56 Suppl 4: 135-42. Available: http://www.ncbi.nlm.nih.gov/pubmed/16204787 $123-8$

8. Sadowska AM, Verbraecken J, Darquennes K, De Backer WA. Role of N-acetylcysteine in the management of COPD. Int J Chron Obstruct Pulmon Dis. Dove Press; 2006;1: 425-34. Available: http://www.ncbi nim.nih.gov/pubmed/18044098

9. Poole P, Chong J, Cates CJ. Mucolytic agents versus placebo for chronic bronchitis or chronic obstructive pulmonary disease. Cochrane Database of Systematic Reviews. 2015:8:451-61. doi:10.1002/14651858 CD001287.pub5

10. Sheffner AL. The reduction in vitro in viscosity of mucoprotein solutions by a new mucolytic agent N-acetyl-L-cysteine. Ann N Y Acad Sci. 1963;106: 298-310. Available: http://www.ncbi.nlm.nih.gov/ pubmed/13977050

11. Cazzola M, Calzetta L, Page C, Jardim J, Chuchalin AG, Rogliani P, et al. Influence of N-acetylcysteine on chronic bronchitis or COPD exacerbations: a meta-analysis. Eur Respir Rev. 2015;24: 451-61. doi:10.1183/16000617.00002215

12. Sethi S, Murphy TF. Infection in the pathogenesis and course of chronic obstructive pulmonary disease N Engl J Med. 2008/11/29. 2008;359: 2355-2365. doi:10.1056/NEJMra0800353

13. King PT, MacDonald M, Bardin PG. Bacteria in COPD; their potential role and treatment. Transl Respir Med. 2013;1: 13. doi:10.1186/2213-0802-1-13

14. Desai H, Eschberger K, Wrona C, Grove L, Agrawal A, Grant B, et al. Bacterial colonization increases daily symptoms in patients with chronic obstructive pulmonary disease. Ann Am Thorac Soc. 2014;11: 303-9. doi:10.1513/AnnalsATS.201310-3500C

15. Marin A, Garcia-Aymerich J, Sauleda J, Belda J, Millares L, García-Núñez M, et al. Effect of bronchial colonisation on airway and systemic inflammation in stable COPD. COPD. 2012;9: 121-30. doi:10.3109 /15412555.2011.636407

16. Parry MF, Neu HC. Effect of N-acetylcysteine on antibiotic activity and bacterial growth in vitro. $J$ Clin Microbiol. 1977;5: 58-61. Available: http://www.pubmedcentral.nih.gov/articlerender.fcgi?artid $=274532 \&$ tool $=$ pmcentrez\&rendertype $=$ abstract

17. Riise GC, Qvarfordt I, Larsson S, Eliasson V, Andersson BA. Inhibitory effect of N-acetylcysteine on adherence of Streptococcus pneumoniae and Haemophilus influenzae to human oropharyngeal epithelial cells in vitro. Respiration. 2000;67: 552-8. doi:67473

18. Zhao T, Liu Y. N-acetylcysteine inhibit biofilms produced by Pseudomonas aeruginosa. BMC Microbiol. 2010;10: 140. doi:10.1186/1471-2180-10-140 
Olofsson A-C, Hermansson M, Elwing H. N-acetyl-L-cysteine affects growth, extracellular polysaccharide production, and bacterial biofilm formation on solid surfaces. Appl Environ Microbiol. 2003;69: 4814-22. Available: http://www.pubmedcentral.nih.gov/articlerender.fcgi?artid=169071\&tool=pmcentrez\&rendertype $=$ abstract

20. Huynh HQ, Couper RTL, Tran CD, Moore L, Kelso R, Butler RN. N-acetylcysteine, a novel treatment for Helicobacter pylori infection. Dig Dis Sci. 49: 1853-61. Available: http://www.ncbi.nlm.nih.gov/ pubmed/15628716

21. van de Waterbeemd B, Zomer G, van den IJssel J, van Keulen L, Eppink MH, van der Ley P, et al. Cysteine Depletion Causes Oxidative Stress and Triggers Outer Membrane Vesicle Release by Neisseria meningitidis; Implications for Vaccine Development. PLoS One. 2013;8: e54314. doi:10.1371/journal. pone.0054314

22. Schwechheimer C, Kuehn MJ. Outer-membrane vesicles from Gram-negative bacteria: biogenesis and functions. Nat Rev Microbiol. 2015;13: 605-619. doi:10.1038/nrmicro3525

23. Brown L, Wolf JM, Prados-Rosales R, Casadevall A. Through the wall: extracellular vesicles in Gram-positive bacteria, mycobacteria and fungi. Nat Rev Microbiol. 2015;13: 620-30. doi:10.1038/nrmicro3480

24. Lobb RJ, Becker M, Wen SW, Wong CSF, Wiegmans AP, Leimgruber A, et al. Optimized exosome isolation protocol for cell culture supernatant and human plasma. J Extracell Vesicles. 2015;1: 1-11. doi:10.3402/ jev.v4.27031

25. Böing AN, van der Pol E, Grootemaat AE, Coumans FAW, Sturk A, Nieuwland R. Single-step isolation of extracellular vesicles by size-exclusion chromatography. J Extracell Vesicles. 2014; 3:23430. doi:10.3402/ jev.v3.23430.

26. Nordin JZ, Lee Y, Vader P, M??ger I, Johansson HJ, Heusermann W, et al. Ultrafiltration with size-exclusion liquid chromatography for high yield isolation of extracellular vesicles preserving intact biophysical and functional properties. Nanomedicine 2015;11: 879-883. doi:10.1016/j.nano.2015.01.003

27. Ostrowski M, Carmo NB, Krumeich S, Fanget I, Raposo G, Savina A, et al. Rab27a and Rab27b control different steps of the exosome secretion pathway. Nat Cell Biol. 2010;12: 13-19. doi:10.1038/ncb2000

28. Kapustin AN, Chatrou MLL, Drozdov I, Zheng Y, Davidson SM, Soong D, et al. Vascular smooth muscle cell calcification is mediated by regulated exosome secretion. Circ Res. 2015;116: 1312-1323. doi:10.1161/ CIRCRESAHA.116.305012

29. Volgers C, Benedikter BJ, Grauls GE, Savelkoul PHM, Stassen FRM. Bead-based flow-cytometry for semi-quantitative analysis of complex membrane vesicle populations released by bacteria and host cells. Microbiol Res. 2017;200: 25-32. doi:https://doi.org/10.1016/j.micres.2017.04.003

30. Sutton S. Measurement of microbial cells by optical density. J Valid Techn. 2011; 46-49. Available: http:// www.microbiologynetwork.com/content/JVT_2011_V17n1_Measurement-of-Microbial-Cells-by-Optical-Density.pdf

31. Szkudlarek U, Zdziechowski A, Witkowski K, Kasielski M, Luczynska M, Luczynski R, et al. Effect of inhaled $\mathrm{N}$-acetylcysteine on hydrogen peroxide exhalation in healthy subjects. Pulm Pharmacol Ther. 2004;17 155-162. doi:10.1016/j.pupt.2004.01.007

32. Martin TR, Frevert CW. Innate immunity in the lungs. Proc Am Thorac Soc. 2005;2: 403-11. doi:10.1513/ pats.200508-090JS

33. Soni S, Wilson MR, O'Dea KP, Yoshida M, Katbeh U, Woods SJ, et al. Alveolar macrophage-derived microvesicles mediate acute lung injury. Thorax. 2016; thoraxjnl-2015-208032. doi:10.1136/thoraxjnl-2015-208032

34. Qazi KR, Torregrosa Paredes P Fau - Dahlberg B, Dahlberg B Fau - Grunewald J, Grunewald J Fau - Eklund A, Eklund A Fau - Gabrielsson S, Gabrielsson S, et al. Proinflammatory exosomes in bronchoalveolar lavage fluid of patients with sarcoidosis. Thorax. 2010;65: 1016-1024

35. Kulshreshtha A, Ahmad T, Agrawal A, Ghosh B. Proinflammatory role of epithelial cell-derived exosomes in allergic airway inflammation. J Allergy Clin Immunol. 2013;131: 1194-1203.e14. doi:10.1016/j. jaci.2012.12.1565 
36. Hafez MM, Aboulwafa MM, Yassien MA, Hassouna NA. Activity of some mucolytics against bacterial adherence to mammalian cells. Appl Biochem Biotechnol. 2009;158: 97-112. doi:10.1007/s12010-008-8312-2

37. Barnes PJ. Chronic obstructive pulmonary disease: New treatments for COPD. Thorax. 2003;58: 803808. doi:10.1136/thorax.58.9.803

38. Riise GC, Larsson S, Larsson P, Jeansson S, Andersson B a. The intrabronchial microbial flora in chronic bronchitis patients: A target for N-acetylcysteine therapy? Eur Respir J. 1994;7: 94-101. doi:10.1183/09 031936.94.07010094

39. Niederman MS, Rafferty TD, Sasaki CT, Merrill WW, Matthay RA, Reynolds HY. Comparison of bacterial adherence to ciliated and squamous epithelial cells obtained from the human respiratory tract. Am Rev Respir Dis. 1983;127: 85-90. Available: http://ovidsp.ovid.com/ovidweb.cgi? T=JS\&CSC=Y\&NEWS=N\&PAGE=fulltext\&D $=$ med2\&AN $=6401417$

40. Zheng $\mathrm{CH}$, Ahmed K, Rikitomi N, Martinez G, Nagatake T. The effects of S-carboxymethylcysteine and $\mathrm{N}$-acetylcysteine on the adherence of Moraxella catarrhalis to human pharyngeal epithelial cells. Microbiol Immunol. 1999;43: 107-13. Available: http://www.ncbi.nlm.nih.gov/pubmed/10229264

41. Schwechheimer C, Kuehn MJ. Outer-membrane vesicles from Gram-negative bacteria: biogenesis and functions. Nat Rev Microbiol. 2015;13: 605-619. doi:10.1038/nrmicro3525

42. Ren D, Nelson KL, Uchakin PN, Smith AL, Gu X-X, Daines DA, et al. Characterization of extended co-culture of non-typeable Haemophilus influenzae with primary human respiratory tissues. Exp Biol Med. 2012:237:540-7. doi:10.1258/ebm.2012.011377

43. Perez Vidakovics MLA, Jendholm J, Mörgelin M, Månsson A, Larsson C, Cardell L-O, et al. B Cell Activation by Outer Membrane Vesicles-A Novel Virulence Mechanism. PLoS Pathog. 2010; 6: e1000724. doi:10.1371/journal.ppat.1000724

44. Bauman SJ, Kuehn MJ. Purification of outer membrane vesicles from Pseudomonas aeruginosa and their activation of an IL-8 response. Microbes Infect. 2006;8: 2400-2408. doi:10.1016/j.micinf.2006.05.001

45. Kim Y-KY-S, Lee W-H, Choi E-J, Choi J-P, Heo YJ, Gho YS, et al. Extracellular vesicles derived from Gram-negative bacteria, such as Escherichia coli, induce emphysema mainly via IL-17A-mediated neutrophilic inflammation. J Immunol. 2015;194: 3361-8. doi:10.4049/jimmunol.1402268

46. Jung AL, Stoiber C, Herkt CE, Schulz C, Bertrams W, Schmeck B, et al. Legionella pneumophila-Derived Outer Membrane Vesicles Promote Bacterial Replication in Macrophages. PLOS Pathog. 2016;12: e1005592. doi:10.1371/journal.ppat.1005592

47. Guédon E, Martin-Verstraete I. Cysteine Metabolism and Its Regulation in Bacteria. Microbiol Monogr. Amino Acid Biosynthesis; 2006; doi:10.1007/7171_2006_060/

48. Lee JC, Lee EJ, Lee JH, Jun SH, Choi CW, Kim S II, et al. Klebsiella pneumoniae secretes outer membrane vesicles that induce the innate immune response. FEMS Microbiol Lett. 2012;331: 17-24. doi:10.1111/ j.1574-6968.2012.02549.x

49. Schaar V, De Vries SPW, Perez Vidakovics MLA, Bootsma HJ, Larsson L, Hermans PWM, et al. Multicomponent Moraxella catarrhalis outer membrane vesicles induce an inflammatory response and are internalized by human epithelial cells. Cell Microbiol. 2011;13: 432-449. doi:10.1111/j.1462-5822.2010.01546.x

50. Sharpe SW, Kuehn MJ, Mason KM. Elicitation of epithelial cell-derived immune effectors by outer membrane vesicles of nontypeable haemophilus influenzae. Infect Immun. 2011;79: 4361-4369. doi:10.1128/ |Al.05332-11

51. Park KS, Lee J, Jang SC, Kim SR, Jang MH, Lötvall J, et al. Pulmonary inflammation induced by bacteria-free outer membrane vesicles from Pseudomonas aeruginosa. Am J Respir Cell Mol Biol. 2013;49. 637-645. doi:10.1165/rcmb.2012-03700C

52. Sadowska AM, Manuel-Y-Keenoy B, De Backer WA. Antioxidant and anti-inflammatory efficacy of NAC in the treatment of COPD: discordant in vitro and in vivo dose-effects: a review. Pulm Pharmacol Ther. 2007:20: 9-22. doi:10.1016/j.pupt.2005.12.007 
53. Bridgeman MM, Marsden M, Selby C, Morrison D, MacNee W. Effect of N-acetyl cysteine on the concentrations of thiols in plasma, bronchoalveolar lavage fluid, and lung tissue. Thorax. 1994;49: 670-5. Available: http://www.pubmedcentral.nih.gov/articlerender.fcgi? artid=4750558tool=pmcentrez\&rendertype $=$ abstract

54. Cotgreave IA, Eklund A, Larsson K, Moldéus PW. No penetration of orally administered N-acetylcysteine into bronchoalveolar lavage fluid. Eur J Respir Dis. 1987;70: 73-7. Available: http://www.ncbi.nlm.nih. gov/pubmed/3817074

55. Homma S, Azuma A, Taniguchi H, Ogura T, Mochiduki Y, Sugiyama Y, et al. Efficacy of inhaled N-acetylcysteine monotherapy in patients with early stage idiopathic pulmonary fibrosis. Respirology. 2012;17: 467-477. doi:10.1111/j.1440-1843.2012.02132.x

56. Tam J, Nash EF, Ratjen F, Tullis E, Stephenson A. Nebulized and oral thiol derivatives for pulmonary disease in cystic fibrosis. Cochrane Database of Systematic Reviews. 2013; CD007168. doi:10.1002/14651858. CD007168.pub3

57 Volgers C, Benedikter BJ, Grauls GE, Savelkoul PHM, Stassen FRM. Immuno-modulatory membrane vesicles are released during macrophage infection with respiratory pathogens. BMC Microbiology. 2017 in press. 



\section{Chapter 7}

General discussion and future directions 



\section{GENERAL DISCUSSION}

The outcome of bacterial infections of the respiratory tract is critically determined by interactions between bacteria and host cells. And because of conflicting aims, there is great complexity in the execution of these interactions. Membrane vesicles (MVs) are released by cells from all branches of life and may facilitate communication. Moreover, they may fulfil functions that are beyond communication and provide the cell with additional advantages. The release of MVs is highly dynamic and context dependent. Past studies on the release of bacterial MVs were mostly based on bacterial monocultures in the late exponential or stationary phase. Now, in this thesis the central aim was to assess the release of both bacterial and host cell-derived MVs during bacterial infection of macrophages. The central hypothesis was that both bacterial and host cell-derived membrane vesicles released upon infection convey a physiological activity and affect host-pathogen interactions. Additionally, we hypothesized that the release of membrane vesicles is affected by therapeutics. Therefore, we also studied how therapeutics that are frequently used for treatment of chronic obstructive pulmonary disease (COPD), affect the release of bacterial and host cell-derived membrane vesicles. 


\section{Methods to study vesicle release upon infection}

In recent literature, a substantial amount of work on bacterial MVs is based on studies where MVs were isolated from bacterial monocultures [1-7]. However, in our studies we aimed to study the release of not only bacterial MVs but also host cell MVs during active infection of macrophages. To address this, we had to establish methodologies to isolate, measure and characterize both bacterial and host cell MVs.

As the release of membrane vesicles is such a dynamic process where the composition of membrane vesicles is determined by intra- and intercellular processes, it is key to choose a physiological approach to study the expression of membrane vesicles. This, however, is highly complicated as the membrane vesicle population released during infection is extremely heterogeneous and consists of both host-derived vesicles as well as bacterial vesicles. Because of this complexity, intracellular bacteria have been mainly used to study vesicle release during infection, as this model assumed that MVs released upon infection were mainly host cell-derived and therefore easier to characterize. In contrast, the dynamics and functionality of MVs shed during infection with extracellular bacteria have remained less well studied and as far as we know, no studies on both vesicle populations have been published thus far.

The evaluation of existing methods to study MV release was therefore critical. At the onset of the work presented in this thesis, differential ultracentrifugation followed by sucrose cushion purification or purification by a sucrose or iodixanol density-gradient was considered the gold standard for the isolation and purification of MVs [8,9]. Yet, developments in the field indicated that ultrafiltration followed by size exclusion chromatography might be superior as this technique does not compromise the vesicle integrity, results in a higher vesicle concentration, and might affect the physiological activity of the vesicles to a lesser extent as has been suggested for 'matrix-based' purification methods such as sucrose and iodixanol [10-14]. Therefore, ultrafiltration was chosen for the initial isolation of vesicles from both bacteria and host cells. For further characterization and quantification of the vesicles three methods were selected: i) Cryo-electronmicroscopy (cryo-EM), ii) tunable-resistive pulse sensing (TRPS: for the detection and characterization of single particles), and iii) flow-cytometry [15-17]. Regarding the latter, conventional flow cytometry is not suitable to detect MVs because of their small size. To overcome this problem, we used bead-based flow cytometry. This technique is based on an existing method for the determination of host cell-derived vesicles $[9,18]$. In chapter 3 , we demonstrated the applicability of this technique for the semi-quantitative determination of bacterial MVs. We additionally showed that this method can be applied on small sample volumes (which makes it suitable for a wide number of applications including high throughput screening) to study the release kinetics of multiple MV subpopulations within complex vesicle populations.

In summary, we developed a suitable method that allowed us to study heterogeneous and complex vesicle populations (e.g. composed of bacterial and host cell-derived MVs). This allowed us to determine the kinetics of bacterial and host cell MVs during infection (chapter 4) and to establish how the release was affected by drugs frequently prescribed to patients with chronic respiratory disease (chapters 5 and 6 ). 
To study functional aspects of one specific vesicle population within a mixed population (e.g. bacterial and host cell-derived MVs), separation of the different vesicle populations is required. To this end, several approaches, including methods based on antibody-coated (magnetic-)beads and Optiprep-based techniques, were tested $[8,11,19]$. Unfortunately, none of these approaches gave an adequate separation (results not shown). Novel techniques based on affinity capture of heat shock proteins or heparin for the isolation of specific vesicle populations were considered inadequate, as heat-shock proteins (e.g. vn96) are also highly conserved in bacteria. Moreover, bacteria (and most likely also MVs) contain many heparin binding proteins, which also makes heparin not useful for the discrimination between host cell-derived and bacterial vesicles [20]. Nonetheless, tailor made methods can provide a way to isolate specific vesicle populations. An example hereof is a platform developed by Ihalin et al. based on immuno-affinity chromatography. Yet, the development of such a platform is complicated, timely, and requires validation, especially as the success of such a method is highly dependent on the affinity and specificity of the antibodies [21]. Therefore, we decided to take vesicles from macrophages stimulated with heat-inactivated bacteria (which do not release MVs) to study functional characteristics of MVs released by macrophages after bacterial challenge.

To summarize, the assessment of MVs requires highly advanced techniques that need to be optimized and verified a priori. We selected and verified several techniques and modified an existing method which allowed us to study bacterial and host cell-derived MVs released during infection and culture.

\section{Characterization of bacterial MVs released upon culture}

Previous studies have demonstrated that MVs are released by bacteria during culture. Most of these studies assessed the release of bacterial MVs during the stationary growth phase of the cultures in specialized culture media [1-7]. In chapter 2 we highlighted that the culture conditions, e.g. the availability of nutrients or the presence of host cells, can affect the release of MVs by bacteria. Therefore, in chapter 4 we characterized bacterial $\mathrm{MV}$ release under culture conditions that resemble those as used during infection (short culture periods in standard cell culture medium). With the use of cryo-EM and TRPS we confirmed that MVs are being released during bacterial culture. Moreover, our results revealed that the vesicles released by the four bacterial species tested were comparable in size and number. Unfortunately, it is difficult to directly compare our results to other studies that were based on the same species. Most studies used different culture media and culturing times and mostly base their quantifications on the protein concentration of ultracentrifugation pellets [3,22-24], while our quantifications are based on TRPS-based analysis, which makes it difficult to compare.

To summarize, our results demonstrate that MVs are being released by bacterial cultures, already in the early exponential phase. 


\section{Characterization of bacterial MVs released upon infection}

That bacterial behaviour, including the release of MVs, is altered in the presence of host cells is generally recognized. As reviewed in chapter 2, cationic antimicrobial peptides and certain other host cell-derived products can induce the release of bacterial MVs. On the other hand, it cannot be excluded that during infection phagocytes eliminate bacteria thereby reducing the number of MVs being released. Future studies, however, will be necessary to perform more detailed studies on how host cells and the physiological context can (in-)directly affect bacterial MV biogenesis. We suggest this can be done using a platform based on fluorescent antibodies e.g. by our bead-based flow-cytometric assay or by dedicated flow cytometry (e.g. Apogee A50 flow cytometric analysis)[25-27].

To summarize, our results indicate that bacterial MVs are released during macrophage infection and we addressed this in more detail in chapter 4.

\section{Characterization of host cell-derived MVs released upon infection}

During infection host cells are exposed to a variety of stressors that may be a consequence of infection [28,29]. Exposure to stressors (i.e. heat stress or oxidative stress) has previously been shown to induce the release of MVs [30,31]. However, the effect of bacterial infections have been studied less intensively. In chapter 4 we studied the dynamics of vesicle shedding by macrophages under control conditions and during infection by cryo-EM and TRPS. We showed that MVs could be detected already after 4 hours of culture. The average concentration of the host cell-derived vesicles under control conditions was established at $5.8 \times 10^{8}$ particles $/ \mathrm{ml}$. The median diameter of these vesicles was established at $117 \mathrm{~nm}$ (IQR 98-146) and $111 \mathrm{~nm}$ (IQ 105-118) by TRPS and cryo-EM, which once more confirms the resemblance between host cell-derived and bacterial vesicles at least at the size level. To determine more specifically the release of host cell-derived vesicles following infection, we used bead-based flow-cytometry. Results showed that infection enhanced the release of CD63+/CD81+ vesicles. This is in accordance with earlier studies by Carriére et al., who demonstrated that in vitro macrophage infection with $E$. coli resulted in an increased release of $\mathrm{CD}^{+} 3^{+} \mathrm{MVs}$ [32]. Also in vivo the release of MVs was shown to be augmented in the bronchoalveolar fluid of mice after the instillation of LPS [33,34], and neutrophils, macrophages, and epithelial cells were all found to contribute to this increase [33]. In

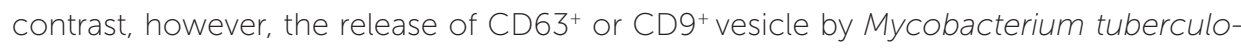
sis-infected macrophages was not altered, suggesting that the nature of infection may determine whether the release of host cell vesicles changes [35].

In summary, our results presented in chapter 4 demonstrated that macrophages release MVs during short term culture conditions. Moreover, we observed that macrophage infection with extracellular bacteria enhances the release of MVs.

\section{Bacterial MVs released upon infection exert a strong pro-inflammatory activity} It has been recognized that bacteria release MVs with immuno-stimulatory and -modulatory properties. These properties can mainly be attributed to components such as lipopolysaccharides and various (other) virulence factors [36,37]. In chapter 4 we could confirm that bacterial MVs possess a strong pro-inflammatory potential, which was however limited to the Gram-negative bacteria as MVs of S. pneumoniae did not induce the 
release of TNF-a. Additionally, we demonstrate this response was induced in a TLR-4 dependent manner for vesicles from non-typeable $H$. influenzae and $P$. aeruginosa, which was as expected since others identified LOS and LPS, respectively, as important vesicle components $[5,24,38]$. M. catarrhalis MVs, on the other hand, induced inflammatory responses independently of TLR-4 which is in line with a previous study demonstrating that this occurs in a TLR-2 dependent manner [39].

As membrane vesicle shedding occurs constitutively it is possible that host cells are exposed to bacterial vesicles for prolonged periods of time. In chapter 4 we established how prolonged macrophage exposure to infection-associated MVs affects the response to subsequent stimulation with bacterial mimetics. Interestingly, we observed that particularly pre-exposure to MVs from non-typeable $H$. influenzae significantly decreased the pro-inflammatory response to a secondary challenge with TLR-4 or TLR-2/1 ligands. This is likely to be the consequence of TLR-desensitisation which can occur upon prolonged TLR-4 activation $[40,41]$. This may compromise innate immune responses required to resolve infection [28,42]. Another important finding presented in chapter 4 is the increased bacterial adhesion to and internalization of macrophages upon pre-exposure to MVs. As proteomic analyses identified several adhesins on these vesicles it is likely that these account for part of the effects $[2,4,43,44]$. However, these results ask for a careful interpretation as they may also have been caused by an augmented bacterial phagocytosis. Therefore, additional studies are required to determine the true effects of MVs in this respect.

To conclude, the results we present in chapter 4 demonstrate that bacterial MVs shed during the initial phase of infection provoke strong inflammatory responses by naive macrophages but can also induce tolerance and enhance bacterial adhesion and internalization. Future research is needed to determine the consequences of bacterial MV shedding on bacterial clearance.

\section{The physiological activity of host cell-derived MVs}

Various functional characteristics have been attributed to host cell-derived vesicles released in the context of infection or inflammation. These include pro-inflammatory properties which have been accredited to the presence of pathogen-associated molecular patterns or pro-inflammatory cytokines such as IL-1 $\beta$ or TNF- $\alpha$ on or inside the vesicles [33,34,45-47]. Therefore, we determined the pro-inflammatory properties of host cell-derived vesicles released upon infection. By using MVs released by macrophages after stimulation with heat-inactivated bacteria (where no bacterial vesicles are present), we demonstrated in chapter 4 that these macrophage-derived MVs did not induce the release of TNF-a by naive macrophages. Moreover, we showed that the release of TNF-a by naïve macrophages following stimulation with mixed membrane population (host cell-derived and bacterial) was comparable to the results achieved when stimulated with bacterial vesicles only. This indicates that host cell-derived vesicles have little pro-inflammatory potential. This is in line with recent findings by Athman et al. who demonstrated that MVs released during macrophage infection with M. tuberculosis consist of bacterial and host-derived MVs and that only the bacterial MVs induced an inflammatory response [16]. There are conditions, however, where pro-inflammatory MVs can be released by mac- 
rophages, which for example has been shown to occur in response to stimulation with LPS $[33,34,45]$. Thus, the release of inflammatory MVs by host cells seems highly context and cell-type specific and a plethora of other physiological properties has been ascribed to MVs of innate immune cells. For example, it has been shown that dendritic cell or macrophage-derived MVs can carry (functional) MHC-II-peptide complexes [48-51]. Therefore, future studies are required to assess other physiological aspects of MVs released by innate immune cells upon infection with extracellular bacteria.

\section{Bacterial MV release in response to conventional therapeutics in chronic airway disease}

Bacterial infections of the respiratory tract have been shown to be the main cause of exacerbations in patients with chronic bronchitis or COPD [52-56]. Usually such exacerbations are treated with corticoids and/or antibiotics to prevent excessive inflammation and to kill bacteria, respectively [57-59]. Moreover, a few studies recently demonstrated that glucocorticoids can directly affect the bacterial growth and the sensitivity to antibiotics in a species-dependent fashion [60-62]. To further extent these findings, in chapter 5 we investigated the effects of the glucocorticoids fluticasone, budesonide, and the antibiotic azithromycin on bacterial growth. However, in contrast to these earlier findings, in our hands bacterial growth was in general not significantly affected by these pharmacological agents. Previous studies demonstrate that certain antibiotics induce the release of MVs and that this contributes to an enhanced bacterial resistance. Therefore, we also determined the effects of these drugs on the shedding of bacterial MVs. We found that none of the pharmacological agents had any effect on the release of bacterial vesicles. This was an interesting finding as there was considerable reason to suspect that glucocorticoids can affect the release of these vesicles. This motive was provided by a recent study that shows a high resemblance in the bacterial behaviour of $\mathrm{H}$. influenzae exposed to a glucocorticoid and RpoE deletions strains [60]. RpoE encodes sigma factor $E\left(s^{E}\right)$ and the activation of $S^{E}$ is a well-known trigger for MV release (reviewed in chapter 2 ). Therefore, we anticipated that glucocorticoids exerted an inhibitory effect on the release of MVs. Yet, for this no evidence was found for the therapeutically relevant concentration tested in our study. Also in chapter 5, we showed that fluticasone propionate, budesonide, and azithromycin strongly inhibited the pro-inflammatory response to bacterial MVs. This was in line with previous studies which demonstrated immune-silencing by glucocorticoids as well as azithromycin $[63,64]$. So, together our findings implicate that treatment with these glucocorticoids and/or azithromycin has beneficial effects on inflammation (figure 1). This positive effect is further supported by findings of others who demonstrated a decreased invasion of airway epithelial cells and lungs by S. pneumoniae and $H$. influenzae upon treatment with glucocorticoids $[65,66]$. These effects were dependent on a reduction of inflammation and consequently a reduced expression of platelet-activating factor receptor (PAF-R)[66]. PAF-R is important for the bacterial adhesion of certain airway pathogens, including S. pneumoniae and H. influenzae but not for other bacteria such as Klebsiella pneumonia. This may explain why fluticasone treatment did not result in a decreased invasion and even impaired clearance of $K$. pneumoniae [67]. Therefore, not only should the impact of treatment with glucocortocoids on adhesion/invasion be determined, also the impact on bacterial clearance needs to be addressed before an appropriate indication for treatment can be given. 
Thus, our results suggest that the potentially positive effects of glucocorticoids or azithromycin on airway inflammation and infection in patients with bacterial exacerbations may depend on additional mechanisms besides the well-known anti-inflammatory and anti-bacterial effects.

\section{Bacterial MV release in response to non-conventional therapeutics in chronic airway disease}

Despite the positive effects of glucocorticoids and antibiotics in severe chronic lung diseases, there might also be a downside as they may alter the lung microenvironment (e.g. presence of oxidative stress, inflammatory cells and components, or by lung remodelling) when administered over a long period of time. This may ultimately impact the bacterial growth and behaviour [61,68]. As these therapeutics are frequently administered over a longer time span [69-73], future studies will be required to determine how they affect the lung microenvironment [68]. This is particularly important for three major reasons. Firstly, the bacterial composition in the lower airways of patients with stable COPD is markedly different from healthy subjects, both in number and composition, characterized by an increased prevalence of $H$. influenzae, S. pneumoniae, M. catarrhalis, and P. aeruginosa [74-80]. Secondly, respiratory infections and bacterial sputum counts are associated with a decline in lung function in COPD [81-85]. Finally, it is not known whether this difference is the result of pathology, treatment, or a combination. Irrespectively, large randomized trials have demonstrated that the majority of the COPD patients does not benefit from treatment with immuno-corticoids [57-59]. Therefore, new therapies that are effective over long periods of time and free of side effects are required.

One such promising alternative may consist of $\mathrm{N}$-acetyl-L-cysteine (NAC) administration by nebulization. As a mucolytic, NAC is currently used in the treatment of patients with chronic bronchitis and COPD, where it is administered orally $[86,87]$. As administration by nebulization results in a higher local availability, this may form an attractive treatment approach. In chapter 6 we tested the effects of NAC on bacterial behaviour regarding bacterial growth and MV release of/by common respiratory pathogens. We observed that, under culture conditions, NAC exerts a strong bacteriostatic effect on non-typeable H. influenzae, M. catarrhalis, S. pneumoniae, and $P$. aeruginosa, which was in agreement with previous studies [88-93]. For H. influenzae and M. catarrhalis our results also showed that treatment with NAC resulted in a markedly enhanced MV release. Interestingly, both observations may be closely linked and dependent on the inhibition of bacterial cysteine utilisation by NAC. Cysteine deprivation drastically reduces bacterial growth [88] but also has been shown a trigger for the release of bacterial MVs (as reviewed in chapter 2) [94]. However, in chapter 4 we demonstrated that such enhanced release of vesicles may be detrimental and initiate pro-inflammatory processes. Nonetheless, we additionally demonstrate (chapter 6 ) that NAC treatment reduced these potentially dangerous pro-inflammatory responses to bacterial MVs and therefore the increased shedding of pro-inflammatory MVs due to NAC treatment is allegedly of little consequence. 
Thus, although bacterial exposure to NAC initially induced an increased release of pro-inflammatory MVs by Gram-negative bacteria, NAC at the same time exerts strong bacteriostatic and anti-inflammatory effects (figure 1). This led us to speculate that the net-effect of NAC when administered at a high dose by nebulization may be beneficial for patients with COPD. Future studies on the long-term effects of NAC on bacterial airway infection and inflammation will be required to follow up on this theory.

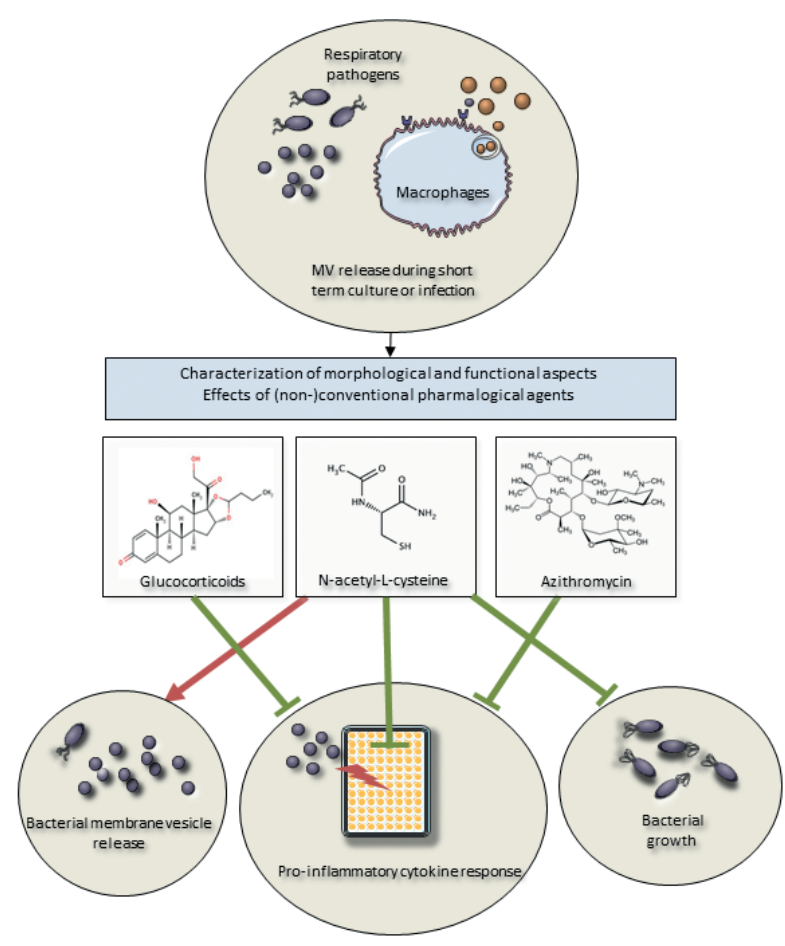

FIGURE 1: summarising the effect of therapeutics on the bacterial behaviour in terms of bacterial growth and membrane vesicle release and on the pro-inflammatory response to pro-inflammatory bacterial MVs. 


\section{DIRECTIONS FOR FUTURE RESEARCH}

\section{Pre-clinical models}

Previous studies have shown that MVs are released by host cells during infection with intracellular bacteria $[46,47,95,96]$, upon stimulation with bacterial mimetics such as LPS [33,45], but also by bacteria over longer periods of culture $[1,4,7,97]$. The data presented in this thesis improved our insight concerning the dynamics of membrane vesicle shedding during infection with extracellular bacteria during relatively short infection periods. However, most studies were performed in a "1-dimensional" environment (one cell type and one species of bacteria). Yet, as delineated in chapter 2, the (micro-)environment is of relevance for host cell and bacterial stress responses. Therefore, studies that are performed in a physiological setting are of great importance. The easiest and most efficient way to make fast progress involves the use of in vitro infection models. In recent years, significant progress has been made in the development of 2D co-culture and 3D organotypic models. The application of such models allows to study in greater detail the involvement of different cell types and their interaction with respect to the release of both host cell and bacterial vesicles. For example, membrane vesicle shedding by respiratory pathogens can be assessed using a 2D air-liquid interface co-culture model based on differentiated airway epithelial cells and macrophages. From the host perspective, this will help to determine their true physiologically value over the course of infection and to unravel if these vesicles contribute to innate immunity-mediated bacterial clearance. From the perspective of the bacteria, these models will help to understand how bacteria shape their outer membrane (e.g. lipid-A region) over the course of infection or during niche occupation and the involvement of MVs in virulence and defence and nutrient acquisition.

\section{Therapy}

As was shown in studies presented in this thesis and by others, certain therapeutic agents may be accompanied by undesired side-effects as they can affect bacterial stress responses in terms of antibiotic resistance [60,62], biofilm formation [60] and the release of immunogenic MVs (chapter 6 [98,99]). Future research on the mechanisms for vesicle biogenesis may help to predict and prevent these undesired outcomes. It is at present unknown to what extend MVs contribute to bacterial resistance to certain cationic antibiotics. Nevertheless, it is known that membrane remodelling is important for the acquisition for resilience [100-102]. Further elucidation of the role MVs play in this stress response will therefore also help to overcome general bacterial defence mechanisms to antibiotic treatment. An example hereof may be the targeted combination of therapeutics and "smart factors", like the combination of polymyxins and certain components (e.g. nutrients) that stabilize the bacterial outer membrane and/or inhibit bacterial stress responses. In addition, it will be key to establish the physiological conditions that bacteria are exposed to in the host during invasion and niche occupation, and to understand how these can trigger bacteria to modulate their outer membrane and release of MVs. This will be essential to determine whether and how bacterial membrane vesicle release can be targeted and how this can be modulated. 


\section{Environment}

A better understanding of the mechanisms of bacterial defence against environmental factors is highly relevant as the virulence and pathogenicity of bacteria is predominantly determined by their ability to overcome these challenges. MVs are an important aspect of the bacterial arsenal that enables them to cope with their environment and thus may be a determinant for virulence and pathogenicity. Also, they may help to overcome host defences and confer with protection against antimicrobial compounds. Therefore, future research is essential to understand how environmental and host-related factors as well as conventional treatments affect bacterial stress responses. This can prevent the release of vesicle-associated toxins and inflammatory components such as lipopolysaccharide.

\section{CONCLUDING REMARKS}

In this thesis, we have shown that MVs are released by both host cells and the common respiratory pathogens $H$. influenzae, M. catarrhalis, S. pneumoniae, and $P$. aeruginosa in the context of infection and demonstrate that bacterial vesicles are of physiological importance as they can induce and modulate inflammatory responses and may as well affect bacterial internalization. Finally, we have demonstrated how (non-)conventional therapeutics may affect inflammatory responses by modulating the release of and response to these pro-inflammatory MVs. Overall, these results provide a solid ground for innovative and exciting research in the field of bacterial and host cell MVs especially in the context of (chronic) respiratory diseases. 


\section{REFERENCES}

1. Ren D, Nelson KL, Uchakin PN, Smith AL, Gu X-X, Daines DA, et al. Characterization of extended co-culture of non-typeable Haemophilus influenzae with primary human respiratory tissues. Exp Biol Med. 2012;237:540-7. doi:10.1258/ebm.2012.011377

2. Sharpe SW, Kuehn MJ, Mason KM. Elicitation of epithelial cell-derived immune effectors by outer membrane vesicles of nontypeable haemophilus influenzae. Infect Immun. 2011;79: 4361-4369. doi:10.1128/ IAl.05332-11

3. Roier S, Zingl FG, Cakar F, Durakovic S, Kohl P, Eichmann TO, et al. A novel mechanism for the biogenesis of outer membrane vesicles in Gram-negative bacteria. Nat Commun. 2016;7: 10515. doi:10.1038/ ncomms10515

4. Olaya-Abril A, Prados-Rosales R, McConnell MJ, Martín-Peña R, González-Reyes JA, Jiménez-Munguía I, et al. Characterization of protective extracellular membrane-derived vesicles produced by Streptococcus pneumoniae. J Proteomics. 2014;106: 46-60. doi:10.1016/j.jprot.2014.04.023

5. Ellis TN, Leiman SA, Kuehn MJ. Naturally Produced Outer Membrane Vesicles from Pseudomonas aeruginosa Elicit a Potent Innate Immune Response via Combined Sensing of Both Lipopolysaccharide and Protein Components. Infect Immun. 2010;78: 3822-3831. doi:10.1128/IAI.00433-10

6. MacDonald IA, Kuehn MJ. Stress-induced outer membrane vesicle production by Pseudomonas aeruginosa. J Bacteriol. 2013;195:2971-81. doi:10.1128/JB.02267-12

7. Schaar V, de Vries SPW, Perez Vidakovics MLA, Bootsma HJ, Larsson L, Hermans PWM, et al. Multicomponent Moraxella catarrhalis outer membrane vesicles induce an inflammatory response and are internalized by human epithelial cells. Cell Microbiol. 2011;13: 432-449. doi:10.1111/j.1462-5822.2010.01546.x

8. Tauro BJ, Greening DW, Mathias RA, Mathias RA, Ji H, Mathivanan S, Scott AM, Simpson RJ, et al. Comparison of ultracentrifugation, density gradient separation, and immunoaffinity capture methods for isolating human colon cancer cell line LIM1863-derived exosomes. Methods. 2012;56: 293-304. doi:10.1016/j. ymeth.2012.01.002

9. Clotilde Thery, Aled Clayton, Sebastian Amigorena GR. Isolation and Characterization of Exosomes from Cell Culture Supernatants. Curr Protoc Cell Biol. 2006;Chapter 3: 1-29. doi:10.1002/0471143030. cb0322s30

10. Lobb RJ, Becker M, Wen SW, Wong CSF, Wiegmans AP, Leimgruber A, et al. Optimized exosome isolation protocol for cell culture supernatant and human plasma. J Extracell Vesicles. 2015;1: 1-11. doi:10.3402/ jev.v4.27031

11. Van Deun J, Mestdagh P, Sormunen R, Cocquyt V, Vermaelen K, Vandesompele J, et al. The impact of disparate isolation methods for extracellular vesicles on downstream RNA profiling. J Extracell vesicles. 2014;1: 1-14. doi:10.3402/jev.v3.24858

12. Böing AN, van der Pol E, Grootemaat AE, Coumans FAW, Sturk A, Nieuwland R. Single-step isolation of extracellular vesicles by size-exclusion chromatography. J Extracell Vesicles. 2014; 3:23430. doi:10.3402/ jev.v3.23430.

13. Nordin JZ, Lee Y, Vader P, Mager I, Johansson HJ, Heusermann W, et al. Ultrafiltration with size-exclusion liquid chromatography for high yield isolation of extracellular vesicles preserving intact biophysical and functional properties. Nanomedicine. 2015;11: 879-883. doi:10.1016/j.nano.2015.01.003

14. Paolini L, Zendrini A, Noto G Di, Busatto S, Lottini E, Radeghieri A, et al. Residual matrix from different separation techniques impacts exosome biological activity. Sci Rep. 2016;6: 23550. doi:10.1038/srep23550

15. Hoen ENMN-'t, van der Vlist EJ, Aalberts M, Mertens HCH, Bosch BJ, Bartelink W, et al. Quantitative and qualitative flow cytometric analysis of nanosized cell-derived membrane vesicles. Nanomedicine. 2012;8: 712-720. doi:10.1016/j.nano.2011.09.006 
16. Coumans FAW, Pol E van der, Böing AN, Hajji N, Sturk G, Leeuwen TG van, et al. Reproducible extracellular vesicle size and concentration determination with tunable resistive pulse sensing. J Extracell Vesicles. 2014:3:25922. doi:10.3402/jev.v3.25922

17. van der Pol E, Coumans F a W, Grootemaat a. E, Gardiner C, Sargent IL, Harrison P, et al. Particle size distribution of exosomes and microvesicles determined by transmission electron microscopy, flow cytometry, nanoparticle tracking analysis, and resistive pulse sensing. J Thromb Haemost. 2014;12: 1182-1192. doi:10.1111/jth.12602

18. Ostrowski M, Carmo NB, Krumeich S, Fanget I, Raposo G, Savina A, et al. Rab27a and Rab27b control different steps of the exosome secretion pathway. Nat Cell Biol. 2010;12: 13-19. doi:10.1038/ncb2000

19. Hong CS, Muller L, Boyiadzis M, Whiteside TL. Isolation and characterization of CD34+ blast-derived exosomes in acute myeloid leukemia. PLoS One. 2014;9: 2-8. doi:10.1371/journal.pone.0103310

20. Ghosh A, Davey M, Chute IC, Griffiths SG, Lewis S, Chacko S, et al. Rapid Isolation of Extracellular Vesicles from Cell Culture and Biological Fluids Using a Synthetic Peptide with Specific Affinity for Heat Shock Proteins. PLoS One. 2014; 9: e110443. doi:10.1371/journal.pone.0110443

21. Ihalin R, Karched M, Eneslätt K, Asikainen S. Characterization of immunoaffinity purified peptidoglycan-associated lipoprotein of Actinobacillus actinomycetemcomitans. J Chromatogr B. 2006;831: 116-125. doi:10.1016/j.jchromb.2005.11.052

22. Klimentová J, Stulík J. Methods of isolation and purification of outer membrane vesicles from Gram-negative bacteria. Microbiol Res. 2015;170: 1-9. doi:10.1016/j.micres.2014.09.006

23. Schwechheimer C, Kulp A, Kuehn MJ, Berleman J, Auer M, Deatherage B, et al. Modulation of bacterial outer membrane vesicle production by envelope structure and content. BMC Microbiol. 2014;14: 324. doi:10.1186/s12866-014-0324-1

24. Sharpe SW, Kuehn MJ, Mason KM. Elicitation of epithelial cell-derived immune effectors by outer membrane vesicles of nontypeable Haemophilus influenzae. Infect Immun. 2011;79:4361-9. doi:10.1128/ |Al.05332-11

25. Cecil JD, O'Brien-Simpson NM, Lenzo JC, Holden JA, Chen Y-Y, Singleton W, et al. Differential Responses of Pattern Recognition Receptors to Outer Membrane Vesicles of Three Periodontal Pathogens. PLoS One; 2016;11(4):e0151967. doi:10.1371/journal.pone.0151967

26. Lacroix R, Robert S, Poncelet P, Dignat-George F. Overcoming limitations of microprticles measurement by flow cytometry. Semin Thromb Hemost. 2010;36: 807-818. doi:10.1055/s-0030-1267034.

27. Pospichalova V, Svoboda J, Dave Z, Kotrbova A, Kaiser K, Klemova D, et al. Simplified protocol for flow cytometry analysis of fluorescently labeled exosomes and microvesicles using dedicated flow cytometer. J Extracell Vesicles. 2015;4: 25530. doi:10.3402/jev.v4.25530

28. Kaufmann SHE, Dorhoi A. Molecular Determinants in Phagocyte-Bacteria Interactions. Immunity. 2016;44: 476-491. doi:10.1016/j.immuni.2016.02.014

29. Ribet D, Cossart P. How bacterial pathogens colonize their hosts and invade deeper tissues. Microbes Infect. 2015;17: 173-183. doi:10.1016/j.micinf.2015.01.004

30. Beninson LA, Fleshner M. Exosomes: An emerging factor in stress-induced immunomodulation. Semin Immunol. 2014;26: 394-401. doi:10.1016/j.smim.2013.12.001

31. Eldh M, Ekstrom K, Valadi H, Sjöstrand M, Olsson B, Jernos M, et al. Exosomes Communicate Protective Messages during Oxidative Stress; Possible Role of Exosomal Shuttle RNA. PLoS One. 2010;5: 1-8. doi:10.1371/journal.pone.0015353

32. Carrière J, Bretin A, Darfeuille-Michaud A, Barnich N, Thi H, Nguyen T. Exosomes Released from Cells Infected with Crohn's Disease-associated Adherent-Invasive Escherichia coli Activate Host Innate Immune Responses and Enhance Bacterial Intracellular Replication. Inflamm Bowel Dis. 2016; 3:516-28. doi:10.1097/MIB.0000000000000635

33. Soni S, Wilson MR, O'Dea KP, Yoshida M, Katbeh U, Woods SJ, et al. Alveolar macrophage-derived microvesicles mediate acute lung injury. Thorax. 2016;71:1020-1029. doi:10.1136/thoraxjnl-2015-208032 
34. Eltom S, Dale N, Raemdonck KR, Stevenson CS, Snelgrove RJ, Sacitharan PK, et al. Respiratory infections cause the release of extracellular vesicles: implications in exacerbation of asthma/COPD. PLoS One. 2014; 9: e101087. doi:10.1371/journal.pone.0101087

35. Athman JJ, Wang Y, McDonald DJ, Boom WH, Harding C V., Wearsch PA. Bacterial Membrane Vesicles Mediate the Release of Mycobacterium tuberculosis Lipoglycans and Lipoproteins from Infected Macrophages. J Immunol. 2015;195: 1044-1053. doi:10.4049/jimmunol.1402894

36. Bonnington KE, Kuehn MJ. Biochimica et Biophysica Acta Protein selection and export via outer membrane vesicles. Mol Cell Res. 2014;1843: 1612-1619. doi:10.1016/j.bbamcr.2013.12.011

37. Schwechheimer C, Kuehn MJ. Outer-membrane vesicles from Gram-negative bacteria: biogenesis and functions. Nat Rev Microbiol. 2015;13: 605-619. doi:10.1038/nrmicro3525

38. King PT, Sharma R. The lung immune response to nontypeable haemophilus influenzae (lung immunity to nthi). J Immunol Res. 2015;2015. doi:10.1155/2015/706376

39. Schaar V, Uddbä I, Nordströ T, Riesbeck K. Group A streptococci are protected from amoxicillin-mediated killing by vesicles containing b-lactamase derived from Haemophilus influenzae. J Antimicrob Chemother. 2014:69:117-20. doi:10.1093/jac/dkt307

40. Fahmi H, Chaby R. Desensitization of Macrophages to Endotoxin Effects Is Not Correlated with a Down-Regulation of Lipopolysaccharide-Binding Sites. Cell Immunol. 1993;150: 219-229. doi:10.1006/ cimm.1993.1191

41. Sato S, Nomura F, Kawai T, Takeuchi O, Muhlradt PF, Takeda K, et al. Synergy and cross-tolerance between toll-like receptor (TLR) 2- and TLR4-mediated signaling pathways. J Immunol. 2000;165: 7096-7101. doi:10.4049/jimmunol.165.12.7096

42. Griffin GK, Newton G, Tarrio ML, Bu D -x., Maganto-Garcia E, Azcutia V, et al. IL-17 and TNF- Sustain Neutrophil Recruitment during Inflammation through Synergistic Effects on Endothelial Activation. J Immunol. 2012;188: 6287-6299. doi:10.4049/jimmunol.1200385

43. Riesbeck K, Nordstrom T. Structure and immunological action of the human pathogen Moraxella catarrhalis IgD-binding protein. Crit Rev Immunol. 2006;26: 353-76. doi:10.1615/CritRevImmunol.v26.i4.40

44. Choi D-S, Kim D-K, Choi SJ, Lee J, Choi J-P, Rho S, et al. Proteomic analysis of outer membrane vesicles derived from Pseudomonas aeruginosa. Proteomics. 2011;11: 3424-9. doi:10.1002/pmic.201000212

45. MacKenzie A, Wilson HL, Kiss-Toth E, Dower SK, North RA, Surprenant A. Rapid secretion of interleukin-1beta by microvesicle shedding. Immunity. 2001;15: 825-35. doi:10.1016/S1074-7613(01)00229-1

46. Bhatnagar S, Shinagawa K, Castellino FJ, Schorey JS. Exosomes released from macrophages infected with intracellular pathogens stimulate a proinflammatory response in vitro and in vivo. Blood. 2007;110: 3234-3244. doi:10.1182/blood-2007-03-079152

47. Bhatnagar S, Schorey JS. Exosomes released from infected macrophages contain Mycobacterium avium glycopeptidolipids and are proinflammatory. J Biol Chem. 2007;282:25779-89. doi: 10.1074/jbc. M702277200

48. Ramachandra L, QuY, Wang Y, Lewis CJ, Cobb BA, Takatsu K, Boom WH, et al. Mycobacterium tuberculosis synergizes with ATP to induce release of microvesicles and exosomes containing major histocompatibility complex class II molecules capable of antigen presentation. Infec Immun. 2010;78(12):5116-5125. doi: 10.1128/IAI.01089-09

49. Qu Y, Ramachandra L, Mohr S, Franchi L, Harding C V, Nunez G, et al. P2X7 receptor-stimulated secretion of MHC class II-containing exosomes requires the ASC/NLRP3 inflammasome but is independent of caspase-1. J Immunol. 2009;182: 5052-5062. doi:10.4049/jimmunol.0802968

50. Giri PK, Schorey JS. Exosomes derived from M. Bovis BCG infected macrophages activate antigen-specific CD4+ and CD8+ T cells in vitro and in vivo. PloS One. 2008;3(6):e2461. doi:10.1371/journal. pone.0002461

51. Buschow SI, Nolte-'t Hoen ENM, van Niel G, Pols MS, ten Broeke T, Lauwen M, et al. MHC II in Dendritic Cells is Targeted to Lysosomes or T Cell-Induced Exosomes Via Distinct Multivesicular Body Pathways. Traffic. 2009;10: 1528-1542. doi:10.1111/j.1600-0854.2009.00963.x 
52. Sethi S, Murphy TF. Infection in the pathogenesis and course of chronic obstructive pulmonary disease. N Engl J Med. 2008;359: 2355-2365. doi:10.1056/NEJMra0800353

53. Dickson RP, Martinez FJ, Huffnagle GB. The role of the microbiome in exacerbations of chronic lung diseases. Lancet. 2014;384: 691-702. doi:10.1016/S0140-6736(14)61136-3

54. Marin A, Garcia-Aymerich J, Sauleda J, Belda J, Millares L, García-Núñez M, et al. Effect of bronchial colonisation on airway and systemic inflammation in stable COPD. COPD. 2012;9: 121-30. doi:10.3109 /15412555.2011.636407

55. Desai H, Eschberger K, Wrona C, Grove L, Agrawal A, Grant B, et al. Bacterial colonization increases daily symptoms in patients with chronic obstructive pulmonary disease. Ann Am Thorac Soc. 2014;11: 303-9. doi:10.1513/AnnalsATS.201310-3500C

56. King PT, MacDonald M, Bardin PG. Bacteria in COPD; their potential role and treatment. Transl Respir Med. 2013;1: 13. doi:10.1186/2213-0802-1-13

57. Laue J, Reierth E, Melbye H. When should acute exacerbations of COPD be treated with systemic corticosteroids and antibiotics in primary care: a systematic review of current COPD guidelines. npj Prim Care Respir Med. 2015;25: 15002. doi:10.1038/npjpcrm.2015.2

58. Ram FS, Rodriguez-Roisin R, Granados-Navarrete a, Garcia-Aymerich J, Barnes NC. Antibiotics for exacerbations of chronic obstructive pulmonary disease. Cochrane database Syst Rev. 2016; 2-4. doi:10.1002/14651858.CD004403.pub2.Copyright

59. Walters JA, Gibson PG, Wood-Baker R, Hannay M, Walters EH. Systemic corticosteroids for acute exacerbations of chronic obstructive pulmonary disease. Cochrane database Syst Rev. 2009; CD001288. doi:10.1002/14651858.CD001288.pub3

60. Earl CS, Keong TW, An S, Murdoch S, McCarthy Y, Garmendia J, et al. Haemophilus influenzae responds to glucocorticoids used in asthma therapy by modulation of biofilm formation and antibiotic resistance. EMBO Mol Med. 2015;7: 1018-33. doi:10.15252/emmm.201505088

61. Freestone P. Communication between Bacteria and Their Hosts. Scientifica. 2013;2013: 361073. doi:10.1155/2013/361073

62. Reidl J, Monsó E. Glucocorticoids and antibiotics, how do they get together? EMBO Mol Med. 2015;7(8):992-3. doi:10.15252/emmm.201505336

63. Banjanac M, Munić Kos V, Nujić K, Vrančić M, Belamarić D, Crnković S, et al. Anti-inflammatory mechanism of action of azithromycin in LPS-stimulated J774A.1 cells. Pharmacol Res. 2012;66: 357-362. doi:10.1016/j.phrs.2012.06.011

64. Legssyer R, Huaux F, Lebacq J, Delos M, Marbaix E, Lebecque P, et al. Azithromycin reduces spontaneous and induced inflammation in $\Delta F 508$ cystic fibrosis mice. Respir Res. 2006;7: 134. doi:10.1186/14659921-7-134

65. Barbier M, Agustí A, Albertí S. Fluticasone propionate reduces bacterial airway epithelial invasion. Eur Respir J. 2008:32: 1283-8. doi:10.1183/09031936.00020608

66. Wagner C, Goldmann T, Rohmann K, Rupp J, Marwitz S, Loria JR detto, et al. Budesonide Inhibits Intracellular Infection with Non-Typeable Haemophilus influenzae despite Its Anti-Inflammatory Effects in Respiratory Cells and Human Lung Tissue: A Role for p38 MAP Kinase. Respiration. 2015; 90(5):416-25. doi:10.1159/000439226

67. Patterson CM, Morrison RL, D'Souza A, Teng XS, Happel KI. Inhaled fluticasone propionate impairs pulmonary clearance of Klebsiella pneumoniae in mice. Respir Res. 2012;13: 40. doi:10.1186/1465-9921-13-40

68. Marsland BJ, Gollwitzer ES. Host-microorganism interactions in lung diseases. Nat Rev Immunol. 2014;14 827-35. doi:10.1038/nri3769

69. Burge PS, Calverley PM, Jones PW, Spencer S, Anderson J a, Maslen TK. Randomised, double blind, placebo controlled study of fluticasone propionate in patients with moderate to severe chronic obstructive pulmonary disease: the ISOLDE trial. BMJ. 2000;320: 1297-303. doi:10.1136/bmj.320.7245.1297

70. Poole PJ. Role of mucolytics in the management of COPD. Int J Chron Obstruct Pulmon Dis. 2006;1: $123-8$. 
71. Brusselle GG, Joos GF, Bracke KR. New insights into the immunology of chronic obstructive pulmonary disease. Lancet. 2011;378: 1015-1026. doi:10.1016/S0140-6736(11)60988-4

72. Donath E, Chaudhry A, Hernandez-Aya LF, Lit L. A meta-analysis on the prophylactic use of macrolide antibiotics for the prevention of disease exacerbations in patients with Chronic Obstructive Pulmonary Disease. Respir Med. 2013;107: 1385-1392. doi:10.1016/j.rmed.2013.05.004

73. Kim K, Dias S, Cj C. Long-acting inhaled therapy (beta-agonists, anticholinergics and steroids) for COPD: a network meta-analysis. Cochrane database Syst Rev. 2014;(3)CD010844. doi: 10.1002/14651858. CD010844.pub2.

74. Beasley V, Joshi P V. Singanayagam A, Molyneaux PL, Johnston SL, Mallia P. Lung microbiology and exacerbations in COPD. Int J Chron Obstruct Pulmon Dis.2012;7: 555-69. doi:10.2147/COPD.S28286

75. Morris A, Beck JM, Schloss PD, Campbell TB, Crothers K, Curtis JL, et al. Comparison of the respiratory microbiome in healthy nonsmokers and smokers. Am J Respir Crit Care Med. 2013;187: 1067-1075. doi:10.1164/rccm.201210-19130C

76. Hilty M, Burke C, Pedro H, Cardenas P, Bush A, Bossley C, et al. Disordered microbial communities in asthmatic airways. PLoS One. 2010;5: e8578. doi:10.1371/journal.pone.0008578

77. Charlson ES, Chen J, Custers-Allen R, Bittinger K, Li H, Sinha R, et al. Disordered microbial communities in the upper respiratory tract of cigarette smokers. PLoS One. 2010;5. doi:10.1371/journal.pone.0015216

78. Erb-Downward JR, Thompson DL, Han MK, Freeman CM, MCCloskey L, Schmidt LA, et al. Analysis of the Lung Microbiome in the 'Healthy' Smoker and in COPD. PLoS One. 2011;6: e16384. doi:10.1371/ journal.pone.0016384

79. Sze M, Hogg JC, Sin DD. Bacterial microbiome of lungs in COPD. Int J COPD. 2014;9: 229-238. doi:10.2147/COPD.S38932

80. Pragman AA, Kim HB, Reilly CS, Wendt C, Isaacson RE, Gold P, et al. The Lung Microbiome in Moderate and Severe Chronic Obstructive Pulmonary Disease. PLoS One. 2012;7: e47305. doi:10.1371/journal. pone.0047305

81. Matkovic Z, Miravitlles M. Chronic bronchial infection in COPD. Is there an infective phenotype? Respir Med. 2013;107: 10-22. doi:10.1016/j.rmed.2012.10.024

82. Kim V, Criner GJ. Chronic Bronchitis and Chronic Obstructive Pulmonary Disease. Am J Respir Crit Care Med. American Thoracic Society; 2013;187: 228-237. doi:10.1164/rccm.201210-1843Cl

83. Vestbo J, Prescott E, Lange P. Association of chronic mucus hypersecretion with FEV1 decline and chronic obstructive pulmonary disease morbidity. Am J Respir Crit Care Med. 1996;153: 1530-5. doi:10.1164/ ajrccm.153.5.8630597

84. Kanner RE, Anthonisen NR, Connett JE. Lower Respiratory Illnesses Promote FEV 1 Decline in Current Smokers But Not Ex-Smokers with Mild Chronic Obstructive Pulmonary Disease. Am J Respir Crit Care Med. 2001;164: 358-364. doi:10.1164/ajrccm.164.3.2010017

85. Donaldson GC, Seemungal TAR, Bhowmik A, Wedzicha JA. Relationship between exacerbation frequency and lung function decline in chronic obstructive pulmonary disease. Thorax. 2002;57: 847-52. doi:10.1136/THORAX.57.10.847

86. Cazzola M, Calzetta L, Page C, Jardim J, Chuchalin AG, Rogliani P, et al. Influence of N-acetylcysteine on chronic bronchitis or COPD exacerbations: a meta-analysis. Eur Respir Rev. 2015;24: 451-61. doi:10.1183/16000617.00002215

87. Poole P, Chong J, Cates CJ. Mucolytic agents versus placebo for chronic bronchitis or chronic obstructive pulmonary disease. Cochrane database of Systematic Reviews. 2015;7:CD001287. doi:10.1002/14651858. CD001287.pub5

88. Parry MF, Neu HC. Effect of N-acetylcysteine on antibiotic activity and bacterial growth in vitro. J Clin Microbiol. 1977; 5: 58-61.

89. Hafez MM, Aboulwafa MM, Yassien MA, Hassouna NA. Activity of some mucolytics against bacterial adherence to mammalian cells. Appl Biochem Biotechnol. 2009;158: 97-112. doi:10.1007/s12010-008-8312-2 
90. Olofsson A-C, Hermansson M, Elwing H. N-acetyl-L-cysteine affects growth, extracellular polysaccharide production, and bacterial biofilm formation on solid surfaces. Appl Environ Microbiol. 2003;69: 4814-22.

91. Riise GC, Qvarfordt I, Larsson S, Eliasson V, Andersson BA. Inhibitory effect of N-acetylcysteine on adherence of Streptococcus pneumoniae and Haemophilus influenzae to human oropharyngeal epithelial cells in vitro. Respiration. 2000;67: 552-8. doi:67473

92. Huynh HQ, Couper RTL, Tran CD, Moore L, Kelso R, Butler RN. N-acetylcysteine, a novel treatment for Helicobacter pylori infection. Dig Dis Sci. 2004;49(11-12):1853-61. doi:10.1002/lsm.20770

93. Zheng $\mathrm{CH}$, Ahmed K, Rikitomi N, Martinez G, Nagatake T. The effects of S-carboxymethylcysteine and $\mathrm{N}$-acetylcysteine on the adherence of Moraxella catarrhalis to human pharyngeal epithelial cells. Microbiol Immunol. 1999;43: 107-13.

94. van de Waterbeemd B, Zomer G, van den IJssel J, van Keulen L, Eppink MH, van der Ley P, et al. Cysteine Depletion Causes Oxidative Stress and Triggers Outer Membrane Vesicle Release by Neisseria meningitidis; Implications for Vaccine Development. PLoS One. 2013;8: e54314. doi:10.1371/journal. pone.0054314

95. Singh PP, LeMaire C, Tan JC, Zeng E, Schorey JS. Exosomes released from M. tuberculosis infected cells can suppress IFN-gamma mediated activation of naive macrophages. PLoS One. 2011; 6(4):e18564. doi:v10.1371/journal.pone.0018564

96. Athman JJ, Wang Y, McDonald DJ, Boom WH, Harding C V, Wearsch PA. Bacterial Membrane Vesicles Mediate the Release of Mycobacterium tuberculosis Lipoglycans and Lipoproteins from Infected Macrophages. J Immunol. 2015;195: 1044-53. doi:10.4049/jimmunol.1402894

97. Macdonald IA, Kuehn MJ. Stress-induced outer membrane vesicle production by Pseudomonas aeruginosa. J Bacteriol. 2013;195: 2971-81. doi:10.1128/JB.02267-12

98. Manning AJ, Kuehn MJMJ, McDermott P, Walker R, White D, Kulp A, et al. Contribution of bacterial outer membrane vesicles to innate bacterial defense. BMC Microbiol. 2011;11: 258. doi:10.1186/1471-2180$11-258$

99. Kadurugamuwa JL, Beveridge TJ. Natural release of virulence factors in membrane vesicles by Pseudomonas aeruginosa and the effect of aminoglycoside antibiotics on their release. J Antimicrob Chemother. 1997;40: 615-21.

100. Kwon DH, Lu CD. Polyamines induce resistance to cationic peptide, aminoglycoside, and quinolone antibiotics in Pseudomonas aeruginosa PAO1. Antimicrob Agents Chemother. 2006;50: 1615-1622. doi:10.1128/AAC.50.5.1615-1622.2006

101. Brogden KA. Antimicrobial peptides: pore formers or metabolic inhibitors in bacteria? Nat Rev Microbiol. 2005;3: 238-50. doi:10.1038/nrmicro1098

102. Fernández L, Gooderham WJ, Bains M, McPhee JB, Wiegand I, Hancock REW. Adaptive resistance to the 'last hope' antibiotics polymyxin B and colistin in Pseudomonas aeruginosa is mediated by the novel two-component regulatory system ParR-ParS. Antimicrob Agents Chemother. 2010;54: 3372-3382. doi:10.1128/AAC.00242-10 




\section{Addendum}

Summary

Nederlandse samenvatting

Valorisation

List of abbreviations

Dankwoord

List of publications

Vita 



\section{SUMMARY}

The release of membrane vesicles is a process that is conserved amongst cells of all branches of life and the physiological functions and release are highly dynamic and context dependent. In this thesis, we presented studies that addressed the release of host cell and bacterial membrane vesicles in the context of infection with the common respiratory pathogens non-typeable Haemophilus influenzae, Moraxella catarrhalis, Streptococcus pneumoniae, and Pseudomonas aeruginosa.

In the general introduction (chapter 1 ) the context for this thesis was outlined by describing bacterial infections of the airways by common respiratory pathogens, innate immunity to infection, and intercellular communication by means of membrane vesicles during infection and inflammation.

In chapter 2, we reviewed how vesicle shedding is affected by a plethora of host-associated factors. These factors include physiological barriers, antimicrobial peptides released by host tissues, bacterial antimicrobial peptides found within host niches, and antibiotics. Another aspect that is covered in this review is how these vesicles confer bacteria with a means to cope with challenges that bacteria are faced with during invasion and occupation of host niches.

It is important to study the release of membrane vesicles in a physiological situation. This, however, remains challenging as most currently available techniques for characterization and isolation have specific shortcomings. One such shortcoming is that it is difficult to determine the release kinetics of specific membrane vesicle subpopulations in mixed vesicle populations (e.g. composed of host and bacterial vesicles). In chapter 3 an assay is presented which was developed by us to overcome this problem and which allows the semi-quantitative analysis of specific membrane vesicle subpopulations within such heterogeneous vesicle populations.

In chapter 4 the release and functional activity of bacterial and host cell membrane vesicles released during macrophage infection with non-typeable $H$. influenzae, $M$. catarrhalis, S. pneumoniae, and $P$. aeruginosa were determined. This study revealed that during infection both host cells and bacteria release membrane vesicles. Moreover, we demonstrated that host cell-derived vesicles do not induce a significant pro-inflammatory cytokine release whereas bacterial membrane vesicles do. Conversely, these membrane vesicles were also found to result in host cell desensitisation to secondary immunogenic stimuli and to lead to an increased number of adherent and intracellular bacteria. This implies that bacterial membrane vesicles may on one hand aid in the immunity to infection and on the other contribute to bacterial survival.

The release of membrane vesicles can be triggered by various factors, including therapeutic agents. A sudden release of potent immuno-stimulatory membrane vesicles may form a potential hazard. In chapter 5 the release of bacterial membrane vesicle in response to conventional therapeutics that are used to treat airway inflammation (the glucorticosteroids fluticasone propionate and budesonide and the macrolide antibiotic azithromycin), 
was studied. Again, this was assessed in the context of infection to account for direct and indirect effects of these components (by affecting host cell behaviour) on bacterial membrane vesicle shedding. We determined that the release of membrane vesicles by none of the bacteria was affected by treatment. Moreover, we found that these therapeutics resulted in a significantly decreased pro-inflammatory response to bacterial vesicles.

As conventional therapeutics fall short in the treatment of patients with chronic obstructive pulmonary disease, there is a great need for novel effective treatment approaches that are free of side effects and can be used over long periods of time. N-acetyl-L-cysteine (NAC) is a frequently used mucolyticum that is administered orally. Alternatively, it can also be applied by nebulization, but it is unknown how this affects bacterial behaviour. In chapter 6 we established the effect of NAC on the bacterial behaviour. Results showed that NAC treatment not only significantly inhibited the growth of all bacteria, it also strongly induced the release of bacterial membrane vesicles. Alternatively, we also revealed that NAC markedly reduced the pro-inflammatory response to membrane vesicles. Therefore, it seems that this initial discharge of pro-inflammatory vesicles is of little consequence and that the overall treatment outcome is most likely positive. Future studies are required to further establish the effects of NAC on airway infection.

In the final chapter of this thesis, chapter 7 we discussed the major findings and make suggestions for future research. We started this discussion with the technical challenges that come with studying vesicle release in more complex models based on multiple cell types. Hereafter we discussed the physiological activity of host cell-derived and bacterial membrane vesicles. Finally, we discussed how the release of membrane vesicles is affected by external factors with a focus on the therapeutics tested in this studies.

This thesis provides with background on the release of bacterial membrane vesicle release in the context of a host environment. In our studies we show that bacterial membrane vesicles have immuno-stimulatory and modulatory properties. Moreover it was shown how therapeutics may affect inflammatory responses by modulating the release of and the response to pro-inflammatory membrane vesicles. Overall, this thesis provides with an improved insight on the release and functionality of the membrane vesicle release during infection. The gained insights and methodology can guide direction and provide with a means to follow up on this. 


\section{SAMENVATTING}

De vrijstelling van membraan blaasjes (vesicles) door cellen is een sterk geconserveerd proces en vindt plaats in alle domeinen van het leven waarbij zowel de functionaliteit als de uitscheiding uiterst dynamisch en context afhankelijk zijn. De verschillende studies opgenomen in dit proefschrift richtten zich op de uitscheiding van membraan vesicles door gastheercellen en bacteriën, in de context van infectie met de veelvoorkomende luchtwegpathogenen non-typeable Haemophilus influenzae, Moraxella catarrhalis, Streptococcus pneumoniae en Pseudomonas aeruginosa.

In de algemene introductie (hoofdstuk 1) wordt de achtergrond voor dit proefschrift gegeven door in te gaan op bacteriële infecties van de luchtwegen, de aangeboren immuunreactie op infecties en de intercellulaire communicatie door middel van membraan vesicles tijdens infecties en ontstekingen.

In hoofdstuk 2 (het overzichtsartikel) hebben we uitgebreid beschreven hoe de uitscheiding van membraan vesicles beïnvloedt kan worden door een scala aan verschillende gastheer-geassocieerde factoren. Voorbeelden van deze factoren zijn fysiologische barrières, antimicrobiële peptides die worden uitgescheiden door verschillende weefsels in het lichaam, bacteriële antimicrobiële peptides die kunnen worden aangetroffen op specifieke locaties in het lichaam en bepaalde antibiotica. Een ander aspect dat in dit overzichtsartikel wordt besproken is hoe membraan vesicles bacteriën kunnen assisteren bij het omgaan met bedreigingen die ze tegenkomen tijdens de invasie en kolonisatie van gastheer-geassocieerde niches.

Het is belangrijk om membraan vesicles te bestuderen in een fysiologische situatie. Dit blijkt echter complex te zijn omdat het merendeel van de beschikbare conventionele technieken voor het karakteriseren en isoleren van membraan vesicles bepaalde tekortkomingen hebben. Een van deze beperkingen is dat het moeilijk is om het aandeel van een specifieke membraan vesicle populatie in een samengestelde populatie te bepalen (bijvoorbeeld een populatie die is samengesteld uit gastheer-afkomstige en bacteriële vesicles). In hoofdstuk 3 presenteren we een door ons ontwikkelde methode. Deze methode stelde ons in staat dit probleem op te lossen door gebruik te maken van met specifieke antilichamen gecoate "beads", waarmee het mogelijk bleek om zowel de membraan vesicles afkomstig van de bacteriën als de gastheer vesicles semi-kwantitatief te bepalen.

In hoofdstuk 4 hebben we de vrijstelling en functionaliteit van bacteriële en van de gastheercel afkomstige membraan vesicles bepaald tijdens de infectie van macrofagen met de eerder genoemde luchtwegpathogenen. In deze studie konden we aantonen dat de uitscheiding van membraan vesicles tijdens infectie plaats vindt door zowel de gastheercellen als de bacteriën. Voorts hebben we hier aangetoond dat blootstelling van macrofagen aan vesicles afkomstig van gastheercellen niet zorgen voor de uitscheiding van ontstekingsbevorderende cytokinen terwijl dit wel het geval was na blootstelling aan bacteriële vesicles. Anderzijds konden we ook aantonen dat deze bacteriële vesicles kunnen zorgen voor een verminderde ontstekingsreactie op een daaropvolgende immunogene prikkel. Ook zagen we dat de blootstelling aan bacteriële vesicles zorgde voor 
een verhoogde bacteriële adhesie en meer intracellulaire bacteriën. Dit suggereert dat de bacteriële membraan vesicles de immuunreactie op een infectie kunnen bevorderen maar dat deze ook kunnen bijdragen tot infectie.

De uitscheiding van membraan vesicles kan worden veroorzaakt door verscheidene factoren inclusief therapeutische middelen. Een onverhoedse vrijstelling van sterk ontstekingsbevorderende membraan vesicles als resultaat van een bepaalde therapeutische interventie zou potentieel gevaarlijk kunnen zijn. In hoofdstuk 5 wordt de uitscheiding van bacteriële membraan vesicles na blootstelling aan conventionele therapeutische middelen (de glucocorticosterö̈den fluticasone propionate en budesonide en het macrolide antibioticum azithromycine) nader bepaald. Wederom werd dit uitgezocht in de context van een infectie om zo de directe als ook indirecte effecten (door de beïnvloeding van het gedrag van de gastheercellen) van deze componenten op de vrijstelling van bacteriele membraan vesicles mee te kunnen nemen. We konden vaststellen dat geen van de therapeutische middelen de vrijstelling van membraan vesicles door de bacteriën beïnvloedde. Daarnaast vonden we dat deze middelen leidden tot een aanzienlijk verminderde ontstekingsreactie na blootstelling aan bacteriële vesicles.

Omdat conventionele therapeutische middelen tekortschieten in de behandeling van patiënten met chronische obstructieve luchtwegaandoeningen, zoals COPD en astma, is er een grote behoefte aan nieuwe effectieve behandelingsmethoden die vrij zijn van bijwerkingen en die gedurende langere tijd gebruikt kunnen worden. $\mathrm{N}$-acetyl-L-cysteine (NAC) is een veelvuldig gebruikt slijmoplossend middel dat over het algemeen oraal wordt toegediend. Optioneel kan het ook worden toegediend door middel van verneveling. Het is echter niet bekend hoe dit middel het gedrag van bacteriën beïnvloedt. In hoofdstuk 6 hebben we uitgezocht hoe een blootstelling aan NAC het gedrag van bacteriën beïnvloedt. Onze resultaten lieten zien dat blootstelling aan NAC niet alleen leidde tot een aanzienlijke remming van de bacteriële groei, maar daarnaast ook leidde tot een sterk verhoogde uitscheiding van bacteriële membraan vesicles. Echter, we konden ook een sterke verlaging van door membraan vesicles geïnduceerde ontstekingsreactie na blootstelling aan NAC aantonen. Derhalve lijkt het ons waarschijnlijk dat de aanvankelijke vrijstelling van ontstekingsbevorderende vesicles minimale consequenties heeft en dat de uiteindelijke uitkomst van de behandeling vermoedelijk positief is. Vervolgstudies zijn echter nodig om de effecten van NAC op luchtweginfecties nader te bepalen.

In het laatste hoofdstuk van dit proefschrift (hoofdstuk 7) zijn de belangrijkste bevindingen besproken en zijn er suggesties gedaan voor toekomstig onderzoek. We zijn in deze discussie begonnen met de technische uitdagingen die zich aandienden bij aanvang van het hier beschreven promotietraject bij het bestuderen van de uitscheiding van membraan vesicles in gecompliceerdere modellen die zijn samengesteld uit meerdere celtypen. Vervolgens is de fysiologische activiteit van vesicles afkomstig van zowel bacteriën als gastheercellen besproken. Tot slot hebben we besproken hoe de uitscheiding van membraan vesicles beïnvloed wordt door externe factoren, waarbij de focus lag op de therapeutische middelen die gebruikt worden bij de behandeling van patiënten met chronische obstructieve luchtwegaandoeningen. 
Dit proefschrift geeft achtergrond over de uitscheiding van bacteriële membraan vesicles in een omgeving zoals deze zich voordoet in de gastheer. In dit onderzoek konden we aantonen dat bacteriële membraan vesicles een ontstekingsbevorderend, maar ook een immuun-modulerend effect kunnen hebben. Daarnaast werd aangetoond hoe therapeutische middelen de ontstekingsreactie kunnen beïnvloeden door effect uit te oefenen op de vesicle-uitscheiding en op de ontstekingsreactie van macrofagen na blootstelling aan deze vesicles. Alleszins geeft dit proefschrift een beter inzicht in de uitscheiding en functionaliteit van membraan vesicles zoals die worden vrijgesteld tijdens infectie. De verkregen inzichten kunnen helpen bij het bepalen van een toekomstige koers voor vervolgstudies en de ontwikkelde methodologieën kunnen hierbij van toegevoegde waarde zijn bij de uitvoering van deze toekomstige studies. 


\section{VALORISATION}

"The importance of asking questions purely out of curiosity and carrying out experiments to test models that arise from these questions - the paradigm of basic biological researchcannot be dismissed as 'old-style' thinking; it is the main driving force of scientific freedom and originality." - Schvartzman [1] -

\section{INTRODUCTION}

This chapter will provide an overview on the valorisation of this thesis. This was done in accordance with the guidelines introduced by the Maastricht University in 2014 that state all dissertations should include a chapter on the valorisation of the research. Valorisation of research lays in the potential use of its outcomes, so if these outcomes are of direct or indirect benefit for society. Or as defined by the national valorisation committee: "valorisation is the process of creating value from knowledge by making knowledge suitable and/or available for economic and/or societal use and translating that knowledge into competitive products, services, processes, and entrepreneurial activity" [2].

It is easy to realize a valorisation of research biased by valorisation policies with a defined measureable outcome set a priori. This type of research usually concerns well designed research, marked-out as a controlled trajectory. If you would compare designing and realising a research project with the design and realization of a building design this would almost guarantee you to achieve the plotted end product. However, sometimes one needs to make a leap beyond the practical and set out on an exploration. This, in part, applies for basic research that aims at identifying and describing biologic processes to deepen understanding. In my opinion, the gain of fundamental knowledge on a subject, in itself should be its valorisation. Because isn't it so that an increasing knowledge of a phenomenon usually leads to the valorisation of the phenomenon.

This study focused on small membrane 'bags' once thought of as garbage bags observed to be released by certain cells of our body. Also in the field of microbiology the release of the membrane vesicles was reported. To date, around 30 years after their discovery, the value of these membrane vesicles is being increasingly recognized. It is now clear that the release of these vesicles is a highly-conserved process that occurs by cells that belong to all branches of life. They are involved in intercellular communication and processes that lay beyond, such as the acquisition of nutrients and the protection against environmental factors. Hereby their physiological activities affect and enable a wide range of biological processes. In this thesis, we investigated the release of membrane vesicles in an in vitro infection-model based on macrophages and bacteria associated with airway disease to obtain a better understanding of the biological significance of vesicles shed by the host and bacteria during infection. 


\section{RELEVANCE FOR SOCIETY}

Respiratory infections have a large impact on the global health. The World Health Organisation established that acute respiratory tract infections are the most important cause of morbidity and mortality worldwide and account annually for 4 million deaths [3]. Besides the direct consequences for patients that succumb to such an infectious disease, there is also a substantial economic burden. Over the years, a better understanding of the determinants for the process of bacterial invasion, manifestation, and spread has led to improved means to fight infection. As was reviewed in this thesis (chapter 2) and by others [4,5], bacteria release membrane vesicles that provide them with a means to cope with host cell-associated environmental challenges, both during bacterial growth and during infection. Membrane vesicles contain e.g. lipopoly- or lipooligosaccharides and a multitude of proteins and they can aid in the acquisition of nutrients and the defence against antimicrobial peptides. Importantly, host-associated environmental stressors (such as nutrient limitation and the exposure to antimicrobial peptides) can trigger the release of membrane vesicles. In this thesis we studied the release and functionality of membrane vesicles released during macrophage infection with respiratory pathogens. Additionally, we determined the effects of frequently prescribed pharmacological agents and a promising new regimen on the vesicle shedding. We and others observed that the application of pharmacological regimens may substantially boost the vesicle production (chapters 5 and $6,[6,7])$, thereby liberating a multitude of vesicle-associated virulence factors into the host-environment $[8,9]$. Future studies that focus on bacterial behaviour and growth in response to therapeutics and host factors can help to predict (or explain) treatment outcome and may aid in the development of novel therapeutics. 


\section{VALORISATION OF PROJECT OUTCOMES}

\subsection{Communication}

As mentioned previously, the research field of membrane vesicles is relatively young and dynamic. The value of these vesicles becomes increasingly recognized and it is now understood that they are involved in a plethora of pathologies including infectious diseases. A critical appraisal on the release and physiological activity of bacterial membrane vesicles in the context of a host-environment is given in chapter 2, which has been published in Critical Reviews in Microbiology. The studies presented in this thesis provide novel insights in the release of bacterial and host cell membrane vesicles during infection and the findings presented in chapters 2-6 of this thesis have been made available for the scientific society through publications in peer-reviewed journals.

Moreover, most of the results obtained during these studies were communicated at several international conferences. Especially the sharing of experiences, results, and techniques during the annual conference of the International Society for Extracellular Vesicles was highly valuable. As this field is still rather young and involves many research fields it is particularly constructive to exchange information with fellow researchers that work within the same niche. Finally, as this project was a pioneering project at the department of Medical Microbiology, the experimental techniques and results this project delivered facilitate follow-up projects and opened new possibilities for collaboration between the departments' research groups.

\subsection{Activities, products, and innovation}

Researchers that work with membrane vesicles face the challenge of working in a field that is subject to constant change and expansion, foremost with respect to the techniques used to study these vesicles. Oftentimes, highly specialized techniques are required for the study of membrane vesicles and technical limitations can hamper assessment of their release and functionality, techniques and experimental parameters are constantly evolving. As a consequence, there were several shifts in consensus as to which techniques were best suited for the isolation and purification as well as for the characterization. To reach consensus on this an ISEV position paper was published several years ago followed by the establishment of the EV-TRACK consortium, this year. This consortium established a knowledgebase that facilitates the registration of a study and its research procedures, hereby not only improving clarity and easing the interpretation of studies, but also providing with guidelines to improve reporting. The studies presented in this thesis were all registered in this database.

Often, existing techniques to study membrane vesicles need to be customized to enable addressing specific research questions. Also in this study, we had to overcome a technical limitation by customizing a conventional method in order to be able to assess the release of specific membrane vesicle populations within a mixed vesicle population. To this end, we developed a semi-quantitative method that allowed us to determine the release of bacterial vesicles. The manuscript in which this application was presented (chapter 3) was published in Microbiology Research. The introduction of this method provides a new way to study bacterial vesicle release during infection and allows e.g. to establish 
the impact how host environment-associated factors affect bacterial membrane vesicle release. Moreover, this method can be taken over directly by researchers in the field as it provides with a platform that can easily be adopted for alternative applications and is therefore highly accessible and versatile.

Finally, innovation is being described as the application of an invention. Inventing literally means to create a new concept or conception. One of the concepts or take-home messages of this thesis is that a host-environment can alter bacterial behaviour. In this thesis, we focussed on one aspect of this behaviour, namely the release of membrane vesicles. In chapter 2 we introduced the concept that the transformation of the bacterial outer membrane and the release of membrane vesicles can provide bacteria with a selective advantage in the host environment. In chapter 3, we studied this by assessing the bacterial membrane vesicle release in the context of infection. We took a first step to study how the interaction with host cells may affect the bacterial membrane vesicle release in chapters 4-6. The discussion of this thesis provides with directions for future research. We think studying this concept will eventually help us to understand how bacteria succeed in overcoming host defence mechanisms and thrive in a host environment, because it is in the interaction with the host that their pathogenicity is determined. 


\section{REFERENCES}

1. Schvartzman J, Schvartzman J. How do we ask for money? EMBO Rep. 2008;9: 216 LP-220

2. Maastricht Valorisation Center - Maastricht University. Maastricht Valorisation Centre. Internet. Available: http://www.maastrichtuniversity.nl/web/show/id=406582/langid $=42$

3. WHO | The world health report 2004 - changing history. WHO. World Health Organization; 2013.

4. Schwechheimer C, Kulp A, Kuehn MJ, Berleman J, Auer M, Deatherage B, et al. Modulation of bacterial outer membrane vesicle production by envelope structure and content. BMC Microbiol. 2014;14: 324. doi:10.1186/s12866-014-0324-1

5. Kaparakis-Liaskos M, Ferrero RL. Immune modulation by bacterial outer membrane vesicles. Nat Rev Immunol. 2015;15: 375-387. doi:10.1038/nri3837

6. Kadurugamuwa JL, Beveridge TJ. Virulence factors are released from Pseudomonas aeruginosa in association with membrane vesicles during normal growth and exposure to gentamicin: a novel mechanism of enzyme secretion. J Bacteriol. 1995;177: 3998-4008.

7. Manning AJ, Kuehn MJMJ, McDermott P, Walker R, White D, Kulp A, et al. Contribution of bacterial outer membrane vesicles to innate bacterial defense. BMC Microbiol. 2011;11: 258. doi:10.1186/1471-2180$11-258$

8. Ellis TN, Kuehn MJ. Virulence and Immunomodulatory Roles of Bacterial Outer Membrane Vesicles. Microbiol Mol Biol Rev. 2010;74: 81-94. doi:10.1128/MMBR.00031-09

9. Schwechheimer C, Kulp A, Kuehn MJ, Berleman J, Auer M, Deatherage B, et al. Modulation of bacterial outer membrane vesicle production by envelope structure and content. BMC Microbiol. 2014;14: 324. doi:10.1186/s12866-014-0324-1 



\section{LIST OF ABBREVIATIONS}

\begin{tabular}{|c|c|}
\hline AMP & Antimicrobial peptide \\
\hline $\mathrm{AU}$ & Arbitrary Units \\
\hline$A Z I$ & Azithromycin \\
\hline BALF & Bronchoalveolar lining fluid \\
\hline BUD & Budesonide \\
\hline CFU & Colony forming units \\
\hline COPD & Chronic obstructive pulmonary disease \\
\hline ELF & Epithelial lining fluid \\
\hline ELISA & Enzyme linked immunosorbent assay \\
\hline EM & Electron microscopy \\
\hline EVs & Extracellular vesicles \\
\hline FLUT & Fluticasone propionate \\
\hline $\mathrm{Hi}$ & Heat inactivated \\
\hline IM & Inner membrane \\
\hline IL & Interleukin \\
\hline LPS & Lipopolysaccharide \\
\hline LOS & Lipooligosaccharide \\
\hline MFI & Mean fluorescence intensity \\
\hline MIC & Minimal inhibitory concentration \\
\hline $\mathrm{MOI}$ & Multiplicity of infection \\
\hline Mphis & Macrophages \\
\hline Mrc & Moraxella catarrhalis \\
\hline MVs & Membrane vesicles \\
\hline MVB & Multivesicular body \\
\hline NF-KB & Nuclear factor-kappa B \\
\hline NTHi & Non-typeable Haemophilus influenzae \\
\hline OD & Optical density \\
\hline OM & Outer membrane \\
\hline OMP & Outer membrane protein \\
\hline OMV & Outer membrane vesicle \\
\hline PAMPS & Pathogen-associated molecular pattern \\
\hline$P G$ & Peptidoglycan \\
\hline$P Q S$ & Pseudomonas quinolone signal \\
\hline PRRs & Pattern recognition receptors \\
\hline Psa & Pseudomonas aeruginosa \\
\hline
\end{tabular}


RIG-1 Retinoic acid-inducible Gene 5

ROS Reactive oxygen species

$\sigma^{e}$

Sigma factor $\mathrm{E}$

Spn

Streptococcus pneumoniae

TLR Toll-like receptor

TNF-a Tumor necrosis factor-a

WT Wild-type 


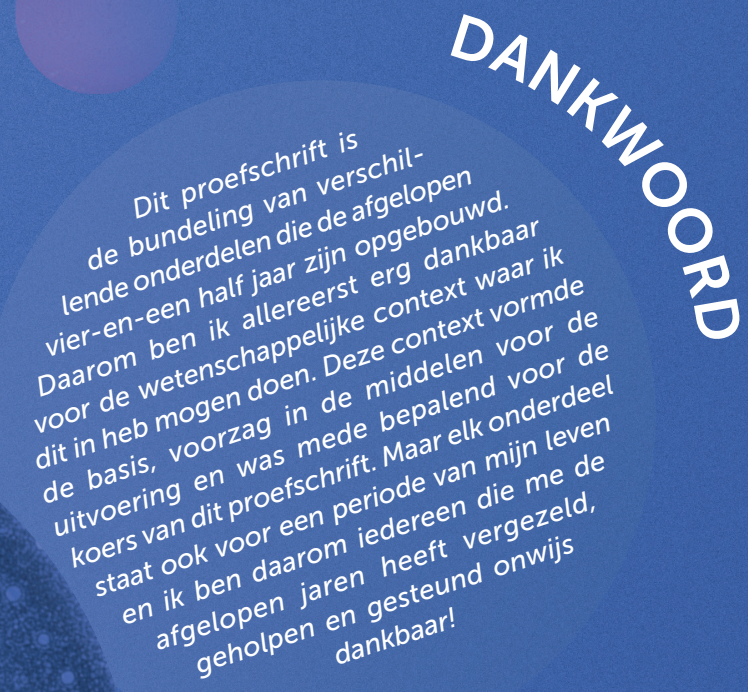




\section{Carla,}

dankjewel voor alle

gezelligheid en steun de a gelopet komt

jaren. Ik begon een maand na jou mag verdedigen.

nu zo uit dat ik ook een mbaak en ik heb veel van je danken voor

Je was naast Gert deste Gert, ik wil je ontzente positieve kracht met

bedankt daarvoor. Besteid. Je was de consanco . Erik, jij bent een belangrijke je hulp en betrokkenheringsvermogen. veel humor en relafdeling en ik wil you for your help, you we Also for your constante voor Fahad. Hattie, thasions even in the weeken long after you left betrokkenheid. Fan several occasions that still lasts, even mijanimf, we begonnen there for US, and and your involven natuurlijk Birke, mistage en ik als PhD student. encouragements ates, thank you! En met je laatste master soan als PhD student, en to work in the Staj op de MMB, Ji) ij stage ook door en samen veel congre 2015 in bijna tegelikertend blij dat je nauw samengewerk ontzere natuurlijk de begin af aan hebben we haun de meest bijzon, je steun en ook dijn paranimf! symposia bezocht, wewel voor je vriends gerelateerde zaken met je kon jus chap. Het was Allereerst bedalik de afgelopen periode
even makkelitieve instelling en je jaren en voor je (bijna) nooit aflate gezelligheid de afje onderzoek (al ook bedankt delen van je verhalen over je onzes soms voor het de ze tijdens onze lunchpauzeerde een klein beetje op het
moment (-)).

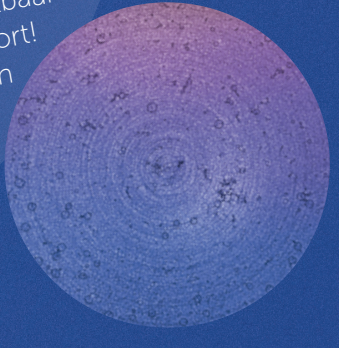

(oud) Mijn

collegarere) mede-promootjes,

vorde: Guy cen soort van chendi en

Tanja, Kai, Chris, Niels, Fleur, Elly, Amologische bedank, Gianluca, Liene Natherine, Kmita, Anne, maar vooral jullie hulp, steun en en Abdullah, Julius,

etentjes, feestjor de gezellige het uitwisselen, allereerst

erg bedankt vies, congressen en tijd tijdens de van ideeën voor je hulp voor de gezellige tij uitstapjes. Mayk of je tijd had geduld als ik weer de afgelopen jaren ook heel een figuur. Marg me te helpen eens aanklopte jaren en ook jullie bedank rgriet, Christel, met het in elka kennis. Zeker voor de samenwe en John, bij deze wtelen van

ik bij deze ook alle andere colling, hulp en het wil ik ook

delen van

en Gernot is en voor de fijner jullie hulp, voling wi

dankit, ook jullie mogen samenwerking. An het

het wel voor jullie betror niet ontbreken

het meedenken lie betrokkenheid, voor en jullie hulp. 
Olga and

Jacqueline, for you also a special word of gratitude. Your support and encouragements and the opportunity to work together meant a lot to me, thank you for this!

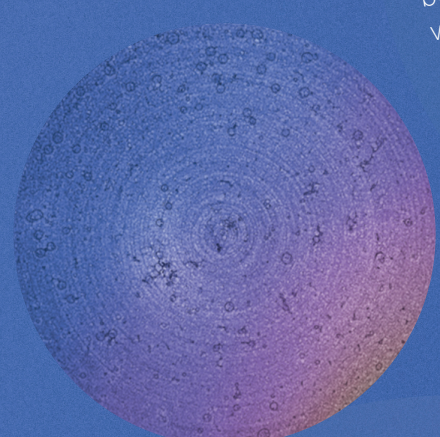

Friends.

Carin, bedankt voor je vriendschap en goor je support en de afgelopen jaren jawewel! Gesiele and As for the great luisterend oor, daur friendship and for the attempts to thank you for your fesiele I am afraid your wasted on me. times together. Glay the timbrel wex to paphne en Ramona teach me still very much enjoyed it $@$. Alid tijdens de "klaar-kollili en dank jullie wel voor de gezmen maar ook voor julle Monika, we i), brunches en het zwelopen tijd! Gintare but our friendship betrokkenheid de arge St. Monulphusw for the nice times we were flatmates at moved. Thank you for thog mijn vrienden stayed after living together an, Tim, Lydia, Cien en Myriam uit Gent, Mozes, Nagore, leuke tijd samen in Gent maas dank jullijdens jullie bezoekjes aan Mab: Elke, Jo de leden van de dinner-clum bedankt

Thomas, Kevin en Talligheid!

Familie.

je onvoorwaardankjewel voor positieve instelling en stijke steun, begrip, je

Ik heb veet

mogelijkhed van je geleerd en ben je super overnemen.

en enthousiasme die je me hebt gegeven. Papa dankbaar voor alle

en heeft er denk ik (wer en voor alles wat groeit , jouw bevlogenheid

nodig het in een klas terecht kwam zeker) voor gezorgd dat ik besmettelijk beroepskeuze hel natuur en techniek met alleen maar jongens oit als enige steun en vo reb gemaakt. Daarnaast moest kiezen en dat ik uite nu ligt is zekr je interesse in mijn onast ook bedankt voor ik uiteindelijk deze maar zeker ook aan jou te danken. Vizoek. Chris, broertje, dat betrokkenheid en hebben me ook je pragmatische ' $h a$ ooral jouw humor en relatik deze thesis er staat en de door tij en ontij heen gehols'-denken en je nooit aringsvermogen being there with altijd van een zonnige nice times tog encouragements and kant bekijkt! Micha, thank voor me klaar steun. Ook van j! Dan Mien, ik ben je erg dan and also thank you for always duidelijkheid jou heb ik heel veel gerg dankbaar voor je betrok for all the

manier zoals dat je de dingen altijd zo, vooral van je doortastenheid en

instantie lijk weet dat ze goed zl zo veel mogelijk moet doen dheid

wil ik ook dankjewel hiervoor.

jullie steun erg bedanken Peter en To, Rob en Henny,

interesse in mijn onderzelligheid en voor

familie ontzettend

motiverende betrokkenheid en 


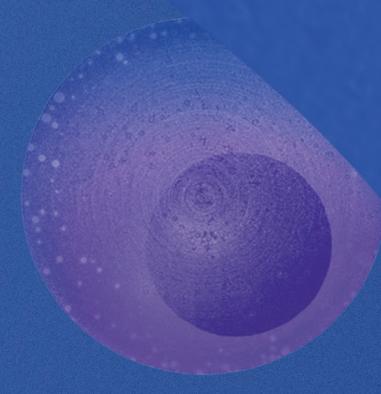

Dan last but (zeker) not least, de leden van de leescommissie Prof. Dr. P.J. Peters, Prof. Dr. M.H.M. Wauben, Dr. R. Nieuwland,
Prof. Dr. B.W.W. Kramer W.T.V. Germera. Kramer en Dr. de tijd die und bedankt voor voor het $u$ heeft genomen beoordelen proefschrift. mijn 


\section{LIST OF PUBLICATIONS}

\section{Full articles}

Volgers C, Benedikter BJ, Hellebrand PHM, Grauls GE, Savelkoul PHM, Stassen FRM. Effects of N-acetyl-L-cysteine on the membrane vesicle release and growth of respiratory pathogens. FEMS Microbiology letters. 2017 Apr 1; 364(9); fnx087. doi: 10.1093/femsle/fnx087.

Volgers C, Benedikter BJ, Hellebrand PHM, Grauls GE, Savelkoul PHM, Stassen FRM. Effects of budesonide, fluticasone propionate, and azithromycin on the release of membrane vesicles by macrophages and respiratory pathogens during infection. Inflammopharmacology. 2017 May 20. doi: 10.1007/s10787017-0359-7. [Epub ahead of print].

Volgers C, Benedikter BJ, Grauls GE, Savelkoul PHM, Stassen FRM. Bead-based flowcytometry for semi-quantitative analysis of complex membrane vesicle populations released by bacteria and host-cells. Microbiology Research. 2017 Jul; 20025-32. doi: 10.1016/j.micres.2017.04.003.

Volgers C, Savelkoul PHM, Stassen FRM. Gram-negative bacterial membrane vesicle in response to the host-environment: different threats, same trick? Critical reviews in Microbiology. 2017 July 25. doi: 10.1080/1040841X.2017.1353949. [Epub ahead of print].

Volgers C, Benedikter BJ, Grauls GE, Savelkoul PHM, Stassen FRM. Immuno-modulatory membrane vesicles are released during macrophage infection with respiratory pathogens. BMC Microbiology. 2017

Benedikter BJ, Volgers C, Wouters EFM, Savelkoul PHM, Reynaert NL, Haenen GRMM, Rohde GGU, Weseler AR, Stassen FRM. Cigarette smoke extract induced exosome release is mediated by depletion of exofacial thiols and can be inhibited by thiol-antioxidants. Free Radical Biology and Medicine. 2017 July: 108:334-344. doi: 10.1016/j.freeradbiomed.2017.03.026 


\section{Abstracts}

Volgers C, Benedikter BJ, Savelkoul PHM, Stassen FRM. Extracellular vesicle release by macrophages during infection with non-typeable Haemophilus influenzae. Poster presentation, European Respiratory Society's 25th International Congress, 26-30th September 2015, Amsterdam, The Netherlands.

Volgers C, Benedikter BJ, Savelkoul PHM, Stassen FRM. Non-typeable Haemophilus influenzae induces the release of pro-inflammatory extracellular vesicles by macrophages. Poster presentation, $4^{\text {th }}$ Annual Meeting of International Society for Extracellular Vesicles, 22-26 ${ }^{\text {th }}$ April 2015, Washington DC, USA.

Volgers C, Benedikter BJ, Savelkoul PHM, Stassen FRM. Extracellular vesicle release by macrophages during infection with non-typeable Haemophilus influenzae. $13^{\text {th }}$, European Respiratory Society Lung Science Conference, 13-15 th March 2015, Estoril, Portugal

Volgers C, Benedikter BJ, Savelkoul PHM, Stassen FRM. Membrane vesicles released during macrophage-infection with airway pathogens modulate innate immune responses. Journal of Extracellular Vesicles. Poster presentation, $5^{\text {th }}$ Annual Meeting of International Society for Extracellular Vesicles, 4-7 $7^{\text {th }}$ May 2016, Rotterdam, The Netherlands 


\section{VITA}

Charlotte Volgers was born on July 22th, 1985 in Arnhem, the Netherlands. After finishing her Higher Secondary Education she continued with the Bachelor of Applied Science in Biochemistry, at the HAN University in Nijmegen. This was where she developed her interest in the fields of Immunology and Microbiology. She graduated in 2007 and went on to attend the Radboud University in Nijmegen. During her master's program in Medical Biology, she worked as an undergraduate at the departments of Rheumatology and Tumor immunology at the Radboud Institute of Molecular Life Sciences (RIMLS). Here she gained further interest in the fields of immunology and medical microbiology. After her graduation in 2010, she continued as a research assistant the Ghent University at the department of Molecular Signaling and Cell Death. From 2012 on, she worked as a PhD candidate under the supervision of Dr. Frank Stassen and Prof. Dr. Paul Savelkoul at the department of Medical Microbiology at Maastricht University where she studied membrane vesicles, released by bacteria and host-cells during infection with respiratory pathogens. 